\title{
Management of atrial fibrillation in Europe
}

Citation for published version (APA):

Nieuwlaat, R. (2007). Management of atrial fibrillation in Europe. [Doctoral Thesis, Maastricht University]. Datawyse / Universitaire Pers Maastricht. https://doi.org/10.26481/dis.20070921rn

Document status and date:

Published: 01/01/2007

DOI:

10.26481/dis.20070921rn

Document Version:

Publisher's PDF, also known as Version of record

\section{Please check the document version of this publication:}

- A submitted manuscript is the version of the article upon submission and before peer-review. There can be important differences between the submitted version and the official published version of record.

People interested in the research are advised to contact the author for the final version of the publication, or visit the DOI to the publisher's website.

- The final author version and the galley proof are versions of the publication after peer review.

- The final published version features the final layout of the paper including the volume, issue and page numbers.

Link to publication

\footnotetext{
General rights rights.

- You may freely distribute the URL identifying the publication in the public portal. please follow below link for the End User Agreement:

www.umlib.nl/taverne-license

Take down policy

If you believe that this document breaches copyright please contact us at:

repository@maastrichtuniversity.nl

providing details and we will investigate your claim.
}

Copyright and moral rights for the publications made accessible in the public portal are retained by the authors and/or other copyright owners and it is a condition of accessing publications that users recognise and abide by the legal requirements associated with these

- Users may download and print one copy of any publication from the public portal for the purpose of private study or research.

- You may not further distribute the material or use it for any profit-making activity or commercial gain

If the publication is distributed under the terms of Article $25 \mathrm{fa}$ of the Dutch Copyright Act, indicated by the "Taverne" license above, 


\section{Management of atrial fibrillation in Europe}


(C) Copyright Robby Nieuwlaat, Maastricht 2007 ISBN 978-90-9022134-2

Cover design: Rogier Trompert Medical Art (www.medical-art.nl)

Lay out \& printing: Datawyse / Universitaire Pers Maastricht (www.datawyse.nl) 


\title{
Management of atrial fibrillation in Europe
}

\author{
PROEFSCHRIFT \\ ter verkrijging van de graad van doctor \\ aan de Universiteit Maastricht \\ op gezag van de Rector Magnificus, \\ Prof. mr. G.P.M.F. Mols \\ volgens het besluit van het college van Decanen, \\ in het openbaar te verdedigen \\ op vrijdag 21 september om 12:00 uur \\ door \\ Robby Nieuwlaat \\ geboren op 1 juni 1975 te Roosendaal
}

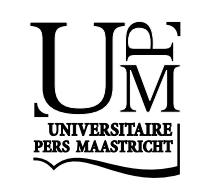




\section{PROMOTOR}

Prof. dr. H.J.G.M. Crijns

\section{BEOORDELINGSCOMMISSIE}

Prof. dr. C.D.A. Stehouwer (voorzitter)

Prof. dr. M.A. Allessie

Prof. dr. M. Limburg

Prof. dr. Y.M. Pinto

Prof. dr. M.L. Simoons (Erasmus Medisch Centrum, Rotterdam)

The study in this thesis was supported by a grant of the Netherlands Heart Foundation (NHS-2000T101)

Financial support by the Netherlands Heart Foundation and Rescar Foundation Maastricht is gratefully acknowledged.

Further financial support from AstraZeneca, Sanofi-Aventis, Meda Pharma, Medtronic Bakken Research, St. Jude Medical and Pfizer is gratefully acknowledged. 


\section{Contents}

Chapter 1: General introduction

Part I. General results of the Euro Heart Survey on atrial fibrillation

Chapter 2: Atrial fibrillation management: a prospective survey in ESC member countries. The Euro Heart Survey on atrial fibrillation

Editorial: The Euro Heart Survey on atrial fibrillation: a picture and a thousand words

Chapter 3: Prognosis, disease progression, quality of life and treatment of atrial fibrillation patients during 1 year: Follow-up of the Euro Heart Survey on atrial fibrillation

\section{Part II. Antithrombotic treatment in atrial fibrillation}

Chapter 4: Antithrombotic treatment in real-life atrial fibrillation patients

Chapter 5: Guideline-adherent antithrombotic treatment is associated with improved outcomes compared to undertreatment in high-risk patients with atrial fibrillation

Chapter 6: Should we abandon the paradigm of withholding oral anticoagulation in paroxysmal atrial fibrillation?

Chapter 7: Antithrombotic drug prescription in atrial fibrillation and its rationale among general practitioners, internists and cardiologists in The Netherlands - The EXAMINE-AF study

Editorial: Stroke risk stratification in atrial fibrillation: something to EXAMINE more closely 


\section{Part III. Management of important subgroups with atrial fibrillation}

Chapter 8: Gender-related differences in presentation, treatment and outcome of patients with atrial fibrillation in Europe

Chapter 9: Atrial fibrillation and heart failure: reciprocal impact and combined management from the perspective of atrial fibrillation 159

Chapter 10: General discussion

Summary

Samenvatting

Dankwoord

Curriculum vitae

List of publications 
1

General introduction

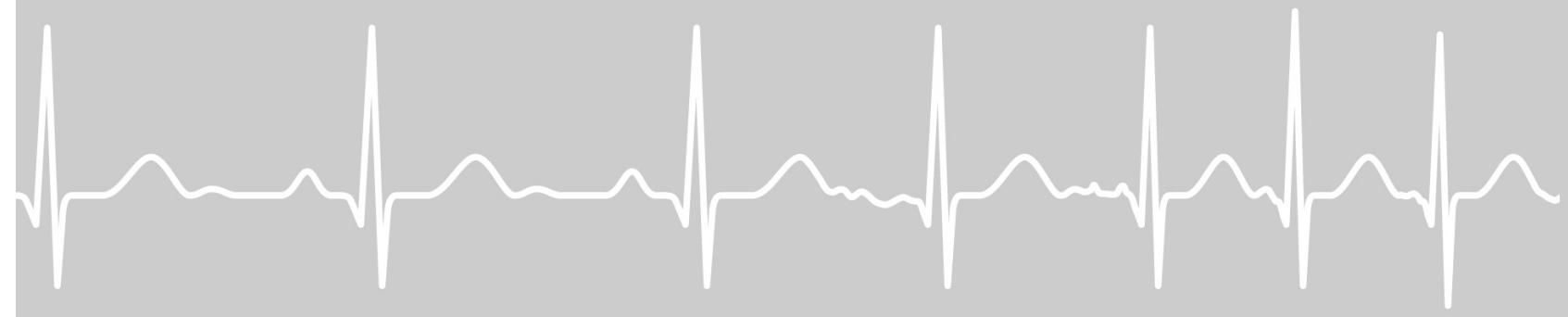


"To reduce the burden of cardiovascular disease in Europe". ${ }^{1}$ This is the mission statement of the European Society of Cardiology (ESC). It is for this purpose that the ESC wants to assess quality of cardiovascular patient care. An important issue in this regard is how we define optimal patient management.

\section{Evidence based medicine}

A widely used term for optimal medical treatment is "evidence based medicine". Evidence based means that results from interventional and observational studies form the basis for management decisions. For the last few decades the implementation of newly developed management strategies and the improvement of existing strategies have led to an improvement in quality of patient care, and concomitantly in a decreasing trend of mortality from cardiovascular diseases. ${ }^{2}$ However, a huge number of cardiovascular studies have been published in the past, and nowadays the rate of publishing papers is dramatically increasing. How can medical personnel recognise those studies that are of true importance for patient management in this abundance of research? And following an adequate selection of studies, how will this evidence be communicated to the appropriate specialists and implemented in clinical practice?

\section{Management guidelines}

Management guidelines for a specified disease, constituted by specialists with expertise on the concerning topic, aim to select and summarise the available evidence thereby providing recommendations for patient care. These recommendations concern the patients that resemble the patient population in the cited studies, but where considered appropriate by the specialists, these results might be extrapolated to a larger patient group. If evidence is scarce, unambiguous or even absent, the specialists are allowed to provide recommendations based on case studies, their own expertise and standard of care for items that are perceived to be of importance. Management aspects are either recommended unconditionally, recommended conditionally or dissuaded. The strength with which an aspect of management is recommended or dissuaded depends on whether it is supported by a number of high-quality randomised controlled clinical trials, or solely by case studies, experts' agreement or standard-of-care. Guidelines should be used literally as a guide in the management of patients, whereby every individual patient should receive treatment tailored to his/her specific situation.

By publishing the guidelines in international high-impact cardiovascular journals, by making electronic versions which can easily be used in the clinical setting, and by providing comprehensive summaries, the ESC aims at the implementation of evidence based medicine through the guidelines in local management protocols. The question remains how effective these implementation strategies are and to what extent the guidelines are followed in daily real-life practice. In addition, it is 
interesting to see which consequences guideline deviance has in terms of cardiovascular outcome.

\section{Euro Heart Survey \& EXAMINE-AF}

In order to assess guideline adherence for the management of cardiovascular diseases the ESC initiated the Euro Heart Survey (EHS) programme. This programme contained surveys on a wide spectrum of cardiovascular diseases, providing a contemporary transversal view (snapshot) on patient management for a specific disease. In addition, a one year follow-up was performed for the enrolled patients, to investigate short-term changes in and consequences of management. One of these surveys was performed between 2003 and 2005 for the cardiac arrhythmia atrial fibrillation (AF). By means of a joint effort of the American College of Cardiology (ACC), American Heart Association (AHA) and the ESC, guidelines for the management of AF were published in $2001 .^{3}$ This was the first time ever that these associations made a combined effort on writing guidelines and these guidelines were updated in $2006 .{ }^{4}$ The Euro Heart Survey on AF aimed to describe the management of AF in daily clinical practice, to compare AF management with the 2001 guideline recommendations and to assess short-term outcome during 1 year follow-up. No data exist on the adherence to these AF guidelines in 'real-life' cardiology practice across Europe. In addition, guideline adherence has been shown to be beneficial in terms of cardiovascular outcome for several cardiovascular diseases ${ }^{5-8}$, but if the same holds for AF remains to be seen.

The Dutch EXAMINE-AF study was designed to investigate guideline adherence for antithrombotic treatment in AF in The Netherlands, thereby comparing practice of general physicians, internists and cardiologists. The hypothesis for this study was that variations in antithrombotic treatment might exist, since slight differences exist between recommendations of the cardiological ACC/AHA/ESC guidelines $^{3}$ and the general practice ACCP guidelines ${ }^{9}$, and since no specific AF guidelines exist for internists.

\section{Atrial fibrillation}

What is AF? AF is a supraventricular arrhythmia characterized by rapid and uncoordinated atrial activation, which leads to deterioration of the atrial pump function. As a consequence, the ventricular response rate becomes irregular and rapid, which can cause symptoms such as palpitations, syncope, dyspnea, chest pain, dizziness and fatigue.

AF can appear in many forms, from a single short-lasting episode to being permanently present. For the sake of management, the guidelines reduced all possible variations to 4 clinical types of $\mathrm{AF}^{3} \mathrm{~A}$ first detected episode is the starting point for further investigation of AF characteristics and potential associated diseases. Paroxysmal AF is defined as recurrent short-lasting episodes - less than 7 days, but 
usually less than 48 hours - which will terminate spontaneously, but can be terminated with an intervention to keep the episode as short as possible. Persistent AF has long-lasting episodes - more than 7 days - which are unlikely to terminate spontaneously and require an intervention to terminate. And finally, permanent AF indicates the continuous presence of $\mathrm{AF}$, for which termination in the past has not been successful or even attempted, and in which no more attempts will be undertaken to terminate AF.

In the majority of AF patients an associated disease is found, which causes $\mathrm{AF}$ or which is the consequence of AF, or both. ${ }^{10,11}$ If the associated disease caused AF, successful management of this condition might terminate AF. The most frequent encountered associated disease is hypertension, but also heart failure (HF), valvular heart disease and coronary artery disease are found in AF patients. ${ }^{10-13}$ When no associated disease is present, $\mathrm{AF}$ is considered to be idiopathic (lone AF), which was found in approximately $30 \%$ of the ALFA population. ${ }^{10}$

\section{The impact of atrial fibrillation}

AF is the most prevalent sustained cardiac arrhythmia. The Rotterdam Study showed that AF is found in 5.5\% of the general population of 55 years or older. ${ }^{14}$ AF incidence increases with advancing age from 1.1 per 1000 person-years in age 55-59 years to 19.6 per 1000 person-years in age $>80$ years, and AF incidence is approximately 1.5 times higher in men than in women. ${ }^{14-16} \mathrm{AF}$ incidence in young patients ( $<40$ years) is very low, around 0.1 per 1000 person years. ${ }^{17}$ The lifetime risk to develop AF at the age of 40 years is approximately $25 \%$, which remains stable with advancing age despite a decrease in remaining years of life. ${ }^{14,18}$

AF itself is associated with a two-fold increased risk for death as compared to persons in normal sinus rhythm, and mortality is closely linked to the presence and severity of associated diseases. ${ }^{17,19,20}$ The chief hazard of AF is the increased risk for stroke. Patients with AF have approximately a five-fold increased risk for stroke compared to patients in sinus rhythm, ${ }^{20,21}$ and on top of that, when a stroke occurs AF worsens prognosis. ${ }^{22-24}$ Stroke incidence in AF increases dramatically with advancing age, as well as the proportion of strokes that is attributable to $\mathrm{AF}^{21}$ Thrombus formation in the left atrium caused by haemostasis is thought to underlie the stroke risk in AF. However, only half of the strokes in AF are of cardioembolic origin, and other mechanisms seem to play a role. ${ }^{25} \mathrm{AF}$ can also cause HF (tachycardiomyopathy), which might be reversed by successful management of $\mathrm{AF}^{26}$ The Framingham study showed that when AF develops in the presence of HF it may worsen prognosis of these patients, which is also the case when chronic HF develops in the presence of $\mathrm{AF}^{13}$ The high risk for disabling stroke, and the potential to worsen HF and to cause severe symptoms, mean that AF can substantially diminish quality of life. ${ }^{27-29}$ 
In the past decades, $A F$ prevalence $e^{30,31}$, hospitalisations ${ }^{32,33}$ and mortality ${ }^{32,34}$ have increased significantly. This is probably mainly caused by ageing and the deteriorated cardiovascular risk profile of the general population, as well as improvements in the detection and diagnosis of AF. These processes are expected to continue, thereby increasing AF prevalence 2.5 times by the year $2050 .{ }^{11} \mathrm{AF}$ is currently already a significant burden to the general population's health and health care costs, and this burden will avalanche in the next decades. Primary prevention of AF can currently only target classical modifiable cardiovascular risk factors that are known to be associated with AF occurrence, such as obesity, hypertension, diabetes and excessive alcohol intake. ${ }^{16,35-37}$ The SAFE study showed that systematic screening for AF in the general population has several drawbacks, and is not yet convincingly cost-effective. ${ }^{38}$ In the battle against AF, management is therefore currently the weapon of choice.

\section{Management of atrial fibrillation}

When considering current best knowledge, management of AF basically boils down to Figure 1. AF can be detected when typical symptoms are present, by screening in case AF is suspected to be present or simply by coincidence (for example with pre-operative screening). Patients who are hemodynamically unstable or who suffer from severe symptoms should be cardioverted immediately or have their rate aggressively controlled. It should be noted that when pharmacological cardioversion with a class I antiarrhythmic drug is considered, the patient has to be checked for the presence or history of coronary artery disease and HF, since these drugs can cause life threatening side effects in these patients. Hereafter, or for more stable patients as a first step, a rate control drug will be prescribed to most patients to slow down the ventricular response and prevent deterioration of the ventricular function. After these first actions, management comprises three pathways that need to be explored simultaneously.

Associated diseases

AF often coincides with another disease which might cause AF, facilitate progression of AF or worsen the prognosis of patients with AF. Therefore an adequate diagnostic work-up should identify potential associated diseases and consequent management of such a disease could lead to termination of AF, slowing down progression of $\mathrm{AF}$ and improving prognosis of patients with AF. For example, the combination of heart failure (HF) and AF is often found in clinical practice. AF can cause $\mathrm{HF}$ due to a chronic high ventricular response rate, whereby adequate control of the ventricular rate might reverse HF. Nevertheless, rhythm control could prevent AF recurrences in the first place and should at least be attempted. On the other hand, HF can also be the underlying pathology of AF, thereby causing or promoting AF through left atrial dilatation and myocardial fibrosis. Adequate management of HF, by means of strict rate control and drugs blocking the 


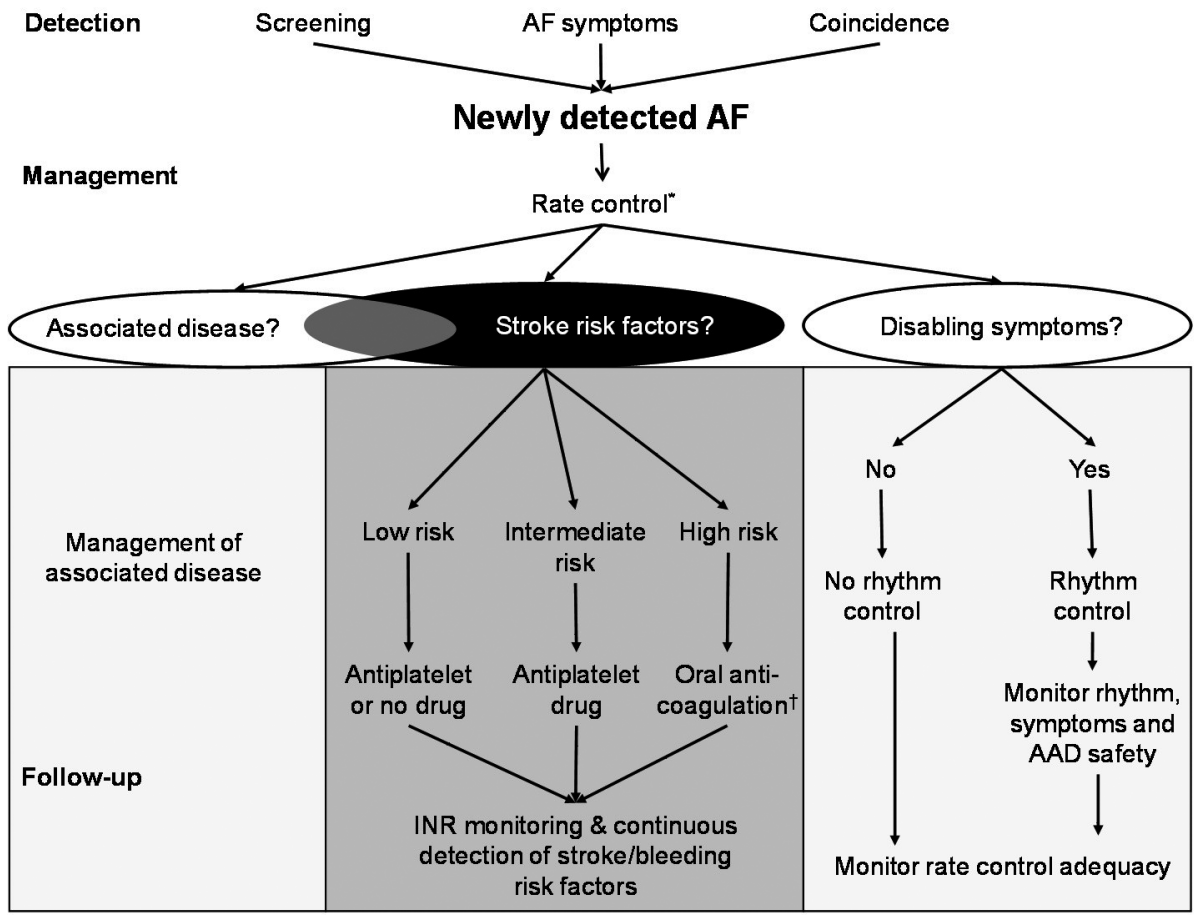

Figure 1. Flow-chart of AF management. INR, international normalized ratio; AAD, antiarrhythmic drug. ${ }^{\star}$ Rate control as needed, immediate cardioversion might be warranted in case of severe symptoms. $†$ A highly increased bleeding risk might be reason to deny oral anticoagulation in high risk patients.

renin-angiotensin-aldosteron system, might prevent $\mathrm{AF}$ recurrences and progression. HF is also a generally accepted risk factor for stroke in $\mathrm{AF}$, and the combination of AF and HF requires oral anticoagulation (OAC) according to the $2001 \mathrm{AF}$ guidelines. ${ }^{3}$ Due to the complex perception of disease and the existence of two separate management guidelines, it is hypothesized that patients with the combination of AF and HF might be treated less adequate than patients with either single pathology.

Stroke risk stratification and antithrombotic therapy

Stroke is the chief hazard of AF and antithrombotic therapy for the prevention of stroke is therefore the vanguard of AF management. In high-risk AF patients, OAC has been shown to be effective in preventing strokes, despite an increased bleeding risk. ${ }^{39,40}$ Application rates of OAC have increased over time, but are often still lagging behind. ${ }^{41-46}$ Figure 2 confirms the suboptimal use of OAC, and also shows that most studies until now were North-American, that European evidence is mainly British and that application rates tend to improve over time, but also highly vary among regions throughout the western world. 


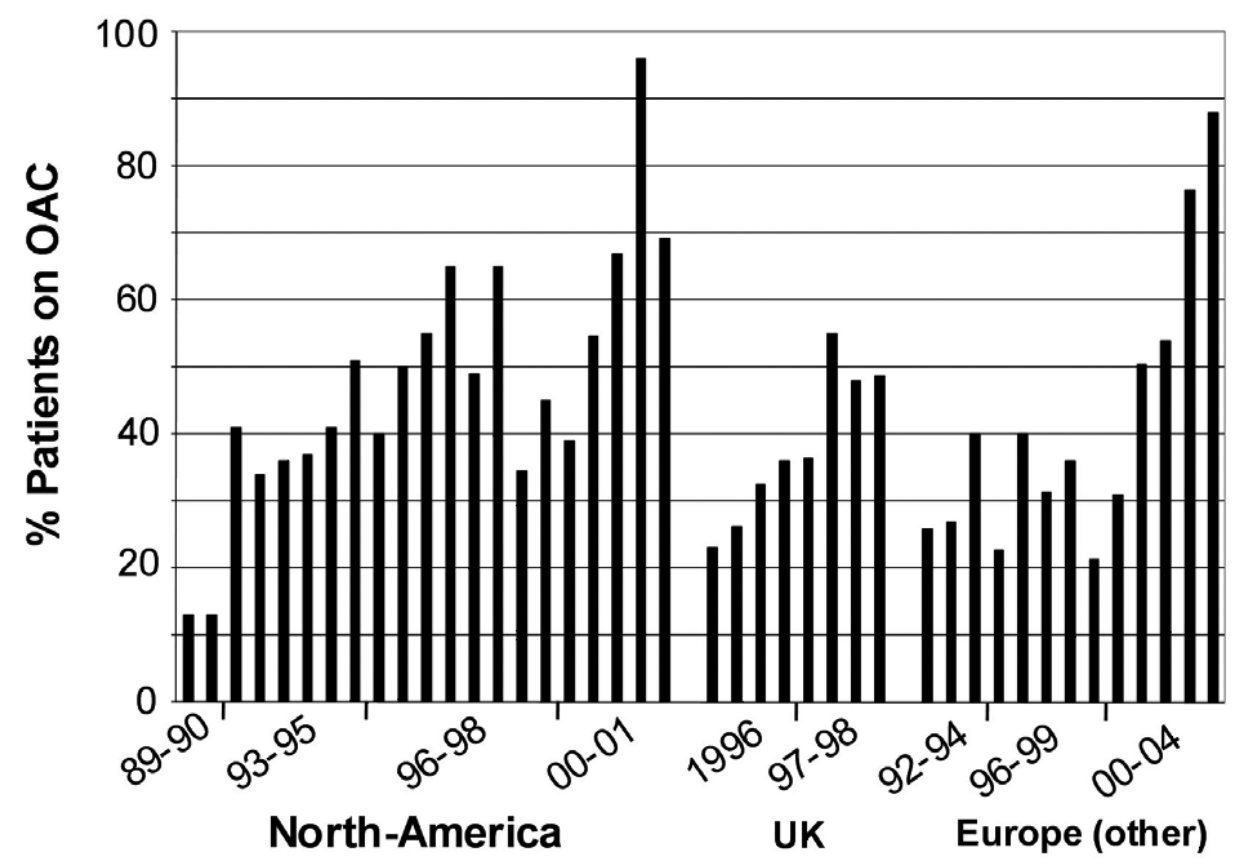

Figure 2. Contemporary OAC application rates in observational studies from North-America, United Kingdom (UK) and other European countries than the UK.

Withholding OAC in AF patients with a stroke or TIA is just partially explained by the presence of contraindications ${ }^{47}$ and other factors are in play, such as lack of facilities for adequate INR monitoring, fear of bleeding ${ }^{48,49}$ and patient preferences ${ }^{50}$, but also lack of knowledge about trials and guidelines. ${ }^{51}$ In low-risk patients the small benefit of OAC for stroke prevention does not weigh up to the increased bleeding risk, and an antiplatelet drug should suffice. ${ }^{39,52}$ The only exception for which low-risk patients should receive OAC is when they undergo cardioversion for an AF episode lasting longer than 48 hours or with unknown duration. ${ }^{3}$ The guidelines indicate which patient characteristics are considered to be high-risk factors for stroke. Many of the well-known stroke risk factors are also well-known associated diseases, and a significant overlap of these factors exists (Figure 1). Antithrombotic treatment should be tailored according to the stroke risk profile, thereby also considering a potential high risk for major bleedings. ${ }^{3}$ However, several other stroke risk stratification schemes exist, providing (slightly) different risk calculations than the guidelines. ${ }^{9,53,54}$ In addition, there remains dispute on some less well established stroke risk factors. For example, there is still some discussion about female gender being an independent risk factor for stroke. This relates to inconsistent evidence and the lack of knowledge regarding the potential underlying pathophysiologic mechanism. As a consequence, female gender is incorporated in the Framingham stroke risk score, but not in other schemes such as the 
ACC/AHA/ESC guidelines, ACCP guidelines and the CHADS score. $^{4,53-55}$ This does not explain why on some occasions women had an even lower chance for receiving OAC. ${ }^{56-58}$ Equivocal guidelines and the existence of multiple stroke risk schemes may mean that they are not properly followed. Also, dispute on some less validated risk factors such as female gender, may cause deviance. Even so OAC efficacy seems confirmed in daily practice ${ }^{56,59,60}$, it is still unknown which consequences guideline deviance in general has for the prognosis of patients.

Rhythm and rate control

The aim of AF treatment may be to solely normalize the ventricular response rate without targetting AF itself (rate control), or to terminate AF episodes and to maintain a normal sinus rhythm (rhythm control). Several randomized controlled trials showed that no difference exists in applying either strategy for mortality, occurrence of major adverse events, and quality of life improvement. ${ }^{61-68}$ As a consequence, a rhythm control strategy is currently recommended only if AF causes severe limiting symptoms. In case no or minor symptoms are present, a rhythm control strategy is not needed and rate control only will suffice. These trial results were not yet convincingly available at the time of the construction of the 2001 guidelines and were therefore not incorporated. Of note, the drawback of currently available antiarrhythmic drugs is the limited efficacy to maintain sinus rhythm in the long run and also the significant potential to cause severe side-effects. More successful rhythm control drugs with less side effects might make a rhythm control strategy superior to rate control, since reduction of the AF burden may limit cardiovascular complications and suppress AF symptoms.

\section{Aims and outline of this thesis}

This thesis aims to describe AF management in cardiology practices throughout Europe. More specifically, the aim is to assess guideline adherence for the management of AF, which subgroups might be less adequately treated and which consequences guideline deviance has in terms of adverse outcomes.

Part I (chapters $2 \& 3$ ) describes the general baseline and 1 year follow-up results of the Euro Heart Survey on AF. Part II (chapters 4-7) concerns European and Netherlands stroke prevention practice for AF patients. It reports adherence to antithrombotic guidelines and the consequences of guideline deviance. In addition, antithrombotic therapy and stroke incidence in paroxysmal AF is compared with that in more persistent forms of AF and antithrombotic drug prescription patterns are compared among Dutch cardiologists, internists and general physicians in the EXAMINE-AF study. Part III (chapters $8 \& 9$ ) describes management of women with AF and of patients with the frequently found combination of AF and HF. We hypothesized that these subgroups are being treated less adequately than their counterparts and that the study of these subgroups would reveal distinctive causes of guideline deviance. 


\section{REFERENCES}

1. The European Society of Cardiology. http://www.escardio.org/bodies/about/ March 2007.

2. Scholte op Reimer W, Simoons ML, Boersma E, Gitt AK (eds.). Cardiovascular diseases in Europe. The Euro Heart Survey. Sophia Antipolis: European Society of Cardiology 2006.

3. Fuster V, Ryden LE, Asinger RW, Cannom DS, Crijns HJ, Frye RL, Halperin JL, Kay GN, Klein WW, Levy S, McNamara RL, Prystowsky EN, Wann LS, Wyse DG. ACC/AHA/ESC guidelines for the management of patients with atrial fibrillation. A report of the American College of Cardiology/American Heart Association Task Force on Practice Guidelines and the European Society of Cardiology Committee for Practice Guidelines and Policy Conferences (Committee to develop guidelines for the management of patients with atrial fibrillation) developed in collaboration with the North American Society of Pacing and Electrophysiology. Eur Heart J 2001;22:1852-923.

4. Fuster V, Ryden LE, Cannom DS, Crijns HJ, Curtis AB, Ellenbogen KA, Halperin JL, Le Heuzey JY, Kay GN, Lowe JE, Olsson SB, Prystowsky EN, Tamargo JL, Wann S. ACC/AHA/ESC 2006 guidelines for the management of patients with atrial fibrillation-executive summary: a report of the American College of Cardiology/American Heart Association Task Force on practice guidelines and the European Society of Cardiology Committee for Practice Guidelines (Writing Committee to Revise the 2001 Guidelines for the Management of Patients with Atrial Fibrillation). Eur Heart J 2006;27:1979-2030.

5. Vikman S, Airaksinen KE, Tierala I, Peuhkurinen K, Majamaa-Voltti K, Niemela M, Tuunanen $\mathrm{H}$, Nieminen MS, Niemela K. Improved adherence to practice guidelines yields better outcome in high-risk patients with acute coronary syndrome without ST elevation: findings from nationwide FINACS studies. J Intern Med 2004;256:316-23.

6. Micieli G, Cavallini A, Quaglini S. Guideline compliance improves stroke outcome: a preliminary study in 4 districts in the Italian region of Lombardia. Stroke 2002;33:1341-7.

7. Komajda M, Lapuerta P, Hermans N, Gonzalez-Juanatey JR, van Veldhuisen DJ, Erdmann E, Tavazzi L, Poole-Wilson P, Le Pen C. Adherence to guidelines is a predictor of outcome in chronic heart failure: the MAHLER survey. Eur Heart J 2005;26:1653-9.

8. Giugliano RP, Lloyd-Jones DM, Camargo CA, Jr., Makary MA, O’Donnell CJ. Association of unstable angina guideline care with improved survival. Arch Intern Med 2000;160:1775-80.

9. Singer DE, Go AS. Antithrombotic therapy in atrial fibrillation. Clin Geriatr Med 2001;17:131-47.

10. Levy S, Maarek M, Coumel P, Guize L, Lekieffre J, Medvedowsky JL, Sebaoun A. Characterization of different subsets of atrial fibrillation in general practice in France: the ALFA study. The College of French Cardiologists. Circulation 1999;99:3028-35.

11. Go AS, Hylek EM, Phillips KA, Chang Y, Henault LE, Selby JV, Singer DE. Prevalence of diagnosed atrial fibrillation in adults: national implications for rhythm management and stroke prevention: the AnTicoagulation and Risk Factors in Atrial Fibrillation (ATRIA) Study. JAMA 2001;285:2370-5.

12. Cleland JG, Swedberg K, Follath F, Komajda M, Cohen-Solal A, Aguilar JC, Dietz R, Gavazzi A, Hobbs R, Korewicki J, Madeira HC, Moiseyev VS, Preda I, van Gilst WH, Widimsky J, Freemantle N, Eastaugh J, Mason J. The EuroHeart Failure survey programme- a survey on the quality of care among patients with heart failure in Europe. Part 1: patient characteristics and diagnosis. Eur Heart J 2003;24:442-63.

13. Wang TJ, Larson MG, Levy D, Vasan RS, Leip EP, Wolf PA, D’Agostino RB, Murabito JM, Kannel WB, Benjamin EJ. Temporal relations of atrial fibrillation and congestive heart failure and their joint influence on mortality: the Framingham Heart Study. Circulation 2003;107:2920-5.

14. Heeringa J, van der Kuip DA, Hofman A, Kors JA, van Herpen G, Stricker BH, Stijnen T, Lip GY, Witteman JC. Prevalence, incidence and lifetime risk of atrial fibrillation: the Rotterdam study. Eur Heart J 2006;27:949-53. 
15. Benjamin EJ, Levy D, Vaziri SM, D’Agostino RB, Belanger AJ, Wolf PA. Independent risk factors for atrial fibrillation in a population-based cohort. The Framingham Heart Study. JAMA 1994;271:840-4.

16. Stewart S, Hart CL, Hole DJ, McMurray JJ. Population prevalence, incidence, and predictors of atrial fibrillation in the Renfrew/Paisley study. Heart 2001;86:516-21.

17. Krahn AD, Manfreda J, Tate RB, Mathewson FA, Cuddy TE. The natural history of atrial fibrillation: incidence, risk factors, and prognosis in the Manitoba Follow-Up Study. Am J Med 1995;98:476-84.

18. Lloyd-Jones DM, Wang TJ, Leip EP, Larson MG, Levy D, Vasan RS, D’Agostino RB, Massaro JM, Beiser A, Wolf PA, Benjamin EJ. Lifetime risk for development of atrial fibrillation: the Framingham Heart Study. Circulation 2004;110:1042-6.

19. Benjamin EJ, Wolf PA, D'Agostino RB, Silbershatz H, Kannel WB, Levy D. Impact of atrial fibrillation on the risk of death: the Framingham Heart Study. Circulation 1998;98:946-52.

20. Stewart S, Hart CL, Hole DJ, McMurray JJ. A population-based study of the long-term risks associated with atrial fibrillation: 20-year follow-up of the Renfrew/Paisley study. Am J Med 2002;113:359-64.

21. Wolf PA, Abbott RD, Kannel WB. Atrial fibrillation as an independent risk factor for stroke: the Framingham Study. Stroke 1991;22:983-8.

22. Steger C, Pratter A, Martinek-Bregel M, Avanzini M, Valentin A, Slany J, Stollberger C. Stroke patients with atrial fibrillation have a worse prognosis than patients without: data from the Austrian Stroke registry. Eur Heart J 2004;25:1734-40.

23. Lamassa M, Di Carlo A, Pracucci G, Basile AM, Trefoloni G, Vanni P, Spolveri S, Baruffi MC, Landini G, Ghetti A, Wolfe CD, Inzitari D. Characteristics, outcome, and care of stroke associated with atrial fibrillation in Europe: data from a multicenter multinational hospital-based registry (The European Community Stroke Project). Stroke 2001;32:392-8.

24. Kammersgaard LP, Olsen TS. Cardiovascular risk factors and 5-year mortality in the Copenhagen Stroke Study. Cerebrovasc Dis 2006;21:187-93.

25. Hart RG, Pearce LA, Miller VT, Anderson DC, Rothrock JF, Albers GW, Nasco E. Cardioembolic vs. noncardioembolic strokes in atrial fibrillation: frequency and effect of antithrombotic agents in the stroke prevention in atrial fibrillation studies. Cerebrovasc Dis 2000;10:39-43.

26. Packer DL, Bardy GH, Worley SJ, Smith MS, Cobb FR, Coleman RE, Gallagher JJ, German LD. Tachycardia-induced cardiomyopathy: a reversible form of left ventricular dysfunction. Am J Cardiol 1986;57:563-70.

27. Kang Y, Bahler R. Health-related quality of life in patients newly diagnosed with atrial fibrillation. Eur J Cardiovasc Nurs 2004;3:71-6.

28. Dorian P, Jung W, Newman D, Paquette M, Wood K, Ayers GM, Camm J, Akhtar M, Luderitz B. The impairment of health-related quality of life in patients with intermittent atrial fibrillation: implications for the assessment of investigational therapy. J Am Coll Cardiol 2000;36:1303-9.

29. van den Berg MP, Hassink RJ, Tuinenburg AE, van Sonderen EF, Lefrandt JD, de Kam PJ, van Gelder IC, Smit AJ, Sanderman R, Crijns HJ. Quality of life in patients with paroxysmal atrial fibrillation and its predictors: importance of the autonomic nervous system. Eur Heart J 2001;22:247-53

30. Miyasaka Y, Barnes ME, Gersh BJ, Cha SS, Bailey KR, Abhayaratna WP, Seward JB, Tsang TS. Secular trends in incidence of atrial fibrillation in Olmsted County, Minnesota, 1980 to 2000, and implications on the projections for future prevalence. Circulation 2006;114:119-25.

31. Wolf PA, Benjamin EJ, Belanger AJ, Kannel WB, Levy D, D'Agostino RB. Secular trends in the prevalence of atrial fibrillation: The Framingham Study. Am Heart J 1996;131:790-5.

32. Stewart S, MacIntyre K, MacLeod MM, Bailey AE, Capewell S, McMurray JJ. Trends in hospital activity, morbidity and case fatality related to atrial fibrillation in Scotland, 1986-1996. Eur Heart J 2001;22:693-701. 
33. Wattigney WA, Mensah GA, Croft JB. Increasing trends in hospitalization for atrial fibrillation in the United States, 1985 through 1999: implications for primary prevention. Circulation 2003;108:711-6.

34. Wattigney WA, Mensah GA, Croft JB. Increased atrial fibrillation mortality: United States, 1980-1998. Am J Epidemiol 2002;155:819-26.

35. Wang TJ, Parise H, Levy D, D'Agostino RB, Sr., Wolf PA, Vasan RS, Benjamin EJ. Obesity and the risk of new-onset atrial fibrillation. JAMA 2004;292:2471-7.

36. Djousse L, Levy D, Benjamin EJ, Blease SJ, Russ A, Larson MG, Massaro JM, D’Agostino RB, Wolf PA, Ellison RC. Long-term alcohol consumption and the risk of atrial fibrillation in the Framingham Study. Am J Cardiol 2004;93:710-3.

37. Kannel WB, Wolf PA, Benjamin EJ, Levy D. Prevalence, incidence, prognosis, and predisposing conditions for atrial fibrillation: population-based estimates. Am J Cardiol 1998;82:2N-9N.

38. Hobbs FD, Fitzmaurice DA, Mant J, Murray E, Jowett S, Bryan S, Raftery J, Davies M, Lip G. A randomised controlled trial and cost-effectiveness study of systematic screening (targeted and total population screening) versus routine practice for the detection of atrial fibrillation in people aged 65 and over. The SAFE study. Health Technol Assess 2005;9:iii-iv, ix-x, 1-74.

39. Cooper NJ, Sutton AJ, Lu G, Khunti K. Mixed comparison of stroke prevention treatments in individuals with nonrheumatic atrial fibrillation. Arch Intern Med 2006;166:1269-75.

40. Lip GY, Edwards SJ. Stroke prevention with aspirin, warfarin and ximelagatran in patients with non-valvular atrial fibrillation: A systematic review and meta-analysis. Thromb Res 2006;118: 321-33.

41. Tapson VF, Hyers TM, Waldo AL, Ballard DJ, Becker RC, Caprini JA, Khetan R, Wittkowsky AK, Colgan KJ, Shillington AC. Antithrombotic therapy practices in US hospitals in an era of practice guidelines. Arch Intern Med 2005;165:1458-64.

42. McCormick D, Gurwitz JH, Goldberg RJ, Becker R, Tate JP, Elwell A, Radford MJ. Prevalence and quality of warfarin use for patients with atrial fibrillation in the long-term care setting. Arch Intern Med 2001;161:2458-63.

43. Bradley BC, Perdue KS, Tisdel KA, Gilligan DM. Frequency of anticoagulation for atrial fibrillation and reasons for its non-use at a Veterans Affairs medical center. Am J Cardiol 2000;85:568-72.

44. Darkow T, Vanderplas AM, Lew KH, Kim J, Hauch O. Treatment patterns and real-world effectiveness of warfarin in nonvalvular atrial fibrillation within a managed care system. Curr Med Res Opin 2005;21:1583-94.

45. Go AS, Hylek EM, Borowsky LH, Phillips KA, Selby JV, Singer DE. Warfarin use among ambulatory patients with nonvalvular atrial fibrillation: the anticoagulation and risk factors in atrial fibrillation (ATRIA) study. Ann Intern Med 1999;131:927-34.

46. Stafford RS, Singer DE. Recent national patterns of warfarin use in atrial fibrillation. Circulation 1998;97:1231-3.

47. Deplanque D, Corea F, Arquizan C, Parnetti L, Mas JL, Gallai V, Leys D. Stroke and atrial fibrillation: is stroke prevention treatment appropriate beforehand? SAFE I Study Investigators. Heart 1999;82:563-9.

48. Man-Son-Hing M, Laupacis A. Anticoagulant-related bleeding in older persons with atrial fibrillation: physicians' fears often unfounded. Arch Intern Med 2003;163:1580-6.

49. Flaker GC, Schutz J. Why is warfarin underutilized in patients with atrial fibrillation? J Interv Card Electrophysiol 2004;10 Suppl 1:21-5.

50. Man-Son-Hing M, Gage BF, Montgomery AA, Howitt A, Thomson R, Devereaux PJ, Protheroe J, Fahey T, Armstrong D, Laupacis A. Preference-based antithrombotic therapy in atrial fibrillation: implications for clinical decision making. Med Decis Making 2005;25:548-59.

51. Deplanque D, Leys D, Parnetti L, Schmidt R, Ferro J, De Reuck J, Mas JL, Gallai V. Stroke prevention and atrial fibrillation: reasons leading to an inappropriate management. Main results of the SAFE II study. Br J Clin Pharmacol 2004;57:798-806. 
52. Aguilar M, Hart R. Antiplatelet therapy for preventing stroke in patients with non-valvular atrial fibrillation and no previous history of stroke or transient ischemic attacks. Cochrane Database Syst Rev 2005;4:CD001925.

53. Gage BF, Waterman AD, Shannon W, Boechler M, Rich MW, Radford MJ. Validation of clinical classification schemes for predicting stroke: results from the National Registry of Atrial Fibrillation. JAMA 2001;285:2864-70.

54. Wang TJ, Massaro JM, Levy D, Vasan RS, Wolf PA, D’Agostino RB, Larson MG, Kannel WB, Benjamin EJ. A risk score for predicting stroke or death in individuals with new-onset atrial fibrillation in the community: the Framingham Heart Study. JAMA 2003;290:1049-56.

55. Singer DE, Albers GW, Dalen JE, Go AS, Halperin JL, Manning WJ. Antithrombotic therapy in atrial fibrillation: the Seventh ACCP Conference on Antithrombotic and Thrombolytic Therapy. Chest 2004;126:429S-56S.

56. Gage BF, Boechler M, Doggette AL, Fortune G, Flaker GC, Rich MW, Radford MJ. Adverse outcomes and predictors of underuse of antithrombotic therapy in medicare beneficiaries with chronic atrial fibrillation. Stroke 2000;31:822-7.

57. Humphries KH, Kerr CR, Connolly SJ, Klein G, Boone JA, Green M, Sheldon R, Talajic M, Dorian P, Newman D. New-onset atrial fibrillation: sex differences in presentation, treatment, and outcome. Circulation 2001;103:2365-70.

58. Sudlow M, Thomson R, Thwaites B, Rodgers H, Kenny RA. Prevalence of atrial fibrillation and eligibility for anticoagulants in the community. Lancet 1998;352:1167-71.

59. Willems R, Exner DV. Do population studies confirm the benefit of oral anticoagulation in atrial fibrillation demonstrated in clinical trials? J Interv Card Electrophysiol 2004;10 Suppl 1:9-16.

60. Kalra L, Yu G, Perez I, Lakhani A, Donaldson N. Prospective cohort study to determine if trial efficacy of anticoagulation for stroke prevention in atrial fibrillation translates into clinical effectiveness. BMJ 2000;320:1236-9.

61. Opolski G, Torbicki A, Kosior DA, Szulc M, Wozakowska-Kaplon B, Kolodziej P, Achremczyk P. Rate control vs rhythm control in patients with nonvalvular persistent atrial fibrillation: the results of the Polish How to Treat Chronic Atrial Fibrillation (HOT CAFE) Study. Chest 2004;126:476-86.

62. Van Gelder IC, Hagens VE, Bosker HA, Kingma JH, Kamp O, Kingma T, Said SA, Darmanata JI, Timmermans AJ, Tijssen JG, Crijns HJ. A comparison of rate control and rhythm control in patients with recurrent persistent atrial fibrillation. N Engl J Med 2002;347:1834-40.

63. Wyse DG, Waldo AL, DiMarco JP, Domanski MJ, Rosenberg Y, Schron EB, Kellen JC, Greene HL, Mickel MC, Dalquist JE, Corley SD. A comparison of rate control and rhythm control in patients with atrial fibrillation. N Engl J Med 2002;347:1825-33.

64. Hohnloser SH, Kuck KH, Lilienthal J. Rhythm or rate control in atrial fibrillation-Pharmacological Intervention in Atrial Fibrillation (PIAF): a randomised trial. Lancet 2000;356:1789-94.

65. Carlsson J, Miketic S, Windeler J, Cuneo A, Haun S, Micus S, Walter S, Tebbe U. Randomized trial of rate-control versus rhythm-control in persistent atrial fibrillation: the Strategies of Treatment of Atrial Fibrillation (STAF) study. J Am Coll Cardiol 2003;41:1690-6.

66. Gronefeld GC, Lilienthal J, Kuck KH, Hohnloser SH. Impact of rate versus rhythm control on quality of life in patients with persistent atrial fibrillation. Results from a prospective randomized study. Eur Heart J 2003;24:1430-6.

67. Jenkins LS, Brodsky M, Schron E, Chung M, Rocco T, Jr., Lader E, Constantine M, Sheppard R, Holmes D, Mateski D, Floden L, Prasun M, Greene HL, Shemanski L. Quality of life in atrial fibrillation: the Atrial Fibrillation Follow-up Investigation of Rhythm Management (AFFIRM) study. Am Heart J 2005;149:112-20.

68. Hagens VE, Ranchor AV, Van Sonderen E, Bosker HA, Kamp O, Tijssen JG, Kingma JH, Crijns HJ, Van Gelder IC. Effect of rate or rhythm control on quality of life in persistent atrial fibrillation. Results from the Rate Control Versus Electrical Cardioversion (RACE) Study. J Am Coll Cardiol 2004;43:241-7. 


\section{PART I}

General results of the Euro Heart Survey on atrial fibrillation

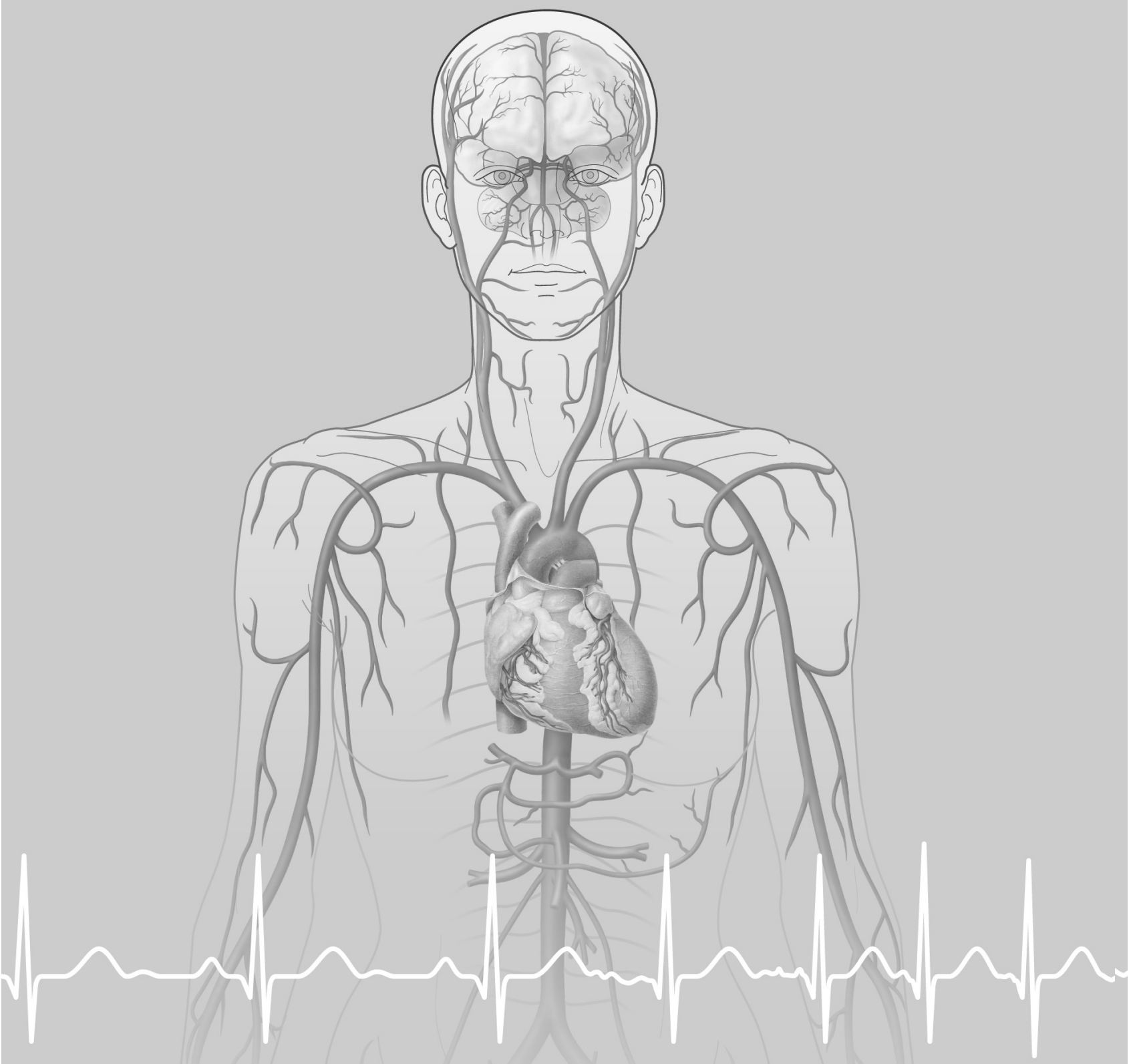



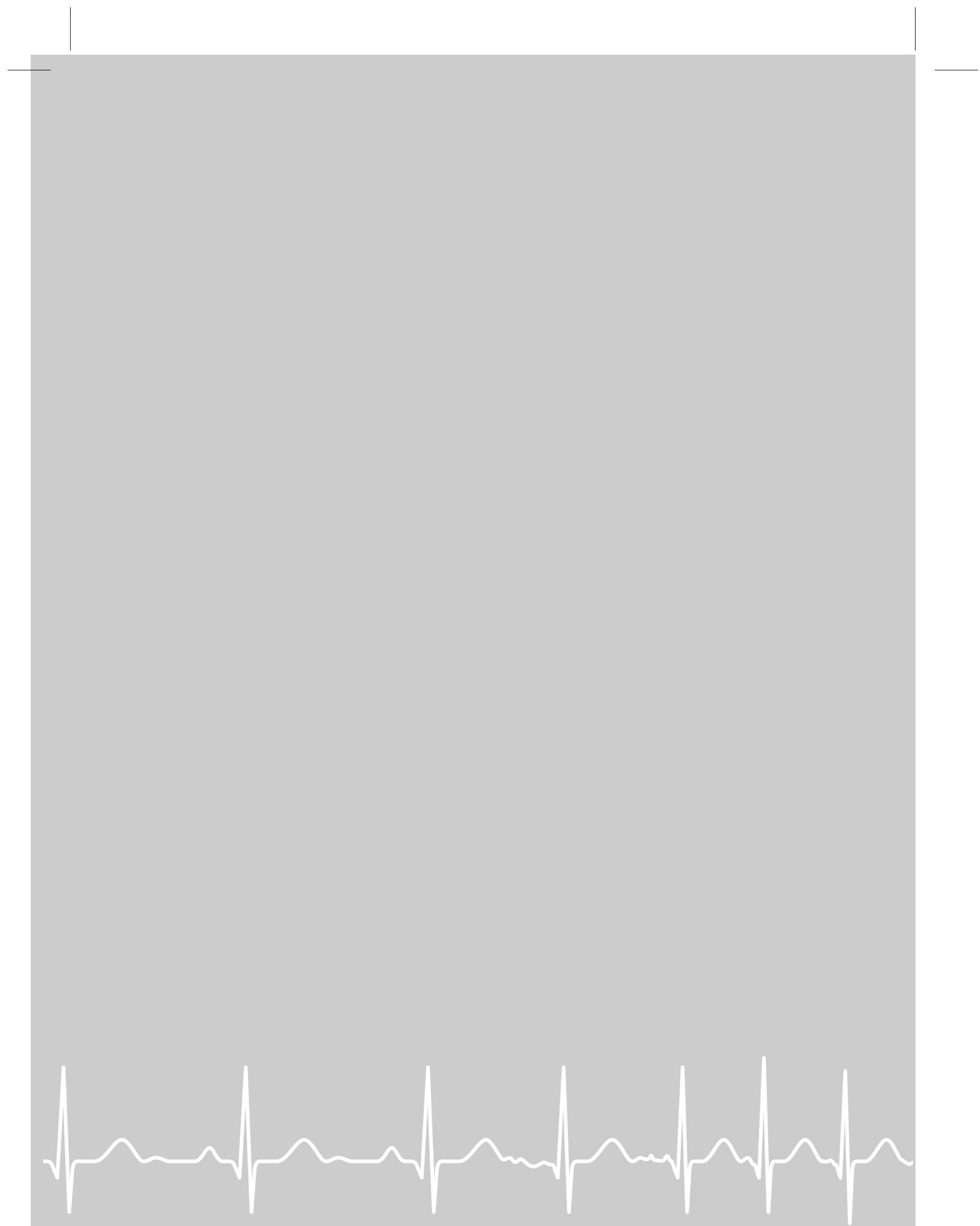
2

\section{Atrial fibrillation management: a} prospective survey in ESC member countries

The Euro Heart Survey on atrial fibrillation

Robby Nieuwlaat, Alessandro Capucci, A. John Camm, S. Bertil Olsson, Dietrich Andresen, Wyn Davies, Stuart M. Cobbe, Günter Breithardt, Jean-Yves Le Heuzey, Martin H. Prins, Samuel Lévy, Harry J. G. M. Crijns

Eur Heart J. 2005;26(22):2422-34

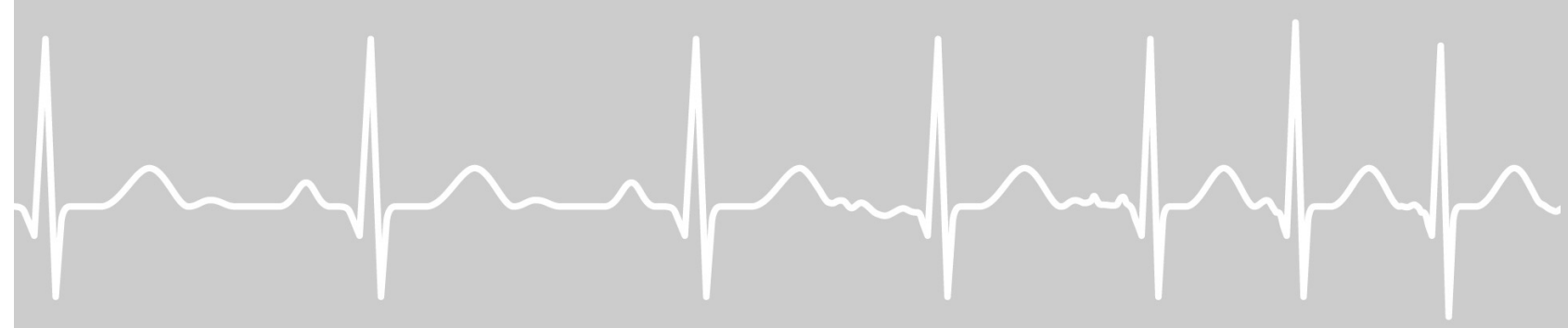




\section{ABSTRACT}

Aims. To describe atrial fibrillation (AF) management in member countries of the European Society of Cardiology (ESC) and to verify cardiology practices against guidelines.

Methods and results. Among 182 hospitals in 35 countries, 5333 ambulant and hospitalized AF patients were enrolled, in 2003 and 2004. AF was primary or secondary diagnosis, and was confirmed on ECG in the preceding 12 months. Clinical type of AF was reported to be first detected in 978, paroxysmal in 1517, persistent in 1167, and permanent in 1547 patients. Concomitant diseases were present in $90 \%$ of all patients, causing risk factors for stroke to be also highly prevalent $(86 \%)$. As many as $69 \%$ of patients were symptomatic at the time of the survey; among asymptomatic patients, $54 \%$ were previously experienced symptoms. Oral anticoagulation was prescribed in 67 and $49 \%$ of eligible and ineligible patients, respectively. A rhythm control strategy was applied in $67 \%$ of currently symptomatic patients and in $44 \%$ of patients who never experienced symptoms.

Conclusion. This survey provides a unique snapshot of current AF management in ESC member countries. Discordance between guidelines and practice was found regarding several issues on stroke prevention and antiarrhythmic therapy 


\section{INTRODUCTION}

Atrial fibrillation (AF) is associated with an increased mortality. ${ }^{1,2}$ In addition, AF causes a five-fold rise in stroke risk and frequently coexists with heart failure, both leading to an even further increase in mortality. ${ }^{3-6}$ Altogether, AF causes a significant economic burden which has grown in the past decades and is expected to grow even further in the upcoming period with the increasing trend in AF prevalence and hospitalizations. ${ }^{7-9}$ Therefore, an adequate treatment strategy is warranted.

In the past decades, treatment modalities of AF have been studied extensively. Two arrhythmia strategies for the treatment of AF are actually proposed: rate control and rhythm control. Rate control aims at slowing the ventricular rate during AF, whereas rhythm control targets termination of AF and maintenance of sinus rhythm. Recent randomised studies indicated that there is no significant difference in long-term outcome between both treatments. ${ }^{10-15}$ For stroke prevention, numerous trials showed a beneficial effect of anticoagulation above aspirin or placebo in patients with a high risk for stroke, although the risk for bleeding is increased. ${ }^{16,17}$ In patients with a low risk for stroke, the bleeding risk of anticoagulation therapy outweighs the benefit of stroke prevention, but aspirin is recommended in these patients. ${ }^{17,18}$

Owing to the variety of clinical presentations and treatment options for AF, heterogeneity in 'real-life' management of AF is expected. The European Society of Cardiology (ESC), the American Heart Association (AHA), and the American College of Cardiology (ACC) recognized the need to review the currently available information on $\mathrm{AF}$, and produced guidelines for $\mathrm{AF}$ management (ACC/AHA/ ESC guidelines on AF). ${ }^{19}$ The guidelines have been distributed from 2001, but it remains unclear how well clinicians adhere to them.

Several population-based studies provided information on the incidence, prevalence, and outcome of AF in the general population. ${ }^{1,2,8,20-26} \mathrm{AF}$ management has also been described by national and local surveys and registries in general practices, ${ }^{27-29}$ and hospitals. ${ }^{30-32}$ However, there are no prospective data so far regarding the frequency and outcome of the different types of AF in the clinical setting for the total spectrum of ESC member countries. Furthermore, it is unknown whether the actual clinical management of $\mathrm{AF}$ in the member countries conforms to the ACC/AHA/ESC guidelines. Therefore, the Euro Heart Survey (EHS) committee of the ESC decided to perform a survey on the management of AF to verify practice against AF guidelines, to compare AF patients in clinical studies with AF patients in clinical practice, and to compare different management strategies in relation to outcome.

The first results of the Euro Heart Survey on atrial fibrillation are presented here. 


\section{METHODS}

The Euro Heart Survey on AF is a multi-centre prospective observational study among cardiology practices in ESC member countries. For each country, the national coordinator supplied a list of centres that would be suitable to participate in the survey, aiming on a composition of university and non-university centres, and specialized centres that would be representative for local medical practice. Consecutive patients per site of enrolment were requested from the following sites: outpatient clinic, cardiology ward, first (heart) aid, electrical cardioversion department, electrophysiology laboratory, pacemaker and ICD implantation department, and cardiac surgery. All patients were managed according to the usual local institutional practice. Each centre filled in an electronic questionnaire on local infrastructure for AF care. Patients were enrolled if they were 18 years or older and had AF on ECG or Holter recording during the qualifying admission/consultation, or in the preceding 12 months. Patients with only atrial flutter on their ECGs were excluded. Enrolment started on 19 September 2003 and continued till 16 July 2004. Data collection was finished on 11 August 2004. Patients were enrolled in 182 centres from 35 ESC member countries. Participating countries were divided among three regions (Table 1).

\section{Data collection and validation}

In each centre, data were collected using an electronic case report form (CRF: www.euroheartsurvey.org). Data were transferred through Internet to the central database in the European Heart House. Data were either entered online or offline with frequent data transfer. By using a validation plan, integrated in the data entry software, data were checked for missing or contradictory entries and values out of the normal range. Additional edit checks were performed by the EHS staff at the European Heart House and by the EHS-AF Data Analysis Centre at the University Hospital Maastricht. Patient identification was registered in the participating centres, but was not transferred to the central database.

\section{Data analysis}

Data analysis was performed with SPSS statistical software (SPSS, Inc., release 12.01). Continuous variables are reported as mean \pm standard deviation, and categorical variables as number of observed patients (percentage). Owing to incomplete answers, missing variables and multiple answering options, observed numbers and percentages do not always add up to exactly $100 \%$. Tables are presented according to type of AF. Differences for continuous variables were tested with independent t-test when comparing two groups and with ANOVA when comparing the four clinical types of AF, and categorical variables were tested with $\chi^{2}$ statistic. Because of 
the large population sample, comparisons that are reported as different had $\mathrm{P}<0.001$ in all instances.

\section{RESULTS}

\section{Patient enrolment}

We enrolled 5333 AF patients in 35 countries; 1354 in western European, 1530 in central European, and 2449 in Mediterranean countries. Details of centre participation and patient enrolment per country and per region are shown in Table 1. Patient enrolment varied significantly among participating countries, with Spain, Italy, and the Netherlands as very high contributors. Nevertheless, the proportion of enrolled patients in relation to all prevalent AF patients in the participating countries appeared to be comparable among the three regions. ${ }^{33}$ Of 182 participating centres, 141 centres $(78 \%)$ enrolled more than 10 patients. Almost half of the participating centres $(46 \%)$ were a university centre, and within centres the vast majority of patients was enrolled at the cardiology ward (56\%) or cardiology outpatient clinic (34\%). An electrophysiology department was present in 101 centres (56\%), and 114 centres $(63 \%)$ had an outpatient clinic for anticoagulation monitoring.

Patients were categorized into a clinical type of AF, based on the physician's perception of the $A F$ at the time of presentation for the survey (for definitions of clinical AF types, see Appendix A). First detected AF was reported in 978 patients, paroxysmal AF in 1517 patients, persistent AF in 1167 patients, permanent $\mathrm{AF}$ in 1541 patients, and unknown AF in 130 patients. The four clinical types of AF were equally often enrolled in the different types of centres, but permanent AF patients were more often enrolled at the outpatient cardiology clinic (Table 2).

\section{Patient characteristics}

Patients with permanent AF as their qualifying arrhythmia were older and more often had heart failure, valvular heart disease, or a previous stroke/TIA (Table 3). In addition, artificial pacemakers were more prevalent in these patients. Paroxysmal and first detected AF were more often idiopathic than the other two AF types. Patients with an unknown AF type were comparable to permanent AF patients regarding age $(70 \pm 13)$ years), gender $(55 \%$ males $)$, previous pharmacological cardioversion (16\%), electrical cardioversion $(21 \%)$ and catheter ablation (2\%). However, prevalence of heart failure (34\%) and a previous stroke/TIA (10\%) were more comparable with persistent $\mathrm{AF}$, whereas idiopathic $\mathrm{AF}$ was even equally often present as in paroxysmal AF (15\%).

Hypertension was by far the most prevalent associated medical condition. Coronary artery disease and heart failure were present in one out of three patients. Combinations of associated diseases were found in $60 \%$ of patients, of which hypertension with coronary artery disease and hypertension with heart failure 
26 | CHAPTER 2

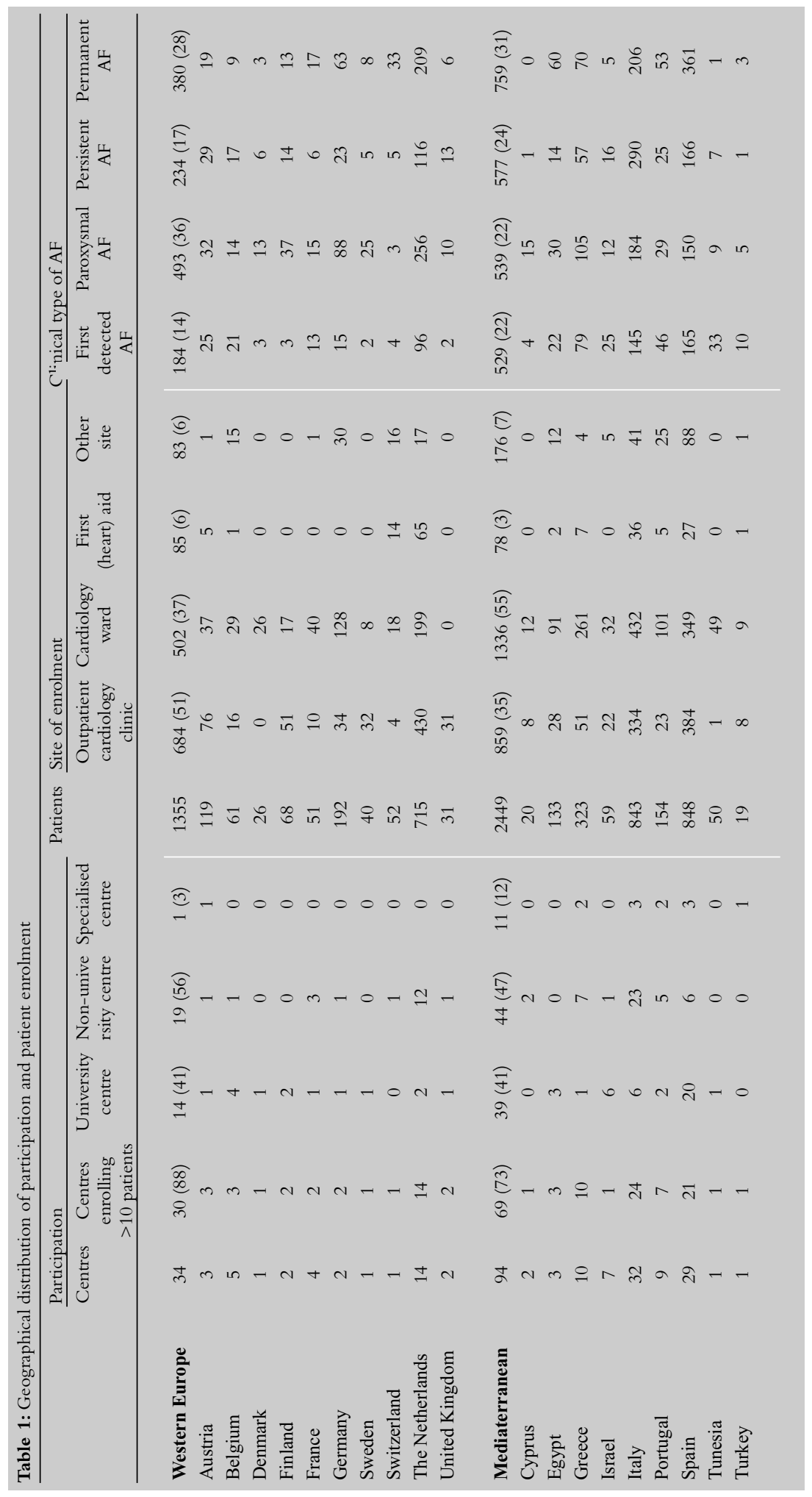




\begin{tabular}{|c|c|c|}
\hline 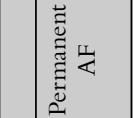 & 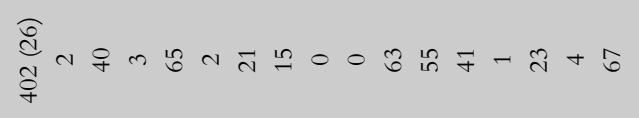 & 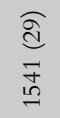 \\
\hline 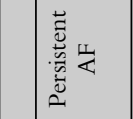 & 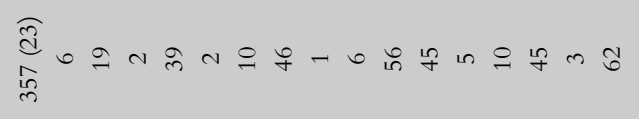 & $\begin{array}{l}\underset{d}{d} \\
\infty \\
\stackrel{0}{=}\end{array}$ \\
\hline 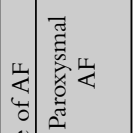 & 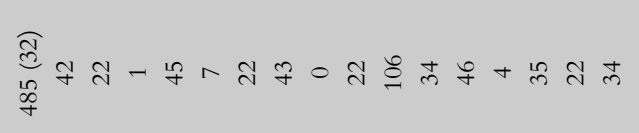 & $\begin{array}{c}\stackrel{\infty}{d} \\
\stackrel{i}{i n}\end{array}$ \\
\hline 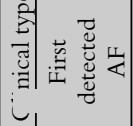 & 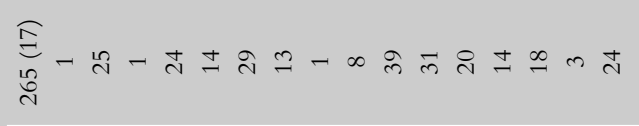 & $\underset{\substack{\infty \\
\infty \\
\infty}}{\infty}$ \\
\hline 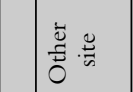 & 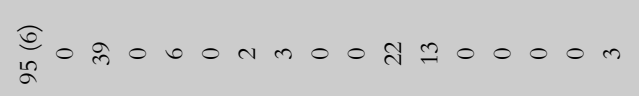 & E \\
\hline 尊 & $\int_{0}^{\mathrm{d}}--0,00-00 \mathrm{y} 000000$ & $\begin{array}{l}\text { I } \\
\stackrel{5}{\sigma}\end{array}$ \\
\hline 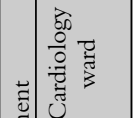 & 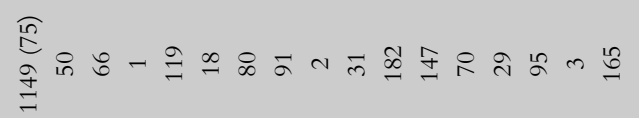 & 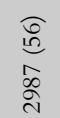 \\
\hline 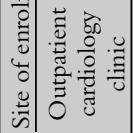 & 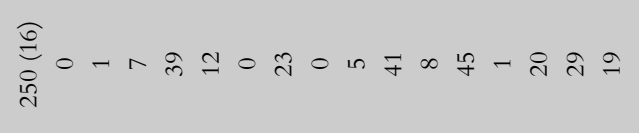 & 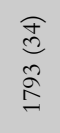 \\
\hline & 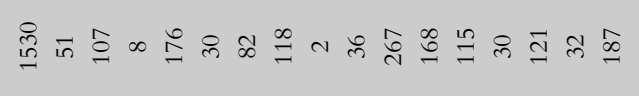 & 总 \\
\hline 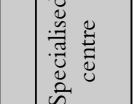 & 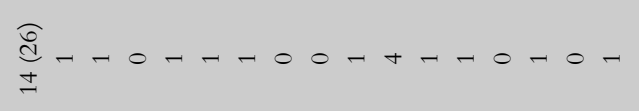 & 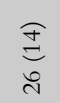 \\
\hline 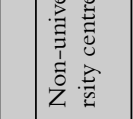 & 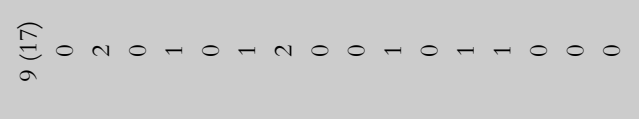 & 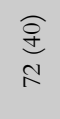 \\
\hline 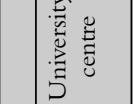 & $\int_{0}^{\infty} 0 a-40-4-0,0 \ln n-m-m$ & $\underset{\infty}{\infty} \underset{\infty}{\infty}$ \\
\hline : & $\frac{d}{a^{2}}-+0+-4+0-\infty+t \rightarrow+t m$ & 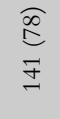 \\
\hline 离 & 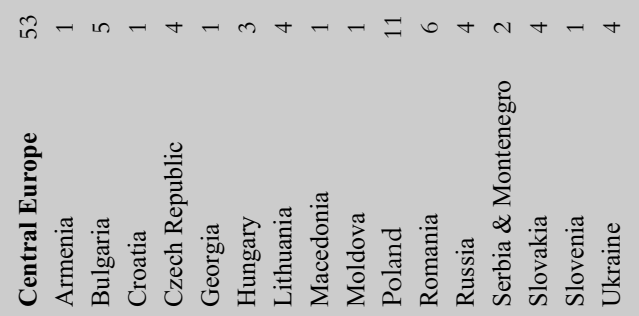 & $\overline{\overline{\tilde{g}}}$ \\
\hline
\end{tabular}


Table 2. Distribution of participation and patient enrolment per clinical type of atrial fibrillation.

\begin{tabular}{lccccc}
\hline & $\begin{array}{c}\text { First detected } \\
(\mathrm{n}=978)\end{array}$ & $\begin{array}{c}\text { Paroxysmal } \\
(\mathrm{n}=1517)\end{array}$ & $\begin{array}{c}\text { Persistent } \\
(\mathrm{n}=1167)\end{array}$ & $\begin{array}{c}\text { Permanent } \\
(\mathrm{n}=1541)\end{array}$ & P-value \\
\hline $\begin{array}{l}\text { Type of centre } \\
\text { University }\end{array}$ & $481(49)$ & $669(44)$ & $572(49)$ & $731(48)$ & \\
$\quad$ Non-university & $344(35)$ & $596(39)$ & $457(39)$ & $619(40)$ & \\
$\quad$ Specialised & $149(15)$ & $247(16)$ & $136(12)$ & $188(12)$ & \\
Site of inclusion & & & & & \\
$\quad$ Cardiology ward & $622(64)$ & $842(56)$ & $711(61)$ & $750(49)$ & $\star$ \\
Outpatient clinic & $209(21)$ & $524(35)$ & $371(32)$ & $633(41)$ & $\star$ \\
First (heart) aid & $54(6)$ & $83(6)$ & $32(3)$ & $25(2)$ & $\star$ \\
Other site & $93(9)$ & $67(4)$ & $53(5)$ & $132(9)$ & $\star$ \\
\hline
\end{tabular}

Data are presented as observed number (\%) within type of AF. ${ }^{\star}$ Difference with $\mathrm{P}<0.001$ among the four AF types.

(both 24\%) were the most frequent ones. Altogether, $90 \%$ of AF patients in this survey had at least one associated medical condition. Besides hypertension, other risk factors for coronary artery disease were remarkably frequent, because $18 \%$ of all patients was diabetic and $25 \%$ severely obese $\left(B M I>30 \mathrm{~kg} / \mathrm{m}^{2}\right)$. Of permanent AF patients, $9 \%$ previously suffered from a stroke, in contrast to $4 \%$ of the other AF patients. Previous pharmacological conversion was most often performed in paroxysmal AF patients and electrical cardioversion most often in persistent AF patients. After first detected AF, permanent AF patients had fewest previous cardioversions. As many as $10-15 \%$ of patients participated in a clinical trial. These patients were more frequently categorized as paroxysmal AF ( 37 vs. $28 \%$ ), far more often enrolled in a specialized centre ( 40 vs. $11 \%$ ), but were of similar age ( $67 \pm 13$ vs. $65 \pm 13$ ) years) compared with patients not participating in a clinical trial.

\section{Patient characteristics on admission or at consultation}

Logically the most frequent reason for the qualifying admission or consultation was AF, but it was often accompanied by other reasons, especially in patients with permanent AF (Table 4). The majority of patients reported current AF symptoms $(69 \%)$ or had suffered from AF symptoms in the past (54\% of currently asymptomatic patients), with relatively the lowest symptom burden in permanent AF. Paroxysmal AF patients were currently least frequent in AF. Patients with a first detected episode had a higher ventricular rate on admission. In accordance with the highest prevalence of heart failure, permanent AF patients more often had NYHA functional class III or IV and a broader QRS complex. An increased left atrial diameter was seen in persistent AF and is more pronounced in permanent AF. Duration of the current AF episode was reported to be longer than 7 days in 61 (4\%) patients 


\begin{tabular}{|c|c|c|c|c|c|}
\hline & $\begin{array}{l}\text { First detected } \\
\quad(\mathrm{n}=978)\end{array}$ & $\begin{array}{c}\text { Paroxysmal } \\
(\mathrm{n}=1517)\end{array}$ & $\begin{array}{l}\text { Persistent } \\
(\mathrm{n}=1167)\end{array}$ & $\begin{array}{l}\text { Permanent } \\
(n=1541)\end{array}$ & P-value \\
\hline \multicolumn{6}{|l|}{ Demographics } \\
\hline Age, years & $65 \pm 14$ & $64 \pm 13$ & $66 \pm 12$ & $71 \pm 11$ & $\star$ \\
\hline Female gender & $418(43)$ & $652(43)$ & $451(39)$ & $668(43)$ & \\
\hline \multicolumn{6}{|l|}{ Concomitant Disease } \\
\hline Hypertension & $620(63)$ & $942(62)$ & $772(66)$ & $984(64)$ & \\
\hline Coronary artery disease & $309(32)$ & $514(34)$ & $338(29)$ & $543(36)$ & \\
\hline Acute infarction & $65(7)$ & $32(2)$ & $24(2)$ & $41(3)$ & $\star$ \\
\hline Old infarction & $124(13)$ & $228(15)$ & $142(12)$ & $259(17)$ & \\
\hline Previous PCI / CABG & $102(11)$ & $187(12)$ & $136(12)$ & $166(11)$ & \\
\hline Angina & $179(19)$ & $350(23)$ & $172(15)$ & $304(20)$ & $\star$ \\
\hline Heart failure & $255(26)$ & $341(23)$ & $401(35)$ & $754(49)$ & $\star$ \\
\hline Valvular heart disease & $203(21)$ & $287(19)$ & $276(24)$ & $607(40)$ & $\star$ \\
\hline Cardiomyopathy & $79(8)$ & $101(7)$ & $148(13)$ & $243(16)$ & $\star$ \\
\hline Tachycardiomyopathy & $9(1)$ & $4(0)$ & $28(2)$ & $14(1)$ & $\star$ \\
\hline Hypertrophic & $25(3)$ & $34(2)$ & $24(2)$ & $21(1)$ & \\
\hline Dilated & $38(4)$ & $49(3)$ & $73(6)$ & $152(10)$ & \\
\hline Other type & $7(1)$ & $14(1)$ & $23(2)$ & $56(4)$ & \\
\hline Sick sinus syndrome & $9(1)$ & $93(6)$ & $55(5)$ & $82(5)$ & $\star$ \\
\hline COPD & $103(11)$ & $185(12)$ & $133(12)$ & $272(18)$ & $\star$ \\
\hline Thyroid disease & $61(7)$ & $148(11)$ & $132(12)$ & $149(11)$ & \\
\hline Idiopathic $\mathrm{AF}^{\mathrm{a}}$ & $130(14)$ & $226(15)$ & $112(10)$ & $61(4)$ & $\star$ \\
\hline \multicolumn{6}{|l|}{ Cardiovascular Risk Factors } \\
\hline Diabetes Mellitus & $187(19)$ & $232(15)$ & $186(16)$ & $336(22)$ & $\star$ \\
\hline Hyperlipidemia & $309(32)$ & $588(40)$ & $413(36)$ & $518(34)$ & \\
\hline Current smoker & $181(19)$ & $204(14)$ & $128(11)$ & $120(8)$ & $\star$ \\
\hline No regular exercise & $484(51)$ & $596(42)$ & $488(44)$ & $785(53)$ & $\star$ \\
\hline Family history of CAD & $111(14)$ & $291(23)$ & $195(20)$ & $252(20)$ & $\star$ \\
\hline \multicolumn{6}{|l|}{ Co-morbidities } \\
\hline Previous thromboembolism & $87(9)$ & $158(11)$ & $122(11)$ & $273(18)$ & $\star$ \\
\hline Stroke & $41(4)$ & $64(4)$ & $51(4)$ & $135(9)$ & $\star$ \\
\hline TIA & $28(3)$ & $83(6)$ & $56(5)$ & $98(6)$ & \\
\hline Other thromboembolism & $24(3)$ & $25(2)$ & $27(2)$ & $72(5)$ & $\star$ \\
\hline Prior major bleeding & $6(1)$ & $19(1)$ & $16(1)$ & $45(3)$ & $\star$ \\
\hline Malignancy & $49(5)$ & $73(5)$ & $54(5)$ & $97(6)$ & \\
\hline Peripheral vascular disease & $59(6)$ & $97(7)$ & $77(7)$ & $162(11)$ & $\star$ \\
\hline Renal failure & $41(4)$ & $84(6)$ & $60(5)$ & $119(8)$ & \\
\hline \multicolumn{6}{|l|}{ Previous interventions } \\
\hline Pharmacological cardioversion & $106(11)$ & $733(49)$ & $435(37)$ & $291(19)$ & $\star$ \\
\hline Electrical cardioversion & $39(4)$ & $388(26)$ & $436(38)$ & $324(21)$ & $\star$ \\
\hline Catheter ablation & $0(0)$ & $78(5)$ & $45(4)$ & $24(2)$ & $\star$ \\
\hline Pacemaker implantation & $19(2)$ & $88(6)$ & $51(4)$ & $145(9)$ & $\star$ \\
\hline ICD implantation & $4(0)$ & $23(2)$ & $11(1)$ & $18(1)$ & \\
\hline Surgery for AF & $2(2)$ & $12(1)$ & $9(1)$ & $6(0)$ & \\
\hline \multicolumn{6}{|l|}{ Miscellaneous } \\
\hline Clinical trial & $96(10)$ & $229(15)$ & $136(12)$ & $163(11)$ & $\star$ \\
\hline
\end{tabular}

Data are presented as mean (standard deviation) or observed number (\%) within type of AF. ${ }^{\star}$ Difference with $\mathrm{P}<0.001$ among the four AF types. ${ }^{a}$ None of the reported concomitant diseases. PCI, percutaneous coronary intervenion; $\mathrm{CABG}$, coronary artery bypass grafting; CAD, coronary artery disease; TIA, transient ischaemic attack; ICD, implantable cardioverter defibrillator. 
Table 4. Admission / consultation information

\begin{tabular}{|c|c|c|c|c|c|}
\hline & $\begin{array}{l}\text { First detected } \\
\qquad(\mathrm{n}=978)\end{array}$ & $\begin{array}{c}\text { Paroxysmal } \\
(\mathrm{n}=1517)\end{array}$ & $\begin{array}{l}\text { Persistent } \\
(n=1167)\end{array}$ & $\begin{array}{c}\text { Permanent } \\
(\mathrm{n}=1541)\end{array}$ & P-value \\
\hline \multicolumn{6}{|l|}{ Reason admission / consultation } \\
\hline AF only & $446(46)$ & $709(47)$ & $577(50)$ & $361(24)$ & $\star$ \\
\hline AF \& other reason & $375(38)$ & $559(37)$ & $472(41)$ & $772(50)$ & $\star$ \\
\hline Other reason only & $156(16)$ & $247(16)$ & $116(10)$ & $404(26)$ & * \\
\hline \multicolumn{6}{|l|}{ Symptoms } \\
\hline Current AF symptoms ${ }^{\mathrm{a}}$ & $749(77)$ & $1167(77)$ & $854(73)$ & $848(55)$ & 夫 \\
\hline Previous AF symptoms & $62(7)$ & $235(16)$ & $173(15)$ & $287(20)$ & $\star$ \\
\hline Never AF symptoms & $150(16)$ & $86(6)$ & $119(10)$ & $293(21)$ & $\star$ \\
\hline Heart failure NYHA class III / IV & $162(17)$ & $113(8)$ & $170(15)$ & $382(25)$ & $\star$ \\
\hline \multicolumn{6}{|l|}{ Physical examination } \\
\hline Body mass index, $\mathrm{kg} / \mathrm{m}^{2}$ & $28 \pm 6$ & $28 \pm 9$ & $28 \pm 9$ & $27 \pm 5$ & \\
\hline Systolic blood pressure, $\mathrm{mmHg}$ & $135 \pm 23$ & $136 \pm 22$ & $136 \pm 22$ & $136 \pm 22$ & \\
\hline Diastolic blood pressure, $\mathrm{mmHg}$ & $80 \pm 14$ & $81 \pm 13$ & $82 \pm 13$ & $79 \pm 13$ & $\star$ \\
\hline \multicolumn{6}{|l|}{ Electrocardiogram } \\
\hline Atrial fibrillation & $736(75)$ & $816(54)$ & $867(74)$ & $1486(97)$ & $\star$ \\
\hline Left ventricular hypertrophy & $160(17)$ & $272(19)$ & $234(21)$ & $344(23)$ & $\star$ \\
\hline Left bundle branch block & $58(6)$ & $101(7)$ & $82(7)$ & $144(10)$ & $\star$ \\
\hline Right bundle branch block & $60(6)$ & $101(7)$ & $73(6)$ & $148(10)$ & $\star$ \\
\hline Heart rate, bpm & $103 \pm 34$ & $91 \pm 32$ & $90 \pm 29$ & $87 \pm 26$ & $\star$ \\
\hline QRS duration, ms & $93 \pm 25$ & $97 \pm 28$ & $99 \pm 27$ & $104 \pm 31$ & $\star$ \\
\hline \multicolumn{6}{|l|}{ Transtoracic echocardiography ${ }^{b}$} \\
\hline Left atrial diameter, $\mathrm{mm}$ & $43 \pm 8$ & $43 \pm 7$ & $46 \pm 8$ & $51 \pm 17$ & $\star$ \\
\hline Left ventricular ejection fraction, $\%$ & $52 \pm 14$ & $53 \pm 14$ & $51 \pm 15$ & $51 \pm 15$ & \\
\hline Left ventricular hypertrophy & $249(34)$ & $380(33)$ & $336(36)$ & $401(35)$ & \\
\hline
\end{tabular}

classified as paroxysmal $\mathrm{AF}$, and $3 \%$ of patients classified as permanent $\mathrm{AF}$ were not currently in AF.

\section{Diagnostics and interventions}

The vast majority of patients underwent a transthoracic echocardiogram and a chest $\mathrm{X}$-ray (Table 5). Either a transthoracic or transesophageal echocardiogram was done in $86 \%$ of patients. The patients who did not undergo echocardiography were older $(69 \pm 14)$ vs. $66 \pm 13)$ years), presented more frequently as first detected AF (28 vs. $17 \%$ ), were more often enrolled in a non-university centre (49 vs. $37 \%$ ), or enrolled in Western European countries (35 vs. 24\%). The other diagnostic procedures were most often used in paroxysmal AF patients, except for transesophageal echo- 


\begin{tabular}{|c|c|c|c|c|c|}
\hline & $\begin{array}{l}\text { First detected } \\
(\mathrm{n}=978)\end{array}$ & $\begin{array}{c}\text { Paroxysmal } \\
(\mathrm{n}=1517)\end{array}$ & $\begin{array}{l}\text { Persistent } \\
(\mathrm{n}=1167)\end{array}$ & $\begin{array}{l}\text { Permanent } \\
(\mathrm{n}=1541)\end{array}$ & P-value \\
\hline \multicolumn{6}{|l|}{ Diagnostics $^{a}$} \\
\hline Transthoracic echocardiography & $757(78)$ & $1275(84)$ & $1025(88)$ & $1332(87)$ & $\star$ \\
\hline Chest X-ray & $803(82)$ & $1155(77)$ & $923(80)$ & $1321(86)$ & $\star$ \\
\hline Holter monitoring & $135(14)$ & $549(36)$ & $323(28)$ & $511(31)$ & $\star$ \\
\hline Exercise Test & $126(13)$ & $442(29)$ & $234(20)$ & $263(17)$ & $\star$ \\
\hline Transesophageal echocardiography & $114(12)$ & $173(11)$ & $227(20)$ & $166(11)$ & $\star$ \\
\hline Electrophysiology study & $14(1)$ & $143(10)$ & $81(7)$ & $66(4)$ & $\star$ \\
\hline Event recorder & $20(2)$ & $36(2)$ & $19(2)$ & $11(1)$ & \\
\hline Thyroid hormone levels measurement & $394(40)$ & $782(52)$ & $644(55)$ & $609(40)$ & $\star$ \\
\hline \multicolumn{6}{|l|}{ Interventions $^{b}$} \\
\hline Pharmacological conversion & $378(39)$ & $496(33)$ & $213(18)$ & $41(3)$ & $\star$ \\
\hline Electrical cardioversion & $191(20)$ & $216(14)$ & $424(36)$ & $69(5)$ & $\star$ \\
\hline Catheter ablation & $0(0)$ & $75(5)$ & $43(4)$ & $16(1)$ & $\star$ \\
\hline Pacemaker implantation & $14(1)$ & $54(4)$ & $29(3)$ & $101(7)$ & $\star$ \\
\hline ICD implantation & $0(0)$ & $4(0)$ & $9(1)$ & $14(1)$ & \\
\hline AF surgery & $0(0)$ & $4(0)$ & $2(0)$ & $1(0)$ & \\
\hline
\end{tabular}

cardiography, which was relatively frequently used in persistent AF patients. Of all current transesophageal echocardiograms, $71 \%$ was used in connection with a current or planned electrical cardioversion. Thyroid hormone levels were reported in only half of the patients. Patients without assessment of thyroid function were of similar age (66 \pm 13$)$ vs. $67 \pm 12$ years), more often male (61 vs. $54 \%)$, presented more frequently with first detected (21 vs. $16 \%$ ) and permanent AF (34 vs. $25 \%)$, and were more often enrolled in a university centre (50 vs. 44\%), a specialized centre (17 vs. $10 \%$ ), or in a Central European country ( 35 vs. $22 \%$ ), compared with patients with thyroid function assessment. In the subset of patients currently on amiodarone thyroid hormone levels, measurement was performed at least once or planned in $60 \%$ of patients, which is just slightly more often than the application in patients not currently on amiodarone $(56 \%)$.

Pharmacological conversions were mainly applied in first detected and paroxysmal AF, whereas electrical cardioversions were preferred in persistent AF. A minority of patients that had been classified as having permanent AF underwent pharmacological or electrical cardioversion. Catheter ablation was infrequently applied, predominantly in paroxysmal and persistent AF. Catheter ablation was related to pacemaker implantation in five paroxysmal, three persistent, and seven permanent AF patients. 
Table 6. Drug therapy at discharge / end of visit

\begin{tabular}{|c|c|c|c|c|c|}
\hline & $\begin{array}{l}\text { First detected } \\
\quad(\mathrm{n}=960)\end{array}$ & $\begin{array}{c}\text { Paroxysmal } \\
(\mathrm{n}=1509)\end{array}$ & $\begin{array}{l}\text { Persistent } \\
(\mathrm{n}=1155)\end{array}$ & $\begin{array}{l}\text { Permanent } \\
(\mathrm{n}=1515)\end{array}$ & P-value \\
\hline \multicolumn{6}{|l|}{ Antithrombotic } \\
\hline Oral anticoagulation & $495(53)$ & $744(51)$ & $898(80)$ & $1134(76)$ & $\star$ \\
\hline Aspirin & $340(36)$ & $535(36)$ & $236(21)$ & $379(25)$ & $\star$ \\
\hline Other $^{\mathrm{a}}$ & $145(16)$ & $188(13)$ & $99(9)$ & $169(11)$ & $\star$ \\
\hline Combination of above & $157(17)$ & $165(11)$ & $145(13)$ & $225(15)$ & $\star$ \\
\hline None & $124(13)$ & $183(12)$ & $46(4)$ & $65(4)$ & $\star$ \\
\hline \multicolumn{6}{|l|}{ Antiarrhythmic / rate control ${ }^{b}$} \\
\hline Type IA $^{c}$ & $4(0)$ & $14(1)$ & $6(1)$ & $1(0)$ & \\
\hline Type IC ${ }^{d}$ & $56(6)$ & $260(17)$ & $151(13)$ & $22(2)$ & $\star$ \\
\hline Type II $^{\mathrm{e}}$ & $278(29)$ & $438(29)$ & $339(30)$ & $443(30)$ & \\
\hline Type III $^{\mathrm{f}}$ & $317(33)$ & $551(37)$ & $483(43)$ & $224(15)$ & $\star$ \\
\hline Type $I V^{\mathrm{g}}$ & $71(8)$ & $126(8)$ & $89(8)$ & $177(12)$ & $\star$ \\
\hline Digitalis $^{\mathrm{h}}$ & $159(17)$ & 207 (14) & $260(23)$ & $743(50)$ & $\star$ \\
\hline None & $213(23)$ & $215(15)$ & $128(11)$ & $280(19)$ & $\star$ \\
\hline \multicolumn{6}{|l|}{ Other medication } \\
\hline ACE inhibitor & $446(48)$ & $660(45)$ & $590(52)$ & $795(53)$ & $\star$ \\
\hline AT II receptor blocker & $105(11)$ & $177(12)$ & $162(14)$ & 205 (14) & \\
\hline Beta blockeri & $140(15)$ & $202(14)$ & $160(14)$ & $236(16)$ & \\
\hline $\begin{array}{l}\text { Dihydropyridin calcium channel } \\
\text { blocker }\end{array}$ & $107(12)$ & $215(15)$ & $151(13)$ & $166(11)$ & \\
\hline Diuretic & $406(44)$ & $570(39)$ & $579(51)$ & $1043(70)$ & $\star$ \\
\hline Nitrate & $146(16)$ & $256(17)$ & $146(13)$ & $310(21)$ & $\star$ \\
\hline Statin & $221(24)$ & $414(28)$ & $286(25)$ & $362(24)$ & \\
\hline Diabetic therapy & $137(15)$ & $166(11)$ & $128(11)$ & $252(17)$ & $\star$ \\
\hline Thyroid therapy & $31(3)$ & $94(6)$ & $85(8)$ & $80(5)$ & $\star$ \\
\hline
\end{tabular}

Data are presented as observed number (\%) within type of AF. ${ }^{*}$ Difference with $\mathrm{P}<0.001$ among the four AF types. a Clopidogrel, ticlopidin, dipyridamole, heparin, or non-specified. b Antiarrhythmic drugs according to the Vaughan Williams classification ${ }^{33}$, if possible. ${ }^{c}$ Bepridil, cibenzoline, disopyramide, procainamide, quinidine. ${ }^{d}$ Flecainide, propafenone. e Beta-blocker for antiarrhythmic indication. Amiodarone, sotalol. g Diltiazem, verapamil. ${ }^{\mathrm{h}}$ Digoxin, digitoxin. ${ }^{\mathrm{i}}$ Beta-blocker not for antiarrhythmic indication.

\section{Drug therapy}

Drug therapy at discharge or end of visit was known for 5157 patients. Oral anticoagulation $(\mathrm{OAC})$ was prescribed in the majority of AF patients, especially in persistent and permanent AF (Table 6). Few patients did not receive any antithrombotic treatment. Of all patients, $40 \%$ received antiarrhythmic medication, $65 \%$ rate control medication, and 12\% neither of these. Type IA drugs (Vaughan Williams classification ${ }^{34}$ ) were hardly used. Type IC antiarrhythmic drugs were mainly prescribed in patients with paroxysmal or persistent AF. Of note, $3 \%$ of 


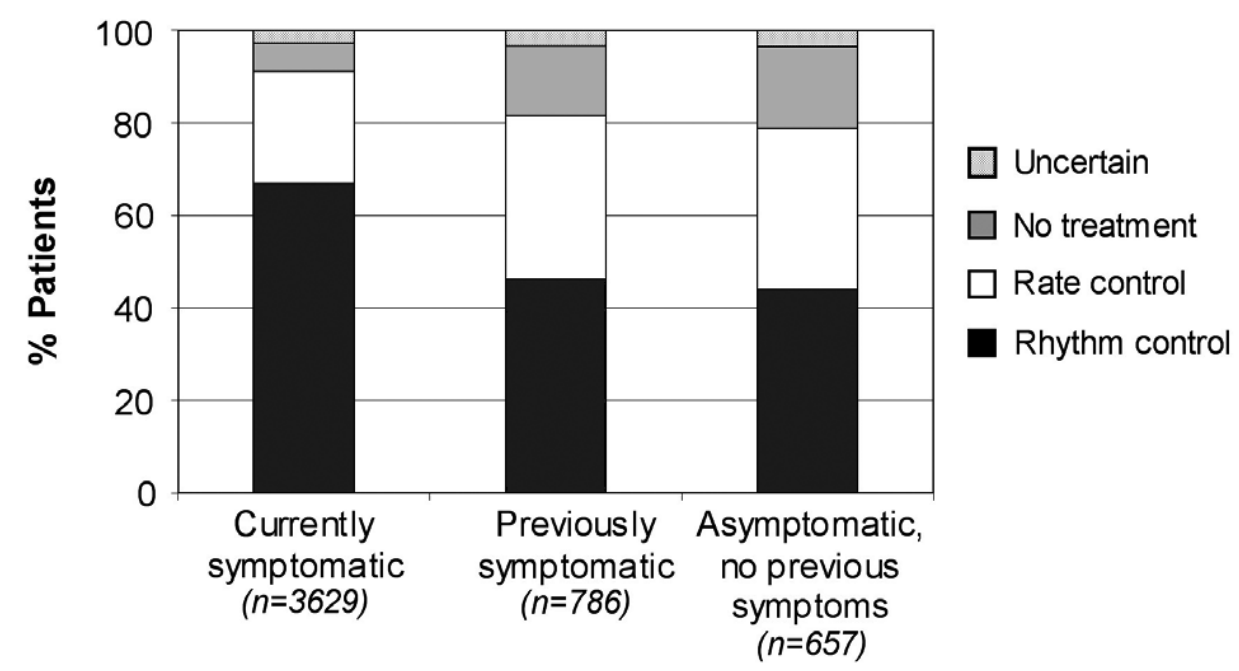

Figure 1. Heart rhythm management strategy in patients who were symptomatic at the time of the survey, in patients who were not symptomatic at the time of the survey but who had been symptomatic in the past, and in patients who had never experienced any symptoms. Definitions for rhythm control, rate control, and symptomatic AF are given in the Appendix. No treatment: none of the procedures and drugs mentioned under 'rhythm control' and 'rate control' were applied; uncertain: not enough information available to determine the treatment strategy.

paroxysmal and persistent AF patients were on a type IC antiarrhythmic drug despite having coronary artery disease or heart failure. Beta-blockers were used for an antiarrhythmic indication in approximately $30 \%$ of patients with almost equal distribution across all subgroups. Type IV antiarrhythmic drugs and digitalis were most frequently prescribed in permanent AF. Type III antiarrhythmic drugs were given in $15 \%$ of permanent AF patients, of which $13 \%$ amiodarone and $2 \%$ sotalol.

\section{Rate and rhythm control}

In the majority of patients with current AF symptoms, rhythm control was applied (67\%), but still $27 \%$ had exclusively rate control (Figure 1). Most symptomatic patients suffered from palpitations and/or syncope (75\%). Of note, in $44 \%$ of patients who never had experienced symptoms, a rhythm control strategy was applied. In previously symptomatic patients (symptoms suppressed or spontaneously disappeared), a rhythm control strategy was equally often applied (46\%) as in the group that had never experienced symptoms.

Of all patients with paroxysmal or persistent AF, 77\% was under rhythm control, $18 \%$ on exclusive rate control, and $5 \%$ did not receive any treatment or information was incomplete. Of all patients with first detected AF, 72\% underwent rhythm control. Of these patients, $79 \%(\mathrm{~N}=553)$ were symptomatic with their AF.

Among all rhythm control patients, 54\% was also on typical rate control drugs (digitalis, beta-blocker, verapamil, or diltiazem) and $52 \%$ was on amiodarone or 
Table 7. ACC/AHA/ESC stroke risk factors

\begin{tabular}{|c|c|c|c|c|c|}
\hline & $\begin{array}{l}\text { First detected } \\
(\mathrm{n}=978)\end{array}$ & $\begin{array}{c}\text { Paroxysmal } \\
(\mathrm{n}=1517)\end{array}$ & $\begin{array}{l}\text { Persistent } \\
(\mathrm{n}=1167)\end{array}$ & $\begin{array}{c}\text { Permanent } \\
(\mathrm{n}=1541)\end{array}$ & P-value \\
\hline \multicolumn{6}{|l|}{ Stroke risk factors } \\
\hline Age $\geq 75$ years & $255(26)$ & $325(21)$ & $271(23)$ & $591(38)$ & 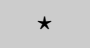 \\
\hline Heart failure or $\mathrm{LVEF} \leq 0.35$ & $291(30)$ & $415(28)$ & $454(39)$ & $796(52)$ & $\star$ \\
\hline Hypertension & $620(63)$ & $942(62)$ & $772(66)$ & $984(63)$ & \\
\hline Mitral stenosis & $34(4)$ & $37(3)$ & $62(5)$ & $188(13)$ & $\star$ \\
\hline Valve surgery & $27(3)$ & $75(5)$ & $72(6)$ & $172(11)$ & $\star$ \\
\hline Stroke / TIA & $70(7)$ & $143(10)$ & $101(9)$ & $228(15)$ & $\star$ \\
\hline Age $60-74$ years, and diabetes or CAD & $212(22)$ & $292(19)$ & $230(20)$ & $334(22)$ & \\
\hline At least one of the above & $808(83)$ & $1200(79)$ & $1010(87)$ & $1447(94)$ & * \\
\hline \multicolumn{6}{|l|}{ Contraindications } \\
\hline Major bleeding & $7(1)$ & $26(2)$ & $23(2)$ & $54(4)$ & 夫 \\
\hline Malignancy & $49(5)$ & $73(5)$ & $54(5)$ & $97(6)$ & \\
\hline
\end{tabular}

Data are presented as observed number (\%) within type of AF. LVEF, left ventricular ejection fraction; TIA, transient ischaemic attack; CAD, coronary artery disease. ${ }^{\star}$ Difference with $\mathrm{P}<0.001$ among the four AF types.

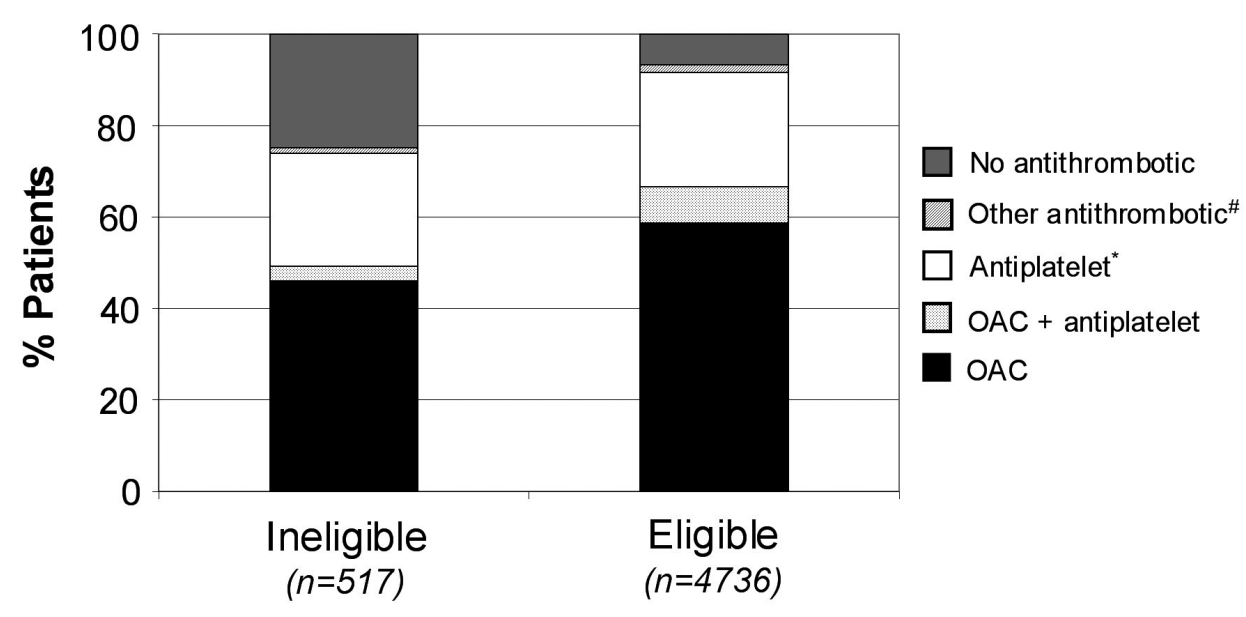

Figure 2. Antithrombotic therapy at discharge or end of visit, in patients considered to be eligible or ineligible for OAC according to the ACC/AHA/ESC guidelines for AF management. Descriptions of stroke risk factors are given in the Appendix. Antiplatelet drug:aspirin, clopidogrel,ticlopidin or dipyridamole; Other antithrombotic: heparin or non-specified antithrombotic agent. ${ }^{\star}$ In the absence of OAC. \# In the absence of OAC and anitplatelet drugs.

sotalol, which are known to also have rate control properties. Taken together, $84 \%$ of patients had some type of rate control besides the rhythm control treatment. Average resting ventricular rate was comparable in patients on solely typical rate control drugs ( $88 \pm 27$ b.p.m.) and patients on solely sotalol or amiodarone $(89 \pm$ 33) b.p.m.), but was higher in patients who were on a combination of amiodarone or sotalol with one or more of the typical rate control drugs (100 \pm 32 b.p.m.). 


\section{Stroke prevention}

According to the ACC/AHA/ESC guidelines, $86 \%$ of this survey population had at least one risk factor for stroke for which they should receive OAC (Table 7), and an additional $4 \%$ of patients without such a stroke risk factor should receive OAC to reduce risk for stroke during a procedure for restoring sinus rhythm. Only a minority of all patients was known with a major bleeding $(2 \%)$ or malignancy $(5 \%)$ as possible contraindications. Figure 2 shows that $67 \%$ of eligible and $49 \%$ of ineligible patients received OAC. The exclusion of patients known with a major bleeding or malignancy did not alter the prescription rates. Only $7 \%$ of eligible patients did not receive any antithrombotic treatment.

\section{DISCUSSION}

The Euro Heart Survey on Atrial Fibrillation provides a unique snapshot of the characteristics and management of AF patients in cardiology departments among ESC member countries. Management guideline application may be suboptimal regarding several issues. Data derived from this survey can be used as a baseline for outcome analysis at follow-up, and as a benchmark for future European surveys on AF management.

This survey provides unique data on AF management from a wide array of medical centres in ESC member countries. Nevertheless, enrolment was not equally divided among participating countries, and in addition an overrepresentation of highly specialized and AF interested centres is suspected. Therefore, one has to keep in mind that these data are representative for the participating centres and may not be representative for all centres in ESC member countries.

Patient characteristics in this survey stress the importance of recognizing AF as a disease that is generally associated with many other cardiac and non-cardiac problems. In accordance with other surveys and registries, hypertension is established as the primary associated cardiovascular disease in AF patients. ${ }^{1,27,28}$ In addition, the majority of patients suffered from a combination of associated medical conditions. As a consequence, cardiologists should realize that the vast majority of AF patients they encounter in clinical practice have at least one stroke risk factor. The latter was also observed in previous studies. ${ }^{35-41}$ To improve prognosis in AF patients, the high prevalence of stroke risk factors in this survey mandates that one should first focus on antithrombotic treatment and management of associated conditions before embarking on rhythm control treatment.

AF has been reported in clinical studies to be idiopathic or lone in $15 \%$ of persistent $\mathrm{AF}$ and in even $60 \%$ of paroxysmal AF patients. ${ }^{42}$ In contrast, in population-based studies the prevalence of idiopathic or lone AF was much lower, between $7.6^{43}$ and $11 \%,{ }^{44}$ and even as low as $2.7 \%$ in a population younger than 60 years. ${ }^{45}$ In this survey, the overall prevalence of idiopathic AF amounted to $10 \%$, 
with an expected highest value in paroxysmal AF (15\%). The fact that prevalence is lower in this survey compared with previous clinical studies probably relates to the higher average age in clinical practice compared with clinical trials. In addition, over the years the awareness of associated disease has grown, especially hypertension and left ventricular dysfunction being recognized as important associated conditions. ${ }^{1,6}$ Especially echocardiography contributed in this respect.

Classification of the type of AF into first detected, paroxysmal, persistent, and permanent (3P classification) $)^{19,46}$ is of importance for choosing appropriate therapy. Overall, misclassifications were not very frequent. Patients registered as having first detected AF could have had a previous arrhythmia intervention if the first episode was diagnosed before the current admission or consultation, and no recurrence was seen since. In this survey, it appeared that only $2 \%$ of first detected patients had more than one previous arrhythmia intervention, suggesting paroxysmal or persistent AF rather than first detected. Similarly, among patients classified as paroxysmal AF, only $4 \%$ should have been classified as persistent AF based on a current AF duration longer than 7 days. In contrast, $11 \%$ of patients classified by the investigators as permanent AF should be considered as having persistent AF, because these patients currently underwent a cardioversion, received a type IA or IC antiarrhythmic drug, or were reported not to be in AF on ECG. If also the use of type III antiarrhythmic drugs is considered in the permanent group, then an additional $11 \%$ could have been classified as persistent AF. Therefore, especially the classification permanent AF might have been regularly confused with persistent AF. The latter is supported by the observation that the group with unknown AF type mostly showed a mix of persistent and permanent AF patient characteristics.

Misclassification may relate to unfamiliarity with definitions of the various AF classes, or that the 3P classification is not used in a uniform manner due to interpretation differences. Bearing in mind the relatively short time that these definitions are being used now, it may very well be that physicians are not yet used to apply them in clinical practice. Nevertheless, we saw significant and clinically important differences concerning treatments among the different types of AF, indicating that management was directed by type of AF. Considering the above, we feel that the $3 \mathrm{P}$ classification is useful and feasible, and satisfies a clinical need in the diagnosis of AF patients. It also helps to identify patients for clinical studies.

A relatively high proportion of patients had first detected AF which could not be explained by site of inclusion, as the proportion was similar for outpatients vs. inpatients as well as for acute vs. non-acute patients (Table 2). In addition, there was no difference in proportion first detected AF between patients with a primary or secondary AF diagnosis. Apparently, relatively many patients seen by ESC cardiologists have only one overt episode of AF which presents right away as persistent or permanent in $75 \%$ of cases (Table 3). The profile of these patients is not dissimilar from the persistent and permanent AF groups, indicating that underlying heart diseases is more important than the 'AF begets AF' principle. ${ }^{47}$ Therefore, primary 
prevention, especially treatment of high blood pressure rather than secondary suppression of the arrhythmia, seems indicated to ameliorate the epidemic of AF.

Minimal evaluation as required by the guidelines is well implemented, as the vast majority of patients underwent an echocardiogram and a chest X-ray. ${ }^{19}$ Transesophageal echocardiography does not seem to play a large role, as it was performed mainly in relation to electrical cardioversion. First detected AF patients and elderly had a lower chance of undergoing echocardiography. This is remarkable and should receive the attention of cardiologists, because these subgroups are at highest risk of stroke or other complications such as heart failure. Improving routines of early echocardiography seem important to prevent early AF-related morbidity.

Thyroid hormone levels were never measured in half of these patients, although this is highly recommended to exclude thyroid dysfunction as the underlying cause of AF. Surprisingly, patients receiving amiodarone did not have a higher chance of undergoing thyroid function tests, while thyroid function monitoring is especially warranted in these patients.

The high prevalence of previous and current pharmacological cardioversions in paroxysmal AF reflects appropriate clinical practice, as pharmacological cardioversion is preferred above electrical cardioversion in these patients. The same holds for the most frequent use of electrical cardioversions in persistent $\mathrm{AF}$, because this is more effective than pharmacological cardioversion. Prior pharmacological conversions were performed in many persistent and permanent AF patients, suggesting that they had paroxysmal AF before progressing to more persistent forms of AF.

In fair agreement with the guidelines, $67 \%$ of currently symptomatic patients received a rhythm control strategy. Note that the symptomatic patients formed the largest group in the survey (69\%) and most rhythm-controlled patients suffered from arrhythmia symptoms rather than complaints due to associated cardiac disease. This indicates that available rhythm control strategies are inadequate and that there is at present an unmet need for safe and efficacious antiarrhythmic drugs for control of AF.

Within the group of patients who never experienced any symptoms, rhythm control was applied in $44 \%$ of cases despite the absence of AF symptoms. In these patients, rate control to prevent late onset heart failure is probably sufficient, and may also help to avoid possible adverse effects of rhythm control. ${ }^{10,11}$ The ACC/AHA/ESC guidelines state that rhythm control should be applied only in symptomatic patients. ${ }^{19}$ This advice is supported by the findings from the large rate vs. rhythm trials which showed that compared with the existing rhythm control strategies, rate control seems safer and as effective as rhythm control. ${ }^{10,11}$

To our knowledge, this survey found one of the highest OAC prescription rates in the clinical setting until now. ${ }^{35,40,48-53}$ Besides increased knowledge about antithrombotic treatment for stroke prevention, this relatively high prevalence may also relate to the fact that the majority of patients came from university and special- 
ized centres. In addition, $63 \%$ of participating centres had an anticoagulation clinic to monitor INR values. Nevertheless, there is still room for improvement, because $33 \%$ of patients with an indication for anticoagulation is not treated as such. In contrast, among the eligible patients who did not receive OAC, a significant number may have had contraindications to OAC other than major bleeding or malignancy, which prevents reaching $100 \%$ in eligible patients. We believe that this gap between guidelines and practice is not completely attributable to the presence of contraindications, because previous studies found a prevalence of contraindications in around $15 \%$ of clinical AF patients. $32,41,54,55$

A remarkable finding is that among patients without an indication for OAC, half of these patients received OAC. This may relate to patient preference due to, e.g. fear of disabling stroke which was also discussed as such by the latest ACCP guidelines on management of stroke in younger AF patients. ${ }^{56}$ Altogether, it seems that in daily practice selection of stroke prevention therapy is not strongly determined by the clinical indications as recommended by the guidelines.

Surprisingly as many as $10-15 \%$ of patients had participated in any one or more clinical trials, mainly in specialized centres. This might indicate high activity regarding AF research in Europe, but it is also likely to reflect the participation of specialized centres with a specific interest in research on AF in this survey.

\section{Limitations}

We intended to collect data from a broad sample of cardiology centres from member countries of the ESC that were willing to participate, to present a broad view on daily practice. However, relatively many centres were university and specialized centres, and also the results point towards an overrepresentation of centres that were highly specialized and interested in AF. In addition, patient enrolment was not equally divided among participating countries. Therefore, these results are representative for the participating centres in the survey, but cannot automatically be extrapolated to all centres in ESC member countries. Data were contributed on a voluntary basis, which may cause incompleteness or inconsistency of data. Data were however quite complete. Among key variables, a maximum of $2 \%$ of missing data points was found. In addition, we checked for inconsistencies by applying logical checks within the database. Inconsistencies were checked with the investigators by issuing queries.

\section{CONCLUSIONS}

Most patients visiting cardiovascular specialist in ESC member countries have one or multiple associated medical conditions and specific stroke risk factors. In addition, most patients are symptomatic with their arrhythmia despite treatment. This survey shows that application of the ESC AF guideline may be suboptimal 
regarding several issues including inappropriate application of rhythm control in asymptomatic patients and the contraindicated or needless use of antiarrhythmic drugs in both rate and rhythm control patients. The survey also illustrates the unmet need for new safe and effective antiarrhythmic drugs to suppress symptoms in paroxysmal and persistent AF. Although the use of OAC was the highest ever reported, stroke risk assessment according to the guidelines just marginally seems to drive the decision to anticoagulate or not. New antithrombotic drugs or strategies including education of the public might help to improve matters. The long-term follow-up of the patients in this survey may indicate whether guideline adherence is associated with better outcomes compared with guideline deviant management.

\section{APPENDIX: DEFINITIONS}

Numerous definitions were used in this survey, with the aim of standardizing data entry. Definitions were given in a short text file attached to the data entry point in the electronic case report form so that this information was readily available. The most important definitions for this manuscript are reported here.

First detected episode of AF: The first detected episode is AF diagnosed for the first time by a physician, in which it is important to distinguish whether it is symptomatic or self-limiting, recognizing that there may be uncertainty about the duration of the episode and about previous undetected episodes.

Paroxysmal AF: Recurrent AF that terminates spontaneously and lasts $\leq 7$ days (mostly $<24$ hours).

Persistent AF: Recurrent AF or sustained AF lasting $>7$ days. Termination of AF by pharmacological therapy or electrical cardioversion does not change the designation. In other words, cardioversion does not necessarily differentiate between paroxysmal and persistent AF, as pharmacological and electrical cardioversions are used in both conditions.

Permanent AF: AF has been present for a long time, cardioversion has not been indicated, or one or several attempts have failed to restore reliable sinus rhythm.

Hypertension: Systolic blood pressure above $160 \mathrm{mmHg}$, diastolic blood pressure above $90 \mathrm{mmHg}$, or receiving blood-pressure-lowering drugs.

Idiopathic AF: No previously or currently diagnosed hypertension, coronary artery disease, heart failure, valvular heart disease, tachycardiomyopathy, sick sinus syndrome, chronic obstructive pulmonary disease, or thyroid disease.

Symptomatic AF: The presence of one or more of the following symptoms in relation to AF: palpitations, dyspnoea, chest pain, syncope, dizziness, fatigue, or other non-specified symptoms.

Rhythm control strategy: Currently applying or planning a pharmacological cardioversion or electrical cardioversion, or prescribing a class IA, IC, or III antiarrhythmic drug (Vaughan Williams classification). ${ }^{34}$ Of note, rhythm control 
patients may be on typical rate control drugs, because the latter drugs are frequently unavoidable as background therapy in rhythm control patients.

Rate control strategy: Prescribing digitalis, class II, or class IV antiarrhythmic drugs, and not currently applying or planning any of the 'rhythm control' procedures and not prescribing a class IA, IC, or III antiarrhythmic drug.

Eligible for anticoagulation: According to the ACC/AHA/ESC guidelines, patients are eligible for anticoagulation when they undergo pharmacological or electrical cardioversion for AF lasting $>48 \mathrm{~h}$, or when one of the following characteristics are present: risk factors for stroke are here: age $\geq 60$ years with diabetes or coronary artery disease, age $\geq 75$ years, heart failure, left ventricular ejection fraction $\leq 0.35$, hypertension, mitral valve stenosis, valve surgery, or prior thromboembolism. In addition, patients undergoing catheter ablation are also considered to be eligible for anticoagulation.

Not eligible for anticoagulation: When none of the abovementioned indications for anticoagulation are present.

\section{REFERENCES}

1. Kannel WB, Wolf PA, Benjamin EJ, Levy D. Prevalence, incidence, prognosis, and predisposing conditions for atrial fibrillation: population-based estimates. Am J Cardiol 1998;82:2N-9N.

2. Vidaillet H, Granada JF, Chyou PH, Maassen K, Ortiz M, Pulido JN, Sharma P, Smith PN, Hayes J. A population-based study of mortality among patients with atrial fibrillation or flutter. Am J Med 2002;113:365-70.

3. Maisel WH, Stevenson LW. Atrial fibrillation in heart failure: epidemiology, pathophysiology, and rationale for therapy. Am J Cardiol 2003;91: 2D-8D.

4. Wolf PA, Dawber TR, Thomas HE Jr, Kannel WB. Epidemiologic assessment of chronic atrial fibrillation and risk of stroke: the Framingham study. Neurology 1978;28:973-7.

5. Wolf PA, Abbott RD, Kannel WB. Atrial fibrillation: a major contributor to stroke in the elderly. The Framingham Study. Arch Intern Med 1987; 147:1561-4.

6. Wang TJ, Larson MG, Levy D, Vasan RS, Leip EP, Wolf PA, D’Agostino RB, Murabito JM, Kannel WB, Benjamin EJ. Temporal relations of atrial fibrillation and congestive heart failure and their joint infiuence on mortality: the Framingham Heart Study. Circulation 2003;107:2920-5.

7. Stewart S, Murphy N, Walker A, McGuire A, McMurray JJ. Cost of an emerging epidemic: an economic analysis of atrial fibrillation in the UK. Heart 2004;90:286-92.

8. Wattigney WA, Mensah GA, Croft JB. Increasing trends in hospitalization for atrial fibrillation in the United States, 1985 through 1999: implications for primary prevention. Circulation 2003;108:711-6.

9. Le Heuzey JY, Paziaud O, Piot O, Said MA, Copie X, Lavergne T, Guize L. Cost of care distribution in atrial fibrillation patients: the COCAF study. Am Heart J 2004;147:121-6.

10. Van Gelder IC, Hagens VE, Bosker HA, Kingma JH, Kamp O, Kingma T, Said SA, Darmanata JI, Timmermans AJ, Tijssen JG, Crijens HJ. A comparison of rate control and rhythm control in patients with recurrent persistent atrial fibrillation. N Engl J Med 2002;347:1834-40.

11. Wyse DG, Waldo AL, DiMarco JP, Domanski MJ, Rosenberg Y, Schron EB, Kellen JC, Greene HL, Mickel MC, Dalquist JE, Corley SD. A comparison of rate control and rhythm control in patients with atrial fibrillation. N Engl J Med 2002;347:1825-33. 
12. Opolski G, Torbicki A, Kosior DA, Szulc M, Wozakowska-Kaplon B, Kolodziej P, Achremczyk P. Rate control vs rhythm control in patients with nonvalvular persistent atrial fibrillation: the results of the Polish How to Treat Chronic Atrial Fibrillation (HOT CAFE) Study. Chest 2004;126:476-86.

13. Hohnloser SH, Kuck KH, Lilienthal J. Rhythm or rate control in atrial fibrillation-pharmacological intervention in atrial fibrillation (PIAF): a randomised trial. Lancet 2000;356:1789-94.

14. Carlsson J, Miketic S, Windeler J, Cuneo A, Haun S, Micus S, Walter S, Tebbe U. Randomized trial of rate-control versus rhythm-control in persistent atrial fibrillation: the strategies of treatment of atrial fibrillation (STAF) study. J Am Coll Cardiol 2003;41:1690-6.

15. de Denus S, Sanoski CA, Carlsson J, Opolski G, Spinler SA. Rate vs rhythm control in patients with atrial fibrillation: a meta-analysis. Arch Intern Med 2005;165:258-62.

16. Saxena R, Koudstaal PJ. Anticoagulants versus antiplatelet therapy for preventing stroke in patients with nonrheumatic atrial fibrillation and a history of stroke or transient ischemic attack. The Cochrane Database of Systematic Reviews 2004;4:CD000187.

17. Segal JB, McNamara RL, Miller MR, Powe NR, Goodman SN, Robinson KA, Bass EB. Anticoagulants or antiplatelet therapy for non-rheumatic atrial fibrillation and flutter. The Cochrane Database of Systematic Reviews 2001;1:CD001938.

18. Benavente O, Hart R, Koudstaal P, Laupacis A, McBride R. Antiplatelet therapy for preventing stroke in patients with non-valvular atrial fibrillation and no previous history of stroke or transient ischemic attacks. The Cochrane Database of Systematic Reviews 1999;2:CD001925.

19. Fuster V, Ryden LE, Asinger RW, Cannom DS, Crijns HJ, Frye RL, Halperin JL, Kay GN, Klein WW, Levy S, McNamara RL, Prystowsky EN, Wann LS, Wyse DG. ACC/AHA/ESC guidelines for the management of patients with atrial fibrillation. A report of the American College of Cardiology/American Heart Association Task Force on Practice Guidelines and the European Society of Cardiology Committee for Practice Guidelines and Policy Conferences (Committee to develop guidelines for the management of patients with atrial fibrillation) developed in collaboration with the North American Society of Pacing and Electrophysiology. Eur Heart J 2001;22:1852-923.

20. Friberg J, Scharling H, Gadsboll N, Jensen GB. Sex-specific increase in the prevalence of atrial fibrillation (The Copenhagen City Heart Study). Am J Cardiol 2003;92:1419-1423.

21. Goudevenos JA, Vakalis JN, Giogiakas V, Lathridou P, Katsouras C, Michalis LK, Sideris DA. An epidemiological study of symptomatic paroxysmal atrial fibrillation in northwest Greece. Europace 1999;1:226-33.

22. Kerr CR, Boone J, Connolly SJ, Dorian P, Green M, Klein G, Newman D, Sheldon R, Talajic M. The Canadian Registry of Atrial Fibrillation: a noninterventional follow-up of patients after the first diagnosis of atrial fibrillation. Am J Cardiol 1998;82:82N-5N.

23. Krahn AD, Manfreda J, Tate RB, Mathewson FA, Cuddy TE. The natural history of atrial fibrillation: incidence, risk factors, and prognosis in the Manitoba Follow-Up Study. Am J Med 1995;98:476-84

24. Stewart S, Hart CL, Hole DJ, McMurray JJ. Population prevalence, incidence, and predictors of atrial fibrillation in the Renfrew/Paisley study. Heart 2001;86:516-21.

25. Wandell PE. A survey of subjects with present or previous atrial fibrillation in a Swedish community. Scand J Prim Health Care 2001;19:20-4.

26. Go AS, Hylek EM, Phillips KA, Chang Y, Henault LE, Selby JV, Singer DE. Prevalence of diagnosed atrial fibrillation in adults: national implications for rhythm management and stroke prevention: the AnTicoagulation and Risk Factors in Atrial Fibrillation (ATRIA) Study. JAMA 2001;285:2370-5.

27. Levy S, Maarek M, Coumel P, Guize L, Lekieffre J, Medvedowsky JL, Sebaoun A. Characterization of different subsets of atrial fibrillation in general practice in France: the ALFA study. The College of French Cardiologists. Circulation 1999;99:3028-35. 
28. Lip GY, Golding DJ, Nazir M, Beevers DG, Child DL, Fletcher RI. A survey of atrial fibrillation in general practice: the West Birmingham Atrial Fibrillation Project. Br J Gen Pract 1997;47:285-9.

29. Majeed A, Moser K, Carroll K. Trends in the prevalence and management of atrial fibrillation in general practice in England and Wales, 1994-1998: analysis of data from the general practice research database. Heart 2001;86:284-8.

30. Carlsson J, Tebbe U, Rox J, Harmjanz D, Haerten K, Neuhaus KL, Seidel F, Niederer W, Miketic S. Cardioversion of atrial fibrillation in the elderly. ALKK-Study Group. Arbeitsgemeinschaft Leitender Kardiologischer Krankenhausaerzte. Am J Cardiol 1996;78:1380-4.

31. Santini M, De Ferrari GM, Pandozi C, Alboni P, Capucci A, Disertori M, Gaita F, Lombardi F, Maggioni AP, Mugelli A, Salerno-Uriarte JA, Sermasi S, Schwartz PJ. Atrial fibrillation requiring urgent medical care: approach and outcome in the various departments of admission. Data from the atrial Fibrillation/flutter Italian REgistry (FIRE). Ital Heart J 2004;5: 205-13.

32. Frykman V, Beerman B, Ryden L, Rosenqvist M. Management of atrial fibrillation: discrepancy between guideline recommendations and actual practice exposes patients to risk for complications. Eur Heart J 2001;22:1954-59.

33. Statistics by Country for Atrial Fibrillation. http://www.wrongdiagnosis.com/a/atrial_fibrillation/stats-country.htm (24 May 2003).

34. Vaughan Williams EM. A classification of antiarrhythmic actions reassessed after a decade of new drugs. J Clin Pharmacol 1984;24:129-47.

35. Laguna P, Martn A, del Arco C, Gargantilla P. Risk factors for stroke and thromboprophylaxis in atrial fibrillation: what happens in daily clinical practice? The GEFAUR-1 study. Ann Emerg Med 2004;44:3-11.

36. Ang SY, Peterson GM, Friesen WT, Vial JH. Review of antithrombotic drug usage in atrial fibrillation. J Clin Pharm Ther 1998;23:97-106.

37. Albers GW, Yim JM, Belew KM, Bittar N, Hattemer CR, Phillips BG, Kemp S, Hall EA, Morton DJ, Vlasses PH. Status of antithrombotic therapy for patients with atrial fibrillation in university hospitals. Arch Intern Med 1996;156:2311-6.

38. Adhiyaman V, Kamalakannan D, Oke A, Shah IU, White AD. Underutilization of antithrombotic therapy in atrial fibrillation. J R Soc Med 2000;93:138-40.

39. Anderson DR, Gardner MJ, Putnam W, Jassal D, Brownell B, Flowerdew G, Nagpal S, Thompson K, Cox JL. Population-based evaluation of the management of antithrombotic therapy for atrial fibrillation. Can J Cardiol 2005;21:257-66.

40. Jackson SL, Peterson GM, Vial JH, Daud R, Ang SY. Outcomes in the management of atrial fibrillation: clinical trial results can apply in practice. Intern Med J 2001;31:329-36.

41. Kalra L, Yu G, Perez I, Lakhani A, Donaldson N. Prospective cohort study to determine if trial efficacy of anticoagulation for stroke prevention in atrial fibrillation translates into clinical effectiveness. BMJ 2000; 320:1236-9.

42. Murgatroyd FD, Camm AJ. Atrial arrhythmias. Lancet 1993;341:1317-22.

43. Furberg CD, Psaty BM, Manolio TA, Gardin JM, Smith VE, Rautaharju PM. Prevalence of atrial fibrillation in elderly subjects (the Cardiovascular Health Study). Am J Cardiol 1994;74:236-41.

44. Brand FN, Abbott RD, Kannel WB, Wolf PA. Characteristics and prognosis of lone atrial fibrillation: 30-year follow-up in the Framingham Study. JAMA 1985;254:3449-53.

45. Kopecky SL, Gersh BJ, McGoon MD, Whisnant JP, Holmes DR Jr, Ilstrup DM, Frye RL. The natural history of lone atrial fibrillation: a population-based study over three decades. $\mathrm{N}$ Engl J Med 1987;317:669-74.

46. Gallagher MM, Camm J. Classification of atrial fibrillation. Am J Cardiol 1998;82:18N-28N.

47. Wijffels MC, Kirchhof CJ, Dorland R, Allessie MA. Atrial fibrillation begets atrial fibrillation: a study in awake chronically instrumented goats. Circulation 1995;92:1954-68. 
48. Frost L, Johnsen SP, Pedersen L, Toft E, Husted S, Sorensen HT. Atrial fibrillation or flutter and stroke: a Danish population-based study of the effectiveness of oral anticoagulation in clinical practice. J Intern Med 2002;252:64-9.

49. Gage BF, Boechler M, Doggette AL, Fortune G, Flaker GC, Rich MW, Radford MJ. Adverse outcomes and predictors of underuse of antithrombotic therapy in medicare beneficiaries with chronic atrial fibrillation. Stroke 2000; 31:822-7.

50. Go AS, Hylek EM, Borowsky LH, Phillips KA, Selby JV, Singer DE. Warfarin use among ambulatory patients with nonvalvular atrial fibrillation: the anticoagulation and risk factors in atrial fibrillation (ATRIA) study. Ann Intern Med 1999;131:927-34.

51. Perez I, Melbourn A, Kalra L. Use of antithrombotic measures for stroke prevention in atrial fibrillation. Heart 1999;82:570-4.

52. Scott PA, Pancioli AM, Davis LA, Frederiksen SM, Eckman J. Prevalence of atrial fibrillation and antithrombotic prophylaxis in emergency department patients. Stroke 2002;33:2664-2669.

53. Weisbord SD, Whittle J, Brooks RC. Is warfarin really underused in patients with atrial fibrillation? J Gen Intern Med 2001;16:743-9.

54. Bravata DM, Rosenbeck K, Kancir S, Brass LM. The use of warfarin in veterans with atrial fibrillation. BMC Cardiovasc Disord 2004;4:18.

55. Whittle J, Wickenheiser L, Venditti LN. Is warfarin underused in the treatment of elderly persons with atrial fibrillation? Arch Intern Med 1997;157:441-5.

56. Singer DE, Albers GW, Dalen JE, Go AS, Halperin JL, Manning WJ. Antithrombotic therapy in atrial fibrillation: the Seventh ACCP Conference on Antithrombotic and Thrombolytic Therapy. Chest 2004;126(Suppl. 3):429S-56S. 


\section{EDITORIAL}

The Euro Heart Survey on atrial fibrillation: a picture and a thousand words

D. George Wyse

Eur Heart J. 2005;26(22):2422-34

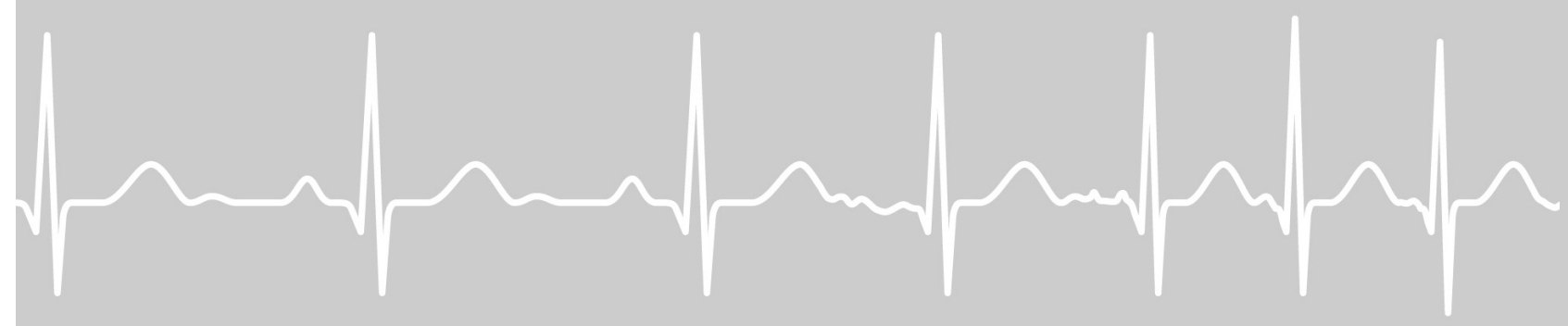


This editorial refers to 'Atrial fibrillation management: a prospective survey in ESC member countries. The Euro Heart Survey on atrial fibrillation' by R. Nieuwlaat et al., doi:10.1093/eurheartj/ehi505

The Euro Heart Survey on atrial fibrillation (AF) is a registry of patients in Europe who were seen by a cardiologist for AF over a 12-month period in 2003 and 2004. In the data presented, ${ }^{1}$ we see a snapshot of several aspects of AF at this particular moment in time in Europe. Registries are an important tool for description of any number of aspects of a particular medical condition, including its management. Their strength lies in the fact that data are provided on a large number of patients and the cross-sectional aspects of the data are advantageous; in this case, the number of countries is also large. Limitations include the degree of adherence to definitions, rigour, completeness and uniformity of data collection, and potential selectivity in patient enrolment (consecutiveness) among others. Nevertheless, they are useful for description of practice patterns among a group of physicians, for development of proposals to modify physician behaviour, and for identifying hypotheses to be tested in randomized, controlled clinical trials. Although subsequent follow-up data from the survey are expected, for now the authors have focused on describing the practices of European cardiologists and contrasting their findings with some of the recommendations of the AF treatment guidelines. ${ }^{2}$ It is often said that 'a picture is worth a thousand words'. In this case, the metaphor of the registry as a picture supports this adage in the number of words needed to describe and discuss the picture we are being shown.

There is also a need for lots of words because of some blurriness in this picture, which leads to some uncertainties. One of the most evident uncertainties is whether the patients in the registry are representative of all European patients with AF or even of all European patients with AF who see a cardiologist. Although I have no idea of how many patients with AF actually get to see a cardiologist in Europe, I suspect that many are treated by primary care physicians and this may vary greatly from country to country. Thus, the registry should not be considered to be a representative of all European patients with AF. It is also not clear that the registry data are even representative of all European patients with $\mathrm{AF}$ who see a cardiologist. It can be seen, for example, that the contribution of patients by country is not proportional to population of the various countries from which patients were enrolled. However, this difference is blurred somewhat by the grouping of the registry countries into regions. In this respect, a registry is not a particularly robust epidemiological data source. Nevertheless, the registry is an impressive compilation of data from widely diverse geopolitical areas.

I was surprised a little by the large number of patients who were seeing a cardiologist because of their 'first detected' episode of AF. I am not sure what to make of this observation. I doubt that it means that most patients see a cardiologist after their 'first detected' episode of AF. This particular datum may be more of a reflection of 
the nature of the enrolling sites. As the authors note, there was probably some blurriness in the picture because of some uncertainties and unfamiliarity with the definitions of various categories of AF. In this article, I found the definition of 'persistent' AF a little unclear, particularly with respect to what was being said about cardioversion. The troublesome area in these definitions is how to categorize an episode of AF that lasts $<7$ days because of cardioversion (either electrical or pharmacological) done before 7 days from the onset of AF has elapsed. My understanding of the definition in the Guidelines ${ }^{2}$ is that any cardioversion leads to labelling the episode as 'persistent' and if that occurs before 7 days of AF, particularly within $24 \mathrm{~h}$ of the onset of AF, then some 'paroxysmal' AF will be erroneously categorized as 'persistent'. In contrast, calling episodes that are cardioverted within 7 days of onset of AF 'paroxysmal' probably results in similar misclassification in the other direction. Nevertheless, the definition of 'permanent' AF is quite clear and yet a small number of these patients were cardioverted or treated with a class-I or class-III antiarrhythmic drug, which seems to dispute that definition and further bring into question the precision of measurement of proportions of patients with various 'classes' of AF in the registry.

Other findings of the survey reinforce findings of other studies. The strong association between AF and hypertension is once again clearly evident. It is also indeed gratifying to see that symptoms appear to be an important determinant of selection of the rhythm control approach. Current evidence suggests that control of symptoms is probably the major indication for selecting the rhythm control approach, as no other benefit has been clearly established for this approach. ${ }^{3}$ Unfortunately, we are not told much more about the nature or severity of the symptoms. In this article, it is said that palpitation and/or syncope was the most common symptoms. The former is not surprising but I was surprised by the prominence of syncope, which in my experience is uncommon, whereas fatigue and dyspnea are very common. ${ }^{4} \mathrm{~A}$ method to easily quantify the severity of symptoms due to AF at the bedside is badly needed as long as the degree of symptoms is a major factor in making therapeutic decisions. However, a surprisingly high number of asymptomatic patients were treated with the rhythm control approach. The reasons for this observation are a little more uncertain. Certainly, patient preference often comes into play in the selection of the approach to rhythm management, but there probably remain a number of physicians who consider the rhythm control approach superior in spite of the evidence. One does wonder whether the risks of therapy have been adequately considered in selection of this approach in asymptomatic patients. It also seems noteworthy that the category of 'permanent' AF is applied to the more elderly patients with more extensive coexisting disease. This would seem to be appropriate. It should be recognized that this categorization is really a judgement decision on the part of the physician.

It is also gratifying to see the high usage of anti-coagulation in those considered 'eligible' for anti-coagulation. It is always difficult to say for certain from this type of 
data who are 'eligible' and who are 'ineligible'. Nevertheless, the observation that $>60 \%$ of 'eligible' patients were receiving an oral anti-coagulant suggests that European cardiologists are paying close attention to this very important aspect of management of AF, at least at first contact. It will be interesting to see whether this finding persists as the use of warfarin tends to fall off over time. ${ }^{5}$ Aside from the issue of whether the data are robust enough to determine who are 'eligible' and who are 'ineligible' for oral anti-coagulants, there is some emerging uncertainty in this area. There are at least five different risk stratification schemes in use for determination of the need for oral anticoagulation in patients with AF. Although generally similar, these schemes are not in complete agreement, particularly with respect to the proper course of action in patients with moderate risk. Some experts consider hypertension in the absence of another risk factor to indicate low risk for stroke when the hypertension is well treated and would recommend aspirin as adequate therapy for stroke prevention in such patients. Some schemes allow for the use of either aspirin or oral anti-coagulants in moderate risk patients. ${ }^{2}$ Thus, it is not surprising that there is some confusion on this point among treating physicians. In the European survey, there is evidence for this confusion from the high proportion of patients considered 'ineligible' who were in fact taking oral anti-coagulants. In contrast, this observation may be due to deficiencies in the database that misclassify 'eligible' and 'ineligible' patients or it may reflect patient preferences. It does appear that European cardiologists have taken the approach that if there is any doubt, patients should be treated with an oral anti-coagulant.

It is not possible to comment on all the findings of the survey in a small space and I have tried to highlight what I consider to be some of the more important and interesting aspects of the survey's findings. Others will take notice of other things. It has been a formidable task to construct the registry, collect, and analyse the data. In spite of the inherent weakness of registries in general, this one appears to have been well done. The data are interesting and will undoubtedly lead to a number of hypotheses that will subsequently be tested in more rigorous studies. We can also look forward with anticipation to follow-up data that are being collected as part of the survey.

\section{REFERENCES}

1. Nieuwlaat R, Capucci A, Camm AJ, Olsson SB, Andresen D, Davies DW, Cobbe S, Breithardt G, Le Heuzey J-Y, Prins MH, Lévy S, Crijns HJGM, on behalf of the Euro Heart Survey Investigators. Atrial fibrillation management: a prospective survey in ESC member countries. The Euro Heart Survey on Atrial fibrillation. Eur Heart J doi:10.1093/eurheartj/ehi505. 
2. Fuster V, Ryden LE, Asinger RW, Cannom DS, Crijns HJ, Frye RL, Halperin JL, Kay GN, Klein WW, Levy S, McNamara RL, Prystowsky EN, Wann LS, Wyse DG. ACC/AHA/ESC Guidelines for the Management of Patients with Atrial Fibrillation. A report of the American College of Cardiology/ American Heart Association Task Force on Practice Guidelines and the European Society of Cardiology Committee for Practice Guidelines and Policy Conferences (Committee to Develop Guidelines for the Management of Atrial Fibrillation) developed in collaboration with the North American Society of Pacing and Electrophysiology. Eur Heart J 2001;22:1852-923

3. Levy S, Maarek M, Coumel P, Guize L, Lekieffre J, Medvedowsky JL, Sebaoun A. Characterization of difference subsets of atrial fibrillation in general practice in France: the ALFA Study: the College of French Cardiologists. Circulation 1999;99:3028-35.

4. Hersi A, Wyse DG. Management of atrial fibrillation. Curr Probl Cardiol 2005;30:175-234.

5. Sherman DG, Kim SG, Boop BS, Corley SD, DiMarco JP, Hart RG, Haywood LJ, Hoyte K, Kaufman ES, Kim MH, Nasco E, Waldo EL, for the AFFIRM Investigators. Occurrence and characteristics of stroke events in the Atrial Fibrillation Follow-up Investigation of Rhythm Management (AFFIRM) Study. Arch Intern Med 2005;165:1185-91. 
3

Prognosis, disease progression, quality of life and treatment of atrial fibrillation patients during 1 year Follow-up of the Euro Heart Survey on atrial fibrillation

Robby Nieuwlaat, Martin H. Prins, Jean-Yves Le Heuzey, Panos E. Vardas, Etienne Aliot, Massimo Santini, Stuart M. Cobbe,Jos W.M. G. Widdershoven, Leo H. Baur, Samuel Lévy, Harry J. G.M. Crijns

Submitted

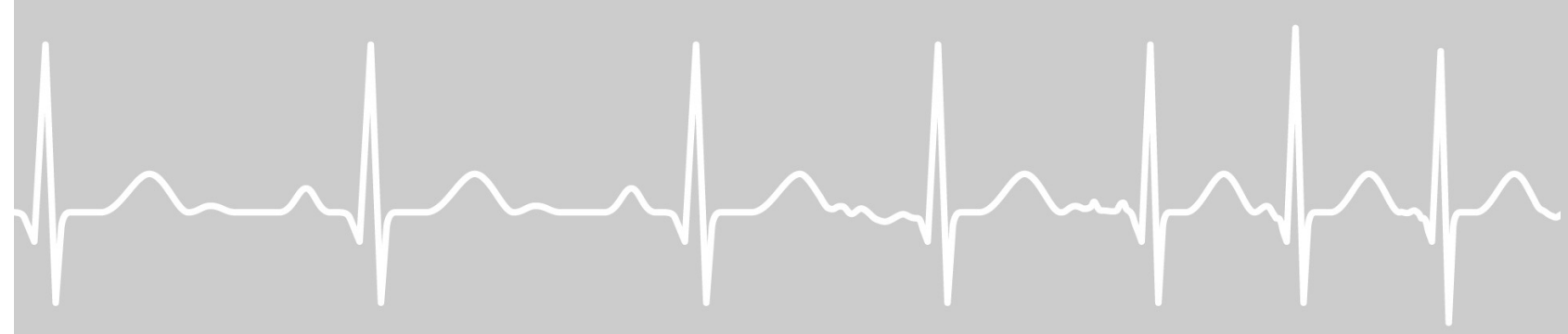




\title{
52 CHAPTER 3
}

\begin{abstract}
Aims. To gain insight in the prognosis and treatment of atrial fibrillation (AF) patients during 1 year follow-up in the Euro Heart Survey on AF.

Methods \& Results. The Euro Heart Survey enrolled 5333 AF patients in 2003-2004. One year follow-up data were available for $80 \%$. Of $1^{\text {st }}$ detected AF patients $46 \%$ did not have a recurrence during 1 year, paroxysmal AF largely remained paroxysmal $\mathrm{AF}(80 \%)$, and $30 \%$ of persistent $\mathrm{AF}$ progressed to permanent AF. Many treatment changes occurred since baseline. OAC was started in 19\% and discontinued in $16 \%$ of all patients. Of patients initially on rhythm control $27 \%$ did not receive rhythm control during follow-up, whereas $15 \%$ of patients initially on rate control received rhythm control. Mortality and morbidity were highest and quality of life lowest in permanent AF. In multivariable analysis, sinus rhythm at baseline was associated with lower mortality, but no significant effect was observed regarding the application of either rhythm or rate control.

Conclusions. The Euro Heart Survey on AF provides unique prospective observational data on AF progression, long-term treatment, quality of life, prognosis and determinants of adverse outcome of the total clinical spectrum of AF in a European cardiology based patient cohort.
\end{abstract}


FOLLOW-UP EURO HEART SURVEY | 53

\section{INTRODUCTION}

The Euro Heart Survey provided a unique snapshot of the characteristics and management of all clinical atrial fibrillation (AF) types in cardiology practices across Europe. ${ }^{1}$ Some discordance with the 2001 ACC/AHA/ESC management guideline recommendations ${ }^{2}$ was observed and management differed highly among patients, mainly due to the variety of clinical AF types and differences in their patient profiles as encountered in cardiology practice. The question remains to what extent prognosis varies among the AF types and management strategies.

Current observational data on mortality and morbidity in AF patients were mainly derived from retrospective analyses in general populations and general practices and few were hospital-based. ${ }^{3-11}$ Five observational studies on quality of life (QoL) in AF exclusively focused on outpatient patients, not including the whole spectrum of clinical AF types and two of them did not assess prospective changes in QoL. ${ }^{12-16}$ Real-life AF progression has been described before ${ }^{10,17}$, but not in cardiology practice. Also, little information is available on AF treatment changes in daily practice over time. ${ }^{18}$

In order to gain insight in the prognosis, disease progression, quality of life and treatment changes in the Euro Heart Survey cohort, a follow-up survey was performed after 1 year.

\section{METHODS}

In the Euro Heart Survey on AF 5333 patients were enrolled in 2003 and 2004. Survey methods, centre participation, patient characteristics, management and definitions have previously been described. ${ }^{1}$ In the preparation phase of the survey a follow-up was planned at 1 year following the baseline survey, containing questions on survival status, morbidity, readmissions, diagnostics, interventions, drug therapy, AF characteristics and QoL. Data were collected through searching medical records and patient interview.

\section{Definitions}

Ischemic stroke: Focal neurological deficit of sudden onset as diagnosed by a neurologist, lasting $>24$ hours and caused by ischemia.

Transient ischemic attack: Focal neurological deficit of sudden onset as diagnosed by a neurologist, lasting $<24$ hours.

Myocardial infarction: New or presumed new ST segment elevation in two or more contiguous leads of $\geq 0.2 \mathrm{mV}$ in leads $\mathrm{V} 1, \mathrm{~V} 2$ or $\mathrm{V} 3$ and $\geq 0.1 \mathrm{mV}$ in other leads, and/or presumably new left bundle branch block, and/or cardiac enzyme rise $>2$ times the upper values.

Peripheral embolism: Embolism outside the heart, brain, eyes and lungs 
Haemorrhagic stroke: Focal neurological deficit of sudden onset as diagnosed by a neurologist, lasting $>24$ hours and caused by bleeding.

Other major bleeding: Major bleeding, other than haemorrhagic stroke, requiring hospitalisation and/or causing a drop of haemoglobin level of more than $2 \mathrm{~g} / \mathrm{L}$ and/or requiring blood transfusion.

Heart failure: Onset of new heart failure, or worsening of known heart failure.

AF progression: $1^{\text {st }}$ detected becoming paroxysmal, persistent or permanent AF; paroxysmal becoming persistent or permanent AF; persistent becoming permanent AF.

Rhythm control strategy: Applying a pharmacological conversion, electrical cardioversion or catheter ablation during 1 year, or prescribing a class IA, IC, or III antiarrhythmic drug (Vaughan Williams classification ${ }^{19}$ ) at 1 year. Of note, rhythm control patients may be on typical rate control drugs, because the latter drugs are frequently unavoidable as background therapy in rhythm control patients.

Rate control strategy: Prescribing digitalis, class II, or class IV antiarrhythmic drugs at 1 year, and not applying any of the 'rhythm control' procedures during 1 year and not prescribing a class IA, IC, or III antiarrhythmic drug at 1 year.

Sinus rhythm at discharge: We considered patients to be in sinus rhythm at discharge of the baseline visit when the first known baseline ECG showed sinus rhythm and no episode of AF was reported, or when patients who were in AF underwent a successful procedure to restore sinus rhythm.

\section{Euro QoL}

The EuroQoL 5 dimensional (EQ-5D) questionnaire was used to assess QoL at baseline and 1 year follow-up. ${ }^{20}$ The EQ-5D consists of 5 questions on mobility, self-care, usual activities, pain/discomfort, anxiety/depression. Based on these 5 answers an EQ-5D utility score could be calculated with score 1.0 being the best possible QoL. In addition, the patient scored his/her perceived QoL on a visual analogue scale (EQ-VAS) with score 100 representing the best possible QoL. Baseline QoL values are reported only for patients with a follow-up QoL measurement available and were categorised into quartiles to assess the effect of EQ-5D and EQ-VAS on outcome during 1 year follow-up.

\section{Statistics}

Data analysis was performed with SPSS statistical software (SPSS Inc., release 12.01). Continuous variables are reported as mean \pm standard deviation or median $\left(25^{\text {th }}-75^{\text {th }}\right.$ percentile) and categorical variables as observed number (percentage within AF type). Total counts of the 4 AF types might be slightly lower than the total of the overall population due to a small proportion of patients who had an unknown AF type at baseline. Whether there was any difference among the four AF types was tested with one-way ANOVA or Kruskal-Wallis $\mathrm{H}$ for continuous 
variables and with $\chi^{2}$ statistic for categorical variables. If statistically significant $(\mathrm{P}<0.05)$, we investigated post-hoc which AF types were different when clinically relevant, and report these specifications in the text. Survival from all-cause mortality per AF type during 1 year is depicted with Kaplan-Meier curves. Other events could not be analysed in a time-dependent manner.

Multivariable logistic regression was performed to assess which factors were associated with all-cause mortality and the combined endpoint of all-cause death, any thromboembolism, major bleeding and heart failure during 1 year follow-up. The following baseline variables were tested in these models: age, gender, hypertension, valvular heart disease, heart failure, coronary artery disease, prior ischemic stroke or transient ischemic attack, prior other thromboembolism, diabetes, prior major bleeding, prior minor bleeding, prior malignancy, renal failure, peripheral vascular disease, chronic obstructive pulmonary disease (COPD), sick sinus syndrome, prior ventricular fibrillation, prior ventricular tachycardia, presence of symptoms, clinical type of AF, undergoing rate or rhythm control, the reason for the admission/visit and also prescription of oral anticoagulation (OAC), an antiplatelet drug, a renin-angiotensin-aldosteron system (RAAS) blocker (ACE inhibitor and/or an AT II receptor blocker), beta blocker, dihydropyridin calcium channel blocker and statin. Diuretics were kept out of the models because it represented a surrogate of heart failure severity and masked the effect of heart failure on outcome due to this collinearity. To assess the effect of EQ-5D and EQ-VAS on outcome, their quartiles were separately added to the models as described above, and their effect was tested with $\chi^{2}$ for trend. The effect of drugs in this observational cohort might be biased due to the absence of randomisation, and therefore it was chosen to add a propensity score for each drug to the models in order to correct as good as possible for the propensity of a physician to prescribe the concerning drug to selected patients. Individual propensity scores were calculated by means of a logistic regression model containing factors that were significantly associated with prescription of the drug.

Variables were removed stepwise from the model when the P-value exceeded 0.10 . Variables with $\mathrm{P}$-value $<0.05$ in the final model were considered to be significant contributors and were kept in the model. Hereafter, all variables in the final models were tested for interactions and significant interactions were added to the models. These models were validated by means of bootstrapping, which was performed with 100 samples for each multivariable logistic regression analysis. Bootstrapping provided information on the effect stability of each factor and interaction as a predictor of the outcome variable. Effects that were instable were stepwise left out of the model, which eventually resulted in the final model with only stable significant associated factors and interactions and these final models are reported here. For each variable in this final model the net odds ratio (OR) and its 95\% confidence interval (CI), backward elimination loglikelihood $\chi^{2}(-2 \mathrm{LL})$, 


\section{CHAPTER 3}

degrees of freedom (df) and P-value are reported. Predictive accuracy of both models is reported as the area under the ROC curve.

\section{RESULTS}

\section{Population}

Of the 5333 patients who were initially enrolled, 5272 were alive and 43 deceased at the end of the baseline admission/visit, whereas survival status was unknown for the remaining 18 patients. At 1 year follow-up, survival status was known for 4192 $(80 \%)$ patients and these patients are described in this manuscript. Median follow-up duration $\left(25^{\text {th }}-75^{\text {th }}\right.$ percentile) was 379 (366-418) days for patients alive at follow-up and 164 (78-312) days until decease. Patient characteristics per AF type were previously reported for all patients enrolled at baseline. ${ }^{1}$ Compared to patients with follow-up data available, patients lost to follow-up were at baseline more often enrolled in central European countries ( 36 vs $27 \%$; $\mathrm{P}<0.001$ ), less often at the outpatient clinic ( 21 vs $37 \% ; \mathrm{P}<0.001)$, more often had heart failure (42 vs $32 \% ; \mathrm{P}<0.001)$, more often were symptomatic $(76$ vs $67 \% ; \mathrm{P}<0.001)$ and less often received OAC (54 vs $68 \% ; \mathrm{P}<0.001$ ). No association was observed between AF type and proportion of patients lost-to-follow-up.

\section{AF characteristics}

Figure 1 shows that $46 \%$ of patients with initially a $1^{\text {st }}$ detected AF episode did not have an AF recurrence during 1 year hereafter. Further, paroxysmal mainly remained paroxysmal $\mathrm{AF}(80 \%), 30 \%$ of persistent $\mathrm{AF}$ progressed to permanent $\mathrm{AF}$ and permanent largely remained permanent AF (96\%). Of all patients 6\% was considered cured. Patients with initially $1^{\text {st }}$ detected AF were least often symptomatic at the time of follow-up (Table 1). Of permanent AF patients, $8 \%$ was not in AF according to the last recorded ECG.

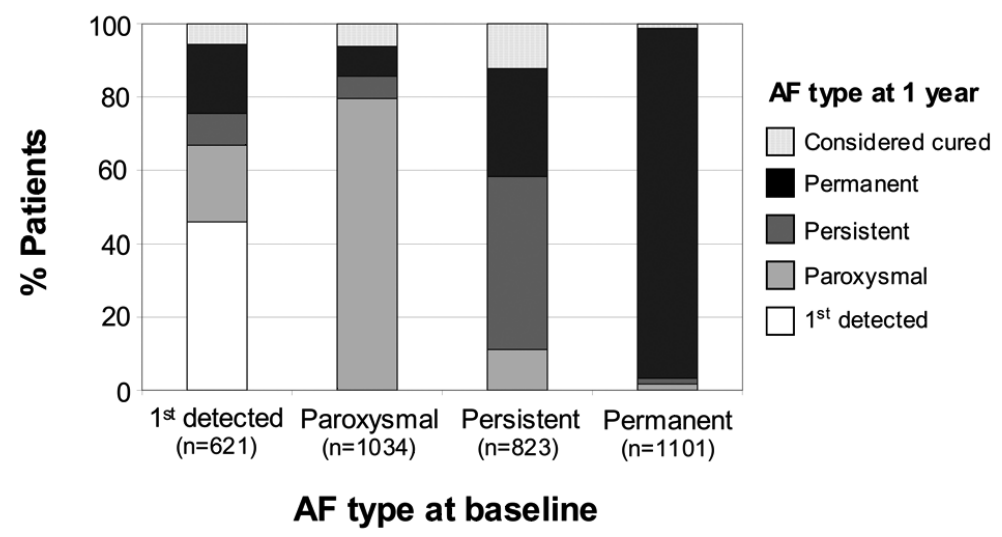

Figure 1. AF type categorization after 1 year per baseline AF type. 


\begin{tabular}{|c|c|c|c|c|c|}
\hline & \multicolumn{5}{|c|}{ Type of AF at baseline } \\
\hline & $\begin{array}{c}\text { 1st detected } \\
(\mathrm{n}=708)\end{array}$ & $\begin{array}{c}\text { Paroxysmal } \\
(\mathrm{n}=1170)\end{array}$ & $\begin{array}{c}\text { Persistent } \\
(\mathrm{n}=886)\end{array}$ & $\begin{array}{c}\text { Permanent } \\
(n=1126)\end{array}$ & P-value \\
\hline Age, years & $65 \pm 14$ & $64 \pm 13$ & $66 \pm 11$ & $70 \pm 11$ & $<0.001$ \\
\hline Female gender & $300(40)$ & $520(43)$ & $348(38)$ & $523(43)$ & 0.088 \\
\hline Follow-up duration, days & $\begin{array}{c}376 \\
(364-430)\end{array}$ & $\begin{array}{c}376 \\
(364-411)\end{array}$ & $\begin{array}{c}375 \\
(363-410)\end{array}$ & $\begin{array}{c}374 \\
(359-406)\end{array}$ & $<0.001$ \\
\hline \multicolumn{6}{|l|}{ AF characteristics at 1 year } \\
\hline Symptoms at 1 year & $93(15)$ & $349(34)$ & $283(35)$ & $403(38)$ & $<0.001$ \\
\hline $\mathrm{AF}$ on last recorded ECG & $154(24)$ & $185(18)$ & $378(45)$ & $998(92)$ & $<0.001$ \\
\hline \multicolumn{6}{|l|}{ Drug therapy at 1 year } \\
\hline \multicolumn{6}{|l|}{ Antithrombotic drugs } \\
\hline Oral anticoagulation & $302(45)$ & $557(50)$ & $614(71)$ & $895(79)$ & $<0.001$ \\
\hline Antiplatelet drug & $264(38)$ & $424(37)$ & $235(27)$ & $265(23)$ & $<0.001$ \\
\hline Heparin & $9(1)$ & $12(1)$ & $9(1)$ & $12(1)$ & 0.944 \\
\hline Nothing & $132(20)$ & $176(16)$ & $66(8)$ & $57(5)$ & $<0.001$ \\
\hline \multicolumn{6}{|l|}{ Rhythm / rate control drugs ${ }^{\mathrm{a}}$} \\
\hline Class $\mathrm{Ia}^{\mathrm{b}}$ & $2(0)$ & $9(1)$ & $5(1)$ & $1(0)$ & 0.068 \\
\hline Class Ic ${ }^{c}$ & $36(5)$ & $157(14)$ & $86(10)$ & $14(1)$ & $<0.001$ \\
\hline Class II $^{\mathrm{d}}$ & $230(34)$ & $479(43)$ & $362(42)$ & $442(39)$ & $<0.001$ \\
\hline Class III $^{\mathrm{e}}$ & $181(27)$ & $346(31)$ & $323(37)$ & $190(17)$ & $<0.001$ \\
\hline Class IV ${ }^{\mathrm{f}}$ & $40(6)$ & $76(7)$ & $70(8)$ & $129(11)$ & $<0.001$ \\
\hline Digitalis $^{\mathrm{g}}$ & $97(15)$ & $147(13)$ & $174(20)$ & $512(45)$ & $<0.001$ \\
\hline \multicolumn{6}{|l|}{ Interventions during 1 year } \\
\hline Pharmacological cardioversion & $89(13)$ & $237(21)$ & $143(16)$ & $39(3)$ & $<0.001$ \\
\hline Electrical cardioversion & $97(14)$ & $152(14)$ & $211(24)$ & $34(3)$ & $<0.001$ \\
\hline Catheter ablation & $4(1)$ & $62(6)$ & $32(4)$ & $12(1)$ & $<0.001$ \\
\hline Implantable defibrillator & $2(0)$ & $6(1)$ & $2(0)$ & $6(1)$ & 0.643 \\
\hline Pacemaker & $12(2)$ & $53(5)$ & $34(4)$ & $57(5)$ & 0.005 \\
\hline AF surgery & $0(0)$ & $3(0)$ & $4(0)$ & $5(0)$ & 0.342 \\
\hline
\end{tabular}

Compared to the remaining patients with $1^{\text {st }}$ detected, paroxysmal or persistent AF, patients who progressed to a more persistent form of AF were older (68 $\pm 12 \mathrm{vs}$ $64 \pm 13$ years; $\mathrm{P}<0.001$ ), more often had heart failure (39 vs $21 \% ; \mathrm{P}<0.001)$ and valvular heart disease ( 28 vs $19 \% ; \mathrm{P}<0.001)$ and had a larger left atrium at baseline $(47 \pm 8$ vs $44 \pm 8 \mathrm{~mm} ; \mathrm{P}<0.001)$. During 1 year follow-up, patients who progressed to persistent forms of AF more often had new onset (10 vs $4 \%$; $\mathrm{P}<0.001$ ) or worsening of existing heart failure (30 vs $19 \% ; \mathrm{P}=0.001$ ) and a thromboembolism (4.5 


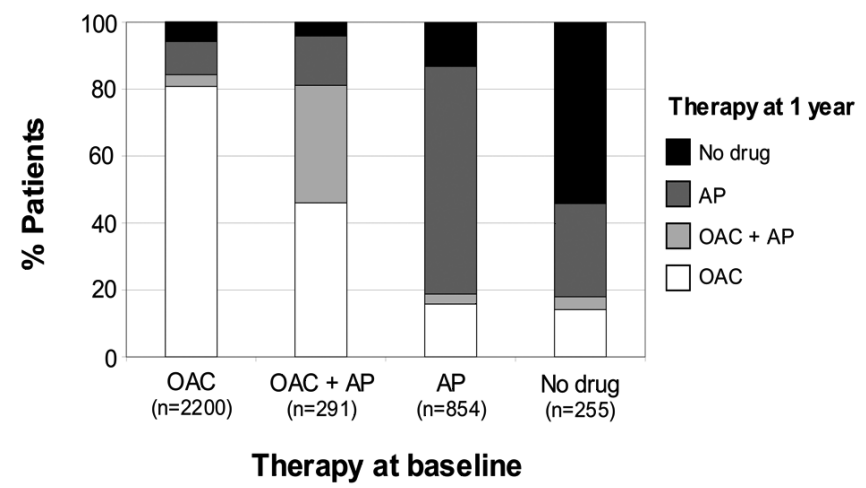

Figure 2. Antithrombotic therapy at 1 year per baseline antithrombotic regimen. AP, antiplatelet drug.

vs $2.0 \% ; \mathrm{P}=0.001$ ), and they more often had AF at the last known ECG (85 vs $12 \%$; $\mathrm{P}<0.001)$ and symptoms at 1 year (41 vs $26 \% ; \mathrm{P}<0.001)$. These patients equally often underwent a cardioversion or catheter ablation (33 vs $37 \%$ in the remaining patients; $\mathrm{P}=0.051$ ) during follow-up.

\section{Management}

Of all patients, 53\% underwent chest X-ray, 62\% echocardiography and 38\% thyroid hormone levels measurement during follow-up, making that respectively $88 \%, 94 \%$ and $68 \%$ had undergone these procedures at least once at any time point.

Any antithrombotic drug in general, and specifically OAC, was applied less often in $1^{\text {st }}$ detected and paroxysmal AF (Table 1). After 1 year, OAC was discontinued in $16 \%$ and started in 19\% of all patients (Figure 2). OAC was discontinued in $45 \%$ of patients with $1^{\text {st }}$ detected AF and no detected recurrence since, and overall in $63 \%$ of patients who were considered cured. The most frequent reported reasons not to prescribe OAC at 1 year in patients at high risk for stroke were "no indication" and "chronic sinus rhythm" (both 26\%). The main reason for starting OAC in patients at high risk for stroke was "persistent/permanent AF" (37\%), followed by "high risk factor for stroke" (28\%).

Class I and III antiarrhythmic drugs were most often prescribed in paroxysmal and persistent $\mathrm{AF}$, but also $17 \%$ of permanent $\mathrm{AF}$ patients received a class III drug. Of surviving patients who underwent rhythm control at baseline $27 \%$ did not receive rhythm control during 1 year follow-up and of patients under rate control at baseline $15 \%$ underwent rhythm control (Figure 3). Either rhythm or rate control was applied in $31 \%$ of patients who initially did not receive any heart rhythm therapy. 


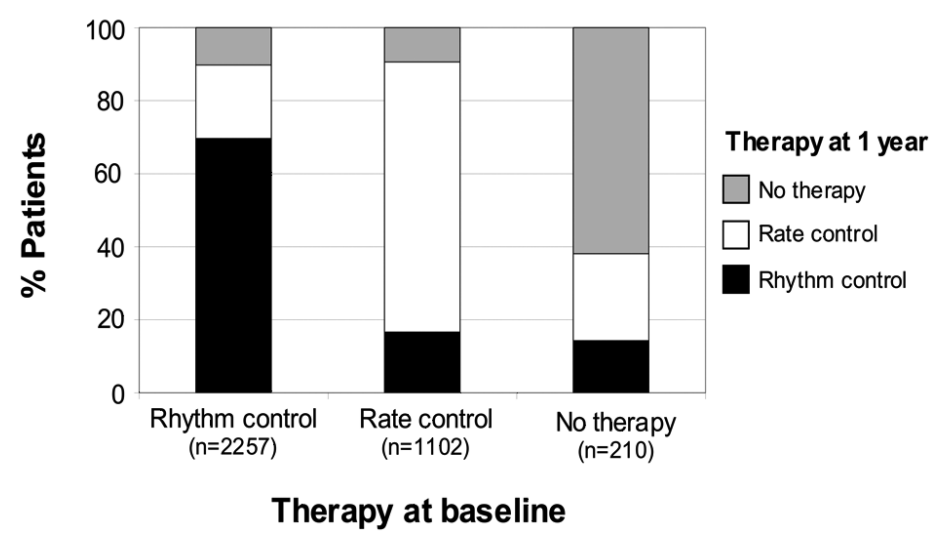

Figure 3. Heart rhythm strategies at 1 year per baseline heart rhythm strategy.

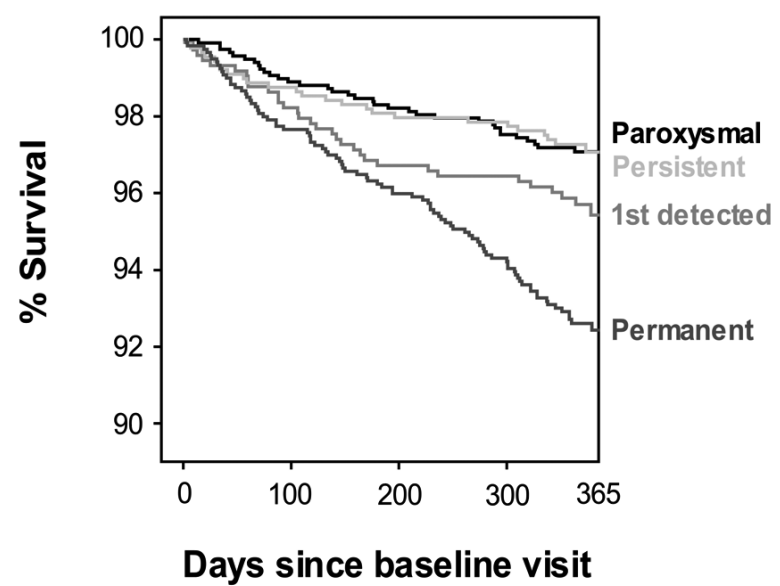

Figure 4. Survival from all-cause mortality during 1 year per baseline AF type.

\section{Morbidity \& mortality}

In the overall population, 63 patients (1.6\%) suffered an ischemic stroke, 173 patients $(4.3 \%)$ any thromboembolic complication, 9 patients $(0.2 \%)$ an intracranial haemorrhage $(\mathrm{ICH})$, and 60 patients $(1.5 \%)$ another type of major bleeding during 1 year. Furthermore, 135 patients $(5.0 \%)$ had new onset heart failure, and 314 $(24.7 \%)$ worsening of existing heart failure. Symptomatic coronary artery disease was observed in 160 patients $(12.1 \%)$, and newly diagnosed coronary artery disease in 62 patients (2.4\%). Table 2 shows that in general permanent AF patients most often suffered from these morbidities.

During 1 year follow-up 221 patients (5.3\%) died. For 156 of these patients the cause of death was reported and was cardiovascular in 97 patients (67\%). Mortality was clearly highest in permanent AF and also higher in $1^{\text {st }}$ detected AF compared to paroxysmal and persistent AF (Table 2 and Figure 4). The increased mortality in $1^{\text {st }}$ 
Table 2. Major adverse events, hospital admissions and quality of life

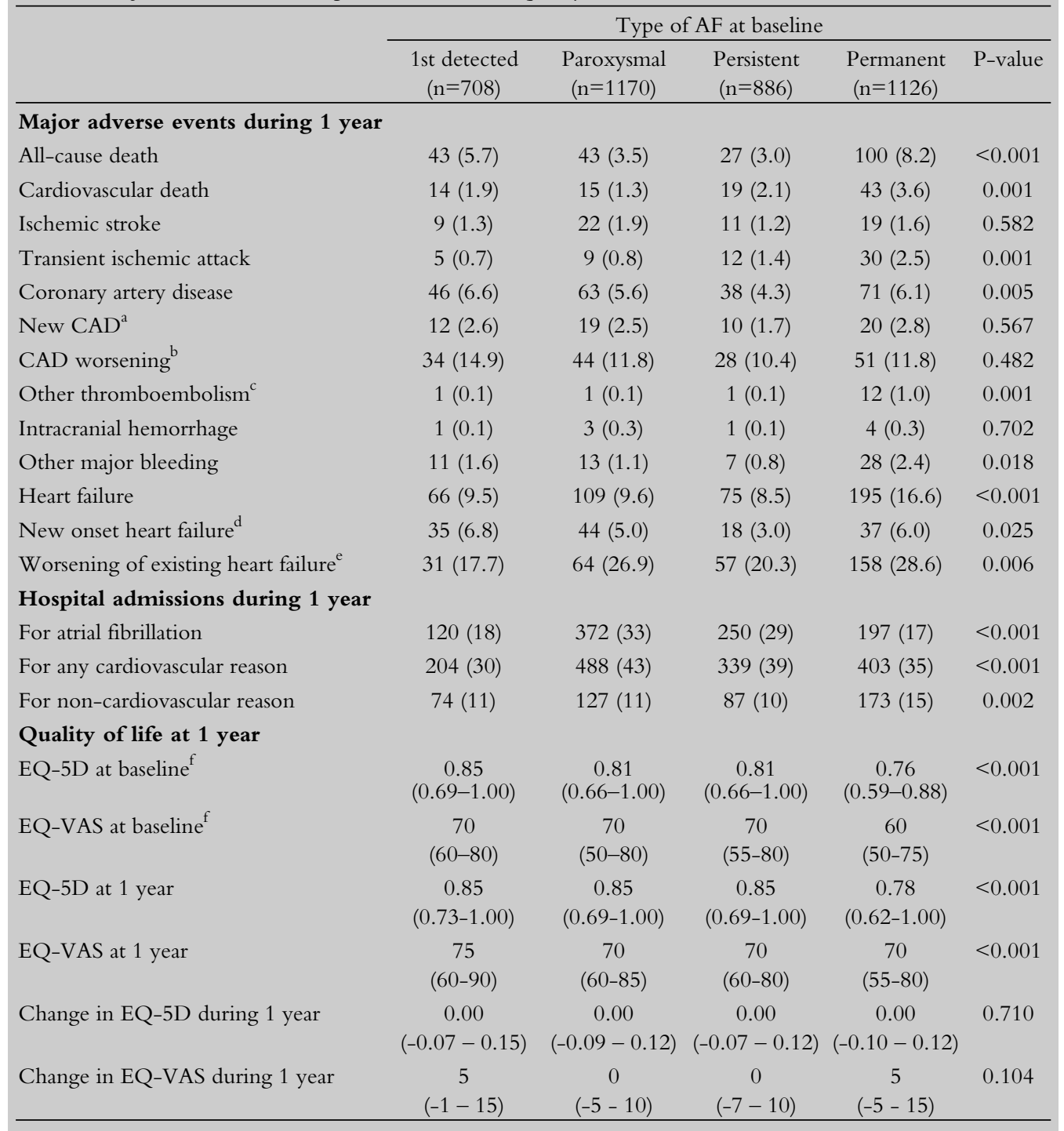

Results are reported as median $\left(25^{\text {th }}-75^{\text {th }}\right.$ percentile $)$ or observed number $(\%)$. CAD $=$ coronary artery disease. a Proportion calculated among patients without coronary artery disease at baseline; b Proportion calculated among patients with coronary artery disease at baseline; c Pulmonary or peripheral embolism; d Proportion calculated among patients without heart failure at baseline; e Proportion calculated among patients with heart failure at baseline; ${ }^{\mathrm{f}}$ Among patients for whom also a follow-up score was known.

detected AF persisted beyond the acute phase, and levelled after approximately 6 months. Mortality among patients with an ischemic stroke was $21 \%$, with intracranial haemorrhage $67 \%$ and with another type of major bleeding $10 \%$.

Old age was strongly associated with mortality, and its effect on the occurrence of any event was highest in the absence of heart failure and valvular heart disease 
Table 3. Baseline factors associated with all-cause mortality during 1 year

\begin{tabular}{|c|c|c|c|c|c|}
\hline & Odds ratio & $95 \% \mathrm{CI}$ & $-2 \mathrm{LL}$ & $\mathrm{df}$ & P-value \\
\hline Age, per year increase & 1.06 & $1.04-1.08$ & 53 & 1 & $<0.001$ \\
\hline \multicolumn{6}{|l|}{ Malignancy } \\
\hline If no heart failure & 4.08 & $2.18-7.64$ & 16 & 1 & $<0.001$ \\
\hline If heart failure & 1.06 & $0.48-2.37$ & $<1$ & 1 & 0.882 \\
\hline If no RAAS blocker ${ }^{\mathrm{a}}$ & 5.48 & $3.00-10.00$ & 26 & 1 & $<0.001$ \\
\hline If RAAS blocker ${ }^{\mathrm{a}}$ & 1.02 & $0.50-2.07$ & $<1$ & 1 & 0.960 \\
\hline \multicolumn{6}{|l|}{ Heart failure } \\
\hline If no malignancy & 2.91 & $1.94-4.36$ & 28 & 1 & $<0.001$ \\
\hline If malignancy & 1.45 & $0.45-4.65$ & $<1$ & 1 & 0.534 \\
\hline Sinus rhythm & 0.45 & $0.30-0.68$ & 16 & 1 & $<0.001$ \\
\hline $\begin{array}{l}\text { Reason admission/visit } \\
\text { (ref. = AF only) }\end{array}$ & & & 13 & 2 & 0.002 \\
\hline AF \& other reason & 1.71 & $1.05-2.80$ & & & \\
\hline Other reason & 2.39 & $1.43-3.99$ & & & \\
\hline Female gender & 0.62 & $0.44-0.88$ & 7 & 1 & 0.007 \\
\hline \multicolumn{6}{|l|}{ RAAS blocker ${ }^{a}$} \\
\hline If no malignancy & 0.67 & $0.43-1.05$ & 3 & 1 & 0.084 \\
\hline If malignancy & 0.15 & $0.04-0.53$ & 10 & 1 & 0.002 \\
\hline Major bleeding & 2.68 & $1.38-5.24$ & 7 & 1 & 0.007 \\
\hline Ventricular tachycardia & 2.65 & $1.41-5.01$ & 8 & 1 & 0.005 \\
\hline Renal failure & 1.83 & $1.12-2.98$ & 5 & 1 & 0.020 \\
\hline
\end{tabular}

(Tables 3 and 4). Also heart failure worsened prognosis, but its effect on mortality was only present when patients were never diagnosed with malignancy. Patients having sinus rhythm after the baseline visit had a better prognosis than patients who were in AF, but no significant effect of rhythm and rate control was observed. The prescription of a RAAS blocker was associated with decreased all-cause mortality, especially in patients who were ever diagnosed with malignancy.

\section{Quality of life}

Overall, EQ-5D and EQ-VAS scores, both at baseline and follow-up, were known for 2786 patients (66\% of patients alive at follow-up). EQ-5D and EQ-VAS scores were lowest in permanent AF, but changes in EQ-5D and EQ-VAS scores after 1 year were not different between AF types (Table 2). Figures $5 a$ and $5 b$ show that few patients had very low EQ-5D and EQ-VAS scores, and also that EQ-VAS ratings were lower than EQ-5D utility scores when assuming a comparable distribution of the scales. One-third of all patients had the maximum EQ-5D score of 1.00. The independent associations of EQ-5D and EQ-VAS with outcome were separately 
Table 4. Baseline factors associated with the combined endpoint of all-cause mortality, thromboembolism, major bleeding and heart failure during 1 year

\begin{tabular}{|c|c|c|c|c|c|}
\hline & Odds ratio & $95 \% \mathrm{CI}$ & $-2 \mathrm{LL}$ & df & P-value \\
\hline \multicolumn{6}{|l|}{ Heart failure } \\
\hline If age $\leq 67$ & 5.01 & $3.55-7.06$ & 89 & 1 & $<0.001$ \\
\hline If age $>67$ & 2.80 & $2.22-3.53$ & 76 & 1 & $<0.001$ \\
\hline \multicolumn{6}{|l|}{ Age, per year } \\
\hline If no heart failure & 1.04 & $1.03-1.06$ & 41 & 1 & $<0.001$ \\
\hline If heart failure & 1.00 & $0.99-1.01$ & $<1$ & 1 & 0.737 \\
\hline If no valvular heart disease & 1.03 & $1.02-1.04$ & 34 & 1 & $<0.001$ \\
\hline If valvular heart disease & 1.00 & $0.99-1.01$ & $<1$ & 1 & 0.802 \\
\hline COPD & 2.01 & $1.59-2.54$ & 32 & 1 & $<0.001$ \\
\hline Ventricular tachycardia & 3.15 & $2.02-4.90$ & 25 & 1 & $<0.001$ \\
\hline Major bleeding & 3.64 & $2.16-6.11$ & 23 & 1 & $<0.001$ \\
\hline Renal failure & 2.17 & $1.57-3.01$ & 21 & 1 & $<0.001$ \\
\hline $\begin{array}{l}\text { Type of AF } \\
(\text { ref. }=1 \text { st detected AF) }\end{array}$ & & & 13 & 3 & 0.004 \\
\hline Paroxysmal AF & 0.98 & $0.73-1.32$ & & & \\
\hline Persistent AF & 0.63 & $0.46-0.87$ & & & \\
\hline Permanent AF & 0.99 & $0.74-1.32$ & & & \\
\hline Sinus rhythm & 0.74 & $0.58-0.93$ & 7 & 1 & 0.010 \\
\hline Malignancy & 1.56 & $1.10-2.20$ & 6 & 1 & 0.014 \\
\hline \multicolumn{6}{|l|}{ Valvular heart disease } \\
\hline If age $\leq 67$ & 1.74 & $1.24-2.44$ & 10 & 1 & 0.002 \\
\hline If age $>67$ & 1.03 & $0.80-1.31$ & $<1$ & 1 & 0.837 \\
\hline
\end{tabular}

Area under the ROC curve $=0.773$. Ref., reference group; COPD, chronic obstructive pulmonary disease.

tested. The risk for all-cause mortality decreased non-significantly with increasing EQ-5D scores $\left(1^{\text {st }}\right.$ quartile is reference: odds ratio $(\mathrm{OR}) 2^{\text {nd }}$ quartile $=0.74$ $(0.44-1.24), 3^{\text {rd }}$ quartile $=0.64(0.35-1.18)$ and $4^{\text {th }}$ quartile $=0.58(0.30-1.13)$ respectively; $\mathrm{P}$ for trend $=0.366)$. The same was observed for the EQ-VAS score $(\mathrm{ORs}=0.80(0.51-1.25), 0.85(0.46-1.60), 0.47(0.22-1.02)$ respectively; $\mathrm{P}$ for trend $=0.235)$. However, the risk for the combined endpoint of all-cause death, any thromboembolism, major bleeding and heart failure, significantly decreased with increasing EQ-5D scores (ORs $=0.61$ (0.47-0.79), 0.53 (0.40-0.71), 0.47 $(0.35-0.64)$ respectively; P for trend $<0.001)$ and with increasing EQ-VAS scores $(\mathrm{ORs}=0.79(0.63-1.00), 0.67(0.49-0.91), 0.53(0.38-0.74)$ respectively; $\mathrm{P}$ for trend $=0.001$. 


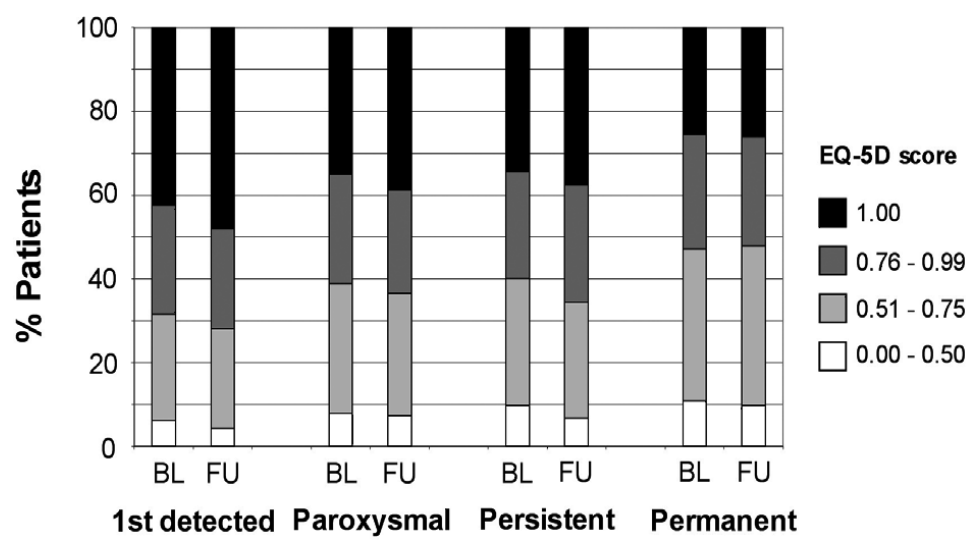

Figure 5a. Distribution of EQ-5D scores per AF type. BL, baseline; FU, follow-up.

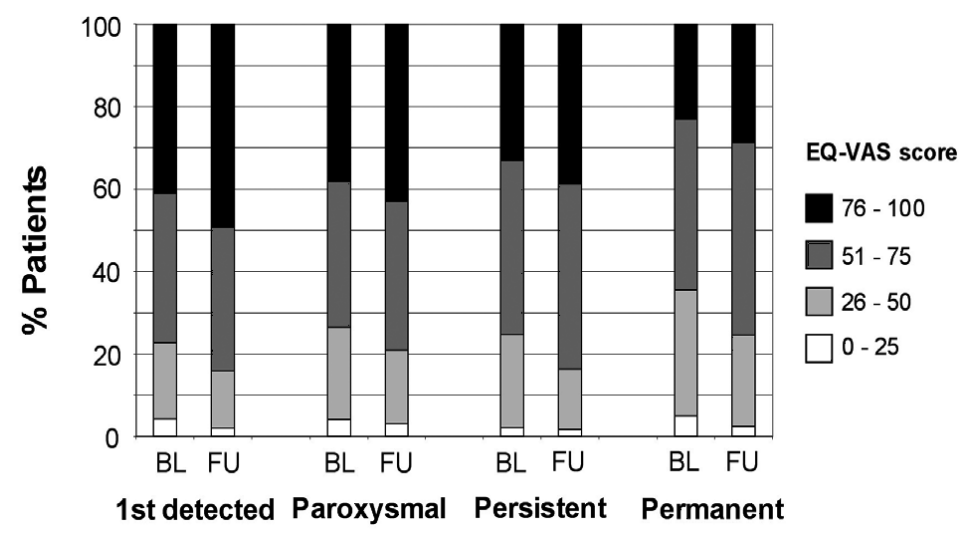

Figure 5b. Distribution of EQ-VAS scores per AF type. BL, baseline. FU, follow-up.

\section{DISCUSSION}

The Euro Heart Survey on AF provides unique prospective data on the management and prognosis of AF in a European cardiology based patient cohort.

\section{AF progression}

Half of the patients with initially $1^{\text {st }}$ detected AF did not have a recurrence during 1 year follow-up, only 1 out of 4 had AF on their last recorded ECG and only 15\% was symptomatic at 1 year. These findings might partly be due to simultaneous detection and consequent management of an associated disease. Furthermore, only a minority of paroxysmal AF patients progressed to persistent or permanent AF. This might indicate that from a clinical perspective paroxysmal AF just slowly progresses to more persistent forms of AF. In contrast, almost one-third of persistent 
AF patients progressed to permanent AF. Overall, progression to a more relentless form of AF is most likely with advancing age, heart failure, valvular heart disease and a large left atrium, which seems plausible. In only one-third of patients progressing to persistent forms of AF a rhythm control intervention was attempted during follow-up, indicating that other factors play a role when the physician indicates that the AF has become more relentless.

Remarkably, permanent AF patients were most often symptomatic at 1 year, which is in contrast to the lowest proportion observed at baseline. This possibly relates to the fact that permanent AF patients more often have chronic symptoms related to the higher prevalence of associated diseases, rather than intermittent symptoms due to AF itself. Also, $8 \%$ of permanent AF patients was reported not to be in $\mathrm{AF}$ at the last recorded ECG. This could mean that either recurrence of AF was not recorded on ECG, but probably noted by symptoms or on simplistic rhythm recordings, which obviously would not be recommended practice, or that there is diffusion about the definitions of persistent and permanent AF. Our findings on AF progression are largely in agreement with previous findings of the ALFA and CARAF studies. ${ }^{10,17}$

\section{Management}

Although almost all patients underwent a chest X-ray and an echocardiographic test, $30 \%$ did not undergo thyroid hormone levels measurement at any point in time, which is nevertheless highly recommended by the guidelines. ${ }^{2}$

OAC was started in $19 \%$ and discontinued in $16 \%$ of patients. In agreement with the baseline survey, $1^{\text {st }}$ detected and paroxysmal AF less often received OAC than persistent and permanent $\mathrm{AF}^{21}$ Also, at 1 year $\mathrm{OAC}$ seemed mainly discontinued when there was no AF recurrence observed or when AF was considered cured. Apparently, physicians weigh the perceived AF burden when deciding on antithrombotic treatment, which is however unreliable due to the high contribution of asymptomatic attacks and lack of adequate non-invasive monitoring tools. The current guidelines dissuade to consider the type of AF for selecting the appropriate antithrombotic drug. ${ }^{22}$

During 1 year, one-third of patients initially on rhythm control did not receive rhythm control therapy anymore and of patients initially on rate control $20 \%$ did receive rhythm control. These results stress the dynamics of assessing on-treatment rhythm and rate control therapy, rather than querying the physician on the intention-to-treat. That $17 \%$ of patients with permanent $\mathrm{AF}$ at follow-up did receive a class III antiarrhythmic drug might relate to diffusion about the definitions of persistent and permanent AF, but possibly also to the fact that these drugs have rate control properties and are given for this purpose. 


\section{Mortality E morbidity}

The overall all-cause mortality in our survey (5.3\%) was comparable with results of previous studies, which is also the case for the observed higher mortality in permanent AF than in other AF types. ${ }^{4,8,10}$ Patients with $1^{\text {st }}$ detected AF had a worse prognosis than patients with paroxysmal or persistent AF. This might relate to the new detection of both AF itself and possibly also associated diseases, which implies more often unstable and less well managed patients as compared to paroxysmal and persistent AF. Survival of ${ }^{\text {st }}$ detected AF patients during 1 year (94\%) was in general much higher than in previous studies on patients hospitalised with newly detected AF, which was around $80 \%{ }^{5,6,9,17,23}$ This difference might be due to Euro Heart Survey patients partly being enrolled at the outpatient clinic and few at the first (heart) aid department.

The multivariable analyses clarify which factors determine adverse outcome in this population. Logically old age, heart failure and malignancy were important determinants of an adverse prognosis. The lower mortality in patients receiving a RAAS blocker is probably due to their proven protective effect in heart failure and possibly hypertension, but might also be mediated by a lower recurrence rate of AF, which has been shown for ACE inhibitors. ${ }^{24,25}$ Sinus rhythm at baseline was associated with improved outcome, whereas the application of rhythm or rate control at baseline was not. Although both variables were temporary snapshot measurements, these results might indicate that patients who remain in sinus rhythm, whether with rhythm or rate control, benefit from the absence of AF.

Incidence of ischemic stroke was as low as that observed in randomised controlled trials (RCT) among patients on OAC, which is probably partially due to the high OAC application rate in our survey. ${ }^{26}$ Also in agreement with RCT results was that ICH rarely occurred, but when it occurred it was more lethal than ischemic stroke and other major bleedings. Heart failure worsened in 1 out of 5 heart failure patients and in agreement with previous findings patients with newly detected AF had approximately a 7\% risk of developing new HF within the first year after diagnosis. ${ }^{27}$

\section{Quality of life}

Five noninterventional QoL studies mainly investigated small population samples comparing AF patients with controls. ${ }^{12-16}$ The Euro Heart Survey is by far the largest observational study up till now to assess QoL in AF. In contrast to the previously mentioned studies which all used the SF-36 questionnaire, we used the EuroQoL questionnaire. Nevertheless, both questionnaires measure general health-related QoL, rather than specifically AF related QoL. This could be the reason that the EQ-5D utility scores were higher than the self-reported EQ-VAS ratings, and more specific AF related problems are not measured by the EQ-5D. As expected, the old permanent AF patients had the lowest QoL, but no differences 
were observed among AF types regarding change in QoL after 1 year. Based on several interventional studies, QoL improvement can be expected by both rate and rhythm control in symptomatic patients. ${ }^{28}$ Surprisingly, low QoL scores were not significantly associated with higher mortality, but were nevertheless associated with a higher risk for any adverse event.

\section{Strengths \& limitations}

The Euro Heart Survey is a unique large observational study that prospectively assesses mortality, morbidity, QoL, AF progression and treatment changes across the broader spectrum of AF patients in daily cardiology practice. Follow-up was available for $80 \%$ of initially enrolled patients, which is adequate for this kind of study.

We might have underestimated mortality and incidence of adverse events and overestimated QoL at 1 year in this cohort, since patients lost to follow-up were more often admitted in the hospital at the time of the baseline survey, more often had heart failure and less often received oral anticoagulation. In addition, it is plausible that lost to follow-up was caused by death, transfer to a nursing home (possibly due to disability as a result of ischemic stroke), or refusal to participate due to a bad health state.

\section{Conclusions}

Mortality was higher in permanent and $1^{\text {st }}$ detected AF than in paroxysmal and persistent AF. Incidence of stroke and major bleeding was as low as among patients on oral anticoagulation in randomised controlled trials. During 1 year, half of the patients with initially $1^{\text {st }}$ detected AF did not have a detected recurrence, paroxysmal mainly remained paroxysmal AF, and almost one-third of persistent progressed to permanent AF. Many treatment changes occurred during 1 year, indicating the difficulty of treating a progressive disease like AF with its variety of clinical presentations and many associated diseases. QoL was lowest in permanent AF, and low QoL scores at baseline were predictive for the occurrence of any major adverse event.

\section{REFERENCES}

1. Nieuwlaat R, Capucci A, Camm AJ, Olsson SB, Andresen D, Davies DW, Cobbe S, Breithardt G, Le Heuzey JY, Prins MH, Levy S, Crijns HJ. Atrial fibrillation management: a prospective survey in ESC member countries: the Euro Heart Survey on Atrial Fibrillation. Eur Heart J 2005;26:2422-34. 
2. Fuster V, Ryden LE, Asinger RW, Cannom DS, Crijns HJ, Frye RL, Halperin JL, Kay GN, Klein WW, Levy S, McNamara RL, Prystowsky EN, Wann LS, Wyse DG. ACC/AHA/ESC guidelines for the management of patients with atrial fibrillation. A report of the American College of Cardiology/American Heart Association Task Force on Practice Guidelines and the European Society of Cardiology Committee for Practice Guidelines and Policy Conferences (Committee to develop guidelines for the management of patients with atrial fibrillation) developed in collaboration with the North American Society of Pacing and Electrophysiology. Eur Heart J 2001;22:1852-923.

3. Khairallah F, Ezzedine R, Ganz LI, London B, Saba S. Epidemiology and determinants of outcome of admissions for atrial fibrillation in the United States from 1996 to 2001. Am J Cardiol 2004;94:500-4.

4. Stollberger C, Winkler-Dworak M, Finsterer J, Hartl E, Chnupa P. Factors influencing mortality in atrial fibrillation. Post hoc analysis of an observational study in outpatients. Int J Cardiol 2005;103:140-4.

5. Vidaillet H, Granada JF, Chyou PH, Maassen K, Ortiz M, Pulido JN, Sharma P, Smith PN, Hayes J. A population-based study of mortality among patients with atrial fibrillation or flutter. Am J Med 2002;113:365-70.

6. Patel PJ, Keating RJ, Gersh BJ, Hodge DO, Hammill SC, Shen WK. Outcome of patients with newly diagnosed atrial fibrillation at the Mayo Clinic and residing in that area. Am J Cardiol 2004;94:1379-82.

7. Benjamin EJ, Wolf PA, D'Agostino RB, Silbershatz H, Kannel WB, Levy D. Impact of atrial fibrillation on the risk of death: the Framingham Heart Study. Circulation 1998;98:946-52.

8. Keating RJ, Gersh BJ, Hodge DO, Weivoda PL, Patel PJ, Hammill SC, Shen WK. Effect of atrial fibrillation pattern on survival in a community-based cohort. Am J Cardiol 2005;96:1420-4.

9. Stewart S, Hart CL, Hole DJ, McMurray JJ. Population prevalence, incidence, and predictors of atrial fibrillation in the Renfrew/Paisley study. Heart 2001;86:516-21.

10. Levy S, Maarek M, Coumel P, Guize L, Lekieffre J, Medvedowsky JL, Sebaoun A. Characterization of different subsets of atrial fibrillation in general practice in France: the ALFA study. The College of French Cardiologists. Circulation 1999;99:3028-35.

11. Krahn AD, Manfreda J, Tate RB, Mathewson FA, Cuddy TE. The natural history of atrial fibrillation: incidence, risk factors, and prognosis in the Manitoba Follow-Up Study. Am J Med 1995;98:476-84

12. Dorian P, Jung W, Newman D, Paquette M, Wood K, Ayers GM, Camm J, Akhtar M, Luderitz B. The impairment of health-related quality of life in patients with intermittent atrial fibrillation: implications for the assessment of investigational therapy. J Am Coll Cardiol 2000;36:1303-9.

13. Paquette M, Roy D, Talajic M, Newman D, Couturier A, Yang C, Dorian P. Role of gender and personality on quality-of-life impairment in intermittent atrial fibrillation. Am J Cardiol 2000;86:764-8.

14. Howes CJ, Reid MC, Brandt C, Ruo B, Yerkey MW, Prasad B, Lin C, Peduzzi P, Ezekowitz MD. Exercise tolerance and quality of life in elderly patients with chronic atrial fibrillation. $\mathrm{J}$ Cardiovasc Pharmacol Ther 2001;6:23-9.

15. van den Berg MP, Hassink RJ, Tuinenburg AE, van Sonderen EF, Lefrandt JD, de Kam PJ, van Gelder IC, Smit AJ. Quality of life in patients with paroxysmal atrial fibrillation and its predictors: importance of the autonomic nervous system. Eur Heart J 2001;22:247-53.

16. Kang Y, Bahler R. Health-related quality of life in patients newly diagnosed with atrial fibrillation. Eur J Cardiovasc Nurs 2004;3:71-6.

17. Kerr CR, Humphries KH, Talajic M, Klein GJ, Connolly SJ, Green M, Boone J, Sheldon R, Dorian P, Newman D. Progression to chronic atrial fibrillation after the initial diagnosis of paroxysmal atrial fibrillation: results from the Canadian Registry of Atrial Fibrillation. Am Heart J 2005;149:489-96. 
18. Reynolds MR, Shah J, Essebag V, Olshansky B, Friedman PA, Hadjis T, Lemery R, Bahnson TD, Cannom DS, Josephson ME, Zimetbaum P. Patterns and predictors of warfarin use in patients with new-onset atrial fibrillation from the FRACTAL Registry. Am J Cardiol 2006;97:538-543.

19. Vaughan Williams EM. A classification of antiarrhythmic actions reassessed after a decade of new drugs. J Clin Pharmacol 1984;24:129-47.

20. Brooks R. EuroQol: the current state of play. Health Policy 1996;37:53-72.

21. Nieuwlaat R, Capucci A, Lip GY, Olsson SB, Prins MH, Nieman FH, Lopez-Sendon J, Vardas PE, Aliot E, Santini M, Crijns HJ. Antithrombotic treatment in real-life atrial fibrillation patients: a report from the Euro Heart Survey on Atrial Fibrillation. Eur Heart J 2006;27(24):3018-26.

22. Fuster V, Ryden LE, Cannom DS, Crijns HJ, Curtis AB, Ellenbogen KA, Halperin JL, Le Heuzey JY, Kay GN, Lowe JE, Olsson SB, Prystowsky EN, Tamargo JL, Wann S. ACC/AHA/ESC 2006 guidelines for the management of patients with atrial fibrillation-executive summary: a report of the American College of Cardiology/American Heart Association Task Force on practice guidelines and the European Society of Cardiology Committee for Practice Guidelines (Writing Committee to Revise the 2001 Guidelines for the Management of Patients with Atrial Fibrillation). Eur Heart J 2006;27:1979-2030.

23. Wolf PA, Mitchell JB, Baker CS, Kannel WB, D'Agostino RB. Impact of atrial fibrillation on mortality, stroke, and medical costs. Arch Intern Med 1998;158:229-34.

24. Pedersen OD, Bagger H, Kober L, Torp-Pedersen C. Trandolapril reduces the incidence of atrial fibrillation after acute myocardial infarction in patients with left ventricular dysfunction. Circulation 1999;100:376-80.

25. Vermes E, Tardif JC, Bourassa MG, Racine N, Levesque S, White M, Guerra PG, Ducharme A. Enalapril decreases the incidence of atrial fibrillation in patients with left ventricular dysfunction: insight from the Studies Of Left Ventricular Dysfunction (SOLVD) trials. Circulation 2003;107:2926-31.

26. Singer DE, Albers GW, Dalen JE, Go AS, Halperin JL, Manning WJ. Antithrombotic therapy in atrial fibrillation: the Seventh ACCP Conference on Antithrombotic and Thrombolytic Therapy. Chest 2004;126:429S-56S.

27. Miyasaka Y, Barnes ME, Gersh BJ, Cha SS, Bailey KR, Abhayaratna W, Seward JB, Iwasaka T, Tsang TS. Incidence and mortality risk of congestive heart failure in atrial fibrillation patients: a community-based study over two decades. Eur Heart J 2006;27:936-41.

28. Thrall G, Lane D, Carroll D, Lip GY. Quality of life in patients with atrial fibrillation: a systematic review. Am J Med 2006;119:448. e1-19. 


\section{PART II}

Antithrombotic therapy in atrial fibrillation

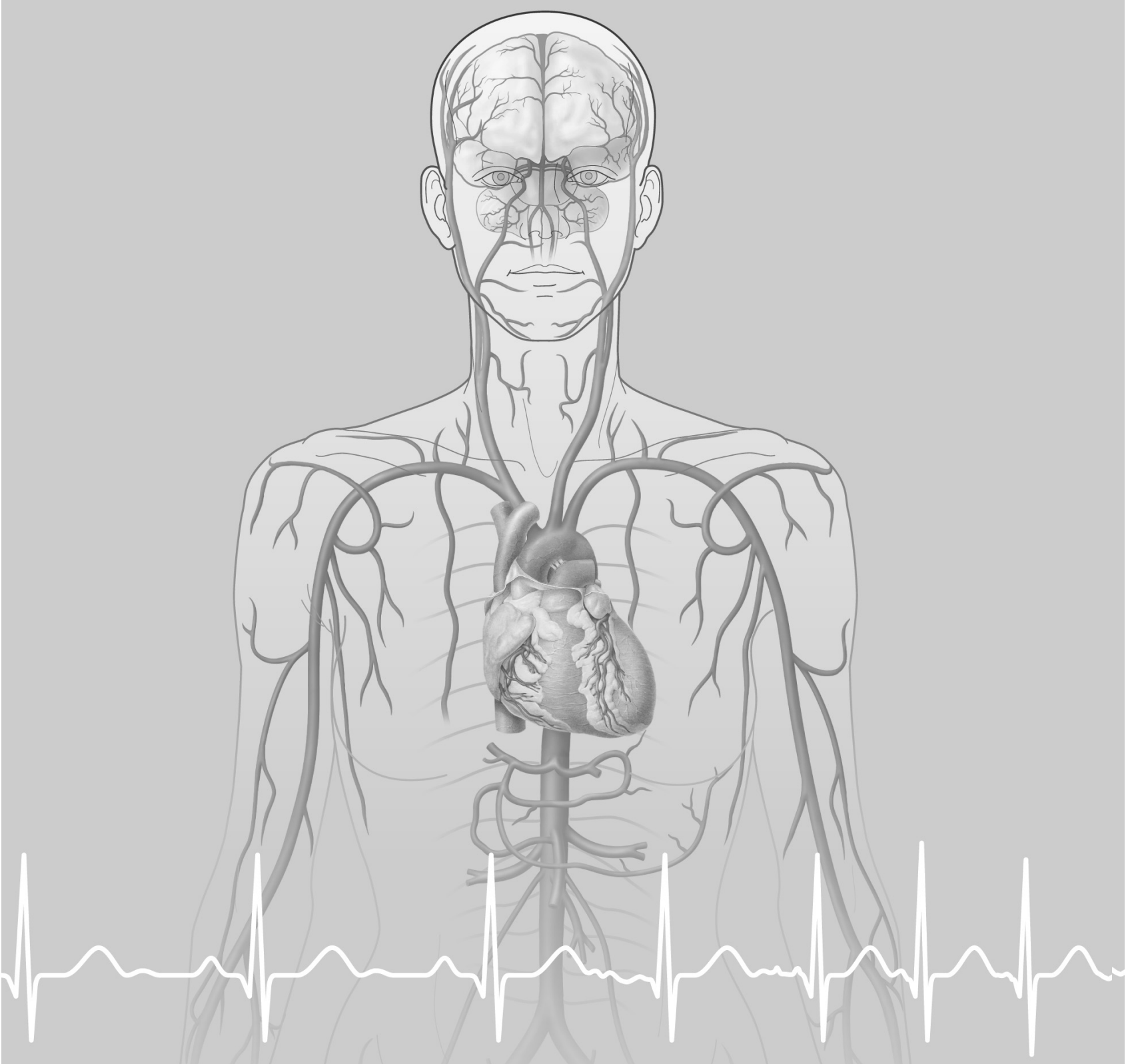



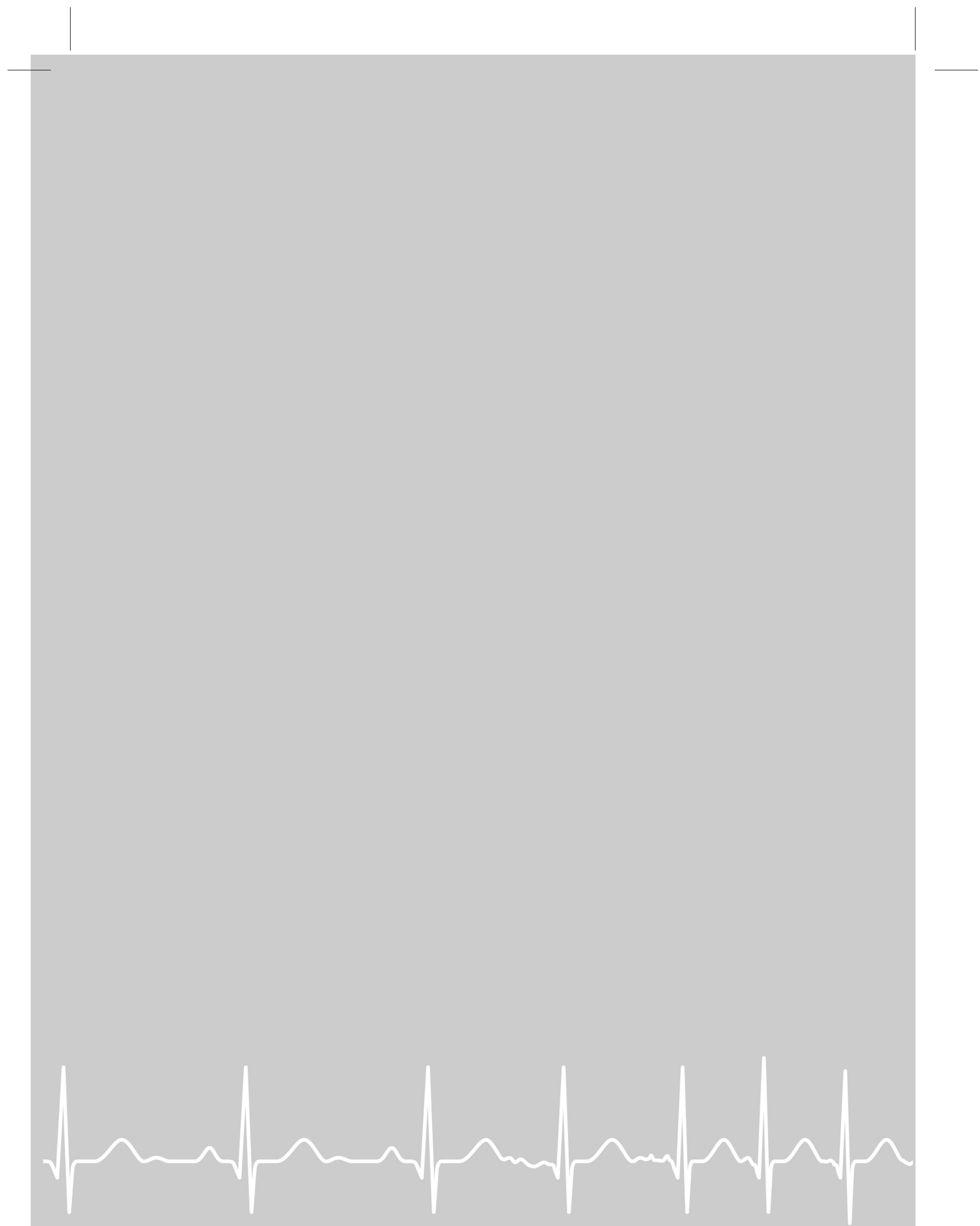


\section{4 \\ Antithrombotic treatment in real-life atrial fibrillation patients}

Robby Nieuwlaat, Alessandro Capucci, Gregory Y.H. Lip, S. Bertil Olsson, Martin H. Prins, Fred H. Nieman, José López-Sendón, Panos E. Vardas, Etienne Aliot, Massimo Santini, Harry J. G. M. Crijns

Eur Heart J. 2006;27(24):3018-26

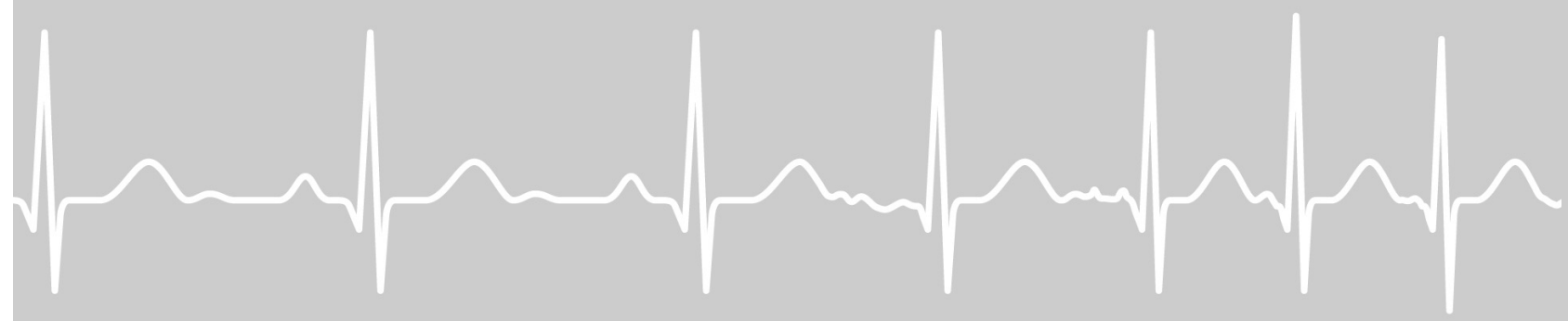




\section{ABSTRACT}

Aims. To describe guideline adherence and application of different stroke risk stratification schemes regarding antithrombotic therapy in real-life atrial fibrillation (AF) patients and to assess which factors influence antithrombotic management decisions.

Methods and results. The Euro Heart Survey enrolled 5333 AF patients in 35 countries, in 2003 and 2004. Prescription of antithrombotic drugs, especially oral anticoagulation (OAC), was hardly tailored to the patient's stroke risk profile as indicated by the joint guidelines of the American College of Cardiology, American Heart Association, and the European Society of Cardiology, the ACCP guidelines, and the $\mathrm{CHADS}_{2}$ and Framingham risk scores. In multivariable analysis, only a limited number of the well-known stroke risk factors triggered OAC prescription. In contrast, less relevant factors, of which clinical type of AF and availability of an OAC monitoring outpatient clinic were the most marked, played a significant role in OAC prescription. Electrical cardioversions and catheter ablations clearly triggered OAC prescription, whereas pharmacological cardioversions even in the presence of stroke risk factors did not.

Conclusion. Antithrombotic therapy in AF is hardly tailored to the patient's stroke risk profile. Factors other than well-known stroke risk factors were significantly involved in antithrombotic management decisions. To facilitate this tailored treatment, guideline writers and physician educators should focus on providing one uniform and easy to use stroke risk stratification scheme. 


\section{INTRODUCTION}

Atrial fibrillation (AF) is a risk factor for stroke and thromboembolism. ${ }^{1}$ When stroke occurs in association with AF, there is a higher mortality and greater disability. ${ }^{2}$ Stroke prevention is therefore a major issue when managing patients with AF, and many clinical risk factors have been identified, which confer a high risk of stroke, and oral anticoagulation (OAC) is recommended for such patients. ${ }^{3,4}$ In the Euro Heart Survey, $90 \%$ of AF patients had at least one or more additional risk factors for stroke. ${ }^{5}$ These risk factors have been used to inform the development of various risk stratification criteria, which are used to aid decision-making for thromboprophylaxis. ${ }^{3,4,6,7}$

Many observational studies have shown that $\mathrm{OAC}$ is frequently underused in AF patients in daily practice, with reported percentages of OAC prescription between 30 and $60 \% .^{8-12}$ This suboptimal use may, among several reasons, relate to unawareness among clinicians to guidelines and various risk stratification criteria or poor appreciation of the risk-benefit ratio, with overestimation of bleeding risks. ${ }^{13,14}$ Although some information is available regarding factors limiting optimal OAC prescription, limited information is available regarding the application of stroke risk stratification schemes, in general as well as around interventions for AF, in real-life clinical practice. Also, it is not well known to what extent stroke risk factors determine the choice for either OAC, antiplatelet drugs, or no antithrombotic therapy.

The first report on the Euro Heart Survey on AF suggested that OAC eligibility hardly determines the prescription of OAC and that other factors might play a role. ${ }^{5}$ The present analysis provides a detailed description of the application of antithrombotic drugs related to stroke risk stratification schemes in real-life cardiology practice throughout Europe and of the factors that influence the decision-making process. In addition, a description of antithrombotic therapy around pharmacological cardioversion (PCV), electrical cardioversion (ECV), and catheter ablation is given.

\section{METHODS}

The details of the Euro Heart Survey on AF have previously been described. ${ }^{5}$ Patients were enrolled in 182 university, non-university, and specialized hospitals among 35 member countries of the European Society of Cardiology (ESC). Consecutive patients per department were requested from the outpatient cardiology clinic, cardiology ward, first (heart) aid, cardiac surgery ward, cardioversion department, and/or device implantation department. Patients of $\geq 18$ years, with AF on ECG or Holter recording during the qualifying admission/consultation or in the preceding 12 months, were enrolled. Enrolment took place in 2003-4. Data were collected from medical records and/or medical information systems, and patient management was according to usual local practice. Central data collection 
was done at the European Heart House of the ESC, Sophia Antipolis, France. Data definitions of several important variables as used in this manuscript were also previously reported. ${ }^{5}$

\section{Stroke risk stratification schemes}

Antithrombotic drug prescription was analysed with reference to the joint guidelines on AF management of the American College of Cardiology (ACC), the American Heart Association (AHA), and $\mathrm{ESC},{ }^{3}$ and also the guidelines on antithrombotic therapy in AF of the American College of Chest Physicians (ACCP). ${ }^{15}$ The 2001 ACCP guidelines were recently superseded by the 2004 guidelines, ${ }^{16}$ but we focus only on the 2001 guidelines because these were published at the time of the survey. Recommendations for antithrombotic therapy in the latter guidelines do not take into account the patients with first detected AF. In addition, two other stroke risk stratification schemes were used for description of antithrombotic drug use. The $\mathrm{CHADS}_{2}$ (Congestive heart failure, Hypertension, Age $\geq 75$ years, Diabetes mellitus, and Stroke/TIA) stroke risk score is based on stroke risk classification schemes of the Stroke Prevention in Atrial Fibrillation (SPAF) trial investigators and the AF Investigators (AFI) and was validated in the National Registry of AF cohort on patients not receiving OAC. ${ }^{6}$ The $\mathrm{CHADS}_{2}$ scheme produces a score from 0 to 6 for patients with non-valvular AF. The Framingham stroke risk score is a population-based score derived from longitudinal follow-up in the Framingham Heart Study and is applicable to patients with newly detected non-valvular AF and produces a score from 0 to $31^{7}$ (see Appendix for an exact description of all four stroke risk stratification schemes).

\section{Data analysis}

Data analysis was done at the Department of Cardiology, University Hospital Maastricht, Maastricht, The Netherlands. Data analysis was performed with SPSS (SPSS Inc., release 12.01) and Stata (Stata corporation, release SE 8.0) statistical software. Continuous variables are reported as mean \pm standard deviation and categorical variables as observed number (percentage within the column). Numbers can add up to a lower count than the total number of patients in a column, because of missing values. The presence of any difference among the four antithrombotic treatment groups was tested with one-way ANOVA for continuous variables and with $\chi^{2}$ statistic for categorical variables, whereby variables with more than two categories were tested on differences in the distribution of all categories. Whether there was an association between antithrombotic drug prescription and a worsening stroke risk profile was tested for all four schemes by means of $\chi^{2}$ for trend. For these analyses, the very small groups of combination therapy and heparin only were left out, in order to assume an ordinal nature of the antithrombotic therapy, i.e. OAC-antiplatelet drug-no drug. Following this analysis, to test whether the 
(absence of) increasing trend was present for all categories, all adjacent risk categories were pairwise compared by means of $\chi^{2}$ statistic. All the above-mentioned tests were two-sided.

Prevalence of stroke risk factors and stroke risk categories was reported per stroke risk stratification scheme among patients who survived hospital admission and for whom the concerning scheme was designed. Antithrombotic drug prescription at discharge was reported in the same patients as described above, with the addition that patients in whom a PCV, an ECV, or catheter ablation was performed or planned were excluded from the analyses, as these interventions may trigger specific antithrombotic treatment regardless of risk schemes. Antithrombotic treatment around these interventions was analysed separately.

Multivariable stepwise logistic regression was performed to identify factors associated with prescribing OAC, with an antiplatelet agent rather than no drug, with any antithrombotic drug rather than no drug, and with a combination of OAC and an antiplatelet agent rather than OAC only. The following 15 variables were put in the multivariable models: age, gender, clinical type of AF, hypertens on, heart failure, coronary artery disease (CAD), diabetes, (prior) stroke or transient ischaemic attack (TIA), valvular heart disease (mitral stenosis or valve surgery), (prior) malignancy, (prior) major bleeding, renal failure, presence of an outpatient clinic for OAC monitoring, reason for admission or visit, and rate/rhythm control. Variables were removed stepwise from the model when the $\mathrm{P}$-value exceeded 0.10. Variables with $\mathrm{P}<0.05$ in the final model were considered to be significant contributors and were kept in the model. Hereafter, these models were validated by means of bootstrapping, which was performed with 100 samples for each reported multivariable logistic regression analysis. Bootstrapping provided information on the effect stability of each factor as a predictor of the outcome variable. Effects that were instable were stepwise left out of the model, which eventually resulted in the final model containing only stable significant effects, and these final models are reported here. For each variable in this model, the net odds ratio (OR) and its $95 \%$ confidence interval (CI), backward elimination log-likelihood ratio $\chi^{2}(-2 \mathrm{LL})$, degrees of freedom (df), and P-value are reported. In addition, predictive accuracy of each model is reported as the area under the ROC curve.

\section{RESULTS}

In the Euro Heart Survey, 5333 ambulant and hospitalized AF patients were enrolled. Table 1 shows characteristics per antithrombotic treatment group of 2706 patients $(52 \%)$ in whom no PCV, ECV, or catheter ablation was performed or planned at the time of the survey. These factors were tested in multivariable logistic regression analyses on association with antithrombotic drug prescription. 


\section{CHAPTER 4}

Table 1. Characteristics vs. antithrombotic drug use of 2706 patients in whom no PCV or ECV or catheter ablation was performed or planned

\begin{tabular}{|c|c|c|c|c|c|}
\hline & OAC only & $\begin{array}{c}\mathrm{OAC}+ \\
\text { antiplatelet }\end{array}$ & $\begin{array}{l}\text { Antiplatelet } \\
\text { only }\end{array}$ & $\begin{array}{l}\text { No antithrombotic } \\
\text { drug }\end{array}$ & P-value \\
\hline $\mathrm{N}$ & 1532 & 201 & 739 & 234 & \\
\hline \multicolumn{6}{|l|}{ Admission/visit } \\
\hline OAC clinic available & $1074(71)$ & $118(59)$ & $455(62)$ & $158(68)$ & $<0.001$ \\
\hline \multicolumn{6}{|l|}{ Reason for visit } \\
\hline AF only reason & $440(29)$ & $37(19)$ & $163(22)$ & $102(44)$ & $<0.001$ \\
\hline $\mathrm{AF}+$ other reason & $723(47)$ & $114(57)$ & $365(50)$ & $72(31)$ & $<0.001$ \\
\hline Other reason only & $365(24)$ & $49(25)$ & 209 (28) & $60(26)$ & 0.148 \\
\hline \multicolumn{6}{|l|}{ Demographics } \\
\hline Age, years & $69 \pm 11$ & $69 \pm 11$ & $71 \pm 12$ & $64 \pm 18$ & $<0.001$ \\
\hline Female gender & $709(46)$ & $73(36)$ & $313(42)$ & $101(43)$ & 0.025 \\
\hline \multicolumn{6}{|l|}{ Stroke Risk Factors } \\
\hline Valvular heart disease & $283(19)$ & $29(15)$ & $23(3)$ & $9(4)$ & $<0.001$ \\
\hline Any thromboembolism & $252(17)$ & $44(22)$ & $105(14)$ & $15(7)$ & $<0.001$ \\
\hline Stroke/TIA & $202(13)$ & $31(16)$ & $89(12)$ & $14(6)$ & 0.010 \\
\hline Heart failure & $631(41)$ & $97(49)$ & 277 (38) & $61(26)$ & $<0.001$ \\
\hline Hypertension & $979(64)$ & $130(65)$ & $522(71)$ & $120(51)$ & $<0.001$ \\
\hline CAD & $480(32)$ & $134(68)$ & $340(47)$ & $36(16)$ & $<0.001$ \\
\hline Diabetes & $325(21)$ & $49(24)$ & $130(18)$ & $26(11)$ & 0.001 \\
\hline \multicolumn{6}{|l|}{ Bleeding risk factors } \\
\hline Major bleeding & $31(2)$ & $6(3)$ & $14(2)$ & $16(7)$ & $<0.001$ \\
\hline Malignancy & $102(7)$ & $14(7)$ & $35(5)$ & $21(9)$ & 0.042 \\
\hline Renal failure & $97(6)$ & $14(7)$ & $52(7)$ & $16(7)$ & 0.197 \\
\hline \multicolumn{6}{|l|}{ Type of AF } \\
\hline First detected & $134(9)$ & $18(9)$ & $109(15)$ & $49(22)$ & $<0.001$ \\
\hline Paroxysmal & $276(19)$ & $38(19)$ & $270(37)$ & $79(43)$ & $<0.001$ \\
\hline Persistent & $219(15)$ & $17(9)$ & $78(11)$ & $20(9)$ & 0.005 \\
\hline Permanent & $864(58)$ & $123(63)$ & $263(37)$ & $58(26)$ & $<0.001$ \\
\hline \multicolumn{6}{|l|}{ Heart Rhythm Strategy } \\
\hline Rhythm control & $355(24)$ & $60(30)$ & $201(28)$ & $77(34)$ & $<0.001$ \\
\hline Rate control & $981(66)$ & $124(62)$ & $404(56)$ & $98(43)$ & $<0.001$ \\
\hline No rhythm/rate control & $158(11)$ & $16(8)$ & $111(16)$ & $52(23)$ & $<0.001$ \\
\hline
\end{tabular}

\section{Risk factors for stroke}

Figure 1 shows the distribution of stroke risk categories as defined according to the joint ACC/AHA/ESC guidelines on AF management, the ACCP guidelines on antithrombotic therapy in $\mathrm{AF}$, the $\mathrm{CHADS}_{2}$ score, and the Framingham score. The low(est) risk category or score was found in $10-18 \%$ of patients, and most AF patients in this survey were at (very) high risk for stroke according to both guide- 


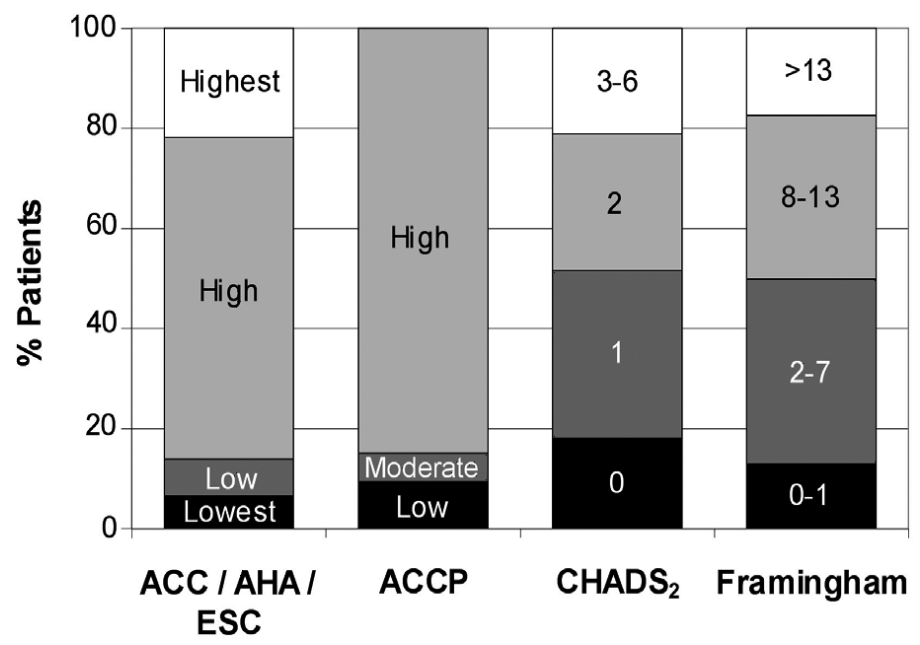

Figure 1. Distribution of stroke risk categories according to the ACC/AHA/ ESC and ACCP guidelines and the $\mathrm{CHADS}_{2}$ and Framingham risk scores. For a detailed description of the risk categories, see Appendix.

lines, whereas higher risk categorization was more shaded according to the $\mathrm{CHADS}_{2}$ and Framingham scores. Hypertension was the main driver for such an impressive prevalence of risk factors, but also heart failure and simply old age were important contributors. For every risk stratification scheme, the exact prevalence of stroke risk factors and classification into risk groups are shown in the Appendix.

\section{Prescription of antithrombotic drugs}

Antithrombotic drug prescription significantly $(\mathrm{P}<0.001)$ increased with a worsening stroke risk profile according to all four risk stratification schemes (Figure 2). However, variation in drug prescription was marginal and a large proportion (40-50\%) of patients at the lowest risk were prescribed OAC. Also, when pairwise comparing the adjacent risk categories, some inconsistencies in the increasing trends were found. Prescription in ACC/AHA/ESC high risk was comparable $(\mathrm{P}=0.506)$ with the low risk, and prescription in ACCP high risk was comparable with the intermediate risk $(\mathrm{P}=0.753)$. Regarding the $\mathrm{CHADS}_{2}$ score, the only pairwise comparison that was significantly different was between score 0 and 1 , which was also the case for the Framingham score regarding the comparison of categories $8-13$ and $>13$.

\section{Factors associated with antithrombotic management decisions}

Tables 2-5 report factors that were in multivariable logistic regression significantly associated with antithrombotic drug prescription. Of all well-known stroke risk factors, valvular heart disease was strongly associated with OAC prescription, as well 

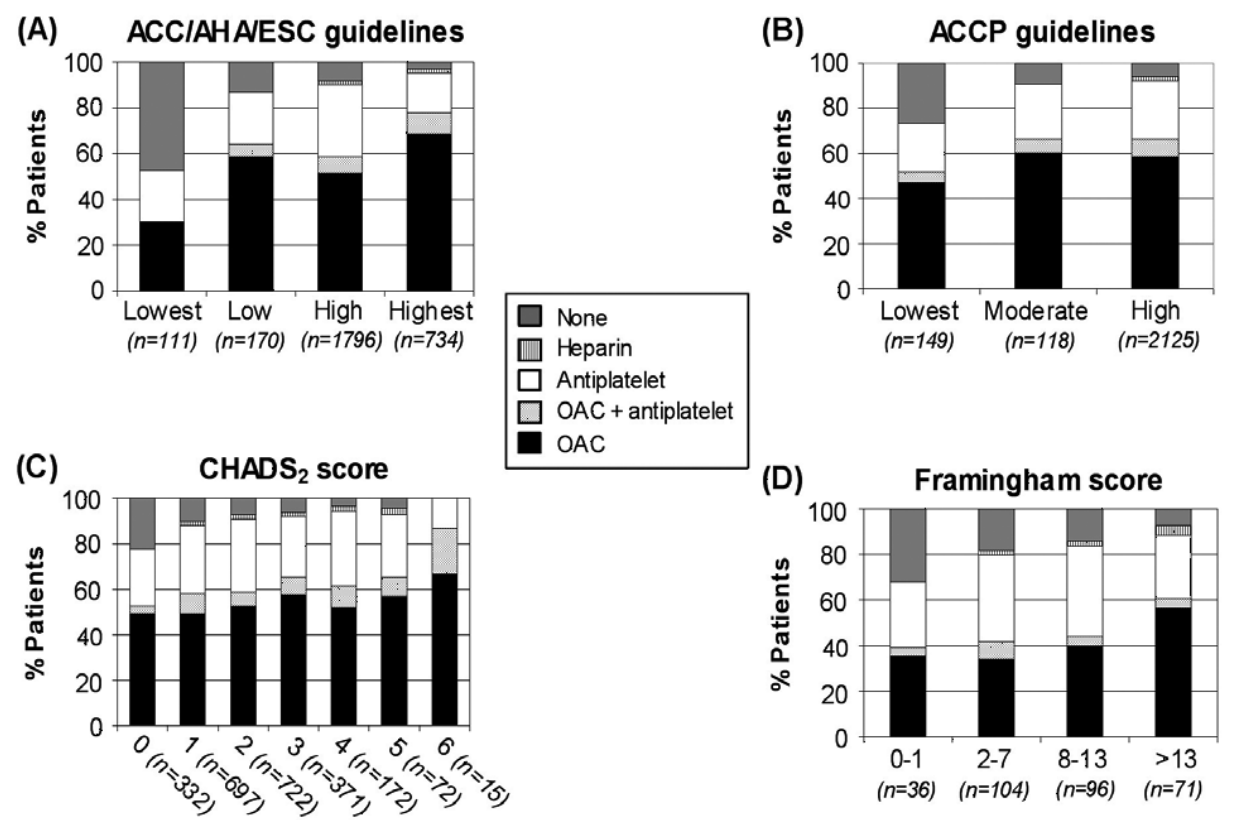

Figure 2. Antithrombotic drug prescription per risk category according to the ACC/AHA/ESC guidelines (A), ACCP guidelines (B), CHADS $_{2}$ score (C), and the Framingham score (D).

\begin{tabular}{|c|c|c|c|c|c|}
\hline & Odds ratio & $95 \% \mathrm{CI}$ & $-2 \mathrm{LL}$ & $\mathrm{df}$ & P-value \\
\hline Valvular heart disease & 5.67 & $3.83-8.38$ & 106 & 1 & $<0.001$ \\
\hline AF type (ref. $=1$ st detected AF) & & & 141 & 3 & $<0.001$ \\
\hline Paroxysmal AF & 0.87 & $0.65-1.16$ & & & \\
\hline Persistent AF & 2.36 & $1.68-3.32$ & & & \\
\hline Permanent AF & 2.83 & $2.16-3.71$ & & & \\
\hline Diabetes & 1.47 & $1.17-1.85$ & 11 & 1 & 0.001 \\
\hline Reason admission/visit (ref. $=$ AF only) & & & 16 & 2 & $<0.001$ \\
\hline $\mathrm{AF}+$ other reason & 0.72 & $0.58-0.90$ & & & \\
\hline Other reason only & 0.63 & $0.49-0.80$ & & & \\
\hline Major bleeding & 0.51 & $0.29-0.89$ & 6 & 1 & 0.019 \\
\hline No OAC monitoring clinic & 0.75 & $0.62-0.91$ & 9 & 1 & 0.003 \\
\hline Rhythm strategy (ref.=Rhythm control) & & & 18 & 2 & $<0.001$ \\
\hline Rate control & 0.99 & $0.80-1.23$ & & & \\
\hline No rhythm/rate control & 0.57 & $0.42-0.76$ & & & \\
\hline
\end{tabular}

Ref., reference group. Area under the ROC curve $=0.7143$. 
Table 3. Factors associated with prescription of an antiplatelet drug alone, rather than nothing

\begin{tabular}{lccccc}
\hline & Odds ratio & $95 \%$ CI & -2 LL & df & P-value \\
\hline CAD & 4.20 & $2.87-6.16$ & 63 & 1 & $<0.001$ \\
Reason admission/visit (ref.=AF only) & & & 16 & 2 & $<0.001$ \\
$\quad$ AF + other reason & 1.92 & $1.33-2.79$ & & & \\
$\quad$ Other reason only & 1.03 & $0.69-1.55$ & & & \\
Age $>75$ years & 1.65 & $1.19-2.28$ & 9 & 1 & 0.002 \\
Hypertension & 1.64 & $1.20-2.26$ & 9 & 1 & 0.002 \\
Malignancy & 0.40 & $0.23-0.72$ & 9 & 1 & 0.002 \\
Major bleeding & 0.22 & $0.10-0.48$ & 14 & 1 & $<0.001$ \\
\hline
\end{tabular}

Ref., reference group. Area under the ROC curve $=0.7366$.

Table 4. Factors associated with prescription of a combination of OAC and an antiplatelet drug, rather than OAC alone

\begin{tabular}{lccccc}
\hline & $\begin{array}{c}\text { Odds } \\
\text { ratio }\end{array}$ & $95 \%$ CI & -2 LL & df & P-value \\
\hline CAD & 4.53 & $3.29-6.23$ & 93 & 1 & $<0.001$ \\
No OAC monitoring clinic & 1.80 & $1.31-2.47$ & 13 & 1 & $<0.001$ \\
\hline
\end{tabular}

Table 5. Factors associated with prescription of any antithrombotic drug

\begin{tabular}{lccccc}
\hline & Odds ratio & $95 \%$ CI & -2 LL & df & P-value \\
\hline CAD & 3.57 & $2.43-5.25$ & 51 & 1 & $<0.001$ \\
AF type (ref.=1st detected AF) & & & 68 & 3 & $<0.001$ \\
$\quad$ Paroxysmal AF & 1.02 & $0.69-1.51$ & & & \\
$\quad$ Persistent AF & 2.99 & $1.69-5.31$ & & & \\
$\quad$ Permanent AF & 3.67 & $2.39-5.64$ & & & \\
Valvular heart disease & 3.77 & $1.86-7.66$ & 19 & 1 & $<0.001$ \\
Hypertension & 1.86 & $1.38-2.49$ & 17 & 1 & $<0.001$ \\
Stroke/TIA & 2.25 & $1.24-4.07$ & 7 & 1 & 0.008 \\
Major bleeding & 0.13 & $0.07-0.26$ & 25 & 1 & $<0.001$ \\
\hline Ref., reference group. Area under the ROC curve $=0.7655$. & & &
\end{tabular}

as diabetes, although to a much lesser extent. A (prior) stroke/TIA, hypertension, age $>75$ years and CAD were not associated with OAC prescription, but they were associated with prescription of an antiplatelet drug or any antithrombotic drug. CAD was also a reason to add an antiplatelet drug to OAC. Heart failure did not play a significant role in any of these four analyses. Patients with a (prior) major bleeding were not only less likely to receive OAC, but were also denied antiplatelet drugs.

Several factors other than well-known stroke risk factors played a significant role in these analyses. Patients with persistent or permanent AF were much more likely to receive OAC than patients with first detected or paroxysmal AF. When AF was the only reason for the admission or visit, OAC was more often prescribed than 
Table 6. Characteristics of patients in whom an intervention to restore sinus rhythm was performed or planned

\begin{tabular}{|c|c|c|c|c|c|c|}
\hline & \multicolumn{2}{|c|}{$\begin{array}{l}\text { Pharmacological } \\
\text { cardioversion }\end{array}$} & \multicolumn{2}{|c|}{$\begin{array}{c}\text { Electrical } \\
\text { cardioversion }\end{array}$} & \multicolumn{2}{|c|}{$\begin{array}{l}\text { Catheter } \\
\text { ablation }\end{array}$} \\
\hline & $\begin{array}{l}\text { Performed } \\
(n=1139)\end{array}$ & $\begin{array}{l}\text { Planned } \\
(\mathrm{n}=128)\end{array}$ & $\begin{array}{l}\text { Performed } \\
(\mathrm{n}=919)\end{array}$ & $\begin{array}{l}\text { Planned } \\
(\mathrm{n}=417)\end{array}$ & $\begin{array}{l}\text { Performed } \\
(n=134)\end{array}$ & $\begin{array}{l}\text { Planned } \\
(\mathrm{n}=118)\end{array}$ \\
\hline \multicolumn{7}{|l|}{ Demographics } \\
\hline Age, years & $64 \pm 13$ & $66 \pm 10$ & $64 \pm 12$ & $65 \pm 11$ & $54 \pm 11$ & $57 \pm 16$ \\
\hline Female gender & $513(45)$ & $41(32)$ & $329(36)$ & $162(39)$ & $40(30)$ & $36(31)$ \\
\hline \multicolumn{7}{|c|}{$\begin{array}{l}\text { Duration of current AF } \\
\text { episode }\end{array}$} \\
\hline$\leq 48$ hours & $569(56)$ & $11(10)$ & $162(19)$ & $24(6)$ & & \\
\hline$>48$ hours & $222(22)$ & $30(27)$ & $341(41)$ & $142(37)$ & & \\
\hline Unknown duration & $219(22)$ & $69(63)$ & $333(40)$ & $216(57)$ & & \\
\hline \multicolumn{7}{|l|}{ ACC/AHA/ESC risk } \\
\hline Lowest & $101(9)$ & $4(3)$ & $77(8)$ & $25(6)$ & $46(35)$ & $22(19)$ \\
\hline Low & $82(7)$ & $10(8)$ & $110(12)$ & $26(6)$ & $19(14)$ & $15(13)$ \\
\hline High & $752(66)$ & $103(81)$ & $555(61)$ & $284(69)$ & $49(37)$ & $51(44)$ \\
\hline Highest & $199(18)$ & $11(9)$ & $173(19)$ & $79(19)$ & $18(14)$ & $29(25)$ \\
\hline
\end{tabular}

(A)

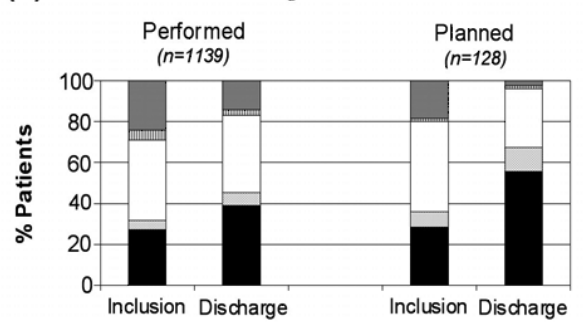

(C)

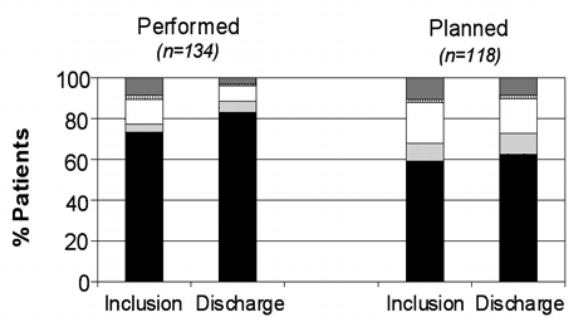

(B) Electrical cardioversion

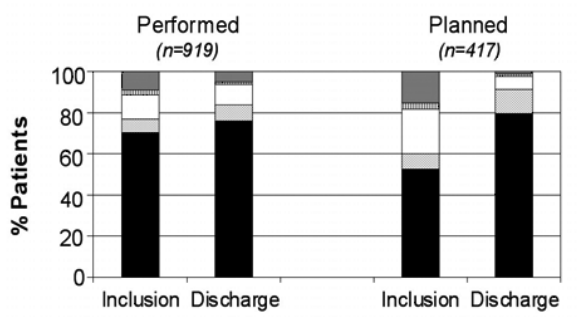

Figure 3. Antithrombotic drug prescription at inclusion and at discharge when the following interventions were either performed at the time of the survey or planned at discharge: PCV (A), ECV (B), or catheter ablation (C). 
when other medical conditions were in play. The absence of an OAC monitoring outpatient clinic lead to a lower probability of prescribing OAC, and also more frequently to addition of an antiplatelet drug when OAC was prescribed. Patients, in whom no rhythm or rate control drugs or interventions were applied, had a lower chance of receiving OAC.

\section{Antithrombotic drug therapy around interventions for $A F$}

When comparing with patients undergoing cardioversion, patients undergoing catheter ablation were younger, less often female, and had a much lower stroke risk burden (Table 6).

Antithrombotic treatment around PCV, ECV, and catheter ablation procedures is depicted in Figure 3. Many patients did not receive OAC before and after their PCV, but OAC prescription clearly increased when a PCV was planned. Most patients received antithrombotic treatment around $\mathrm{ECV}$, and OAC prescription was clearly triggered at discharge when an ECV was planned. Among patients who underwent a current PCV, 47\% $(n=924)$ received OAC at discharge when at least one stroke risk factor according to the ACC/AHA/ESC guidelines was present, $63 \%(\mathrm{n}=50)$ when no risk factor was present but $\mathrm{AF}$ duration was longer than $48 \mathrm{~h}$ or unknown, $48 \%(\mathrm{n}=974)$ when either at least one risk factor was present or AF duration was longer than $48 \mathrm{~h}$ or unknown, and $25 \%(\mathrm{n}=106)$ when no risk factor was present and AF duration was shorter than $48 \mathrm{~h}$. Among patients who underwent a current ECV, these proportions were, respectively, $86(n=713), 88(n=122), 87(n=836)$, and $61 \%(\mathrm{n}=106)$. OAC use around a catheter ablation was high $(\sim 80 \%)$, and of all patients with at least one risk factor, $92 \%$ received OAC. A planned catheter ablation did not trigger OAC prescription, and among these patients, $73 \%$ left the hospital protected by OAC.

\section{DISCUSSION}

Of contemporary surveys, the Euro Heart Survey found one of the highest OAC prescription rates in AF patients until now. Nonetheless, the risk of stroke in AF is not homogeneous, and antithrombotic treatment needs to be tailored according to the patient's risk profile. In low-risk patients, OAC provides a minimal benefit in preventing thrombo-embolic strokes when compared with aspirin, which is largely offset by a higher risk of bleedings with OAC. In contrast, high-risk patients undoubtedly benefit from OAC despite the increased bleeding risk. ${ }^{17-21}$ Of concern, this survey shows that $\mathrm{OAC}$ prescription for $\mathrm{AF}$ was quite high throughout all risk categories, irrespective of the stroke risk stratification scheme used, making that a large proportion of low-risk patients is at an avoidable increased hazard for bleeding and troubled with the inconvenience of constant INR monitoring with little chance for benefit. 


\section{Application of stroke risk stratification schemes}

The ACCP guidelines, and also the Framingham and $\mathrm{CHADS}_{2}$ schemes, have been shown to adequately identify patients at low risk for stroke, whereby the CHADS score was superior in identifying patients at high risk. ${ }^{22}$ In general, these schemes use the same factors to stratify patients, but the vast majority of patients were classified as high(est) risk in the ACC/AHA/ESC and ACCP schemes and less so with the $\mathrm{CHADS}_{2}$ and Framingham scores. The $\mathrm{CHADS}_{2}$ scheme is probably the most user-friendly tool for physicians to visualize the patient's stroke risk profile, as it is less complex than the Framingham score. However, as there is debate about the importance of accounting uncontrolled hypertension as a stroke risk factor rather than the plain diagnosis of hypertension, the Framingham scheme might be more appropriate on this issue as it includes the actual blood pressure. Until sufficient outcome data clarify this issue, the role of uncontrolled hypertension cannot be denied.

Although the ACC/AHA/ESC and ACCP guidelines give management recommendations according to the risk profile, these recommendations are not yet tailored to the $\mathrm{CHADS}_{2}$ and Framingham scores. Those defined as 'high risk' in all four risk stratification schemes had just a slightly higher chance of receiving OAC or any antithrombotic therapy in general, which was also previously shown for the ACC/AHA/ESC guidelines. ${ }^{23}$ Therefore, regardless of the choice for any scheme, antithrombotic therapy prescription seems to be marginally guided by current available stroke risk stratification schemes.

\section{Important factors in the decision-making process regarding antithrombotic treatment}

Some generally accepted stroke risk factors were associated with antithrombotic treatment and patients with a prior major bleeding had a lower chance for OAC, both reflecting adequate clinical management. However, several factors that are not generally accepted as stroke risk factors, or that do not have a direct connection with stroke risk, were significantly associated with antithrombotic management decisions. Patients with first detected or paroxysmal AF had a lower chance of receiving OAC compared with patients with persistent or permanent $\mathrm{AF}$, which was in accordance with previous findings. ${ }^{23}$ This might relate to the fact that a low AF burden is thought to be associated with a low risk for stroke. Because perceived AF burden is lower in paroxysmal AF patients, historically these patients had a lower chance of receiving OAC than patients with chronic (persistent/permanent) AF. This rationale might still be used in this survey, also because patients not receiving any rhythm or rate control drugs or interventions, in whom perceived AF burden is probably low, have a lower chance of receiving OAC. However, one has to keep in mind that to date there is very limited evidence that a high AF burden is associated with an increased risk for stroke $\mathrm{e}^{24,25}$ and that OAC has been shown to be effective in both paroxysmal (intermittent) and persistent AF patients, although evidence to 
support this is also quite limited and addressed patients with long-lasting intermittent episodes of AF rather than paroxysmal AF according to the current definition of the guidelines. ${ }^{26}$ An important factor complicating this issue is that the physicians' perception of AF burden mostly underestimates the true AF burden, as many patients suffer from asymptomatic recurrences. ${ }^{27}$ At the present time, the main focus in this decision-making process should therefore be on the presence of high risk factors for stroke, rather than on the clinical type of AF per se.

When AF was the only reason for the qualifying admission or visit, OAC was prescribed more often. This could be due to less distraction by other medical problems or management by an $\mathrm{AF}$ specialized physician who is more aware of the importance of OAC. In addition, availability of an OAC monitoring outpatient clinic also played a significant role in the decision-making process. The ability for safe INR monitoring is important for OAC prescription, which is not easy to arrange in all patients and also not in all countries because of restrictions in infrastructure. A (prior) major bleeding was a factor against prescribing any antithrombotic drugs. However, we did not know in detail what kind of bleeding was present, nor how long ago it was diagnosed. Remarkable was the finding that a surprising $40-50 \%$ of low-risk patients received OAC. These patients are exposed to an avoidable bleeding hazard, as a platelet inhibitor would suffice in these patients.

When considering the well-known stroke risk factors for which OAC is warranted, logically valvular heart disease played a significant role in the prescription of OAC and to a lesser extent also diabetes. Surprisingly, a (prior) stroke or TIA, but also hypertension and age $>75$ years were not significantly associated with OAC prescription, and even more remarkable was that heart failure did not play a role in any of the multivariable analyses.

\section{Possible reasons for lack of adherence to stroke risk stratification schemes}

Several reasons can underlie the poor application of stroke risk stratification and adherence to antithrombotic treatment guidelines. First, patient factors related to OAC use might contribute to this poor application. Continuing efforts should be made to improve patients' awareness and understanding of the disease process as well as the need for OAC therapy. ${ }^{28}$ Secondly, adherence might be poor because of deficiencies in knowledge of the guidelines, but also because of actual deficiencies in the guidelines, which is probably best illustrated by the limited evidence and therefore ongoing debate on the role of clinical type of AF as well as uncontrolled hypertension in stroke risk stratification. Thirdly, some of the four schemes we analysed are complex, whereas if they were presented more simply, they might be better applied. Fourthly, variability exists in weighing the importance of some of the stroke risk factors, with specific dispute whether hypertension alone is an indication and extra dispute for controlled vs. uncontrolled hypertension. Finally, 
although stroke risk can be estimated in a variety of ways, antithrombotic treatment options are limited to OAC or an antiplatelet agent. Together with the no antithrombotic treatment option, the current therapeutic means as well as the means to risk stratify patients are too limited to tailor treatment properly to the actual stroke risk. Perhaps, new drugs and alternative risk stratification tools, including new imaging modalities, may enhance the use of safe and appropriate antithrombotic treatment in $\mathrm{AF}$.

\section{Combination of $\mathrm{OAC}$ and antiplatelet drugs}

A combination of OAC and an antiplatelet agent is given in $8 \%$ of patients. Little evidence exists for the additive benefit of aspirin to OAC as thromboprophylaxis in AF per se, but it increases the risk of bleeding. ${ }^{29}$ Physicians still consider this combination as beneficial in vascular disease, but in reality the benefits express mainly in the first 35 days after an acute coronary event, rather than in the long-term. ${ }^{30}$ The lower application of combination therapy in the presence of an OAC monitoring clinic might reflect more frequent and strict monitoring of evidence-based antithrombotic drug prescription and confidence that stand alone $\mathrm{OAC}$ is adequate even in very high-risk patients.

\section{$O A C$ around interventions for $A F$}

Anticoagulation is recommended for a minimum of 3-4 weeks prior to, and following, cardioversion of AF lasting $>48 \mathrm{~h}$ or with an unknown AF duration; where there is a high risk of $\mathrm{AF}$ recurrence or risk factors for stroke, more prolonged anticoagulation after cardioversion is recommended. ${ }^{3}$ The low OAC use around PCV in comparison with ECV, even when choosing patients with risk factors or AF of $>48 \mathrm{~h}$ or unknown duration, may reflect physicians' perception that a PCV less urgently warrants stroke prevention therapy than an ECV. In agreement with this is the high OAC use around ECV regardless of stroke risk factors or AF duration. Therefore, attention should be drawn to anticoagulation around PCV and also to tailoring antithrombotic treatment to risk for thrombo-embolism. The ACC/AHA/ESC guideline ${ }^{2}$ clearly states that anticoagulation should be given irrespective of the mode of cardioversion; however, the guideline needs rephrasing concerning the need for considering lifelong anticoagulation in case cardioversion patients harbour risk factors for stroke, rather than simply stating that an extended period of anticoagulation might be beneficial. At the time of the survey, no guidelines on antithrombotic therapy around electrophysiological interventions had been implemented, but recently brief recommendations have been published. ${ }^{31,32}$ Both papers recommend in patients with moderate to high stroke risk, anticoagulation 3 weeks before the procedure and heparin during the procedure and possibly to cover the transition periods. No recommendation is done considering therapy after the procedure, although experienced research groups report to 
continue OAC up to 3 months after successful ablation. Therefore, although OAC use seems well implemented around catheter ablation in this survey, clear evidence-based recommendations are warranted.

\section{Limitations}

This cohort does not represent average Europe, as shown in the first report of this survey. ${ }^{5}$ The high prescription rate of OAC may relate to the relatively high proportion of university and specialized centres participating. Also, we did not ask the physician what the exact reason was for (not) prescribing antithrombotic treatment, but we report associations of characteristics with this prescription. Finally, the multivariable ORs cannot be considered as true relative risks, as the frequency of OAC prescription was very high.

\section{Clinical implications}

Education in the past years on stroke prevention for AF patients has been effective, because cardiologists prescribe antithrombotic therapy in the majority of AF patients who should receive it. However, stroke risk stratification to determine which drug is most appropriate seems scarcely used. Therefore, education should now focus on the importance of tailoring antithrombotic therapy according to the patient's risk profile. To facilitate this tailored treatment, guideline writers and physician educators should focus on providing one uniform and easy to use stroke risk stratification scheme. Extra improvement might be achieved by an information booklet to help improve patient's knowledge about anticoagulation therapy for $\mathrm{AF}^{33}$ and by integrating stroke risk stratification guidelines in supporting information technology, possibly handled by a specialized nurse. There is still an unmet need for safer and more easy to use antithrombotic drugs, but until this is available the application of OAC according to the presented stroke risk stratification deserves full attention. 


\section{APPENDIX: PREVALENCE OF RISK FACTORS FOR THROMBOEMBOLISM}

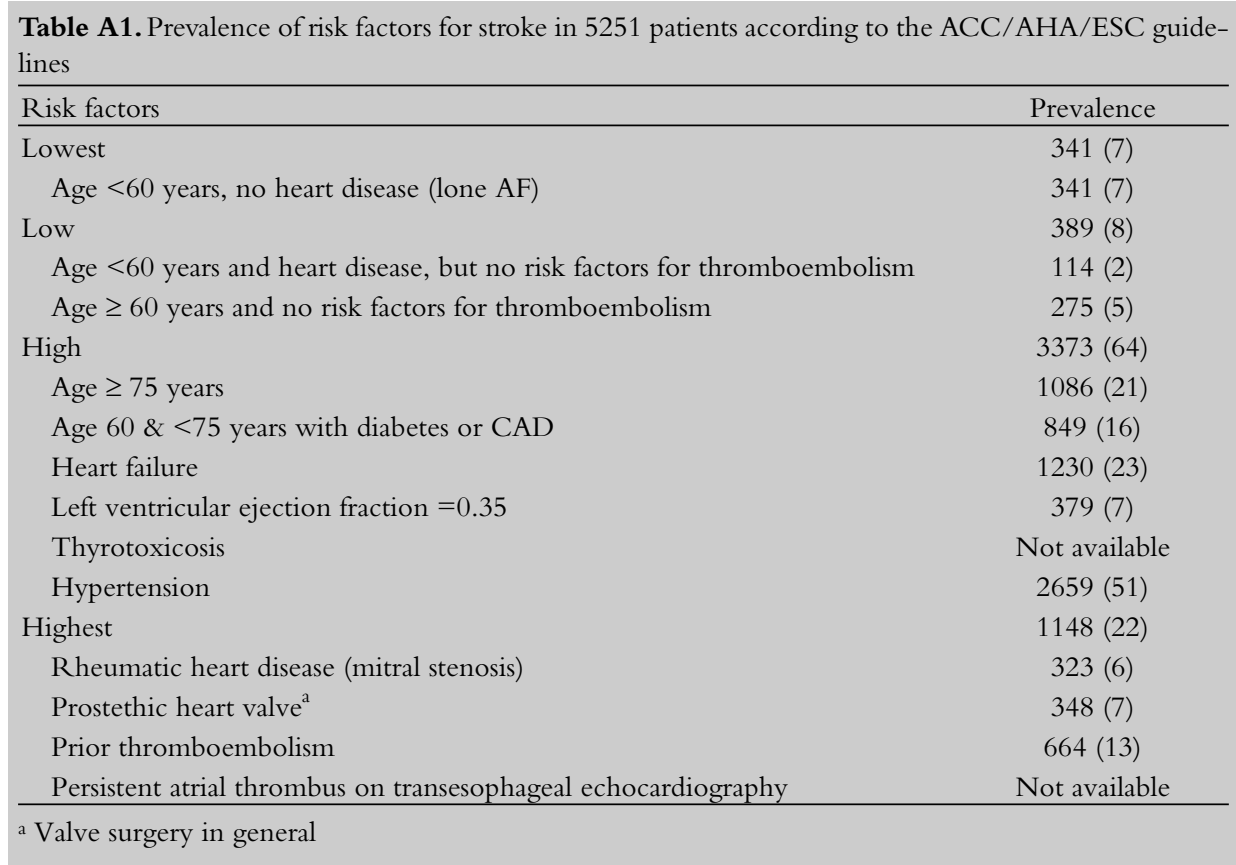

Table A2 Prevalence of risk factors for stroke according to the ACCP guidelines in 4176 patients with paroxysmal, persistent, or permanent $\mathrm{AF}$

\begin{tabular}{lc}
\hline Risk factors & Prevalence \\
\hline Low & $395(9)$ \\
Age $<65$ years, no other risk factors & $395(9)$ \\
Intermediate & $237(6)$ \\
Age 65-75 years & $190(5)$ \\
Diabetes & $39(1)$ \\
CAD \& left ventricular ejection fraction $>0.35$ & $48(1)$ \\
High & $3544(85)$ \\
Stroke, TIA, or systemic embolism & $555(13)$ \\
Age $>75$ years & $1162(28)$ \\
Moderately or severe left ventricular dysfunctiona & $422(10)$ \\
Congestive heart failure & $1473(35)$ \\
Hypertension & $2667(64)$ \\
Mitral stenosis & $281(7)$ \\
Prosthetic heart valve ${ }^{a}$ & $315(8)$ \\
\hline Clinical heart failure and/or LVEF $=0.35 .{ }^{a}$ Valve surgery in general &
\end{tabular}


Table A3. Prevalence of risk factors for stroke according to the $\mathrm{CHADS}_{2}$ score in 4564 patients with non-valvular AF

\begin{tabular}{lc}
\hline Risk factors & Prevalence \\
\hline C Congestive heart failure & $1458(32)$ \\
H Hypertension & $3029(65)$ \\
A Age $\geq 75$ years & $1316(28)$ \\
D Diabetes mellitus & $831(18)$ \\
S $_{2}$ History of stroke or TIA & $473(10)$ \\
Score $^{\mathrm{a}}$ & \\
0 & $828(18)$ \\
1 & $1526(33)$ \\
2 & $1244(27)$ \\
3 & $585(13)$ \\
4 & $255(6)$ \\
5 & $103(2)$ \\
6 & $23(1)$ \\
\hline
\end{tabular}

a Congestive heart failure, hypertension, age $\geq 75$ years, and diabetes have score 1 and stroke/TIA has score 2 .

Table A4 Prevalence of risk factors for stroke according to the Framingham stroke risk score in 866 patients with newly detected, non-valvular AF

\begin{tabular}{|c|c|c|}
\hline Risk Factors & Score & Prevalence \\
\hline \multicolumn{3}{|l|}{ Age, years } \\
\hline$<60$ & 0 & $265(30)$ \\
\hline $60-62$ & 1 & $55(6)$ \\
\hline $63-66$ & 2 & $93(11)$ \\
\hline $67-71$ & 3 & $155(18)$ \\
\hline $72-74$ & 4 & $85(10)$ \\
\hline $75-77$ & 5 & $83(9)$ \\
\hline $78-81$ & 6 & $85(10)$ \\
\hline $82-85$ & 7 & $32(4)$ \\
\hline $86-90$ & 8 & $19(2)$ \\
\hline $91-93$ & 9 & $7(1)$ \\
\hline$>93$ & 10 & $0(0)$ \\
\hline \multicolumn{3}{|c|}{ Systolic blood pressure, $\mathrm{mmHg}$} \\
\hline$<120$ & 0 & $162(19)$ \\
\hline $120-139$ & 1 & $305(35)$ \\
\hline $140-159$ & 2 & $262(30)$ \\
\hline $160-179$ & 3 & $102(12)$ \\
\hline$>179$ & 4 & $47(5)$ \\
\hline \multicolumn{3}{|l|}{ Other factors } \\
\hline Female gender & 6 & $364(41)$ \\
\hline Diabetes & 5 & $170(19)$ \\
\hline Stroke/TIA & 6 & $61(7)$ \\
\hline \multicolumn{3}{|l|}{ Risk Category $^{a}$} \\
\hline Low & $0-1$ & $113(13)$ \\
\hline Intermediate & $2-7$ & $319(37)$ \\
\hline High & $8-13$ & $283(33)$ \\
\hline Highest & $>13$ & $151(17)$ \\
\hline
\end{tabular}

a On the basis of the total score (age + systolic blood pressure + gender + diabetes + stroke/TIA). 


\section{REFERENCES}

1. Wolf PA, Dawber TR, Thomas HE Jr, Kannel WB. Epidemiologic assessment of chronic atrial fibrillation and risk of stroke: the Framingham study. Neurology 1978;28:973-7.

2. Lamassa M, Di Carlo A, Pracucci G, Basile AM, Trefoloni G, Vanni P, Spolveri S, Baruffi MC, Landini G, Ghetti A,Wolfe CD, Inzitari D. Characteristics, outcome, and care of stroke associated with atrial fibrillation in Europe: data from a multicenter multinational hospital-based registry (The European Community Stroke Project). Stroke 2001;32:392-8.

3. Fuster V, Ryden LE, Asinger RW, Cannom DS, Crijns HJ, Frye RL, Halperin JL, Kay GN, Klein WW, Levy S, McNamara RL, Prystowsky EN, Wann LS, Wyse DG, ACC/AHA/ESC guidelines for the management of patients with atrial fibrillation. A report of the American College of Cardiology/American Heart Association Task Force on Practice Guidelines and the European Society of Cardiology Committee for Practice Guidelines and Policy Conferences (Committee to develop guidelines for the management of patients with atrial fibrillation) developed in collaboration with the North American Society of Pacing and Electrophysiology. Eur Heart J 2001;22:1852-923.

4. Albers GW, Dalen JE, Laupacis A, Manning WJ, Petersen P, Singer DE. Antithrombotic therapy in atrial fibrillation. Chest 2001;119(Suppl. 1):194S-206S.

5. Nieuwlaat R, Capucci A, Camm AJ, Olsson SB, Andresen D, Davies DW, Cobbe S, Breithardt G, Le Heuzey JY, Prins MH, Levy S, Crijns HJ. Atrial fibrillation management: a prospective survey in ESC Member Countries. The Euro Heart Survey on Atrial Fibrillation. Eur Heart J 2005;26:2422-34.

6. Gage BF, Waterman AD, Shannon W, Boechler M, Rich MW, Radford MJ. Validation of clinical classification schemes for predicting stroke: results from the National Registry of Atrial Fibrillation. JAMA 2001;285:2864-70.

7. Wang TJ, Massaro JM, Levy D, Vasan RS, Wolf PA, D’Agostino RB, Larson MG, Kannel WB, Benjamin EJ. A risk score for predicting stroke or death in individuals with new-onset atrial fibrillation in the community: the Framingham Heart Study. JAMA 2003;290:1049-56.

8. The Clinical Quality Improvement Network (CQIN) Investigators. Thromboembolic prophylaxis in 3575 hospitalized patients with atrial fibrillation. Can J Cardiol 1998;14:695-702.

9. Go AS, Hylek EM, Borowsky LH, Phillips KA, Selby JV, Singer DE. Warfarin use among ambulatory patients with nonvalvular atrial fibrillation: the anticoagulation and risk factors in atrial fibrillation (ATRIA) study. Ann Intern Med 1999;131:927-34.

10. Stafford RS, Singer DE. Recent national patterns of warfarin use in atrial fibrillation. Circulation 1998;97:1231-3.

11. Levy S, Maarek M, Coumel P, Guize L, Lekieffre J, Medvedowsky JL, Sebaoun A. Characterization of different subsets of atrial fibrillation in general practice in France: the ALFA study. The College of French Cardiologists. Circulation 1999;99:3028-35.

12. Albers GW, Yim JM, Belew KM, Bittar N, Hattemer CR, Phillips BG, Kemp S, Hall EA, Morton DJ, Vlasses PH. Status of antithrombotic therapy for patients with atrial fibrillation in university hospitals. Arch Intern Med 1996;156:2311-6.

13. Deplanque D, Leys D, Parnetti L, Schmidt R, Ferro J, De Reuck J, Mas JL, Gallai V. Stroke prevention and atrial fibrillation: reasons leading to an inappropriate management. Main results of the SAFE II study. Br J Clin Pharmacol 2004;57:798-806.

14. Lip GY, Zarifis J, Watson RD, Beevers DG. Physician variation in the management of patients with atrial fibrillation. Heart 1996;75:200-5.

15. Singer DE, Go AS. Antithrombotic therapy in atrial fibrillation. Clin Geriatr Med 2001;17:131-47.

16. Singer DE, Albers GW, Dalen JE, Go AS, Halperin JL, Manning WJ. Antithrombotic therapy in atrial fibrillation: the Seventh ACCP Conference on Antithrombotic and Thrombolytic Therapy. Chest 2004;126(Suppl. 3):429S-56S. 
17. van Walraven C, Hart RG, Singer DE, Laupacis A, Connolly S, Petersen P, Koudstaal PJ, Chang Y, Hellemons B. Oral anticoagulants vs aspirin in nonvalvular atrial fibrillation: an individual patient meta-analysis. JAMA 2002;288:2441-8.

18. Hart RG, Benavente O, McBride R, Pearce LA. Antithrombotic therapy to prevent stroke in patients with atrial fibrillation: a meta-analysis. Ann Intern Med 1999;131:492-501.

19. Ezekowitz MD, Levine JA. Preventing stroke in patients with atrial fibrillation. JAMA 1999;281:1830-5.

20. Segal JB, McNamara RL, Miller MR, Powe NR, Goodman SN, Robinson KA, Bass EB. Anticoagulants or antiplatelet therapy for non-rheumatic atrial fibrillation and flutter. Cochrane Database Syst Rev 2001;1:CD001938.

21. Taylor FC, Cohen H, Ebrahim S. Systematic review of long term anticoagulation or antiplatelet treatment in patients with non-rheumatic atrial fibrillation. BMJ 2001;322:321-6.

22. Gage BF, van Walraven C, Pearce L, Hart RG, Koudstaal PJ, Boode BS, Petersen P. Selecting patients with atrial fibrillation for anticoagulation: stroke risk stratification in patients taking aspirin. Circulation 2004;110:2287-92.

23. Waldo AL, Becker RC, Tapson VF, Colgan KJ. Hospitalized patients with atrial fibrillation and a high risk of stroke are not being provided with adequate anticoagulation. J Am Coll Cardiol 2005;46:1729-36.

24. Capucci A, Santini M, Padeletti L, Gulizia M, Botto G, Boriani G, Ricci R, Favale S, Zolezzi F, Di Belardino N, Molon G, Drago F, Villani GQ, Mazzini E, Vimercati M, Grammatico A. Monitored atrial fibrillation duration predicts arterial embolic events in patients suffering from bradycardia and atrial fibrillation implanted with antitachycardia pacemakers. J Am Coll Cardiol 2005;46:1913-20.

25. Glotzer TV, Hellkamp AS, Zimmerman J, Sweeney MO, Yee R, Marinchak R, Cook J, Paraschos A, Love J, Radoslovich G, Lee KL, Lamas GA. Atrial high rate episodes detected by pacemaker diagnostics predict death and stroke: report of the Atrial Diagnostics Ancillary Study of the MOde Selection Trial (MOST). Circulation 2003;107:1614-9.

26. Hart RG, Pearce LA, Rothbart RM, McAnulty JH, Asinger RW, Halperin JL. Stroke with intermittent atrial fibrillation: incidence and predictors during aspirin therapy. Stroke Prevention in Atrial Fibrillation Investigators. J Am Coll Cardiol 2000;35:183-7.

27. Israel CW, Gronefeld G, Ehrlich JR, Li YG, Hohnloser SH. Long-term risk of recurrent atrial fibrillation as documented by an implantable monitoring device: implications for optimal patient care. J Am Coll Cardiol 2004;43:47-52.

28. Lip GY, Kamath S, Jafri M, Mohammed A, Bareford D. Ethnic differences in patient perceptions of atrial fibrillation and anticoagulation therapy: the West Birmingham Atrial Fibrillation Project. Stroke 2002;33:238-42.

29. DiMarco JP, Flaker G, Waldo AL, Corley SD, Greene HL, Safford RE, Rosenfeld LE, Mitrani G, Nemeth M. Factors affecting bleeding risk during anticoagulant therapy in patients with atrial fibrillation: observations from the Atrial Fibrillation Follow-up Investigation of Rhythm Management (AFFIRM) study. Am Heart J 2005;149:650-6.

30. Baigent C, Collins R, Appleby P, Parish S, Sleight P, Peto R. ISIS-2: 10 year survival among patients with suspected acute myocardial infarction in randomised comparison of intravenous streptokinase, oral aspirin, both, or neither. The ISIS-2 (Second International Study of Infarct Survival) Collaborative Group. BMJ 1998;316:1337-43.

31. Scholten MF, Thornton AS, Mekel JM, Koudstaal PJ, Jordaens LJ. Anticoagulation in atrial fibrillation and flutter. Europace 2005;7:492-9.

32. Scheinman M, Calkins H, Gillette P, Klein R, Lerman BB, Morady F, Saksena S, Waldo A NASPE policy statement on catheter ablation: personnel, policy, procedures, and therapeutic recommendations. Pacing Clin Electrophysiol 2003;26:789-99. 
90 | CHAPTER 4

33. Lane DA, Ponsford J, Shelley A, Sirpal A, Lip GY. Patient knowledge and perceptions of atrial fibrillation and anticoagulant therapy: Effects of an educational intervention programme The West Birmingham Atrial Fibrillation Project. Int J Cardiol 2006;110:354-8. 
5

Guideline-adherent antithrombotic treatment is associated with improved outcomes compared with undertreatment in high-risk patients with atrial fibrillation

Robby Nieuwlaat, S. Bertil Olsson, Gregory Y.H. Lip, A.John Camm, Günter Breithardt, Alessandro Capucci,Joan G. Meeder, Martin H. Prins, Samuel Lévy, Harry J. G.M. Crijns

Am Heart J. 2007;153(6):1006-12

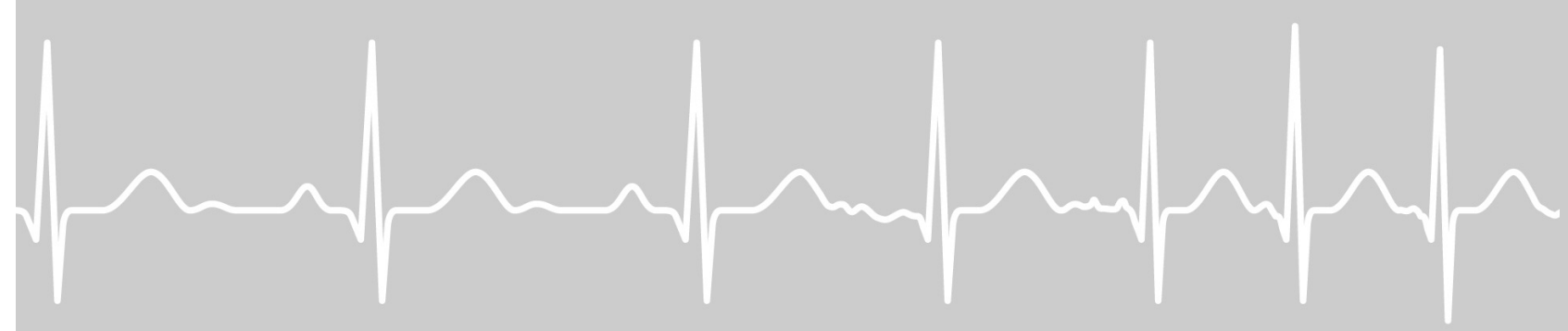




\section{ABSTRACT}

Background. The Euro Heart Survey showed that antithrombotic treatment in patients with atrial fibrillation (AF) was moderately tailored to the 2001 American College of Cardiology, American Heart Association, and European Society of Cardiology (ACC/AHA/ESC) guidelines for the management of AF. What consequences does guideline-deviant antithrombotic treatment have in daily practice?

Methods. In the Euro Heart Survey on AF (2003-2004), an observational study on AF care in European cardiology practices, information was available on baseline stroke risk profile and antithrombotic drug treatment and on cardiovascular events during 1-year follow-up. Antithrombotic guideline adherence is assessed according to the 2001 ACC/AHA/ESC guidelines. Multivariable logistic regression was performed to assess the association of guideline deviance with adverse outcome.

Results. The effect of antithrombotic guideline deviance was analyzed exclusively in 3634 high-risk patients with AF because these composed the majority $(89 \%)$ and because few cardiovascular events occurred in low-risk patients. Among high-risk patients, antithrombotic treatment was in agreement with the guidelines in $61 \%$ of patients, whereas $28 \%$ were undertreated and $11 \%$ overtreated. Compared to guideline adherence, undertreatment was associated with a higher chance of thromboembolism (odds ratio [OR], 1.97; 95\% CI, 1.29-3.01; $\mathrm{P}=0.004$ ) and the combined end point of cardiovascular death, thromboembolism, or major bleeding (OR, 1.54; 95\% CI, 1.14-2.10; $\mathrm{P}=0.024)$. This increased risk was nonsignificant for the end point of stroke alone (OR, 1.42; 95\% CI, 0.82-2.46; $\mathrm{P}=0.170)$. Overtreatment was nonsignificantly associated with a higher risk for major bleeding (OR, 1.52; 95\% CI, 0.76-3.02; $\mathrm{P}=0.405)$.

Conclusions. Antithrombotic undertreatment of high-risk patients with AF was associated with a worse cardiovascular prognosis during 1 year, whereas overtreatment was not associated with a higher chance for major bleeding. 


\section{INTRODUCTION}

Prevention of stroke and thromboembolism (TE) is the vanguard of atrial fibrillation (AF) management. When compared with both placebo and antiplatelet agents, oral anticoagulation (OAC) effectively prevents TEs in patients at high risk for such an event. ${ }^{1}$ In patients at low risk, an antiplatelet agent should suffice because the bleeding risk of OAC neutralizes the benefit of TE prevention in these patients. ${ }^{2}$ Based on this evidence and on expert opinion, the 2001 joint ACC/AHA/ESC guidelines on AF management provided recommendations for thromboprophylaxis in $\mathrm{AF}^{3}$ Despite the availability of trial evidence and guidelines, numerous observational studies have shown suboptimal application rates of OAC in clinical practice. The Euro Heart Survey recently reported that although the application rate of OAC has improved, antithrombotic drug therapy is only moderately tailored according to the risk classification scheme as proposed by the joint ACC/AHA/ESC guidelines. ${ }^{4}$ Several factors are thought to underlie this discordance between guidelines and practice. Regardless of the rationale behind management decisions, it is important to know the consequences lack of guideline adherence may have. Stroke and bleeding rates in observational studies have been shown to compare quite well with event rates in OAC-treated, high-risk patients of randomized controlled trials, although these studies were based on small populations and some had methodological limitations., 5 OAC efficacy in high-risk patients is just one aspect of guideline adherence in the whole spectrum of management of patients with AF, and the consequences of guideline deviance per se have not yet been addressed. The aim of this report was to describe the consequences of guideline deviance in antithrombotic management from cardiology practices in a large European AF population. Our major questions were the following:

1. does undertreatment lead to an increased TE rate, and/or

2. does overtreatment cause avoidable bleedings?

\section{METHODS}

In the Euro Heart Survey on AF (2003-2004), 5333 ambulant and hospitalized patients with AF were enrolled in cardiology practices. Details of the baseline survey have previously been described. ${ }^{7}$ Patients were enrolled if they were 18 years or older and if they had an electrocardiogram or Holter recording showing AF during the qualifying admission/consultation or in the preceding 12 months. Patients with only atrial flutter on their electrocardiograms were excluded. Data were collected through the Internet and stored in a central database at the European Heart House. Data quality was verified by using automatic validation checks in the case report form and with additional edit checks by data monitors and the data analysis center. A follow-up was performed to assess mortality and incidence of major adverse events during 1 year. For the purpose of this study, categorization of 
stroke risk and assessment of guideline adherence for antithrombotic therapy at baseline were assessed according to the ACC/AHA/ESC 2001 guidelines on AF management. ${ }^{3}$

\section{Stroke risk categorization}

In a previous report we appointed patients to high-risk or highest risk groups to assess the influence of stroke risk on antithrombotic drug prescription. ${ }^{4}$ For the present analysis, we combined these 2 groups together as high-risk because both should receive OAC, and guideline adherence and deviance are similar.

High-risk is defined as the presence of at least one of the following factors: mitral stenosis, valve surgery, prior stroke/transient ischemic attack (TIA), age $\geq 75$ years, heart failure or left ventricular ejection fraction $\leq 0.35$, hypertension, or age $\geq 60$ years in combination with diabetes mellitus or coronary artery disease (CAD). In addition, patients undergoing cardioversion (pharmacologic or electrical) when AF duration was $>48$ hours or unknown were also considered high risk.

Low-risk is the absence of the above-mentioned high-risk factors, age $\geq 60$ years, or age $<60$ years with other heart disease.

Lowest-risk is defined as age $<60$ years and none of the above-mentioned risk factors (AF only).

\section{Antithrombotic therapy guideline adherence}

In high-risk patients without a bleeding risk factor (BRF) - a (prior) major bleeding, (prior) malignancy, or renal failure - OAC is recommended and, therefore, withholding $\mathrm{OAC}$ was considered to be undertreatment. In high-risk patients with at least one BRF, use of OAC was considered as overtreatment, use of an antiplatelet agent as appropriate, and no drug treatment as undertreatment. In high-risk patients aged $\geq 60$ years and having either CAD or diabetes, an antiplatelet drug in combination with OAC is optional, and, therefore, all other high-risk patients receiving this combination were considered as overtreated. Low-risk patients should receive an antiplatelet drug, whereby prescribing OAC was considered to be overtreatment and no drug therapy as undertreatment. Finally, lowest-risk patients should receive either an antiplatelet drug or no therapy, and therefore prescription of OAC was categorized as overtreatment.

\section{Major adverse cardiovascular events}

Major adverse events during follow-up were reported by the local data collectors according to the following definitions:

Ischemic stroke: focal neurologic deficit of sudden onset as diagnosed by a neurologist, lasting longer than 24 hours and caused by ischemia. 
Any TE: occurrence of ischemic stroke, myocardial infarction, pulmonary embolism, or peripheral embolism.

Myocardial infarction: new or presumed new ST segment elevation in 2 or more continuous leads of $0.2 \mathrm{mV}$ in leads $\mathrm{V} 1, \mathrm{~V} 2$, or $\mathrm{V} 3$ and $0.1 \mathrm{mV}$ in other leads and/or presumably new left bundle branch block and/or increase in cardiac enzyme level more than 2 times the upper values.

Peripheral embolism: embolism outside the heart, brain, eyes, and lungs.

Major bleeding: either hemorrhagic stroke or another type of major bleeding.

Hemorrhagic stroke: focal neurologic deficit of sudden onset as diagnosed by a neurologist, lasting longer than 24 hours and caused by bleeding.

Other major bleeding: major bleeding other than hemorrhagic stroke requiring hospitalization and/or causing a decrease in hemoglobin level of more than $2 \mathrm{~g} / \mathrm{L}$ and/or requiring blood transfusion.

Cardiovascular death: death due to any cardiovascular reason such as myocardial infarction, heart failure, sudden cardiac death (all sudden deaths without any other known reason), stroke, or rupture of an aortic aneurysm.

\section{Statistical analysis}

Data analysis was performed with SPSS statistical software (release 12.01, SPSS Inc., Chicago, IL). Results are reported as mean \pm standard deviation or as proportion within the column. Multivariable logistic regression was performed to assess whether guideline adherence was independently associated with stroke, any TE, major bleeding, and the combined end point of cardiovascular death, any TE, and major bleeding during 1-year follow-up. Because the variable on antithrombotic guideline adherence was the central variable, it was kept in every final model regardless of its significance.

The following other variables were tested in these models: age, sex, hypertension, valvular AF (mitral stenosis or valve surgery), heart failure, prior ischemic stroke or TIA, prior TE, CAD, diabetes, prior major bleeding, prior minor bleeding, prior malignancy, renal failure, undergoing rate or rhythm control, chronic obstructive pulmonary disease (COPD), sick sinus syndrome (SSS), prior ventricular tachycardia, prior ventricular fibrillation, and prescription of an angiotensin-converting enzyme inhibitor, angiotensin II receptor blocker, diuretic, $\beta$-blocker, dihydropyridin calcium-channel blocker, and statin. Variables were removed stepwise from the model when the P-value exceeded 0.10 .

Variables with P-value 0.05 in the final model were considered to be significant contributors and were kept in the model. Hereafter, these models were validated by means of bootstrapping, which was performed with 100 samples for each reported multivariable logistic regression analysis. Bootstrapping provided information on the effect stability of each factor as a predictor of the outcome variable. Effects that were unstable were left out of the model stepwise, which eventually resulted in the 
final model with only stable significant associated factors, and these final models are reported here. For each variable in this final model the net odds ratio (OR) and its 95\% confidence interval (CI), backward elimination log-likelihood $\chi^{2}(-2 \mathrm{LL})$, degrees of freedom (df), and P-value are reported. In addition, predictive accuracy of each model is reported as the area under the receiver operating characteristic (ROC) curve.

\section{RESULTS}

In the initial survey, data on stroke risk profile and antithrombotic drug therapy at discharge were available for 5130 patients who were alive at the end of the baseline visit. Of these patients, survival status at 1-year follow-up was known for 4086 patients $(80 \%)$. Compared with patients with complete follow-up data, patients for whom no follow-up data were available were enrolled more often at the cardiology ward $(65 \%$ vs $54 \% ; \mathrm{P}<0.001)$ instead of the outpatient clinic $(21 \%$ vs $37 \%$; $\mathrm{P}<0.001)$, with a higher prevalence of heart failure $(42 \%$ vs $32 \% ; \mathrm{P}<0.001)$ and less treatment with OAC $(54 \%$ vs $68 \% ; \mathrm{P}<0.001)$.

\section{Antithrombotic therapy guideline adherence}

Figure 1 shows that among patients with follow-up available, only 254 were classified as lowest- and 326 as low-risk, whereas the majority $(n=3506)$ was classified as high-risk, according to the ACC/AHA/ESC guidelines. Among low(est)-risk patients, 128 underwent pharmacologic or electrical cardioversion when AF duration was either $>48$ hours or unknown. Because these patients should also receive OAC around the time of the cardioversion or at least at discharge in the acute setting, they were classified as high-risk. The proportion with any BRF was clearly largest in high-risk (13\%) compared with low-risk (3\%) and lowest-risk (2\%) patients.

Antithrombotic guidelines were followed in $58 \%$ of the total population, whereas $26 \%$ were undertreated and only $16 \%$ were overtreated. Overtreatment mainly comprised $65 \%$ of high-risk patients with a BRF and receiving OAC; in addition, proportions of low-risk and lowest-risk patients receiving OAC were remarkably high, $66 \%$ and $44 \%$, respectively. The majority of undertreated patients were high-risk patients without a BRF in whom OAC was withheld.

\section{Events in low(est) risk patients}

During the 1-year follow-up, the only major events reported in lowest-risk patients were 1 death associated with a myocardial infarction in a patient in whom the guideline was followed, and a non-cardiovascular death in a patient that was overtreated. In low-risk patients, 1 undertreated patient died in association with a pulmonary embolism and 1 patient in whom the guideline was followed had an 


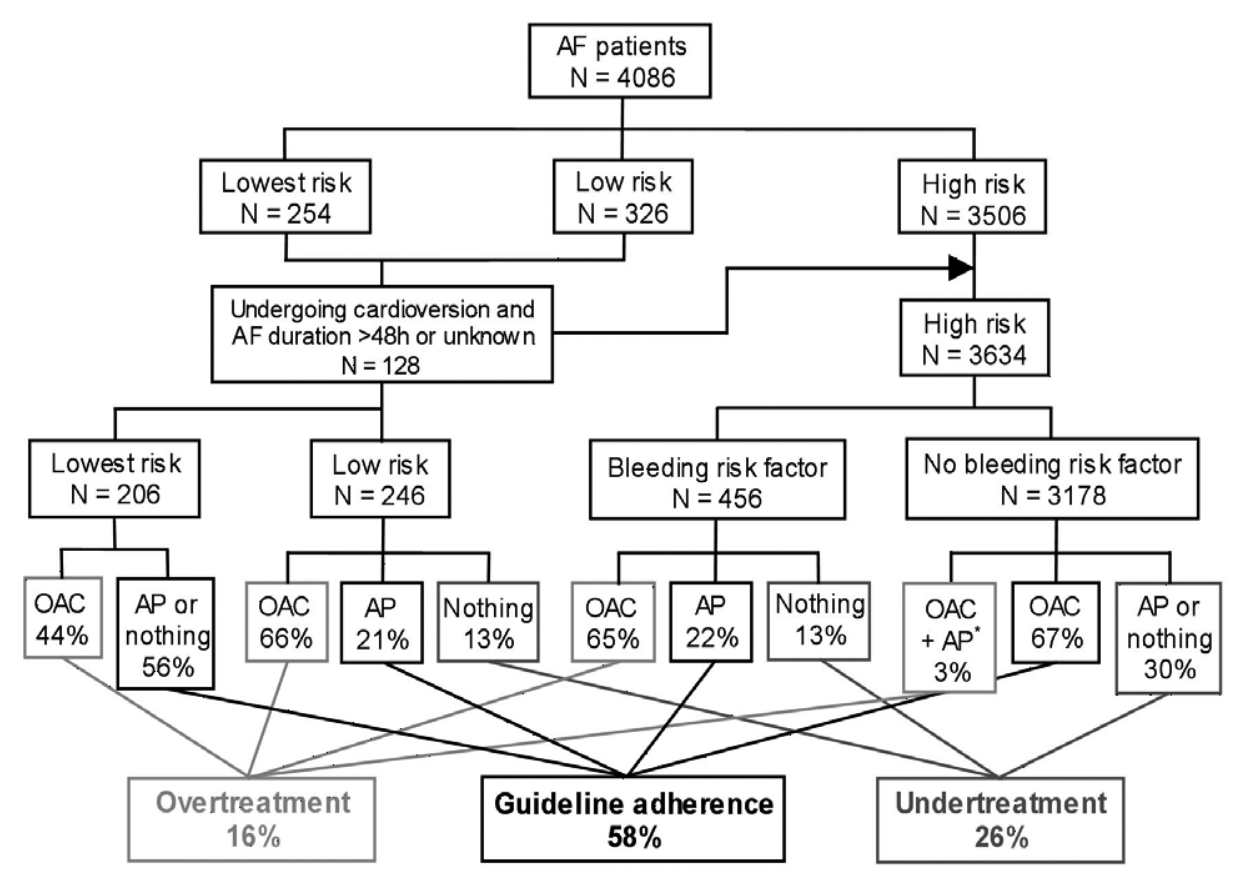

Figure 1. Flow chart for categorizing antithrombotic guideline adherence. ${ }^{\star}$ In high-risk patients $<60$ years or $\geq 60$ years without $\mathrm{CAD}$ and diabetes. AP, antiplatelet agent.

ischemic stroke. When low-risk patients were overtreated, 2 cardiovascular deaths were observed, of which 1 was in association with both an ischemic and a hemorrhagic stroke, and 1 ischemic stroke and 1 major bleeding other than a hemorrhagic stroke among the surviving patients.

\section{Effect of antithrombotic guideline deviance in high-risk patients}

Because of the relatively small sample size of patients at low(est)-risk and the few observed major events in this subgroup, we chose to focus on the 3634 patients at high risk for stroke. Within this subgroup the guidelines were followed in 2093 (61\%) patients, $964(28 \%)$ were undertreated, and $386(11 \%)$ were overtreated. Overtreated patients were oldest and frequently had a (prior) stroke or TIA, heart failure, diabetes, peripheral vascular disease, COPD, SSS, ventricular tachycardia, and potential BRFs (Table 1). They also less frequently underwent a rhythm control strategy, more often had permanent AF and more often received a diuretic or statin. In comparison with the guideline-adherent group, undertreated patients less often had valvular AF, and more often hypertension, $\mathrm{CAD}$, and first detected or paroxysmal AF. 
Table 1. Baseline characteristics of AF patients at high risk for stroke

\begin{tabular}{|c|c|c|c|c|}
\hline & Undertreatment & $\begin{array}{l}\text { Guideline } \\
\text { followed }\end{array}$ & Overtreatment & P-value \\
\hline $\mathrm{N}$ & 1016 & 2214 & 404 & \\
\hline Age, years & $68(12)$ & $68(11)$ & $70(12)$ & 0.001 \\
\hline Female & 44 & 43 & 41 & 0.617 \\
\hline Valvular AF & 4 & 16 & 17 & $<0.001$ \\
\hline Stroke / TIA & 9 & 11 & 22 & $<0.001$ \\
\hline Other thrombo-embolism & 1 & 4 & 4 & 0.001 \\
\hline Heart failure & 32 & 36 & 50 & $<0.001$ \\
\hline Hypertension & 78 & 70 & 71 & $<0.001$ \\
\hline Coronary artery disease & 36 & 28 & 38 & $<0.001$ \\
\hline Diabetes & 20 & 18 & 28 & $<0.001$ \\
\hline Peripheral vascular disease & 7 & 7 & 18 & $<0.001$ \\
\hline COPD & 14 & 12 & 22 & $<0.001$ \\
\hline Sick sinus syndrome & 4 & 5 & 10 & $<0.001$ \\
\hline Ventricular tachycardia & 3 & 2 & 7 & $<0.001$ \\
\hline Ventricular fibrillation & 1 & 1 & 2 & 0.092 \\
\hline \multicolumn{5}{|l|}{ Bleeding risk } \\
\hline Major bleeding & 1 & 1 & 13 & $<0.001$ \\
\hline Malignancy & 3 & 2 & 35 & $<0.001$ \\
\hline Renal failure & 3 & 2 & 35 & $<0.001$ \\
\hline \multicolumn{5}{|l|}{ Heart rhythm strategy } \\
\hline Rhythm control & 60 & 61 & 54 & 0.061 \\
\hline Rate control & 31 & 34 & 41 & 0.005 \\
\hline None & 9 & 5 & 5 & 0.003 \\
\hline \multicolumn{5}{|l|}{ AF type } \\
\hline $1^{\text {st }}$ detected & 25 & 15 & 14 & $<0.001$ \\
\hline Paroxysmal & 42 & 22 & 22 & $<0.001$ \\
\hline Persistent & 13 & 28 & 21 & $<0.001$ \\
\hline Permanent & 21 & 35 & 44 & $<0.001$ \\
\hline \multicolumn{5}{|l|}{ Other drugs } \\
\hline ACE inhibitor & 50 & 50 & 48 & 0.750 \\
\hline AT II receptor blocker & 13 & 14 & 17 & 0.069 \\
\hline Diuretic & 51 & 54 & 69 & $<0.001$ \\
\hline Dihydropyridin CCB & 17 & 14 & 11 & 0.005 \\
\hline Beta blocker & 44 & 45 & 53 & 0.017 \\
\hline Statin & 21 & 26 & 32 & $<0.001$ \\
\hline
\end{tabular}




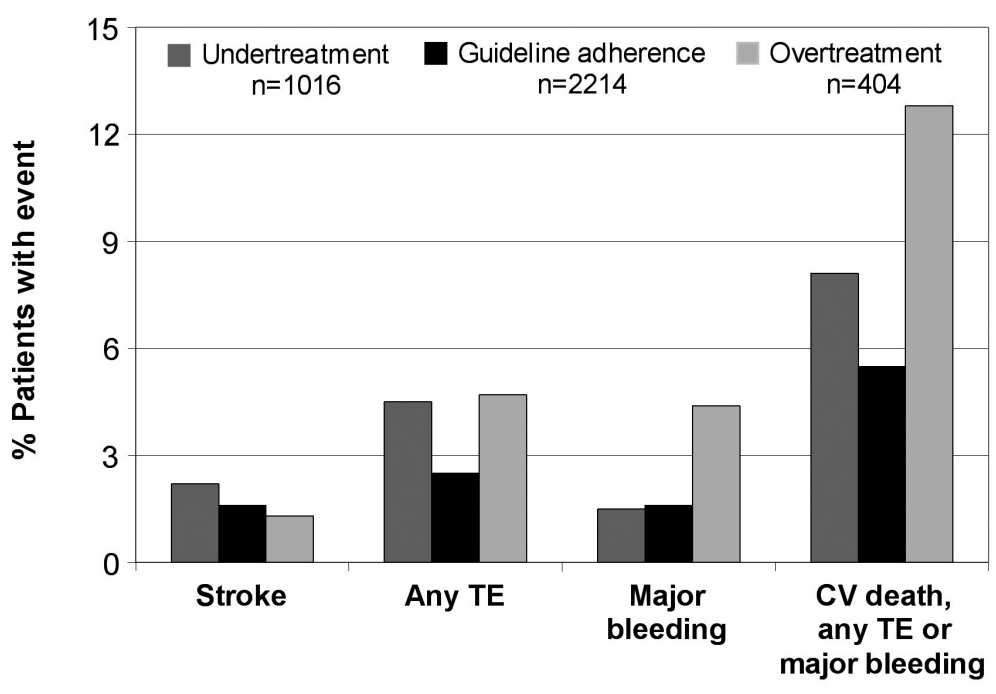

\begin{tabular}{|l|c|c|c|c|}
\hline \multicolumn{5}{|c|}{ Absolute numbers of events } \\
\hline Undertreatment & 21 & 43 & 14 & 78 \\
\hline Guideline adherence & 34 & 52 & 33 & 115 \\
\hline Overtreatment & 5 & 18 & 17 & 49 \\
\hline
\end{tabular}

Figure 2. Univariable absolute and proportional event rates during 1 year versus antithrombotic guideline adherence in patients at high risk for stroke. CV, cardiovascular.

Crude (unadjusted) incidence among high-risk patients of major bleeding, cardiovascular death, and the combined end point of cardiovascular death, any TE, and major bleeding was highest in overtreated patients (Figure 2). Compared with the guideline-adherent group, any TE and the combined end point were more frequently observed in the undertreated group. Incidence of ischemic stroke slightly decreased from undertreatment to overtreatment. Of 64 major bleedings, only 8 were intracranial hemorrhages $(\mathrm{ICH})$, with comparable low proportions in undertreatment $(0.1 \%)$, guideline followed $(0.4 \%)$, and overtreatment $(0.3 \%)$.

Table 2. Factors associated with stroke in patients at high risk for stroke

\begin{tabular}{lccccc}
\hline & Odds ratio & $95 \%$ CI & -2 LL & df & P-value \\
\hline Antithrombotic guideline adherence & & & 4 & 2 & 0.170 \\
$\quad$ Guideline followed & 1 & reference & & & \\
Undertreatment & 1.42 & $0.82-2.46$ & & & $<0.001$ \\
$\quad$ Overtreatment & 0.66 & $0.29-1.49$ & & 1 & 22 \\
Prior stroke / TIA & 4.20 & $2.44-6.94$ & 22
\end{tabular}

All variables that initially entered the multivariable analysis are summarized in the Methods section. Area under the ROC curve $=0.6445$. 
Table 3. Factors associated with any TE in patients at high risk for stroke

\begin{tabular}{lccccc}
\hline & Odds ratio & $95 \%$ CI & -2 LL & df & P-value \\
\hline Antithrombotic guideline adherence & & & 11 & 2 & 0.004 \\
$\quad$ Guideline followed & 1 & reference & & & \\
$\quad$ Undertreatment & 1.97 & $1.29-3.01$ & & & \\
$\quad$ Overtreatment & 0.85 & $0.42-1.74$ & & & \\
Peripheral vascular disease & 2.15 & $1.28-3.64$ & 7 & 1 & 0.006 \\
Prior stroke / TIA & 1.91 & $1.17-3.11$ & 6 & 1 & 0.013 \\
Renal failure & 2.48 & $1.24-4.99$ & 6 & 1 & 0.015 \\
Prior other thromboembolism & 2.66 & $1.26-5.61$ & 5 & 1 & 0.020 \\
Coronary artery disease & 1.61 & $1.08-2.39$ & 5 & 1 & 0.020 \\
\hline All
\end{tabular}

All variables that initially entered the multivariable analysis are summarized in the Methods section. Area under the ROC curve $=0.6933$.

Table 4. Factors associated with major bleeding in patients at high risk for stroke

\begin{tabular}{lccccc}
\hline & Odds ratio & $95 \%$ CI & -2 LL & df & P-value \\
\hline Antithrombotic guideline adherence & & & 2 & 2 & 0.405 \\
$\quad$ Guideline followed & 1 & reference & & & \\
$\quad$ Undertreatment & 0.89 & $0.47-1.69$ & & & \\
$\quad$ Overtreatment & 1.52 & $0.76-3.02$ & & & \\
Prior major bleeding & 7.31 & $3.28-16.27$ & 19 & 1 & $<0.001$ \\
Prior minor bleeding & 4.10 & $1.78-9.51$ & 8 & 1 & 0.004 \\
Age, per year increase & 1.03 & $1.01-1.06$ & 7 & 1 & 0.010 \\
\hline
\end{tabular}

All variables that initially entered the multivariable analysis are summarized in the Methods section. Area under the ROC curve $=0.6851$.

Table 5. Factors associated with combined end point of cardiovascular death, any TE, and major bleeding in patients at high risk for stroke

\begin{tabular}{lccccc}
\hline & Odds ratio & $95 \% \mathrm{CI}$ & $-2 \mathrm{LL}$ & $\mathrm{df}$ & P-value \\
\hline Antithrombotic guideline adherence & & & 7 & 2 & 0.024 \\
$\quad$ Guideline followed & 1 & reference & & & \\
$\quad$ Undertreatment & 1.54 & $1.14-2.10$ & & & \\
$\quad$ Overtreatment & 1.15 & $0.72-1.84$ & & & \\
Heart failure & 2.03 & $1.54-2.67$ & 25 & 1 & $<0.001$ \\
Age, per year increase & 1.03 & $1.01-1.04$ & 14 & 1 & $<0.001$ \\
Peripheral vascular disease & 2.20 & $1.52-3.18$ & 16 & 1 & $<0.001$ \\
Prior major bleeding & 3.59 & $1.98-6.51$ & 16 & 1 & $<0.001$ \\
Renal failure & 1.80 & $1.11-2.93$ & 5 & 1 & 0.020 \\
\hline
\end{tabular}

All variables that initially entered the multivariable analysis are summarized in the Methods section. Area under the ROC curve $=0.6881$. 


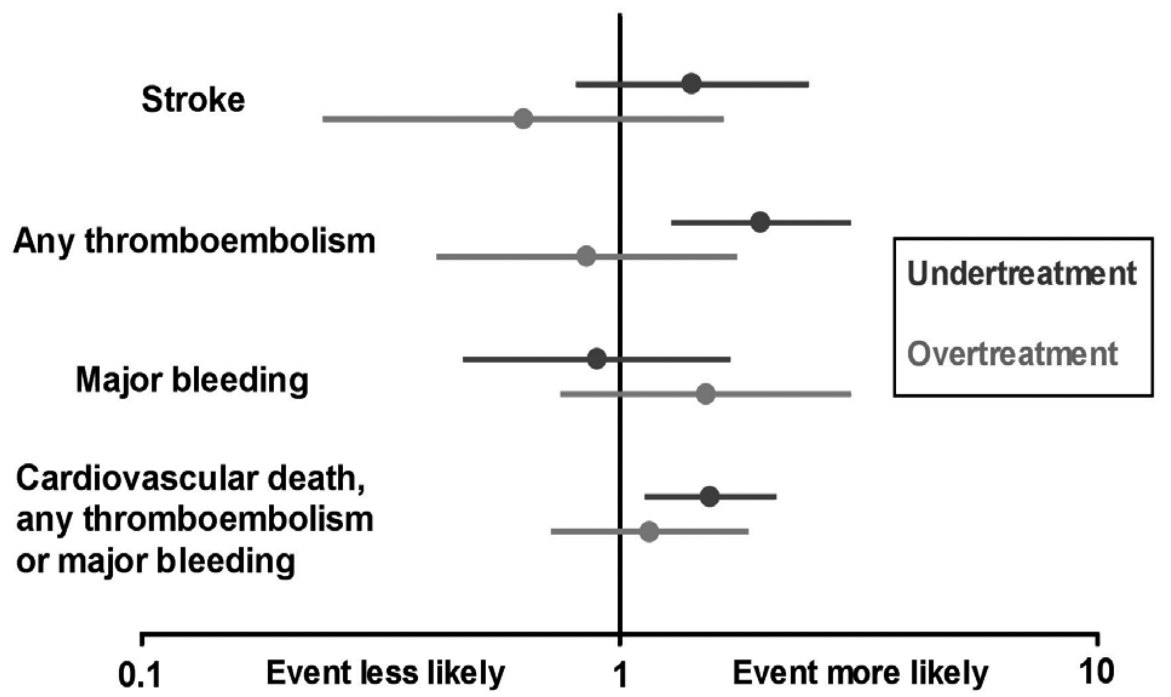

Figure 3. Multivariable effect of antithrombotic guideline deviance on 1-year outcome. Results are reported as OR with 95\% CI compared with the reference group "guideline adherence" $(\mathrm{OR}, 1)$.

Tables 2 through 5 show results of multivariable logistic regression on factors associated with the occurrence of stroke, any TE, major bleeding, and the combined end point of cardiovascular death, any TE, and major bleeding. The effect of underand overtreatment in these 4 analyses is also visualized in Figure 3. Compared to guideline adherence, undertreatment showed a trend toward a higher risk, and overtreatment toward a lower risk for stroke, although both were non-significant. Occurrence of stroke seemed most likely with a prior stroke/TIA (Table 2). Clearly significant was the association of undertreatment with an increased risk for any TE because it was the strongest associated factor in this model (Table 3). Guideline adherence and undertreatment showed a similar risk for major bleeding, but overtreatment did show a non-significant trend toward a higher risk for a major bleeding. Major bleeding was most likely to occur in patients with prior bleedings and with high age (Table 4). When combining any TE and major bleeding and adding cardiovascular death to the end point, undertreatment was associated with a significant higher risk for one of these events. Concomitant pathologies had the strongest association with occurrence of this combined end point (Table 5).

\section{DISCUSSION}

The Euro Heart Survey on AF is the first observational study to show that antithrombotic undertreatment is associated with worse cardiovascular outcome compared to guideline adherence. Overtreatment was not associated with a significant increase in bleeding risk. 


\section{Effect of antithrombotic guideline deviance in daily practice}

In the Euro Heart Survey, most of the patients were at high risk for stroke. Because more of these patients were undertreated than overtreated, undertreatment of high-risk patients seems to be the main problem when analyzing guideline-deviant antithrombotic management in AF. This holds especially true because undertreatment led to an adverse outcome compared to guideline adherence, whereas overtreatment did not. Previous observational studies have shown that OAC is beneficial in clinical practice patients, and that stroke and bleeding rates of randomized controlled trials translate well into daily practice. ${ }^{5,6}$ Because denying OAC in eligible patients constituted the main bulk of undertreatment, this survey indirectly demonstrates OAC efficacy in clinical practice.

Above all, this analysis is the first to show that global undertreatment - as defined by the guidelines - was associated with a worse cardiovascular outcome compared to guideline adherence. On the other hand, overtreatment of high-risk patients was not associated with an increased bleeding risk compared with guideline-adherent treatment. Of note, overtreatment with OAC of low(est)-risk patients hardly led to a marked increase in bleeding events. In agreement with previous findings, our results imply that when deciding on antithrombotic treatment, bleeding risk is subordinate to stroke risk, and that being conservative by withholding appropriate antithrombotic treatment is more harmful than treating patients aggressively. ${ }^{8}$

\section{Weighing the risk for stroke and bleeding to tailor antithrombotic treatment in AF}

Because overtreatment is not associated with a marked excess in bleeding, although the protective effect - as expected - is retained, this suggests that the concept of overtreatment as defined by the guidelines is not completely appropriate in real-life clinical practice. This perhaps encompasses too many clinical situations in which a more aggressive antithrombotic treatment may be justified. For example, our results show that patients with a prior stroke or TIA, irrespective of whether antithrombotic management follows the guidelines or not, have a high risk for stroke recurrence. Taken together, a more aggressive approach may be warranted in these patients, possibly by aiming at higher international normalized ratio (INR) levels (2.5-3.5) or adding an antiplatelet agent, such as those observed from recent data obtained by adding the antiplatelet agent triflusal to acenocoumarol, in high-risk patients with AF. ${ }^{9}$

Overrating the concept of overtreatment probably relates to the fact that the importance of classic BRFs is exaggerated. ${ }^{10,11}$ Gage et al. recently published the HEMORR ${ }_{2}$ HAGES scheme, which identified risk factors for any major bleeding. ${ }^{12}$ In patients with AF, however, OAC-induced ICH is the natural counterpart of ischemic stroke. Although the incidence of ICH is very low, even in randomized clinical trials ${ }^{13}$ its consequences are more devastating than the consequences of major extracranial bleeding. Other major bleedings may be amenable to 
local management, and in specific cases when bleeding risks are available, a secondary decision to stop or not start OAC or the combination of OAC and aspirin may be taken. Therefore, it seems most important to consider mainly ICH risk when performing a risk-benefit assessment for appropriate antithrombotic treatment application.

Prior ischemic stroke, high age, and high INR values $(>4.0)$ are associated with increased ICH risk. ${ }^{14,15}$ However, risk for stroke is much higher than ICH risk in the elderly and in patients with a prior ischemic stroke. ${ }^{13}$ In addition, aiming toward evidence-based INR ranges (2.0-3.0) should not lead to patients spending a large proportion of the time in relatively unsafe INR levels above 4.0. ${ }^{16,17}$ Considering the above, these classic ICH risk factors should not be a reason to withhold OAC. It has to be mentioned that aiming at INR $<2.0$ does not lead to fewer bleedings, especially in elderly patients, but does lead to increased stroke rates. ${ }^{14,18,19}$ We therefore suggest that we should consider only patients with a known or perceived (extreme) high risk for ICH, with recurrence of another type of uncontrollable major bleeding or with specific bleeding disorders, for exclusion from OAC use.

\section{Strengths}

The Euro Heart Survey provides a unique insight into the consequences of antithrombotic guideline deviance - rather than exclusively OAC efficacy - in the total AF spectrum as seen in European cardiology practice.

\section{Limitations}

We might underestimate the magnitude of the effects of both under- and overtreatment because more severely diseased patients dropped out of the follow-up and because our follow-up was restricted to 1 year during which few strokes and bleedings occurred. Information was available on prior major bleeding, prior malignancy, and renal failure as potential contraindications for OAC, but not for other potential contraindications for any major bleeding. We do not know whether patients received the same antithrombotic drug as that given at discharge during the entire duration of the follow-up period. Finally, we did not have information on quality of INR control for patients on OAC.

\section{Clinical implications}

These results stress the importance of antithrombotic therapy guideline implementation in patients with AF especially to prevent undertreatment of patients at high risk for stroke. Based on our results, one might expect that low(est)-risk patients do not seem to bleed excessively on OAC, and by starting OAC the patient is protected against stroke and TE should there be risk factors that are currently unde- 
tected or that will develop in the future. Whether physicians have to focus on risks for any major bleeding or specifically ICH when performing a risk-benefit assessment for appropriate antithrombotic treatment should be discussed.

\section{REFERENCES}

1. Lip GY, Edwards SJ. Stroke prevention with aspirin, warfarin and ximelagatran in patients with non-valvular atrial fibrillation: a systematic review and meta-analysis. Thromb Res 2006;118:321-33.

2. Aguilar M, Hart R. Antiplatelet therapy for preventing stroke in patients with non-valvular atrial fibrillation and no previous history of stroke or transient ischemic attacks. Cochrane Database Syst Rev 2005;10:CD001925.

3. Fuster V, Ryden LE, Asinger RW, Cannom DS, Crijns HJ, Frye RL, Halperin JL, Kay GN, Klein WW, Levy S, McNamara RL, Prystowsky EN, Wann LS, Wyse DG. ACC/AHA/ESC guidelines for the management of patients with atrial fibrillation. A report of the American College of Cardiology/American Heart Association Task Force on Practice Guidelines and the European Society of Cardiology Committee for Practice Guidelines and Policy Conferences (committee to develop guidelines for the management of patients with atrial fibrillation) developed in collaboration with the North American Society of Pacing and Electrophysiology. Eur Heart J 2001;22:1852-923.

4. Nieuwlaat R, Capucci A, Lip GY, Olsson SB, Prins MH, Nieman FH, Lopez-Sendon J, Vardas PE, Aliot E, Santini M, Crijns HJ. Antithrombotic treatment in real-life atrial fibrillation patients: a report from the Euro Heart Survey on Atrial Fibrillation. Eur Heart J 2006;27:3018-26.

5. Willems R, Exner DV. Do population studies confirm the benefit of oral anticoagulation in atrial fibrillation demonstrated in clinical trials? J Interv Card Electrophysiol 2004;10(Suppl 1):9-16.

6. Go AS, Hylek EM, Chang Y, Philips KA, Henault LE, Capra AM, Jensvold NG, Selby JV, Singer DE. Anticoagulation therapy for stroke prevention in atrial fibrillation: how well do randomized trials translate into clinical practice? JAMA 2003;290:2685-92.

7. Nieuwlaat R, Capucci, A, Camm AJ, Olsson SB, Andresen D, Davies DW, Cobbe S, Breithardt G, Le Heuzey JY, Prins MH, Levy S, Crijns HJ. Atrial fibrillation management: a prospective survey in ESC member countries: the Euro Heart Survey on Atrial Fibrillation. Eur Heart J 2005;26:2422-34.

8. Man-Son-Hing M, Laupacis A. Anticoagulant-related bleeding in older persons with atrial fibrillation: physicians' fears often unfounded. Arch Intern Med 2003;163:1580-6.

9. Perez-Gomez F, Alegria E, Berjon J, Iriarte JA, Zumalde J, Salvador A, Mataix L. Comparative effects of antiplatelet, anticoagulant, or combined therapy in patients with valvular and nonvalvular atrial fibrillation: a randomized multicenter study. J Am Coll Cardiol 2004;44:1557-66.

10. Deplanque D, Leys D, Parnetti L, Schmidt R, Ferro J, De Reuck J, Mas JL, Gallai V. Stroke prevention and atrial fibrillation: reasons leading to an inappropriate management. Main results of the SAFE II study. Br J Clin Pharmacol 2004;57:798-806.

11. Peterson GM, Boom K, Jackson SL, Vial JH. Doctors' beliefs on the use of antithrombotic therapy in atrial fibrillation: identifying barriers to stroke prevention. Intern Med J 2002;32:15-23

12. Gage BF, Yan Y, Milligan PE, Waterman AD, Culverhouse R, Rich MW, Radford MJ. Clinical classification schemes for predicting hemorrhage: results from the National Registry of Atrial Fibrillation (NRAF). Am Heart J 2006;151:713-9.

13. Singer DE, Albers GW, Dalen JE, Go AS, Halperin JL, Manning WJ. Antithrombotic therapy in atrial fibrillation: the Seventh ACCP Conference on Antithrombotic and Thrombolytic Therapy. Chest 2004;126:429S-56S. 
14. Hylek EM, Singer DE. Risk factors for intracranial hemorrhage in outpatients taking warfarin. Ann Intern Med 1994;120:897-902.

15. Cannegieter SC, Rosendaal FR, Wintzen AR, van der Meer FJ, Vandenbroucke JP, Briet E. Optimal oral anticoagulant therapy in patients with mechanical heart valves. N Engl J Med 1995;333:11-7.

16. Samsa GP, Matchar DB, Goldstein, LB, Bonito AJ, Lux LJ, Witter DM, Bian J. Quality of anticoagulation management among patients with atrial fibrillation: results of a review of medical records from 2 communities. Arch Intern Med 2000;160:967-73.

17. Nilsson GH, Bjorholt I. Occurrence and quality of anticoagulant treatment of chronic atrial fibrillation in primary health care in Sweden: a retrospective study on electronic patient records. BMC Clin Pharmacol 2004;4:1.

18. Hylek EM, Skates SJ, Sheehan MA, Singer DE. An analysis of the lowest effective intensity of prophylactic anticoagulation for patients with nonrheumatic atrial fibrillation. $\mathrm{N}$ Engl J Med 1996;335:540-6.

19. Fang MC, Chang Y, Hylek EM, Rosand J, Greenberg SM, Go AS, Singer DE. Advanced age, anticoagulation intensity, and risk for intracranial hemorrhage among patients taking warfarin for atrial fibrillation. Ann Intern Med 2004;141:745-52. 
6

Should we abandon the paradigm of withholding oral anticoagulation in paroxysmal atrial fibrillation?

Robby Nieuwlaat, Trang Dinh, A. John Camm, S. Bertil Olsson, Alessandro Capucci, Robert G. Tieleman, Gregory Y.H. Lip, Harry J.G.M. Crijns

Submitted

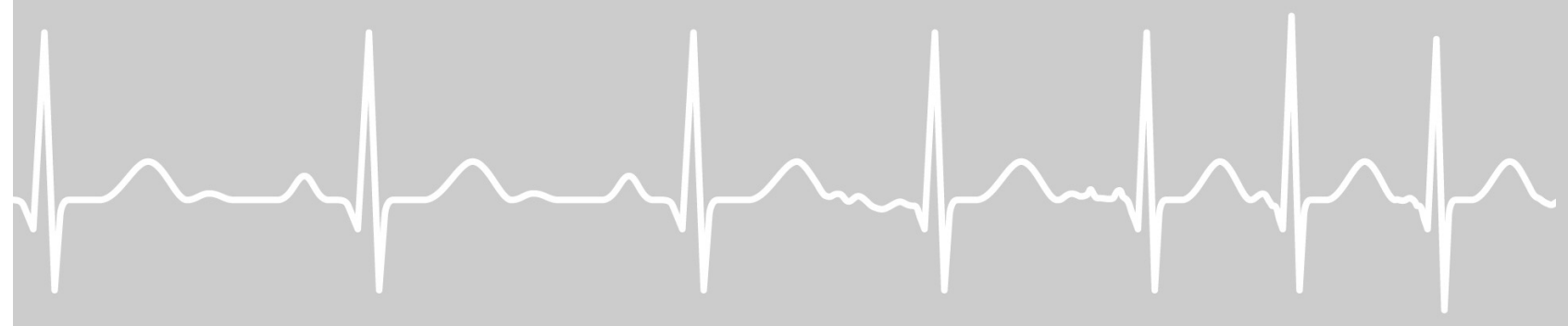




\section{ABSTRACT}

Aim. To assess the relation between the subtype of atrial fibrillation (AF), and the duration and frequency of AF, with thromboembolic events.

Methods. The Euro Heart Survey on AF (2003-2004) enrolled 1509 paroxysmal, 1109 persistent, and 1515 permanent AF patients, according to definitions of the 2001 ACC/AHA/ESC guidelines.

Results. Permanent AF patients were older, more often had a stroke in the past, and were generally at a higher risk for stroke than paroxysmal and persistent AF. Mortality and occurrence of major bleeding during 1 year were highest in permanent $\mathrm{AF}(\mathrm{P}=0.001$ and $\mathrm{P}=0.004$ respectively). Incidence of stroke and any thromboembolism was comparable among AF subtypes in both univariable and multivariable analysis. Also in multivariable analysis, permanent AF had a higher risk for major bleeding $(\mathrm{P}=0.045)$ and the combined endpoint of cardiovascular mortality, any thromboembolism or any major bleeding $(\mathrm{P}=0.021)$ than persistent AF, but both subtypes were not different from paroxysmal AF on these endpoints. Patients suffering from a stroke had a comparable frequency and duration of AF attacks as patients without stroke. Following baseline cardioversion, paroxysmal AF patients had a higher risk for stroke $(\mathrm{P}=0.029)$ and any thromboembolism $(\mathrm{p}=0.001)$ than persistent AF patients during 1 year

Conclusions. The results of the Euro Heart Survey imply that stroke and thromboembolic risk in paroxysmal AF is not lower than in persistent and permanent AF, which strengthens the recommendation that in the presence of risk factors the clinical subtype of AF should not be a consideration in the decision to anticoagulate. 


\section{INTRODUCTION}

The Euro Heart Survey on atrial fibrillation (AF), and also the NABOR program, reported that contemporary paroxysmal $\mathrm{AF}$ patients had a lower chance for receiving oral anticoagulation (OAC) than persistent and permanent $\mathrm{AF}$ patients. ${ }^{1,2}$ This observation probably relates to the traditional paradigm that anticoagulation is considered less essential with short and infrequent AF episodes. However, no clear evidence exists regarding the effect of AF duration and frequency on occurrence of stroke. Is a single, long-lasting AF episode alarming? It seems plausible that a long AF duration increases the risk for thrombus formation. Furthermore, frequent 'stopping and starting' of AF might be of concern, given the cluster of thromboembolism around rhythm transition. ${ }^{3}$ Stroke risk is also increased directly after restoration of sinus rhythm, probably because of the mechanism of atrial stunning, which might also increase stroke risk in paroxysmal $\mathrm{AF}$ with frequent episodes that terminate spontaneously. ${ }^{4}$

However, regardless of the significance of the duration and frequency of AF episodes, it is quite hard in daily practice to measure these variables exactly since asymptomatic episodes or periods are common. ${ }^{5}$ Thus, we rely on the clinical subtype of AF to estimate the effect of AF duration and frequency on stroke risk. Some studies have suggested a lower stroke risk in paroxysmal than in persistent $\mathrm{AF}^{6,7} \mathrm{In}$ contrast, other studies have reported a comparable stroke risk of paroxysmal to permanent AF. The largest dataset is the pooled analysis of aspirin-treated paroxysmal AF subjects in the SPAF trials, which concluded that the risk of stroke in intermittent (paroxysmal) AF was comparable to permanent $\mathrm{AF}^{8}$ Consequently, the 2006 guidelines of the American College of Cardiology (ACC), American Heart Association (AHA) and the European Society of Cardiology (ESC) on AF management dissuade decisions on antithrombotic treatment by clinical subtype of $\mathrm{AF}$, and imply paroxysmal AF subjects should be treated similarly to persistent and permanent $\mathrm{AF}^{9}$

In order to gain further insight into this issue, we report follow-up data of the Euro Heart Survey on AF, which is the first prospective observational survey to report incidence of thromboembolic events in relation to the ACC/AHA/ESC classification of AF type.

\section{METHODS}

In the Euro Heart Survey on AF (2003-2004) hospitalized and ambulant AF patients who had AF at enrolment or had an electrocardiogram or Holter monitor showing AF in the preceding 12 months were included in this multinational survey, sponsored by the ESC. Overall, 1509 paroxysmal, 1109 persistent, and 1515 permanent AF patients were enrolled. First detected AF patients were excluded from this analysis, since AF characteristics and temporal pattern were not sufficiently investi- 
gated or defined. Survey methods and baseline characteristics have been previously described. ${ }^{10}$

Definitions of the AF clinical subtypes were consistent with the 2001 ACC/AHA/ESC guidelines ${ }^{11}$ which were in existence at the time of the survey, as follows:

(i) Paroxysmal AF: recurrent AF that terminates spontaneously and lasts less than or equal to 7 days (mostly less than 24 hours). Termination of AF by pharmacological therapy or electrical cardioversion does not change the designation. In other words, cardioversion does not necessarily differentiate between paroxysmal and persistent AF since pharmacological and electrical cardioversion are used in both conditions;

(ii) Persistent AF: recurrent AF or sustained AF lasting more than 7 days;

(iii) Permanent AF: AF which has been present for a long time, cardioversion has not been indicated or used, or one or several attempts have failed to restore reliable sinus rhythm.

The $\mathrm{CHADS}_{2}$ stroke risk score is an acronym for Congestive heart failure, Hypertension, Age $\geq 75$ years, Diabetes and prior Stroke/TIA. These factors produce a sumscore ranging from 0 to 6 whereby a prior Stroke/TIA receives 2 points and the other factors 1 point. The score is based on stroke risk scores of the Stroke Prevention in AF and Atrial Fibrillation Investigators trials and has been validated in a cohort of the National Registry on AF. ${ }^{12}$

\section{Endpoint definitions}

Stroke was defined as a focal neurological deficit of sudden onset as diagnosed by a neurologist, lasting $>24$ hours and caused by ischemia.

Any thromboembolism was defined as the occurrence of ischemic stroke, myocardial infarction, pulmonary embolism or peripheral embolism.

Myocardial infarction was defined as new or presumed new ST segment elevation in two or more continuous leads of $0.2 \mathrm{mV}$ in leads $\mathrm{V} 1, \mathrm{~V} 2$ or $\mathrm{V} 3$ and $0.1 \mathrm{mV}$ in other leads and/or presumed new left bundle branch block and/or cardiac enzyme rise more than 2 times the upper values.

Peripheral embolism was defined as embolism outside the heart, brain, eyes and lungs.

Cardiovascular mortality was defined as death due to any cardiovascular reason such as myocardial infarction, heart failure, sudden cardiac death (all sudden deaths without any other known reason), stroke or rupture of an aortic aneurysm.

\section{Cardioversions}

A substantial number of paroxysmal and persistent AF patients underwent pharmacological or electrical cardioversion at the time of the baseline survey. In order to assess whether paroxysmal AF has a comparable risk for thromboembolism 
following these procedures, antithrombotic therapy at discharge and thromboembolic event rates during 1 year are reported for paroxysmal and persistent AF patients.

\section{Statistics}

Data analysis was performed with SPSS statistical software (SPSS Inc., release 12.01. Continuous variables are reported as mean \pm standard deviation or median $\left(25^{\text {th }}-75^{\text {th }}\right.$ percentile) and categorical variables as observed number (percentage within AF subtype). For some variables in Table 3 data availability was limited. Beneath Table 3 we report the exact proportion of data available when the information was available in less than $90 \%$ of patients. Whether there was any difference among the three AF subtypes was tested with either Kruskal-Wallis or one-way ANOVA for continuous variables and with $\chi^{2}$ statistic for categorical variables.

Multivariable logistic regression was performed to assess the independent effect of AF subtype on incidence of stroke, any thromboembolism and the combined endpoint of cardiovascular mortality and any thromboembolism. Variables were removed stepwise from the model when the $\mathrm{P}$-value was greater than 0.10 . Subtype of AF was always kept in the models since it was the central variable for these analyses. Variables with $\mathrm{P}$-value $<0.05$ in the final model were considered to be significant contributors and were kept in the model. All potential interactions in the final model were tested and incorporated when significant. By means of bootstrapping the variables and interactions in the final models were internally validated, which resulted in final models with only significant and stable effects, and AF subtype regardless of its significance.

\section{RESULTS}

Permanent AF patients were older and more often had valvular AF, a previous stroke and heart failure (all $\mathrm{P}<0.001)$ than paroxysmal and persistent AF patients (Table 1). As a consequence, permanent AF patients most often were at the highest risk for stroke according to the $\mathrm{CHADS}_{2}$ score (Figure 1). Regardless of the $\mathrm{CHADS}_{2}$ stroke risk score, paroxysmal AF patients had a much lower chance for receiving OAC at baseline (Table 1, Figure 2).

\section{Effect of clinical AF subtype on cardiovascular outcomes}

During 1 year follow-up, the incidence of stroke was comparable among AF subtypes (Table 2). Cardiovascular mortality and other types of major bleedings than hemorrhagic stroke were most often observed in permanent AF. In multivariable analysis (Figure 3), stroke risk was non-significantly lower in persistent and permanent AF compared to paroxysmal AF (odds ratio [OR] $=0.65(0.31-1.37)$ and $\mathrm{OR}$ $=0.62(0.31-1.22)$ respectively; overall $\mathrm{P}$-value $=0.315)$. This was also observed 
Table 1. Baseline characteristics and management of patients with paroxysmal, persistent and permanent $\mathrm{AF}$

\begin{tabular}{|c|c|c|c|c|}
\hline $\mathrm{N}$ & $\begin{array}{c}\text { Paroxysmal AF } \\
1509 \\
\end{array}$ & $\begin{array}{c}\text { Persistent AF } \\
1109 \\
\end{array}$ & $\begin{array}{c}\text { Permanent AF } \\
1515 \\
\end{array}$ & P-value \\
\hline \multicolumn{5}{|l|}{ Patient Characteristics } \\
\hline Age, years & $64 \pm 13$ & $66 \pm 12$ & $71 \pm 11$ & $<0.001$ \\
\hline Female gender & $652(43)$ & $451(39)$ & $668(43)$ & 0.028 \\
\hline Prior stroke & $64(4)$ & $51(4)$ & $135(9)$ & $<0.001$ \\
\hline Prior transient ischemic attack & $83(6)$ & $56(5)$ & $98(6)$ & 0.222 \\
\hline Mitral stenosis / valve surgery & $96(6)$ & $113(10)$ & $279(18)$ & $<0.001$ \\
\hline Heart failure & $342(23)$ & $401(35)$ & $757(49)$ & $<0.001$ \\
\hline Hypertension & $942(62)$ & $772(66)$ & $984(64)$ & 0.078 \\
\hline Coronary artery disease & $514(34)$ & $338(29)$ & $543(36)$ & 0.001 \\
\hline Diabetes mellitus & $232(15)$ & $186(16)$ & $336(22)$ & $<0.001$ \\
\hline \multicolumn{5}{|l|}{ Discharge drug therapy } \\
\hline Oral anticoagulation only & $669(45)$ & $815(72)$ & $889(66)$ & $<0.001$ \\
\hline Combination OAC \& antiplatelet & $75(5)$ & $83(7)$ & $145(10)$ & $<0.001$ \\
\hline Antiplatelet agent only & $522(35)$ & $168(15)$ & $274(18)$ & $<0.001$ \\
\hline Heparin only & $24(2)$ & $16(1)$ & $22(2)$ & 0.891 \\
\hline No antithrombotic therapy & $183(12)$ & $46(4)$ & $65(4)$ & $<0.001$ \\
\hline
\end{tabular}

Age is reported as mean \pm standard deviation and all other variables as observed number (percentage within AF type). Data were previously published. ${ }^{8}$

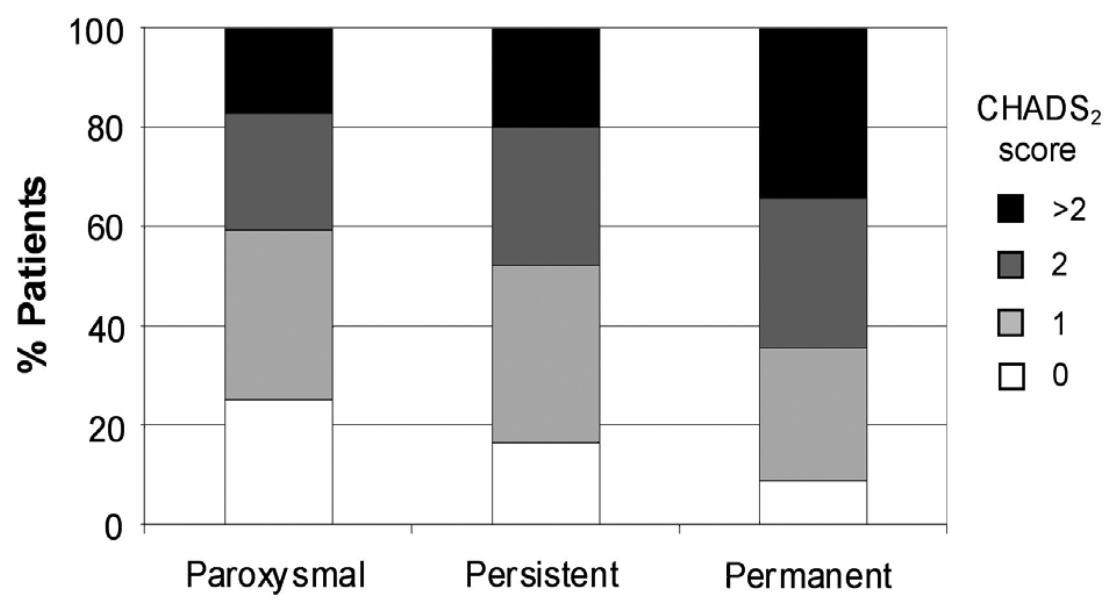

\section{Atrial fibrillation subtype}

Figure 1. $\mathrm{CHADS}_{2}$ stroke risk score per AF subtype. 


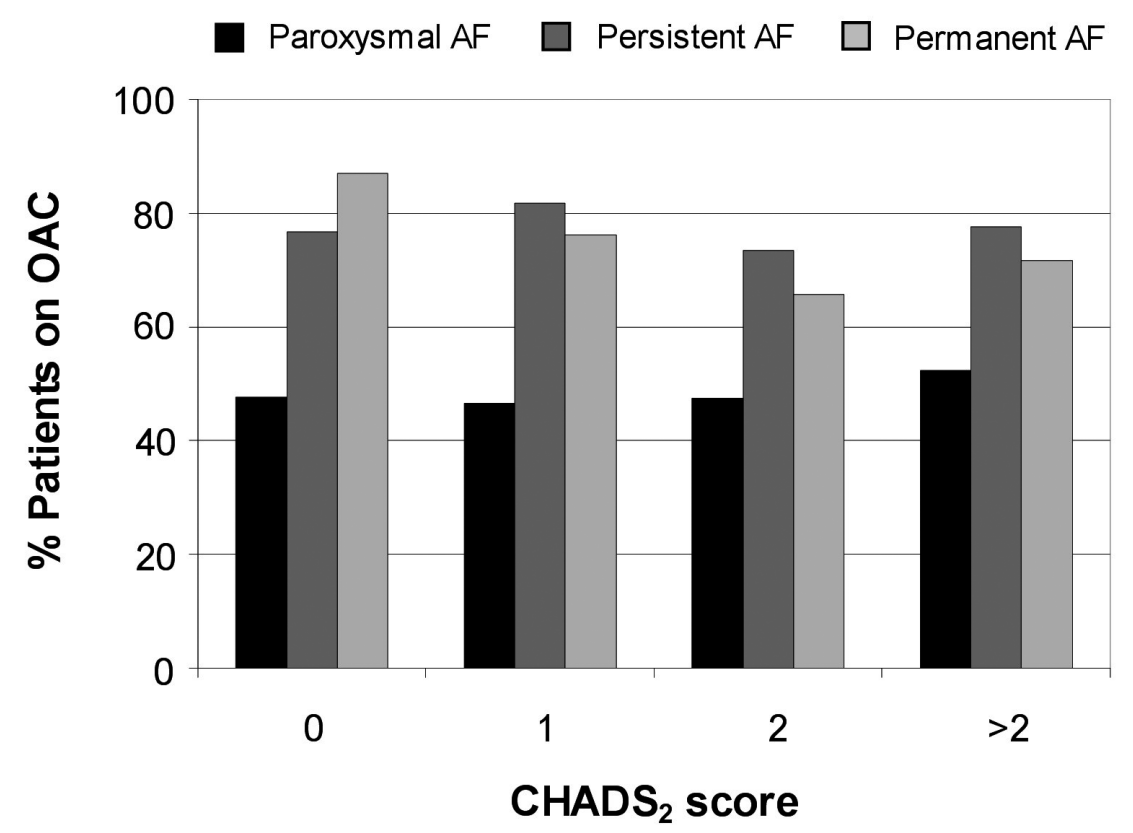

Figure 2. Oral anticoagulation prescription at baseline per AF subtype and per $\mathrm{CHADS}_{2}$ stroke risk score.

Table 2: Major adverse events during 1 year follow-up in patients with paroxysmal, persistent and permanent AF

\begin{tabular}{lcccc}
\hline & $\begin{array}{c}\text { Paroxysmal } \\
(\mathrm{n}=1170)\end{array}$ & $\begin{array}{c}\text { Persistent } \\
(\mathrm{n}=886)\end{array}$ & $\begin{array}{c}\text { Permanent } \\
(\mathrm{n}=1126)\end{array}$ & P-value \\
\hline All-cause death & $43(3.5)$ & $27(3.0)$ & $100(8.2)$ & $<0.001$ \\
Cardiovascular death & $15(1.3)$ & $19(2.1)$ & $43(3.6)$ & 0.001 \\
Any thromboembolism & $37(3.3)$ & $16(1.8)$ & $39(3.3)$ & 0.089 \\
Ischemic stroke & $22(1.9)$ & $11(1.2)$ & $19(1.6)$ & 0.582 \\
Hemorrhagic stroke & $3(0.3)$ & $1(0.1)$ & $4(0.3)$ & 0.592 \\
Other major bleeding & $13(1.1)$ & $7(0.8)$ & $29(2.5)$ & 0.004 \\
\hline Results are reported as observed number (percentage within AF subtype). &
\end{tabular}

for any thromboembolism $(\mathrm{OR}=0.53(0.29-0.96)$ and $\mathrm{OR}=0.82(0.51-1.32)$ respectively; overall $\mathrm{P}$-value $=0.094)$, whereby persistent $\mathrm{AF}$ tended to have an even lower risk than paroxysmal AF. As compared to paroxysmal AF, the risk for any type of major bleeding was non-significantly lower in persistent AF and non-significantly higher in permanent $\mathrm{AF}(\mathrm{OR}=0.64(0.27-1.51)$ and $\mathrm{OR}=1.59$ $(0.85-2.96)$ respectively; overall $\mathrm{P}$-value $=0.045)$. The latter significant overall $\mathrm{P}$-value indicates that the risk for any type of major bleeding was higher in permanent AF than in persistent AF. The risk for the combined endpoint of cardiovascular death, any thromboembolism and any major bleeding tended to be lower in persis- 


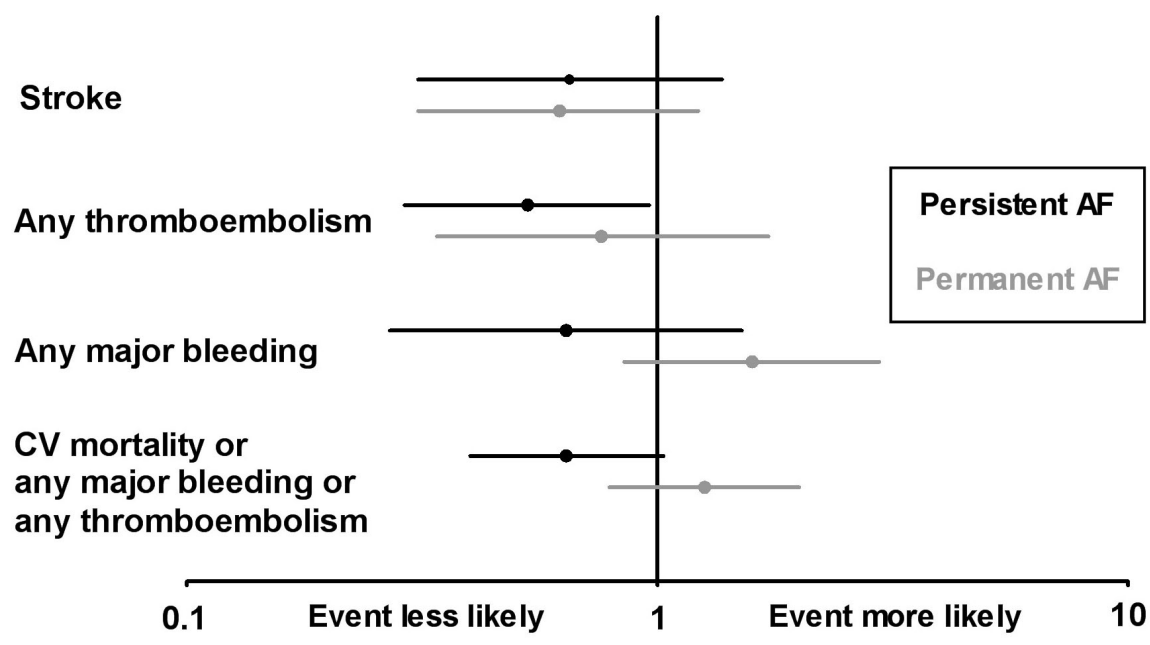

Figure 3. Multivariable effect of AF subtype on outcomes. Results are reported as OR with $95 \%$ confidence interval, as compared to the reference group with paroxysmal AF $(\mathrm{OR}, 1)$.

tent $\mathrm{AF}$ and was non-significantly higher in permanent $\mathrm{AF}(\mathrm{OR}=0.64$ $(0.40-1.03)$ and $1.26(0.79-2.00)$ respectively; overall $\mathrm{P}$-value $=0.021)$, both compared to paroxysmal AF. The latter significant overall $\mathrm{P}$-value indicates that the risk in permanent $\mathrm{AF}$ was higher than in persistent $\mathrm{AF}$.

Characteristics of paroxysmal and persistent AF patients with stroke versus without stroke

The presence of AF on the ECG at inclusion into the survey tended to be higher prevalent in paroxysmal AF patients who suffered a stroke during follow-up compared to stroke free patients (Table 3). The latter was however not observed amongst persistent AF patients. The proportions with an average duration of AF episodes of $>48$ hours and with infrequent (yearly) symptomatic episodes were comparable between patients with and without stroke. On the other hand, paroxysmal and persistent AF patients who suffered from a stroke in the preceding year were more often in $\mathrm{AF}$ at 1 year, and often had progressed to permanent $\mathrm{AF}$ $(\mathrm{P}=0.001)$. No significant difference was observed regarding OAC prescription at baseline, although it tended to be lower in persistent AF patients suffering from a stroke. Finally, at baseline paroxysmal AF patients with a stroke were more often at high risk for stroke, i.e. $\mathrm{CHADS}_{2}$ score $>1$, than patients without a stroke, which was nearly significant among persistent $\mathrm{AF}$ patients. 
Table 3. Characteristics of paroxysmal and persistent AF patients with stroke versus without a stroke during 1 year follow-up

\begin{tabular}{|c|c|c|c|c|c|c|}
\hline & \multicolumn{3}{|c|}{ Paroxysmal AF } & \multicolumn{3}{|c|}{ Persistent AF } \\
\hline & $\begin{array}{l}\text { Stroke } \\
(n=22)\end{array}$ & $\begin{array}{l}\text { No stroke } \\
(\mathrm{n}=1114)\end{array}$ & P-value & $\begin{array}{l}\text { Stroke } \\
(n=11)\end{array}$ & $\begin{array}{l}\text { No stroke } \\
(\mathrm{n}=872)\end{array}$ & $\mathrm{P}$-value \\
\hline \multicolumn{7}{|l|}{ History } \\
\hline $\begin{array}{l}\text { Time since AF diagnosis, } \\
\text { months }^{\mathrm{a}}\end{array}$ & $4(1-25)$ & $8(1-39)$ & 0.446 & $18(1-66)$ & $9(2-42)$ & 0.908 \\
\hline $\begin{array}{l}\text { Average AF duration in the past } \\
\text { year }>48 \text { hours }\end{array}$ & $4(29)$ & $209(29)$ & 0.970 & $7(70)$ & $315(62)$ & 0.606 \\
\hline Infrequent attacks (yearly) ${ }^{c}$ & $7(44)$ & $305(35)$ & 0.329 & $4(40)$ & $237(36)$ & 0.878 \\
\hline \multicolumn{7}{|l|}{ Baseline } \\
\hline In $\mathrm{AF}$ & $16(73)$ & $589(53)$ & 0.065 & $8(73)$ & $641(74)$ & 0.943 \\
\hline $\begin{array}{l}\text { Duration of current episode } \\
>48 \text { hours }\end{array}$ & $11(54)$ & $412(58)$ & 0.897 & $8(89)$ & $677(87)$ & 0.868 \\
\hline $\mathrm{CHADS}_{2}$ score $>1$ & $13(65)$ & $370(37)$ & 0.010 & $7(70)$ & $344(45)$ & 0.121 \\
\hline Oral anticoagulation & $13(59)$ & $570(53)$ & 0.545 & $7(64)$ & $694(82)$ & 0.127 \\
\hline \multicolumn{7}{|l|}{1 Year follow-up } \\
\hline In $\mathrm{AF}$ & $10(53)$ & $174(17)$ & 0.001 & $10(100)$ & $368(45)$ & 0.016 \\
\hline Permanent AF & $6(32)$ & $84(8)$ & 0.005 & $7(70)$ & $244(29)$ & 0.013 \\
\hline
\end{tabular}

\section{Thromboembolic complications associated with cardioversion in paroxysmal and persistent $A F$}

In the Euro Heart Survey, 496 paroxysmal and 213 persistent AF patients underwent pharmacological cardioversion, and 216 paroxysmal and 424 persistent AF patients underwent electrical cardioversion at baseline. Following pharmacological cardioversion, less paroxysmal AF patients received OAC (41 vs $64 \% ; \mathrm{P}<0.001$ ), but more received aspirin (42 vs $31 \% ; \mathrm{P}=0.006$ ) compared to persistent AF. Following electrical cardioversion, the same was observed for OAC (72 vs 92\%; $\mathrm{P}<0.001)$ and aspirin ( 23 vs $13 \% ; \mathrm{P}=0.002)$. When paroxysmal was compared with persistent $\mathrm{AF}$, stroke incidence was non-significantly higher in paroxysmal AF during 1 year following both pharmacological (2.6 vs $0.7 \% ; \mathrm{P}=0.155)$ and electrical cardioversion (1.7 vs $0.6 \% ; \mathrm{P}=0.248$ ), and the incidence of any thromboembolism was higher in paroxysmal AF after pharmacological (4.7 vs $1.3 \% ; \mathrm{P}=0.069)$ and electrical cardioversion ( 3.7 vs $0.7 \% ; \mathrm{P}=0.024$ ). Taking all cardioversions together, the incidence of stroke and any thromboembolism were significantly higher in paroxysmal than in persistent AF (Figure 4).

During follow-up, paroxysmal AF patients more often underwent pharmacological cardioversion (33 vs $18 \% ; \mathrm{P}<0.001)$ and less often electrical cardioversion (21 vs $29 \%$; $\mathrm{P}=0.004)$ compared to persistent AF. Paroxysmal AF patients less often 


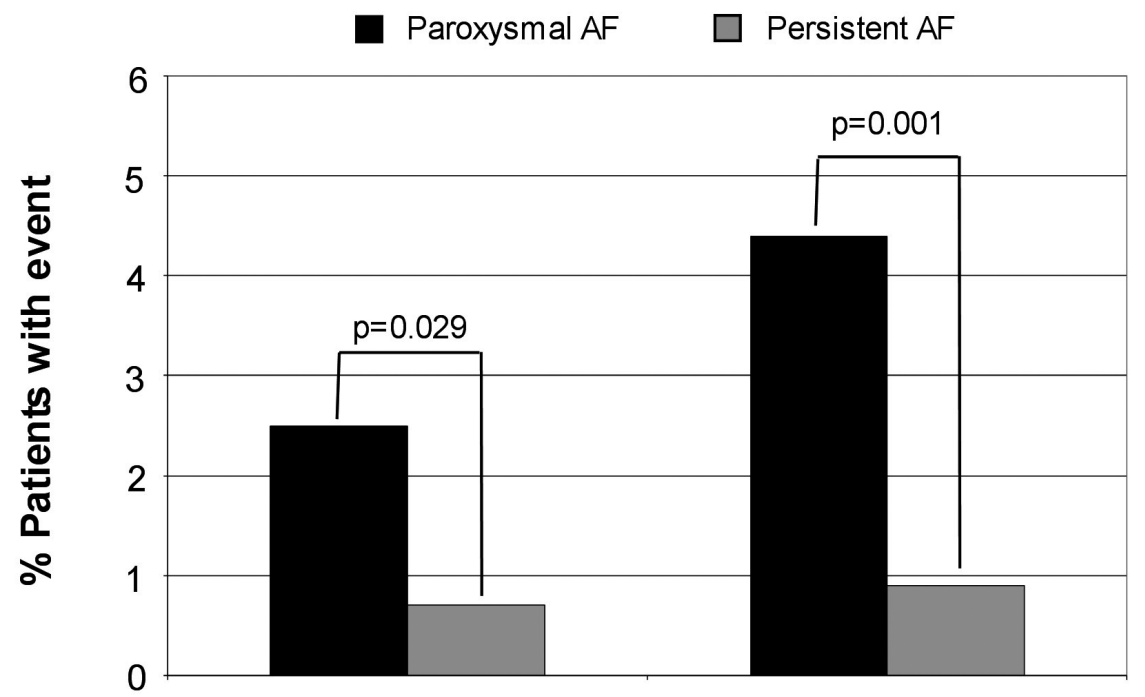

Stroke

Any thromboembolism

Figure 4. Thromboembolic complications during 1 year after baseline cardioversion in paroxysmal and persistent AF.

received OAC than persistent $\mathrm{AF}$ after both pharmacological (41 vs $64 \% ; \mathrm{P}<0.001)$ and electrical cardioversion $(72$ vs $92 \% ; \quad \mathrm{P}<0.001)$. The increased thromboembolism rates in paroxysmal $\mathrm{AF}$ when compared to persistent $\mathrm{AF}$ seemed to be present in both patients on OAC (stroke: 2.5 vs $0.8 \% ; \mathrm{P}=0.100$ and any thromboembolism: 3.7 vs $0.8 \% ; \mathrm{P}=0.012$ ) and off $\mathrm{OAC}$ (stroke: 2.7 vs $0.0 \%$; $\mathrm{P}=0.161$ and any thromboembolism: 5.4 vs $1.4 \% ; \mathrm{P}=0.153$ ). When assessing the independent effect of AF subtype on outcome after baseline cardioversion in multivariable logistic regression, thereby taking in account differences in stroke risk profile and antithrombotic therapy, paroxysmal AF still had a higher risk for stroke $(\mathrm{OR}=4.38(1.21-15.91) ; \mathrm{P}=0.012)$ and any thromboembolism $(\mathrm{OR}=5.93$ (2.00-17.57); $\mathrm{P}<0.001)$ than persistent $\mathrm{AF}$.

\section{DISCUSSION}

The Euro Heart Survey provides valuable observational prospective clinical practice data on the incidence of stroke related to AF subtype. Although no causal conclusions can be drawn from these data, the results do seem to point towards an at least comparable risk for stroke in paroxysmal $\mathrm{AF}$ as compared to persistent and permanent AF. 
Clinical subtype of $A F$

Several co-morbidities are directly associated with an increased risk for stroke in AF, of which valvular AF is undisputed, and other factors increasing stroke risk in non-valvular AF are brought together in the risk calculation score $\mathrm{CHADS}_{2}$ (congestive heart failure, hypertension, age $\geq 75$ years, diabetes, and prior stroke or TIA). Based on these well-known stroke risk factors the 2006 guidelines provide recommendations for antithrombotic treatment, and they also explicitly state that AF subtype should not influence the management decision. ${ }^{9}$ However, evidence on chronic AF being a stroke risk factor as compared to paroxysmal AF is not consistent. $^{6-8,13-15}$

Assessment of stroke risk in relation to clinical subtype of AF depends highly on the definition used for paroxysmal AF, which tends to vary across studies. Based on current guideline definitions the results of the Euro Heart Survey strengthen the recommendation not to take into account the clinical subtype of AF. The risk for stroke might even be higher in paroxysmal AF, as seen after baseline cardioversion in this study. This might relate to the lower OAC application rates in paroxysmal AF after both pharmacological and electrical cardioversion, although the increased thromboembolism rate tended to be present in both patients on and off OAC. Potentially, the intermittent nature of paroxysmal AF may be more thrombogenic than single longstanding AF episodes as in persistent AF. Repeated cardioversions as used in rhythm control strategies may be thrombogenic by creating intermittent ('in-and-out') AF and this may be one of the reasons why no advantage was observed with rhythm control in the randomized studies. ${ }^{16}$

\section{Potential of current qualitative and quantitative methods}

Current qualitative and quantitative methods of stroke risk assessment have also not yet convincingly revealed a different stroke risk in paroxysmal and persistent/permanent AF. Transesophageal echocardiography abnormalities (e.g., spontaneous echo-contrast), abnormal hemostasis and reduced local blood flow velocities in the left atrium contribute to thrombogenesis in AF, and these have also been found to be present in paroxysmal AF. For example, abnormal coagulation, platelet aggregation, endothelial dysfunction and inflammation are elevated in AF, and have also been shown in paroxysmal AF. ${ }^{17,18}$ Future prospective clinical studies could clarify the causal relation between duration and frequency of AF episodes, thromboembolic blood markers and stroke incidence.

The difficulty with measuring 'true' duration and frequency of AF episodes

Although it does seem plausible that long and frequent AF episodes are associated with an increased stroke risk, the Euro Heart Survey results point towards a weak association of AF duration and frequency of attacks with stroke, not only based on 
AF subtype. The fact that paroxysmal and persistent AF patients with a stroke had a similar duration and frequency of attacks, but were more often at high risk for stroke according to the $\mathrm{CHADS}_{2}$ scheme compared to paroxysmal AF patients without a stroke, might indicate that AF duration and frequency play a subordinate role for predicting stroke. Nevertheless, these clinically based estimates depend on the perception and reporting of symptomatic attacks by the patient and are quite crude. A large part of AF attacks is asymptomatic and will not be reported. ${ }^{5}$ In addition, in case of symptomatic attacks, the accuracy of reporting attacks depends on the patient's memory and capacity to distinguish AF symptoms from closely related symptoms, which might explain the limited data availability for some items on AF frequency and duration. To adequately assess the 'true' effect of AF duration and frequency on stroke occurrence, monitoring of both symptomatic and silent $\mathrm{AF}$ is essential. Indeed, there is an increased risk for embolic events in patients with an AF duration $>24$ hours as compared to patients with no AF or AF duration $\leq 24$ hours, ${ }^{19}$ although the latter study was performed in a highly selected patient group with an implanted pacemaker. In patients without such a device it will be quite challenging to estimate the exact AF duration since asymptomatic AF highly contributes. ${ }^{5}$

\section{Future perspectives}

Upcoming trials such as the TRENDS and the ASSERT studies will provide further insight in the direct relation of AF duration and systemic embolisms, in a large group of patients with an implantable device. ${ }^{20,21}$ If this study confirms the findings of Capucci et $\mathrm{al}^{19}$ that a long AF duration increases risk for systemic embolism, the challenge is to measure AF duration in a non-invasive manner and to confirm this relation in a wider spectrum of AF patients. In this regard, the event-loop recorders are promising. ${ }^{22,}{ }^{23}$ When appropriate clinical quantifiable variables are identified to assess the effect of arrhythmia characteristics on stroke risk and adequate non-invasive monitoring tools are available, it will be essential to address this important issue in high-quality clinical trials.

\section{Strengths E limitations}

The Euro Heart Survey provides unique observational data on stroke incidence in relation to the total spectrum of AF subtypes as seen in European cardiology practice. However, we only had estimates, not quantitative information, of the frequency and duration of symptomatic AF episodes. Classification of the clinical subtype of AF and estimation of AF duration and frequency of AF attacks solely relied on the attending physician's interpretation. Unfortunately we only knew the exact timing of mortality during follow-up and not of the other events. Finally, for patients on OAC we did not have information on the time spent within or outside 
the therapeutic INR range - also not at the time of a stroke - and whether OAC was stopped and re-started between the baseline visit and 1 year follow-up.

\section{Conclusions}

The results of the EHS-AF indicate that risk for stroke in paroxysmal AF is at least comparable with that of persistent and permanent AF, and potentially even higher following cardioversion. These findings strengthen the recommendation that clinical subtype of AF, as defined by the ACC/AHA/ESC management guidelines, should currently not influence the decision to anticoagulate, in the presence of appropriate risk factors. Therefore, we should at present abandon the paradigm that is sometimes advocated, that in paroxysmal AF patients, anticoagulation may usually be withheld.

\section{REFERENCES}

1. Nieuwlaat R, Capucci A, Lip GY, Olsson SB, Prins MH, Nieman FH, Lopez-Sendon J, Vardas PE, Aliot E, Santini M, Crijns HJ. Antithrombotic treatment in real-life atrial fibrillation patients: a report from the Euro Heart Survey on Atrial Fibrillation. Eur Heart J 2006;27:3018-26.

2. Waldo AL, Becker RC, Tapson VF, Colgan KJ. Hospitalized patients with atrial fibrillation and a high risk of stroke are not being provided with adequate anticoagulation. J Am Coll Cardiol 2005;46:1729-36.

3. Wolf PA, Kannel WB, McGee DL, Meeks SL, Bharucha NE, McNamara PM. Duration of atrial fibrillation and imminence of stroke: the Framingham study. Stroke 1983;14:664-7.

4. Manning WJ, Silverman DI, Katz SE, Riley MF, Come PC, Doherty RM, Munson JT, Douglas PS. Impaired left atrial mechanical function after cardioversion: relation to the duration of atrial fibrillation. J Am Coll Cardiol 1994;23:1535-40.

5. Israel CW, Gronefeld G, Ehrlich JR, Li YG, Hohnloser SH. Long-term risk of recurrent atrial fibrillation as documented by an implantable monitoring device: implications for optimal patient care. J Am Coll Cardiol 2004;43:47-52.

6. Aboaf AP, Wolf PS. Paroxysmal atrial fibrillation. A common but neglected entity. Arch Intern Med 1996;156:362-7.

7. Petersen P, Godtfredsen J. Embolic complications in paroxysmal atrial fibrillation. Stroke 1986;17:622-6.

8. Hart RG, Pearce LA, Rothbart RM, McAnulty JH, Asinger RW, Halperin JL. Stroke with intermittent atrial fibrillation: incidence and predictors during aspirin therapy. Stroke Prevention in Atrial Fibrillation Investigators. J Am Coll Cardiol 2000;35:183-7.

9. Fuster V, Ryden LE, Cannom DS, Crijns HJ, Curtis AB, Ellenbogen KA, Halperin JL, Le Heuzey JY, Kay GN, Lowe JE, Olsson SB, Prystowsky EN, Tamargo JL, Wann S. ACC/AHA/ESC 2006 guidelines for the management of patients with atrial fibrillation-executive summary: a report of the American College of Cardiology/American Heart Association Task Force on practice guidelines and the European Society of Cardiology Committee for Practice Guidelines (Writing Committee to Revise the 2001 Guidelines for the Management of Patients with Atrial Fibrillation). Eur Heart J 2006;27:1979-2030.

10. Nieuwlaat R, Capucci A, Camm AJ, Olsson SB, Andresen D, Davies DW, Cobbe S, Breithardt G, Le Heuzey JY, Prins MH, Levy S, Crijns HJ. Atrial fibrillation management: a prospective survey in ESC member countries: the Euro Heart Survey on Atrial Fibrillation. Eur Heart J 2005;26:2422-34. 
11. Fuster V, Ryden LE, Asinger RW, Cannom DS, Crijns HJ, Frye RL, Halperin JL, Kay GN, Klein WW, Levy S, McNamara RL, Prystowsky EN, Wann LS, Wyse DG. ACC/AHA/ESC guidelines for the management of patients with atrial fibrillation. A report of the American College of Cardiology/American Heart Association Task Force on Practice Guidelines and the European Society of Cardiology Committee for Practice Guidelines and Policy Conferences (Committee to develop guidelines for the management of patients with atrial fibrillation) developed in collaboration with the North American Society of Pacing and Electrophysiology. Eur Heart J 2001;22:1852-923.

12. Gage BF, Waterman AD, Shannon W, Boechler M, Rich MW, Radford MJ. Validation of clinical classification schemes for predicting stroke: results from the National Registry of Atrial Fibrillation. JAMA 2001;285:2864-70.

13. The effect of low-dose warfarin on the risk of stroke in patients with nonrheumatic atrial fibrillation. The Boston Area Anticoagulation Trial for Atrial Fibrillation Investigators. N Engl J Med 1990;323:1505-11.

14. Risk factors for stroke and efficacy of antithrombotic therapy in atrial fibrillation. Analysis of pooled data from five randomized controlled trials. Arch Intern Med 1994;154:1449-57.

15. Blich M, Gross B. Thromboembolic prophylaxis in nonrheumatic atrial fibrillation: utilization patterns, efficacy, and complications in a long-term follow-up of community patients. Int J Cardiol 2004;96:89-95.

16. de Denus S, Sanoski CA, Carlsson J, Opolski G, Spinler SA. Rate vs rhythm control in patients with atrial fibrillation: a meta-analysis. Arch Intern Med 2005;165:258-62.

17. Sohara H, Amitani S, Kurose M, Miyahara K. Atrial fibrillation activates platelets and coagulation in a time-dependent manner: a study in patients with paroxysmal atrial fibrillation. J Am Coll Cardiol 1997;29:106-12.

18. Li-Saw-Hee FL, Blann AD, Gurney D, Lip GY. Plasma von Willebrand factor, fibrinogen and soluble P-selectin levels in paroxysmal, persistent and permanent atrial fibrillation. Effects of cardioversion and return of left atrial function. Eur Heart J 2001;22:1741-7.

19. Capucci A, Santini M, Padeletti L, Gulizia M, Botto G, Boriani G, Ricci R, Favale S, Zolezzi F, Di Belardino N, Molon G, Drago F, Villani GQ, Mazzini E, Vimercati M, Grammatico A. Monitored atrial fibrillation duration predicts arterial embolic events in patients suffering from bradycardia and atrial fibrillation implanted with antitachycardia pacemakers. J Am Coll Cardiol 2005;46:1913-20.

20. Glotzer TV, Daoud EG, Wyse DG, Singer DE, Holbrook R, Pruett K, Smith K, Hilker CE. Rationale and design of a prospective study of the clinical significance of atrial arrhythmias detected by implanted device diagnostics: The TRENDS study. J Interv Card Electrophysiol 2006;15:9-14.

21. Hohnloser SH, Capucci A, Fain E, Gold MR, van Gelder IC, Healey J, Israel CW, Lau CP, Morillo C, Connolly SJ. ASymptomatic atrial fibrillation and Stroke Evaluation in pacemaker patients and the atrial fibrillation Reduction atrial pacing Trial (ASSERT). Am Heart J 2006;152:442-7.

22. Jabaudon D, Sztajzel J, Sievert K, Landis T, Sztajzel R. Usefulness of ambulatory 7-day ECG monitoring for the detection of atrial fibrillation and flutter after acute stroke and transient ischemic attack. Stroke 2004;35:1647-51.

23. Dinh T, Houben RP, Larik VC, Jongen TD, Janssen MH, Crijns HJGM, Tieleman RG. Clinical validation of the AF-alarm, a dedicated loop recorder for automatic detection of atrial fibrillation. Heart Rhythm 2005;2:S224. 
7

Antithrombotic drug prescription in atrial fibrillation and its rationale among general practitioners, internists and cardiologists in The Netherlands The EXAMINE-AF study

Trang Dinh, Robby Nieuwlaat, Robert G. Tieleman, Harry R. Büller, Nico A. Mensing van Charante, Martin H. Prins, Harry J.G.M. Crijns

Int J Clin Pract. 2007;61(1):24-31

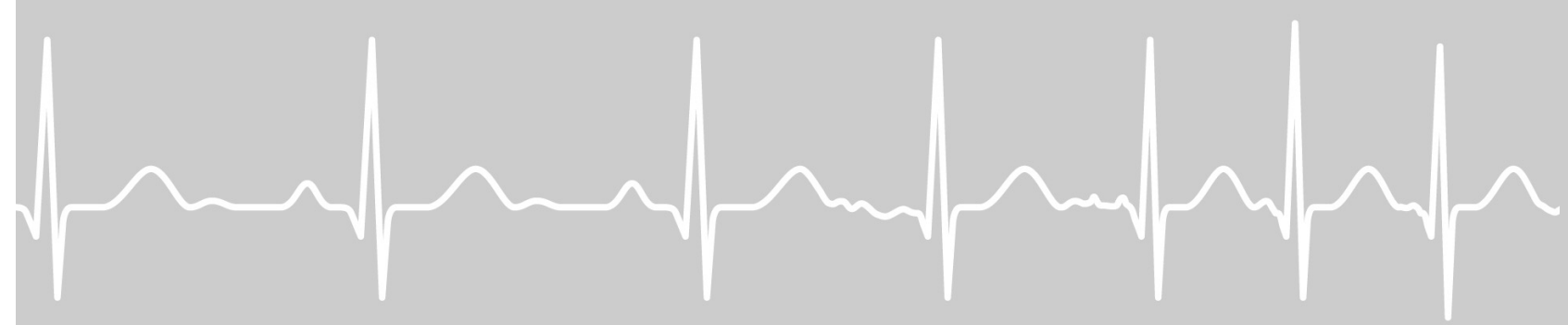




\begin{abstract}
The objective of the EXAMINE-AF study was to record and compare antithrombotic treatment in patients with atrial fibrillation (AF) in daily clinical practice of general practitioners, internists and cardiologists in the Netherlands. Eighty-six general practitioners, 93 internists and 99 cardiologists responded to postal questionnaires and enrolled 1596 patients: 365,351 and 880 respectively. A cardiologist was indicated to be the main treating physician for $\mathrm{AF}$ in $82 \%$ of all patients; current antithrombotic treatment was initiated in $80 \%$ by a cardiologist. Of all patients, $84 \%$ were at high risk for stroke and therefore were eligible for oral anticoagulation treatment, but only $64 \%$ of these patients actually received this. Cardiologists instituted appropriate antithrombotic treatment best, compared with general practitioners and internists $(70 \%$ vs. $58 \%$ and $55 \% ; \mathrm{P}<0.001)$. Positive predictive factors for oral anticoagulation prescription were previous stroke/transient ischaemic attack (OR, 2.31; 95\% CI, 1.33-4.02) and heart failure (OR, 1.72; 95\% CI, 1.23-2.42). Contraindications for oral anticoagulation (OR, 0.46; 95\% CI, $0.32-0.68$ ), treatment by a general practitioner (OR, $0.29 ; 95 \% \mathrm{CI}, 0.20-0.42$ ) or internist (OR, 0.24; 95\% CI, 0.15-0.39) were important factors for withholding treatment. Antithrombotic treatment in AF patients is well instituted in primary and secondary care in the Netherlands. Cardiologists play a key role in the diagnosis and management of the majority of AF patients, even in those regularly attending other physicians. Factors for oral anticoagulation prescription are heart failure, physician specialty and contraindications. Availability of guidelines seems instrumental for application of appropriate antithrombotic treatment.
\end{abstract}




\section{INTRODUCTION}

Atrial fibrillation (AF) is the most common sustained arrhythmia in the Western World with an estimated prevalence in the Netherlands of 300,000 patients. ${ }^{1,2}$ AF is associated with an increased risk of thromboembolism, especially in the elderly and patients with cardiovascular co-morbidities. The presently available guidelines in the Netherlands on management of AF are the Dutch College of General Practitioners guideline $\mathrm{e}^{3}$ and the joint guideline by the American Heart Association (AHA), American College of Cardiology (ACC) and European Society of Cardiology (ESC). ${ }^{4}$ The focal point in these guidelines concerns prevention of thromboembolic complications; both guidelines include risk stratification schemes using several established stroke risk factors. Despite these guidelines and the overwhelming evidence on stroke risk reduction in AF by antithrombotic treatment, including oral anticoagulation (OAC) and antiplatelet drugs, physicians are often hesitant to prescribe OAC. There are no reports on antithrombotic treatment prescription patterns in AF patients in the Netherlands.

The main aim of the EXAMINE-AF study was to make an inventory of the demographics of the physicians and their patient population, and to describe and compare the antithrombotic treatment patterns in patients with AF in daily clinical practice of Dutch general practitioners (GPs), internists and cardiologists.

\section{METHODS}

\section{Study design}

Extensive questionnaires on demographic properties of the patient, stroke risk factors, bleeding risk factors, current and previous antithrombotic treatment (and their rationale for prescription or non-prescription) and echocardiographic properties were sent between October 2004 and April 2005 to a group of dedicated 100 GPs, 100 internists and 100 cardiologists in the Netherlands.

The physicians were asked to fill in the questionnaires for five (GPs and internists) or 10 (cardiologists) consecutive AF patients. AF needed not to be the main reason for the visit. Patients were asked to give their informed consent for use of their data in a coded database before enrollment. Eligible patients were 18 years or older, had no valvular prosthesis and were diagnosed with AF for more than 1 year.

Table 1 shows stroke risk classification and recommended treatment according to the AHA/ACC/ESC and Dutch College of General Physicians guidelines on AF. As internists in the Netherlands do not have their own guidelines, we considered it appropriate for them to follow the cardiologists' guidelines as well.

Inquired bleeding risk factors were previous haemorrhagic stroke, active ulceration of gastrointestinal tract, high intrinsic bleeding risk (e.g. haemorrhagic blood dyscrasias, thrombocytopenia and known bleeding diathesis), frequent falls, severe 
Table 1. Antithrombotic treatment schemes according to the AHA/ACC/ESC guidelines and the guidelines of Dutch College of General Physicians on the management of patients with atrial fibrillation

\begin{tabular}{|c|c|c|c|}
\hline & $\begin{array}{l}\text { AHA/ACC/ESC guidelines } \\
\text { Cardiologists and internists }\end{array}$ & $\begin{array}{l}\text { Dutch CGP guidelines } \\
\text { General practitioners }\end{array}$ & $\begin{array}{l}\text { Recommended treat- } \\
\text { ment }\end{array}$ \\
\hline Very low risk & $\begin{array}{l}\text { Age }<60 \text { years without heart disease } \\
\text { (lone AF) }\end{array}$ & & No drug / aspirin \\
\hline Low risk & $\begin{array}{l}\text { Age }<60 \text { years with heart disease but } \\
\text { no risk factors } \\
\text { Age } \geq 60 \text { years without risk factors }{ }^{\mathrm{a}}\end{array}$ & $\begin{array}{l}\text { No enlarged risk of } \\
\text { thromboembolism }^{c}\end{array}$ & Aspirin \\
\hline High risk & $\begin{array}{l}\text { Age } \geq 60 \text { years with diabetes or coro- } \\
\text { nary artery disease }\end{array}$ & & $\begin{array}{l}\text { OAC, optional addi- } \\
\text { tion of aspirin }\end{array}$ \\
\hline High risk & $\begin{array}{l}\text { Age } \geq 75 \text { years (especially women) } \\
\text { Heart failure } \\
\text { Left ventricular ejection fraction } \\
<0.35 \\
\text { Hypertension } \\
\text { Prior thromboembolism } \\
\text { Thyrotoxicosis } \\
\text { Rheumatic heart disease (mitral } \\
\text { stenosis) } \\
\text { Prosthetic heart valves } \\
\text { Persistent atrial thrombus on } \\
\text { transesophageal echocardiogram }\end{array}$ & $\begin{array}{l}\text { Prior TIA or ischemic } \\
\text { stroke } \\
\text { Hypertension } \\
\text { Diabetes } \\
\text { Heart failure } \\
\text { Coronary artery disease } \\
\text { Rheumatic valve disease }\end{array}$ & OAC \\
\hline \multicolumn{4}{|c|}{$\begin{array}{l}\text { Extracted from the AHA/ACC/ESC guidelines }{ }^{4} \text { and the guidelines of the Dutch College of General } \\
\text { Physicians (CGP). }{ }^{3} \text { The Dutch CGP guidelines do not include patients }<60 \text { years. a Oral anticoagulation } \\
\text { with international normalised ratio approximately equal to } 2.0 \text {. b Stroke risk factors of the } \\
\text { AHA/ACC/ESC: heart failure, left ventricular ejection fraction }<0.35 \text { and history of hypertension. } \\
\text { Stroke risk factors of the Dutch CGP guidelines: hypertension, diabetes, coronary heart disease, heart } \\
\text { failure and rheumatic valve disease. }\end{array}$} \\
\hline
\end{tabular}

kidney dysfunction (creatinine clearance $<30 \mathrm{ml} / \mathrm{min}$ ), severe liver dysfunction, active malignancy, dementia and esophagus varices. Other reasons for withholding OAC were also recorded; unwillingness/refusal of the patient, low patient compliance, incapability to comprehend health status, personal experience/preference of the physician and local routine.

Management was considered to be guideline adherent if patients had (i) no stroke risk factors or bleeding risk factors and received antiplatelet therapy or no antithrombotic treatment, (ii) $\geq 1$ stroke risk factor and no bleeding risk factors and received OAC or (iii) $\geq 1$ bleeding risk factor and received antiplatelet therapy or no antithrombotic treatment. Patients were overtreated if they had (i) no stroke risk factors and received $\mathrm{OAC}$ and (ii) $\geq 1$ bleeding risk factor and received OAC. Patients were undertreated if they had $\geq 1$ stroke risk factor and no bleeding risk factors but received no OAC.

We also classified patients according to a recently published risk stratification scheme: the $\mathrm{CHADS}_{2}$ score $^{5}$ [an acronym for congestive heart failure, hypertension, age $\geq 75$, diabetes mellitus and prior stroke or transient ischaemic attack (TIA)], a cumulative point score system in which patients with nonvalvular AF were assigned 
one point for presence of congestive heart failure, (history of) hypertension, age $\geq 75$ years, diabetes mellitus and two points for prior stroke or TIA.

\section{Data management, statistical analysis and ethical considerations}

Data checks were performed to find missing data and out-of-range values. Data analyses were performed with SPSS statistical software (SPSS Inc., Chicago, IL, USA release 12.01). Continuous variables are reported as mean \pm standard deviation or median $\left(25^{\text {th }}-75^{\text {th }}\right.$ percentile $)$ and categorical variables as percentages. Differences between the three physician groups for continuous variables were tested with ANOVA or Kruskal-Wallis, and for categorical variables with $\chi^{2}$ statistics.

In multivariable logistic regression the following variables were tested for association with OAC prescription: age, gender, mitral stenosis, stroke or TIA, other thromboembolism, (history of) hypertension, hearty failure, coronary artery disease, diabetes, peripheral vascular disease, presence of at least one bleeding risk factor and physician specialty. Variables were removed stepwise from the model when the $\mathrm{P}$-value exceeded 0.10 . Variables with $\mathrm{P}$-value $<0.05$ in the final model were considered to be significant contributors and were kept in the model. Hereafter, this models were validated by means of bootstrapping, which was performed with 100 samples for each reported model. Effects that were instable when bootstrapping, were stepwise left out of the model, which eventually resulted in the final model containing only stable significant effects, and this final models are reported. For each variable in this model the net odds ratio and its $95 \%$ confidence interval, backward elimination $\log$ likelihood ratio $\chi^{2}(-2 \mathrm{LL})$, degrees of freedom $(\mathrm{df})$ and $\mathrm{P}$-value are reported. In addition, predictive accuracy of each model is reported as the area under the ROC curve.

\section{RESULTS}

\section{Physician characteristics}

Eighty-six GPs, 93 internists and 99 cardiologists enrolled 1596 patients (365, 351 and 880 respectively). When comparing participating physicians with their non-participating colleagues in the Netherlands, participators were less often female (GPs $12 \%$ vs. $21 \%$; internists $10 \%$ vs. $21 \%$; cardiologists $5 \%$ vs. $13 \%$ ) and less often situated in the Northeast region (GPs $16 \%$ vs. $32 \%$; internists $25 \%$ vs. $32 \%$ and cardiologists $21 \%$ vs. $34 \%$ ). GPs had a solo practice in $54 \%$ of cases, and $11 \%$ of internists and $12 \%$ of cardiologists were practicing in a university hospital.

Cardiologists reported to encounter most frequently AF patients; $61 \%$ of cardiologists were consulted by over $20 \mathrm{AF}$ patients per month, whereas these proportions were $0 \%$ of GPs and $8 \%$ of internists $(\mathrm{P}<0.001)$. Most GPs $(94 \%)$ and internists (70\%) reported to see not more than $10 \mathrm{AF}$ patients per month. 


\section{Patient characteristics}

Cardiologist patients were younger, were less often female, had less hypertension or heart failure (Table 2). As much as $15 \%$ of all patients suffered from a previous stroke or TIA. Internists' patients had most often co-morbidities. Still, the distribution of $\mathrm{CHADS}_{2}$ stroke risk categories was reasonably comparable among patients in the three physician groups, although cardiologists' patients were slightly less often categorised in the highest risk groups (Figure 1A). Importantly, the prevalence of contraindications for OAC increases with a worsening risk profile according to the $\mathrm{CHADS}_{2}$ score (Figure 1B).

Atrial fibrillation was rarely the primary reason for the current consultation with GPs and internists, whereas this was the case in $66 \%$ of cardiologist patients (Table 3). The majority $(74 \%)$ was diagnosed for the first time by a cardiologist $(\mathrm{P}<0.001)$. Moreover, a cardiologist was indicated to be the main treating physician for AF in $82 \%$ of all patients.

\section{Antithrombotic treatment}

Current antithrombotic treatment was initiated by a cardiologist in $80 \%$ of all patients, also among GPs' (74\%) and internists' (64\%) patients. Compared with GPs and internists, cardiologists prescribed more often OAC (84\% vs. $76 \%$ and $70 \%$ respectively; $\mathrm{P}<0.001)$, and less often antiplatelet drugs ( $12 \%$ vs. $20 \%$ and $18 \%$ respectively; $\mathrm{P}<0.001$ ), making that proportions not receiving any antithrombotic drug were comparable among groups ( $7 \%$ vs. $10 \%$ and $8 \%$ respectively; $\mathrm{P}=0.084$ ).

In only $14 \%$ of patients currently on antithrombotic drugs, prescription was changed in the past, and $4 \%$ of patients not currently on antithrombotic drugs did receive an antithrombotic drug in the past.

In ACC/AHA/ESC high-risk patients without a bleeding risk factor, GPs initiated OAC in $61 \%(n=133)$, cardiologists in $86 \%(n=1088)$ and internists in $46 \%$ $(\mathrm{n}=91)$ of patients. In patients considered at low risk for stroke, GPs prescribed OAC in $39 \%(\mathrm{n}=28)$, cardiologists in $75 \%(\mathrm{n}=205)$ and internists in $75 \%(\mathrm{n}=8)$ (Figure 2).

\section{Guideline adherence}

The current treating physician did not alter antithrombotic treatment in $86 \%$ of patients. Guideline adherence was hence analysed according to initiating physician. Guideline adherence was best in cardiologists compared with GPs and internists (70\% vs. $58 \%$ and $55 \%$ respectively; $\mathrm{P}<0.001$ ). Overtreatment of patients was also frequent $(\mathrm{n}=177,11 \%)$, predominantly by cardiologists and internists $(19 \%$ and $17 \%$ vs. $9 \% ; \mathrm{P}=0.010)$. Of these, $109(65 \%)$ were at high risk for stroke and had (at least one) bleeding risk factor but did receive OAC. Moreover, seven low risk patients with (at least one) bleeding risk factor were overtreated. Undertreatment is 


\begin{tabular}{|c|c|c|c|c|}
\hline & $\begin{array}{l}\text { General Physician } \\
\quad(\mathrm{N}=365)\end{array}$ & $\begin{array}{l}\text { Internist } \\
(\mathrm{N}=352)\end{array}$ & $\begin{array}{l}\text { Cardiologist } \\
(\mathrm{N}=880)\end{array}$ & P-value \\
\hline \multicolumn{5}{|l|}{ Demographics } \\
\hline Age, years & $73 \pm 11$ & $74 \pm 10$ & $71 \pm 10$ & $<0.001$ \\
\hline Female & 46 & 50 & 39 & 0.001 \\
\hline Body mass index, $\mathrm{kg} / \mathrm{m}^{2}$ & $27 \pm 5$ & $27 \pm 5$ & $27 \pm 5$ & 0.059 \\
\hline \multicolumn{5}{|l|}{ Cardiovascular disease } \\
\hline Valvular heart disease & 17 & 22 & 28 & $<0.001$ \\
\hline Mitral stenosis & 4 & 2 & 3 & 0.194 \\
\hline Hypertension & 57 & 56 & 47 & 0.001 \\
\hline Heart failure & 26 & 24 & 21 & 0.247 \\
\hline Coronary artery disease & 26 & 29 & 29 & 0.553 \\
\hline Peripheral vascular disease & 10 & 16 & 7 & $<0.001$ \\
\hline Stroke or TIA & 16 & 17 & 15 & 0.731 \\
\hline Ischemic stroke & 9 & 7 & 8 & 0.768 \\
\hline Hemorrhagic stroke & 1 & 1 & 1 & 0.723 \\
\hline TIA & 9 & 10 & 8 & 0.585 \\
\hline \multicolumn{5}{|l|}{ Other pathology } \\
\hline Diabetes & 20 & 41 & 13 & $<0.001$ \\
\hline Venous thromboembolism & 5 & 4 & 2 & 0.015 \\
\hline Thyroid disease & 8 & 20 & 7 & $<0.001$ \\
\hline \multicolumn{5}{|l|}{ Contraindications for OAC } \\
\hline Active malignancy & 5.2 & 8.0 & 1.9 & $<0.001$ \\
\hline Severe hepatic failure & 0.3 & 0.6 & 0.5 & 0.831 \\
\hline Esophagusvarices & 0.0 & 0.1 & 0.1 & 0.554 \\
\hline Severe renal failure & 1.4 & 12.5 & 3.1 & $<0.001$ \\
\hline $\begin{array}{l}\text { Organic dysfunction with increased } \\
\text { bleeding risk }\end{array}$ & 0.5 & 4.0 & 1.5 & 0.001 \\
\hline $\begin{array}{l}\text { Biological impairment with increased } \\
\text { bleeding risk }\end{array}$ & 0.8 & 2.0 & 0.5 & 0.033 \\
\hline Dementia & 1.1 & 1.4 & 0.1 & 0.014 \\
\hline Any contraindication for OAC & 8.5 & 25.6 & 6.4 & $<0.001$ \\
\hline
\end{tabular}

common among GPs and internists compared with cardiologists (33\% and $28 \%$ vs. $11 \%$ respectively; $\mathrm{P}<0.001)$.

We performed a multivariable analysis on which factors are associated with OAC prescription. There was a significant interaction between physician specialty and prior stroke/TIA. Therefore, we stratified the analysis for these two factors. Cardiologists were more likely to prescribe OAC compared with GPs and internists, which was even more pronounced in patients with prior stroke or TIA (Table 4). Inversely, only in cardiologists' patients, previous stroke/TIA had a positive influ- 


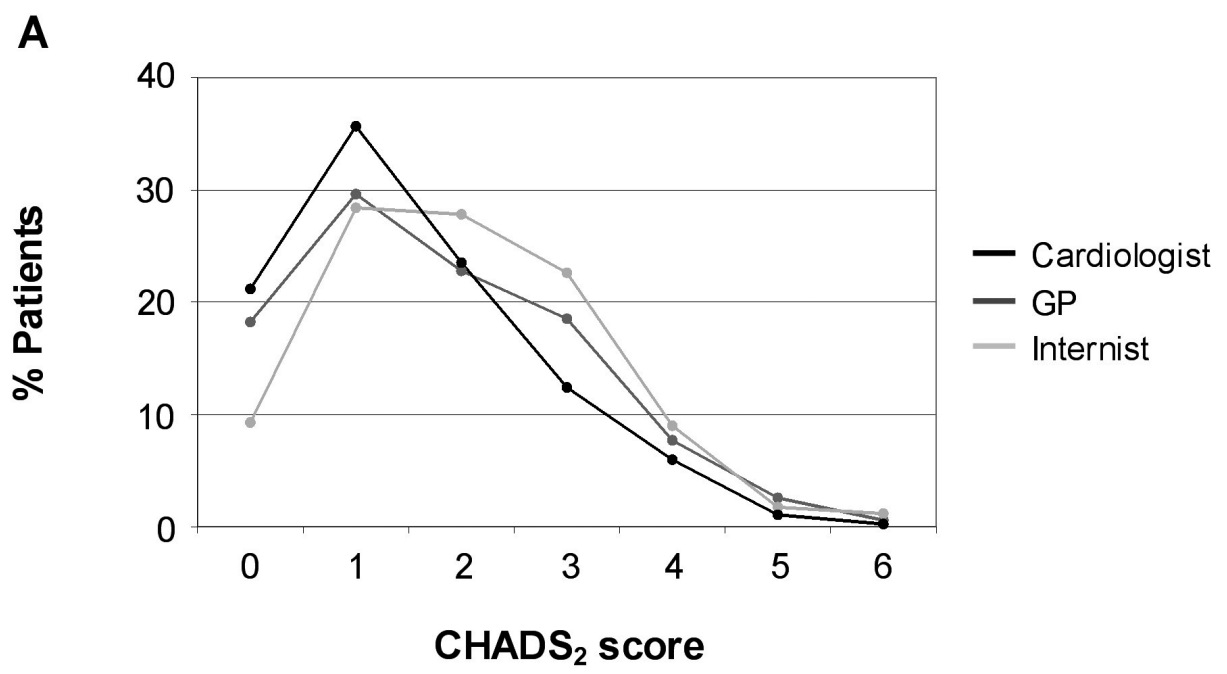

Figure 1A. Distribution of $\mathrm{CHADS}_{2}$ stroke risk categories in general practitioner, internist and cardiologist patients with non-valvular AF and no contraindications for OAC.

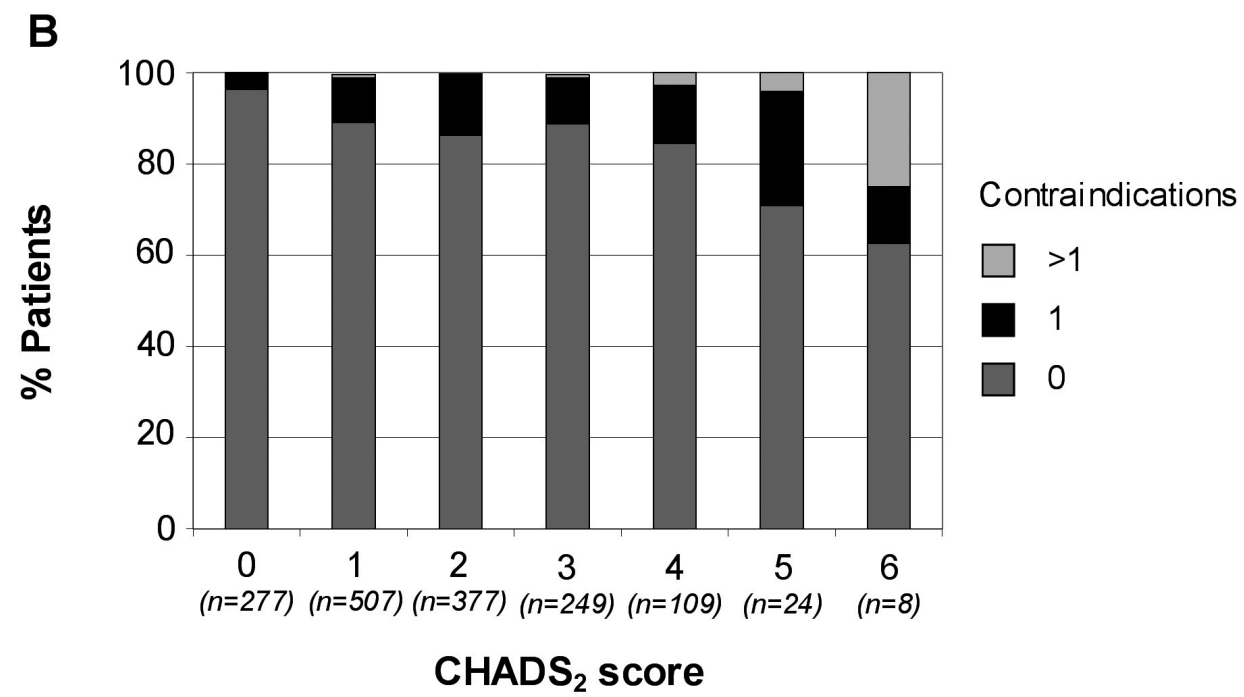

Figure 1B. Relation between $\mathrm{CHADS}_{2}$ stroke risk score and number of contraindications for OAC in non-valvular AF. 
Table 3. Consultation and atrial fibrillation specific information

\begin{tabular}{|c|c|c|c|c|}
\hline & General Physician & Internist & Cardiologist & P-value \\
\hline \multicolumn{5}{|l|}{ Consult } \\
\hline AF primary reason consult & 10 & 8 & 66 & $<0.001$ \\
\hline Systolic blood pressure & $143 \pm 19$ & $141 \pm 22$ & $139 \pm 21$ & 0.039 \\
\hline Diastolic blood pressure & $81 \pm 11$ & $78 \pm 12$ & $80 \pm 11$ & 0.332 \\
\hline \multicolumn{5}{|l|}{ AF diagnosis } \\
\hline Time since $1^{\text {st }}$ diagnosis $\mathrm{AF}$, years & $4(2-8)$ & $4(2-10)$ & $4(2-8)$ & 0.238 \\
\hline \multicolumn{5}{|l|}{ AF $1^{\text {st }}$ diagnosed by: } \\
\hline Cardiologist & 39 & 58 & 84 & $<0.001$ \\
\hline Other & 61 & 42 & 16 & $<0.001$ \\
\hline \multicolumn{5}{|l|}{ AF treatment } \\
\hline \multicolumn{5}{|l|}{ Main treating physician $\mathrm{AF}$} \\
\hline Cardiologist & 65 & 57 & 99 & $<0.001$ \\
\hline Other & 35 & 43 & 1 & $<0.001$ \\
\hline Previous cardioversion & 51 & 35 & 62 & $<0.001$ \\
\hline Pharmacological & 25 & 20 & 25 & 0.003 \\
\hline Electrical & 35 & 23 & 53 & $<0.001$ \\
\hline \multicolumn{5}{|l|}{ Echocardiogram } \\
\hline Echocardiogram performed & 41 & 54 & 93 & $<0.001$ \\
\hline Time since last echocardiogram, days & $\begin{array}{c}652 \\
(260-1420)\end{array}$ & $\begin{array}{c}592 \\
(209-1192)\end{array}$ & $\begin{array}{c}378 \\
(118-863)\end{array}$ & $<0.001$ \\
\hline Left atrial diameter, $\mathrm{mm}$ & $45 \pm 8$ & $48 \pm 11$ & $47 \pm 10$ & 0.862 \\
\hline Left ventricular ejection fraction, $\%$ & $56 \pm 14$ & $54 \pm 17$ & $55 \pm 14$ & 0.614 \\
\hline
\end{tabular}

ence on OAC prescription. Furthermore, among all patients, having at least one contraindication was a strong factor to withhold $\mathrm{OAC}$ and heart failure triggered OAC prescription.

\section{Rationale for withholding or stopping antithrombotic treatment}

Sixty patients did not use antithrombotic treatment while this was stopped in the past; in 49 patients OAC was stopped and in 11 patients antiplatelet drugs were stopped. Of these patients, $62 \%$ was stopped by cardiologist, $23 \%$ by an internist, $8 \%$ by a GP and $7 \%$ by another physician. Most frequent reasons for stopping any antithrombotic treatment were previous bleeding (27\%), presumed low risk of thromboembolism (25\%) and presumed high bleeding risk (20\%). Most frequent reasons for no current or previous antithrombotic treatment $(n=65)$ were presumed low risk of thromboembolism (42\%), older age (12\%), frequent falling (11\%) and local routine $(7 \%)$. 
A

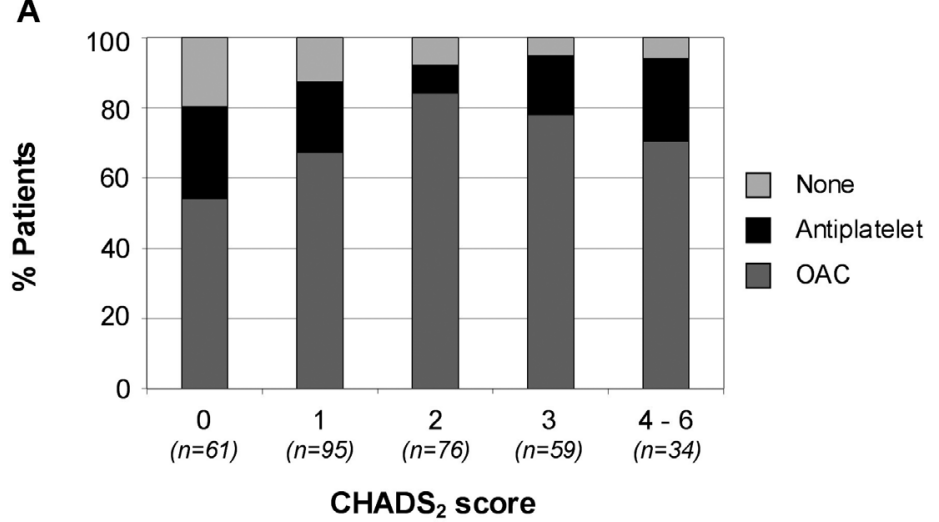

Figure 2A. Antithrombotic treatment per $\mathrm{CHADS}_{2}$ stroke risk category among general practitioner patients with non-valvular atrial fibrillation $(\mathrm{AF})$ and without contraindications for $\mathrm{OAC}$.

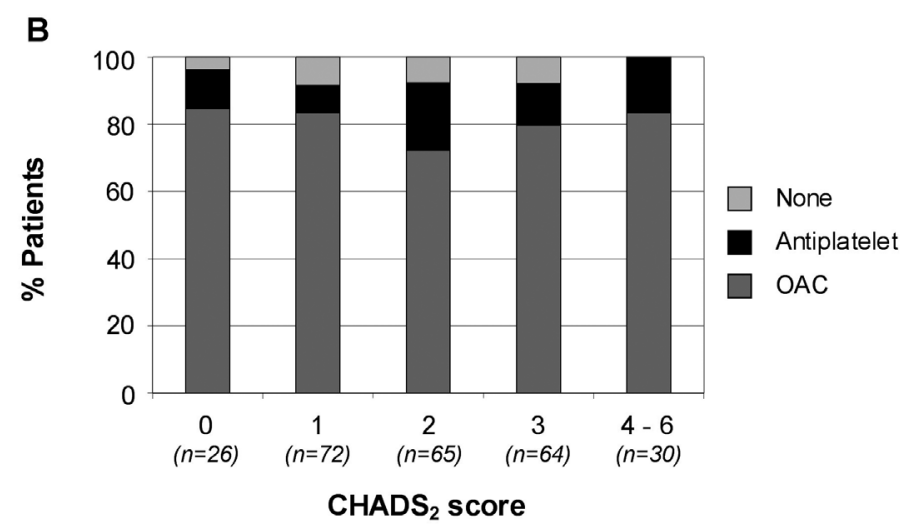

Figure 2B. Antithrombotic treatment per $\mathrm{CHADS}_{2}$ stroke risk category among internist patients with non-valvular AF and without contraindications for OAC.

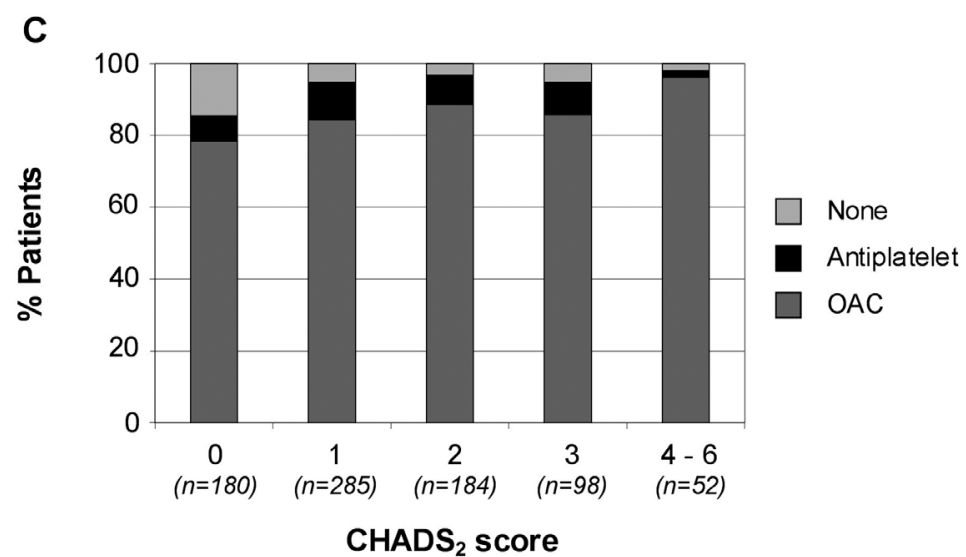

Figure 2C. Antithrombotic treatment per $\mathrm{CHADS}_{2}$ stroke risk category among cardiologist patients with non-valvular AF and without contraindications for OAC. 
Table 4. Multivariable analysis on oral anticoagulation use (physician prescribing current treatment)

\begin{tabular}{|c|c|c|c|c|c|}
\hline & Odds ratio & $95 \% \mathrm{CI}$ & $-2 \mathrm{LL}$ & df & P-value \\
\hline \multicolumn{6}{|l|}{ No stroke/TIA } \\
\hline Specialism (ref. group $=$ Cardiologist $)$ & & & 65 & 2 & $<0.001$ \\
\hline General physician & 0.29 & $0.20-0.42$ & & & \\
\hline Internist & 0.24 & $0.15-0.39$ & & & \\
\hline \multicolumn{6}{|l|}{ Stroke/TIA } \\
\hline Specialism (ref. group $=$ Cardiologist) & & & 39 & 2 & $<0.001$ \\
\hline General physician & 0.08 & $0.03-0.22$ & & & \\
\hline Internist & 0.07 & $0.02-0.21$ & & & \\
\hline \multicolumn{6}{|l|}{ Cardiologist } \\
\hline Stroke/TIA & 2.31 & $1.33-4.02$ & 11 & 1 & 0.001 \\
\hline \multicolumn{6}{|l|}{ General physician } \\
\hline Stroke/TIA & NS & & & & \\
\hline \multicolumn{6}{|l|}{ Internist } \\
\hline Stroke/TIA & NS & & & & \\
\hline \multicolumn{6}{|l|}{ All patients } \\
\hline Contraindication & 0.46 & $0.32-0.68$ & 15 & 1 & $<0.001$ \\
\hline Heart failure & 1.72 & $1.23-2.42$ & 11 & 1 & 0.001 \\
\hline
\end{tabular}

Area under the ROC curve $=0.6897$. Variables tested: age $>75$ years, gender, mitral stenosis, hypertension, heart failure, coronary artery disease, diabetes, non-cardiac vascular surgery, peripheral vascular disease, systolic blood pressure, prior stroke/TIA, other prior thromboembolism, physician prescribing current antithrombotic treatment, and presence of at least 1 contraindication. OR, odds ratio; $\mathrm{Cl}$, confidence interval; -2LL, log likelihood ratio $\chi^{2}$; df, degrees of freedom.

In 25 high-risk patients, OAC was stopped ( $75 \%$ by a cardiologist) and most frequent reasons are frequent falling $(28 \%)$, presumed low compliance $(20 \%)$ and presumed low risk $(14 \%)$.

\section{DISCUSSION}

The EXAMINE-AF study is the first to compare antithrombotic treatment prescription between GPs, internists and cardiologists in The Netherlands. The results show a relatively high rate of appropriate antithrombotic treatment of AF patients $(67-72 \%)$; both in the overall group and in all three physician groups. Cardiologists mainly handle AF diagnosis, and consequently antithrombotic treatment, although also GP's and internists treat their patients fairly well. Cardiologists have the greatest influence on antithrombotic treatment prescription, as most patients have been previously seen by a cardiologist. GPs and internists tend to follow the suggested antithrombotic treatment by the cardiologist and are inclined not to alter this. That more cardiologists consider antithrombotic treatment in AF patients compared with non-cardiologists is also shown in a survey in the UK in $1994 .^{6}$ 
Underutilisation of OAC in patients with $\mathrm{AF}$ is common; $\mathrm{OAC}$ was prescribed in only $22-62 \%$ of eligible patients, whereas $22-42 \%$ received no antithrombotic treatment. ${ }^{7-13}$ Nevertheless, overall OAC use in the past decades has increased importantly from $3 \%$ to $20 \%$ in the 1980 s to $58 \%$ in $2001 .{ }^{14,15}$ As expected, after the publication of the ACC/AHA/ESC guidelines on management of AF, a further increase of OAC use has been reported, but still $45 \%$ of high-risk patients were not receiving $\mathrm{OAC}^{16}$ and $50 \%$ of low risk patients were overtreated. ${ }^{17}$

In our study, the relatively high number of appropriately treated patients might be explained by a number of reasons. First, increase in OAC use might partly be attributed to the establishment of anticoagulation clinics, using a computerised decision program which ensures better international normalised ratio (INR) control than the experienced medical staff. This accounts for more effective INR values (in terms of time-in-therapeutic range) ${ }^{18-20}$ and in less thromboembolism (hazard ratio, 0.61) and bleeding (hazard ratio, 0.73). ${ }^{21}$ In the Netherlands, these so-called Thrombosis Services have actually completely taken over the facilitation of INR assessment and concomitant OAC dosing.

Secondly, this survey was performed in 2004 and 2005, several years after the publication of the current guidelines. Intense education programmes, consequent debate with peer physicians and ever increasing evidence on antithrombotic treatment, even publications of large trials that did not have prevention of stroke as their primary research goal ${ }^{22,23}$, have raised awareness on the importance of individualising antithrombotic treatment.

Thirdly, compared with literature, our results show a lower incidence of contraindications (38-44\% vs. $11 \%)^{7,9}$ The explanation for this low number of contraindications might be that this survey consisted of (mostly stable) patients attending the outpatient clinic. Strikingly, the prevalence of contraindications for OAC increases with a worsening risk profile (according to the $\mathrm{CHADS}_{2}$ score), which means that stroke risk factors and bleeding risk factors go hand in hand; with increasing risk profile, patients have more co-morbidity (that might be contraindications). In other words, patients who have a low risk and are eligible for aspirin treatment, have also few contraindications, and therefore have a low bleeding rate, even under OAC treatment. Our belief is that physicians are intuitively aware of this, and thus tend to treat their whole population with OAC, creating 'overtreatment' of the low risk patients, without increasing bleeding risk. Patients have a limited knowledge of $\mathrm{AF}$, the risks and the benefit of antithrombotic treatment. $^{24}$ They actually prefer OAC over aspirin, mostly out of fear of thromboembolism. ${ }^{25}$ Education on this topic may help to further increase patient compliance to antithrombotic treatment. ${ }^{26}$

The lack of guidelines for internists probably contributes to the fact that internists' patients are less appropriately treated. To our understanding, interdisciplinary guidelines on prevention of thromboembolism (with a chapter especially dedicated to AF patients) for internists are expected to be published next year in the Nether- 
lands. Hopefully, this will raise awareness among internists to also consider antithrombotic treatment in their AF patient population. Worth mentioning is that still $20 \%(n=73)$ of GPs' patients are younger than 60 years, and $4 \%$ of these patients have a GP as the main treating physician, but the current guidelines of the Dutch College of General Practitioners do not mention young patients.

\section{Clinical implications}

Our suggestion is, since one of five AF patients seen in the GP practice is younger than 60 years, this patient group must be taken into account in next GPs' guideline on the management of AF. Furthermore, discrepancies between GPs' guidelines and guidelines for cardiologists should be resolved; the GPs' guidelines might add a comment that combining antiplatelet drugs with $\mathrm{OAC}$ in high risk patients with diabetes or coronary artery disease might be appropriate. Patients with AF should at least be seen by cardiologist once to ensure adequate antithrombotic treatment to prevent thromboembolic complications. In this setting, intense educational programmes might be needed to improve the physicians' awareness that advanced age is not a contraindication for $\mathrm{OAC},{ }^{27}$ and novel disease management systems may improve appropriate AF management.

\section{REFERENCES}

1 Heeringa J, van der Kuip DA, Hofman, A Kors JA, van Herpen G, Stricker BH, Stijnen T, Lip GY, Witteman JC. Prevalence, incidence and lifetime risk of atrial fibrillation: the Rotterdam study. Eur Heart J 2006;27:949-53.

2 Brodsky M, Saini R, Bellinger R, Zoble R, Weiss R, Powers L. Comparative effects of the combination of digoxin and dl-sotalol therapy vs. digoxin monotherapy for control of ventricular response in chronic atrial fibrillation. dl-Sotalol Atrial Fibrillation Study Group. Am Heart J 1994;127:572-7.

3 Van Lieshout J, Boode BS, Assendelft WJ. Summary of the practice guideline 'atrial fibrillation' from the Dutch college of general practitioners. Ned Tijdschr Geneeskd 2004;148:1435-9.

4 Fuster V, Ryden LE, Asinger RW, Cannom DS, Crijns HJ, Frye RL, Halperin JL, Kay GN, Klein WW, Lévy S, McNamara RL, Prystowsky EN, Wann LS, Wyse DG, Gibbons RJ, Antman EM, Alpert JS, Faxon DP, Fuster V, Gregoratos G, Hiratzka LF, Jacobs AK, Russell RO, Smith SC, Klein WW, Alonso-Garcia A, BlomstrÖm-Lundqvist C, De Backer G, Flather M, Hradec J, Oto A, Parkhomenko A, Silber S, Torbicki A. ACC/AHA/ESC guidelines for the management of patients with atrial fibrillation: executive summary. A report of the American College of Cardiology/American Heart Association Task Force on Practice Guidelines and the European Society of Cardiology Committee for Practice Guidelines and Policy Conferences (committee to develop guidelines for the management of patients with atrial fibrillation): developed in collaboration with the North American Society of Pacing and Electrophysiology. J Am Coll Cardiol 2001;38:1231-66.

5 Le Heuzey J, Boutjdir M, Gagey S, Lavergne T, Guize L. Cellular aspects of atrial vulnerability. In: Attuel P, Olsson SB, Schlepper M, eds. The Atrium in Health and Disease. Mount Kisco, NY: Futura Publishing, 1989:81-94.

6 Lip GY, Zarifis J, Watson RD, Beevers DG. Physician variation in the management of patients with atrial fibrillation. Heart 1996;75:200-5. 
7 Albers GW, Yim JM, Belew KM Bittar N, Hattemer CR, Philips BG, Kemp S, Hall EA, Morton DJ, Vlasses PH. Status of antithrombotic therapy for patients with atrial fibrillation in university hospitals. Arch Intern Med 1996;156:2311-6.

8 Birman-Deych E, Radford MJ, Nilasena DS, Gage BF. Use and effectiveness of warfarin in Medicare beneficiaries with atrial fibrillation. Stroke 2006;37:1070-4.

9 Brass LM, Krumholz HM, Scinto JD, Mathur D, Radford M. Warfarin use following ischemic stroke among Medicare patients with atrial fibrillation. Arch Intern Med 1998;158:2093-100.

10 Go AS, Hylek EM, Borowsky LH, Phillips KA, Selby JV, Singer DE. Warfarin use among ambulatory patients with nonvalvular atrial fibrillation: the anticoagulation and risk factors in atrial fibrillation (ATRIA) study. Ann Intern Med 1999;131:927-34.

11 Lip GY, Golding DJ, Nazir M, Beevers DG, Child DL, Fletcher RI. A survey of atrial fibrillation in general practice: the West Birmingham Atrial Fibrillation Project. Br J Gen Pract 1997;47:285-9.

12 Munschauer FE, Priore RL, Hens M, Castilone A. Thromboembolism prophylaxis in chronic atrial fibrillation. Practice patterns in community and tertiary-care hospitals. Stroke 1997;28:72-6.

13 Ruigomez A, Johansson S, Wallander MA, Rodriguez LA. Incidence of chronic atrial fibrillation in general practice and its treatment pattern. J Clin Epidemiol 2002;55:358-63.

14 Stafford PJ, Turner I, Vincent R. Quantitative analysis of signalaveraged P waves in idiopathic paroxysmal atrial fibrillation. Am J Cardiol 1991;68:751-5.

15 Friberg J, Gislason GH, Gadsboll N, Rasmussen JN, Rasmussen S, Abildstrom SZ, Kober L, Madsen M, Torp-Pedersen C. Temporal trends in the prescription of vitamin $\mathrm{K}$ antagonists in patients with atrial fibrillation. J Intern Med 2006;259:173-8.

16 Waldo AL, Becker RC, Tapson VF, Colgan KJ. Hospitalized patients with atrial fibrillation and a high risk of stroke are not being provided with adequate anticoagulation. J Am Coll Cardiol 2005;46:1729-36.

17 Nieuwlaat R, Capucci A, Camm AJ, Olsson SB, Andresen D, Davies DW, Cobbe S, Breithardt G, Le Heuzey JY, Prins MH, Lévy S, Crijns HJ. Atrial fibrillation management: a prospective survey in ESC member countries: the Euro Heart Survey on Atrial Fibrillation. Eur Heart J 2005;26:2422-34.

18 Pengo V, Pegoraro C, Cucchini U, Iliceto S. Worldwide management of oral anticoagulant therapy: the ISAM Study. J Thromb Thrombolysis 2006;21:73-7.

19 Poller L, Shiach CR, MacCallum PK, Johansen AM, Münster AM, Magalhaes A, Jespersen J. Multicentre randomised study of computerised anticoagulant dosage. European concerted action on anticoagulation. Lancet 1998;352:1505-9.

20 Witt DM, Sadler MA, Shanahan RL, Mazzoli G, Tillman DJ. Effect of a centralized clinical pharmacy anticoagulation service on the outcomes of anticoagulation therapy. Chest 2005;127:1515-22.

21 Chiquette E, Amato MG, Bussey HI. Comparison of an anticoagulation clinic with usual medical care: anticoagulation control, patient outcomes, and health care costs. Arch Intern Med 1998;158:1641-7.

22 Van Gelder IC, Hagens VE, Bosker HA, Kingma JH, Kamp O, Kingma T, Said SA, Darmanata JI, Timmermans AJ, Tijssen JG, Crijns HJ. A comparison of rate control and rhythm control in patients with recurrent persistent atrial fibrillation. N Engl J Med 2002;347:1834-40.

23 Wyse DG, Waldo AL, DiMarco JP, Domanski MJ, Rosenberg Y, Schron EB, Kellen JC, Greene HL, Mickel MC, Dalquist JE, Corley SD. A comparison of rate control and rhythm control in patients with atrial fibrillation. N Engl J Med 2002;347:1825-33.

24 Lip GY, Kamath S, Jafri M, Mohammed A, Bareford D. Ethnic differences in patient perceptions of atrial fibrillation and anticoagulation therapy: the West Birmingham Atrial Fibrillation Project. Stroke 2002;33:238-42. 
25 Singer DE, Albers GW, Dalen JE, Go AS, Halperin JL, Manning WJ. Antithrombotic therapy in atrial fibrillation: the Seventh ACCP Conference on Antithrombotic and Thrombolytic Therapy. Chest 2004;126 (Suppl. 3):429S-56S.

26 Lane DA, Ponsford J, Shelley A, Sirpal A, Lip GY. Patient knowledge and perceptions of atrial fibrillation and anticoagulant therapy: effects of an educational intervention programme. The West Birmingham Atrial Fibrillation Project. Int J Cardiol 2006;110:354-8.

27 Fang MC, Chang Y, Hylek EM, Rosand J, Greenberg SM, Go AS, Singer DE. Advanced age, anticoagulation intensity, and risk for intracranial hemorrhage among patients taking warfarin for atrial fibrillation. Ann Intern Med 2004;141:745-52. 


\section{EDITORIAL}

Stroke risk stratification in atrial fibrillation: something to EXAMINE more closely

Timothy Watson, Puneet Kakar, Gregory Y.H. Lip

Int J Clin Pract. 2007;61(1):6-9

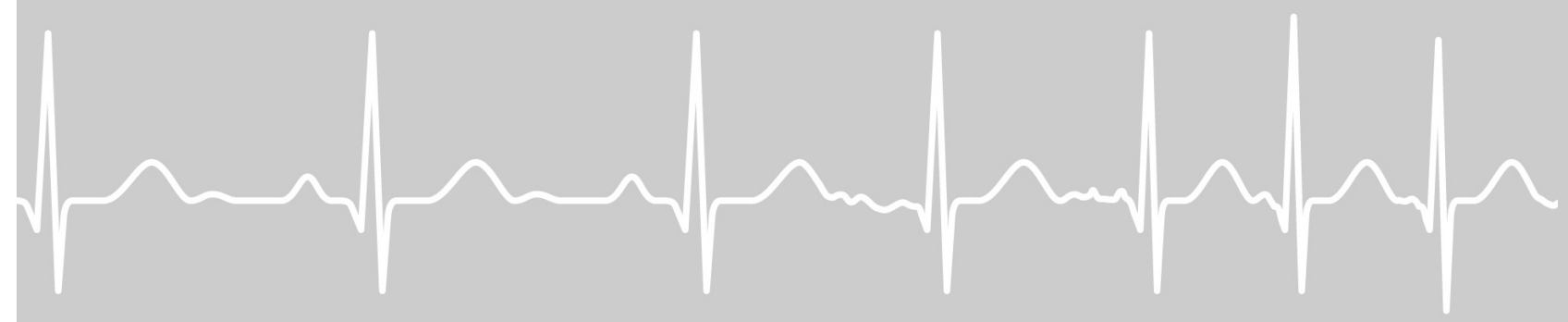


Atrial fibrillation (AF) is the most common sustained cardiac arrhythmia and management of this condition and its complications now consumes a significant slice of healthcare expenditure, particularly in Western countries where the populations continue to advance in age. ${ }^{1,2}$ The recent publication of evidence-based guidelines from the UK National Institute of Health and Clinical Excellence (NICE) and consensus-based guidelines from the American College of Cardiology/American Heart Association/European Society of Cardiology (ACC/AHA/ESC) has underlined the transition in physicians' attitudes/perspectives towards the management of $\mathrm{AF}^{3,4}$ The condition is now in the 'super league' of cardiovascular disorders and as such, needs to be managed accordingly.

Atrial fibrillation is an independent predictor of mortality, and contributes to both substantial ill health, usually as a consequence of stroke, thromboembolism or heart failure. ${ }^{5-8}$ Indeed, of greatest concern is that patients with AF who go on to have a stroke have a much worse outcome with higher mortality and morbidity, greater disability, longer hospital stays and lower rates of discharge to their own home. ${ }^{9-11}$ The strength of the association between AF and stroke is not a recent observation. In fact, for many years it has been a routine practice to offer patients with AF either antiplatelet therapy (usually with aspirin) or anticoagulation (usually with the vitamin $\mathrm{K}$ antagonist, warfarin). The risk of stroke in AF is not homogeneous, and 'high-risk' groups of patients to be targeted for these therapies is increasingly well defined.

The evidence in favour of anticoagulation in AF is robust and is supported by strong evidence from clinical trials. In a meta-analysis of 13 trials of thromboprophylaxis in AF, adjusted-dose warfarin significantly reduced the risk of ischaemic stroke or systemic embolism compared with placebo [relative risk: 0.33; 95\% confidence interval (CI): 0.24-0.45]. ${ }^{12}$ This finding holds true for both primary and secondary prevention, although perhaps unsurprisingly, the absolute risk reduction for all stroke was far greater for secondary stroke prevention (NNT [numbers needed to treat] 12) when compared with primary prevention (NNT 37). ${ }^{12}$ Even aspirin has some evidence albeit less convincing with meta-analysis of the six main randomised trials of aspirin vs. placebo showing that aspirin significantly reduces the risk of stroke by $22 \%$ (95\% CI: $2-38$ ) in $\mathrm{AF}^{8}$

Despite overwhelming evidence in favour of anticoagulation therapy for AF, warfarin is consistently under prescribed in $\mathrm{AF}^{13}$ This pattern occurs consistently across all patient groups, but perhaps most worryingly it is often those at highest risk of stroke, who, continue without adequate stroke protection, usually because these patients are also deemed at high risk of bleeding events. ${ }^{6,14,15}$ Typically the main concern is of significant haemorrhage, but lifestyle restrictions (e.g. alcohol), patient preference, the need for regular therapeutic monitoring and compliance may also be cited as reasons to avoid warfarin. ${ }^{16-19}$ Of primary concern however, is that physicians tend to be rather poor at estimating both the risk of bleeding and 
stroke, ${ }^{20}$ Furthermore, many physicians have erroneously assumed the risk of haemorrhage to be greater than the risk of thromboembolism. ${ }^{21}$

Of further interest is the psychological effect of major bleeding on physician prescribing. Choudhry et $\mathrm{al}^{22}$ recently demonstrated that for those physicians whose patients have had an episode of major bleeding, subsequent patients seen within the next 90 days are less likely to be offered anticoagulation. A striking observation, but one which probably reflects prescribing patterns in other potentially harmful treatments such as thrombolysis. ${ }^{23}$ However, this study at least provides some reassurance in that long-term prescribing patterns appear to remain unchanged. This data only serves to add further amplitude to the calls for a reliable means of identifying those patients at greatest risk of stroke and bleeding events.

\section{Risk stratification for stroke in AF}

A number of risk stratification schema are readily available. ${ }^{13}$ These vary markedly in terms of complexity and accuracy. Most have been derived from pooled analyses of the antithrombotic treatment trials from which various clinical predictors have been identified. These form the basis of the schema, but importantly, none of the risk factors are mutually exclusive and should be regarded as additive, thereby producing a composite risk. Of potential comorbidities that have been examined, age, hypertension, diabetes, congestive cardiac failure, diabetes mellitus and prior stroke appear to be the most predictive and need to be actively sought.

In the recent Congestive heart failure, Hypertension, Age $\geq 75$, Diabetes, prior Stroke or transient ischaemic attack $\left(\mathrm{CHADS}_{2}\right)$ risk stratification scheme, a numerical score is awarded for each risk factor. ${ }^{24}$ The total score $(\leq 6)$ equates to a recognised risk of future stroke and allows the classification into high (score $\geq 3$ ), moderate (score 1-2) or low-risk (score 0) categories. One major pitfall of this particular schema (and many others) is that a patient with AF and no other risk factors except for a prior transient ischaemic attack (TIA), would only have a $\mathrm{CHADS}_{2}$ score of two, but most would agree that such a patient should automatically be offered anticoagulation if no contraindication is apparent. This scheme should perhaps be called $\mathrm{CHADS}_{3}$ - with three points for stroke/TIA - rather than $\mathrm{CHADS}_{2}$.

Nevertheless, adoption of risk stratification schema has proved of paramount clinical relevance and represented by a marked rise in anticoagulation rates of AF patients, with figures of $3-20 \%$ in the 1980 s, surging to $58 \%$ in $2001,{ }^{14,25}$ despite some ambiguity in the $2001 \mathrm{ACC} / \mathrm{AHA} / \mathrm{ESC}$ guidelines for AF management. ${ }^{26}$ This lack of clarity being further emphasised by the Euro Heart Survey which found only a limited number of stroke risk factors were likely to trigger appropriate anticoagulation prescription. ${ }^{27}$ Undoubtedly with the greater simplicity provided by recent NICE guidelines and revised 2006 ESC guidelines, will help to strengthen appropriate anticoagulation therapy prescription. ${ }^{3,4}$ 


\section{Bleeding risk stratification}

Of course, to offer anticoagulation to all patients at intermediate or high risk would be foolhardy, but sadly, despite marked improvements in stroke risk stratification, bleeding risk scores remain underdeveloped, impractical and hence underutilised. ${ }^{28,29}$ Take the bleeding risk index as an example. ${ }^{28}$ In this system, age $>65$ years, previous stroke, previous gastrointestinal bleed, and any one of diabetes, recent myocardial infarction, renal impairment and low haematocrit allows the patient to be allocated a numerical score which stratifies patients as low, intermediate or at high risk for bleeding events whilst receiving oral anticoagulation. It is instantly apparent that many high-risk AF patients will automatically be regarded as high risk for anticoagulation. In reality, advances in therapeutic anticoagulation monitoring may reduce the risk of bleeding significantly. For example, the drive towards community led services and near-patient testing will undoubtedly improve compliance and hence safety of anticoagulation in all patients. The recently introduced point of care (POC) and patient self-testing PT/INR measurements offer the potential to simplify oral anticoagulation testing by allowing greater independence and freedom. POC monitors use capillary blood to measure a thromboplastin mediated clotting time that is converted to a plasma PT/INR. PT results of the newer classes of monitors compare favourably with traditional laboratory PT measurements and indeed recent studies have shown that these measures are safe and effective in the community. ${ }^{30,31}$

\section{How do we EXAMINE risk and bleeding in AF?}

In this issue of the International Journal of Clinical Practice, Dinh et al. ${ }^{32}$ provides further evidence from the EXAMINE-AF study to underline the pragmatic approach that must be taken by all physicians when managing AF. This was an important study of prescribing patterns amongst Dutch general practitioners, internists and cardiologists, which demonstrates a relatively high rate of anticoagulation prescription, much of which is attributed to the development of risk stratification schema.

Predictably, this study highlights the pivotal role of the cardiologist in the management of these patients. In many cases, a cardiologist will initiate antithrombotic therapy and that this tends to be continued by both internists and general practitioners on subsequent patient contacts. Perhaps most importantly, the study also provides yet further evidence to support a telling - but all too common tale that those patients at highest risk of stroke and thromboembolism also tends to have the most risk factors for subsequent bleeding events. If anything, we need to reinforce the message that all patients with AF merit a full and accurate assessment of both bleeding risk and stroke, followed by appropriate thromboprophylaxis. 


\section{REFERENCES}

1. Wolf PA, Abbott RD, Kannel WB. Atrial fibrillation as an independent risk factor for stroke: the Framingham study. Stroke 1991;22:983-8.

2. Stewart S, Murphy N, Walker A, McGuire A, McMurray JJ. Cost of an emerging epidemic - an economic analysis of atrial fibrillation in the UK. Heart 2004; 90:286-92.

3. National Collaborating Centre for Chronic Conditions. Atrial Fibrillation: National Clinical Guideline for Management in Primary and Secondary Care. London: Royal College of Physicians, 2006.

4. Fuster V, Ryden LE, Cannom DS, Crijns HJ, Curtis AB, Ellenbogen KA, Halperin JL, Le Heuzey JY, Kay GN, Lowe JE, Olsson SB, Prystowsky EN, Tamargo JL, Wann S, Smith SC, Jacobs AK, Adams CD, Anderson JL, Antman EM, Halperin JL, Hunt SA, Nishimura R, Ornato JP, Page RL, Riegel B, Priori SG, Blanc JJ, Budaj A, Camm AJ, Dean V, Deckers JW, Despres C, Dickstein K, Lekakis J, McGregor K, Metra M, Morais J, Osterspey, Tamargo JL, Zamorano JL. ACC/AHA/ESC 2006 guidelines for the management of patients with atrial fibrillation: a report of the American College of Cardiology/American Heart Association Task Force on practice guidelines and the European Society of Cardiology Committee for Practice Guidelines (Writing Committee to Revise the 2001 guidelines for the management of patients with atrial fibrillation) developed in collaboration with the European Heart Rhythm Association and the Heart Rhythm Society. Circulation 2006;114:e257-354.

5. Freestone B, Lip GYH. Epidemiology and costs of cardiac arrhythmias. In: Lip GYH, Godtfredsen J, eds. Cardiac Arrhythmias: a Clinical Approach. Edinburgh: Mosby, 2003:3-24.

6. Go AS, Hylek EM, Phillips KA, Chang Y, Henault LE, Selby JV, Singer DE. Prevalence of diagnosed atrial fibrillation in adults: national implications for rhythm management and stroke prevention: the anticoagulation and risk factors in atrial fibrillation (ATRIA) study. JAMA 2001; 285:2370-5.

7. Benjamin EJ, Wolf PA, D'Agostino RB, Silbershatz H, Kannel WB, Levy D. Impact of atrial fibrillation on the risk of death: the Framingham heart study. Circulation 1998;98:946-52.

8. Hart RG, Benavente O, McBride R, Pearce LA. Antithrombotic therapy to prevent stroke in patients with atrial fibrillation: a meta-analysis. Ann Intern Med 1999;131:492-501.

9. Marini C, De Santis F, Sacco S, Russo T, Olivieri L, Totaro R, Carolei A. Contribution of atrial fibrillation to incidence and outcome of ischemic stroke: results from a population-based study. Stroke 2005;36:1115-9.

10. Kimura K, Minematsu K, Yamaguchi T. Japan Multicenter Stroke Investigators' Collaboration (J-MUSIC). Atrial fibrillation as a predictive factor for severe stroke and early death in 15,831 patients with acute ischaemic stroke. J Neurol Neurosurg Psychiatry 2005;76:679-83.

11. Steger C, Pratter A, Martinek-Bregel M, Avanzini M, Valentin A, Slany J, Stöllberger C. Stroke patients with atrial fibrillation have a worse prognosis than patients without: data from the Austrian stroke registry. Eur Heart J 2004;25:1734-40.

12. Lip GYH, Edwards SJ. Stroke prevention with aspirin, warfarin and xilmelagatran in patients with non-valvular atrial fibrillation: a systematic review and meta-analysis. Thromb Res 2006;118:321-33.

13. Lip GY, Boos C. Antithrombotic therapy for atrial fibrillation. Heart 2006; 92:155-61.

14. Stafford RS, Singer DE. Recent national patterns of warfarin use in atrial fibrillation. Circulation 1998;97:1231-3.

15. Mendelson G, Aronow WS. Under-utilization of warfarin in older persons with chronic nonvalvular atrial fibrillation at high risk for developing stroke. J Am Geriatr Soc 1998;46:1423-4.

16. Lane DA, Lip GYH. Anticoagulation as thromboprophylaxis for atrial fibrillation: implications in the 'real world' and the need for risk stratification. Blood Coagul Fibrinolysis 2005;16:461-4. 
17. Bungard TJ, Ghali WA, McAlister FA, Buchan AM, Cave AJ, Hamilton PG, Mitchell LB, Teo KK, Tsuyuki RT. The relative importance of barriers to the prescription of warfarin for nonvalvular atrial fibrillation. Can J Cardiol 2003;19:280-4.

18. Kutner M, Nixon G, Silverstone F. Physicians' attitudes toward oral anticoagulants and anti-platelet agents for stroke prevention in elderly patients with atrial fibrillation. Arch Intern Med 1991;151:1950-3.

19. Protheroe J, Fahey T, Montgomery AA, Peters TJ. The impact of patients' preferences on the treatment of atrial fibrillation: observational study of patient-based decision analysis. BMJ 2000;320:1380-4.

20. Lip GY, Zarifis J, Watson RD, Beevers DG. Physician variation in the management of patients with atrial fibrillation. Heart 1996;75:200-5.

21. Bungard TJ, Ghali WA, Teo KK, McAlister FA, Tsuyuki RT. Why do patients with atrial fibrillation not receive warfarin? Arch Intern Med 2000;160:41-6.

22. Choudhry NK, Anderson GM, Laupacis A, Ross-Degnan D, Normand SL, Soumerai SB. Impact of adverse events on prescribing warfarin in patients with atrial fibrillation: matched pair analysis. BMJ 2006;332:141-5.

23. Soumerai SB, McLaughlin TJ, Gurwitz JH, Guadagnoli E, Hauptman PJ, Borbas C, Morris N, McLaughlin B, Gao X, Willison DJ, Asinger R, Gobel F. Effect of local medical opinion leaders on quality of care for acute myocardial infarction: a randomized controlled trial. JAMA 1998;279:1358-63.

24. Gage BF, Waterman AD, Shannon W, Boechler M, Rich MW, Radford MJ. Validation of clinical classification schemes for predicting stroke: results from the National Registry of Atrial Fibrillation. JAMA 2001;285:2864-70.

25. Friberg J, Gislason GH, Gadsboll N, Rasmussen JN, Rasmussen S, Abildtrøm SZ, Køber L, Madsen M, Torp-Pedersen C. Temporal trends in the prescription of vitamin $\mathrm{K}$ antagonists in patients with atrial fibrillation. J Intern Med 2006;259:173-8.

26. Fuster V, Ryden LE, Asinger RW, Cannom DS, Crijns HJ, Frye RL, Halperin JL, Kay GN, Klein WW, Lévy S, McNamara RL, Prystowsky EN, Wann LS, Wyse DG, Gibbons RJ, Antman EM, Alpert JS, Faxon DP, Fuster V, Gregoratos G, Hiratzka LF, Jacobs AK, Russell RO, Smith SC, Klein WW, Alonso-Garcia A, BlomstrÖm-Lundqvist C, De Backer G, Flather M, Hradec J, Oto A, Parkhomenko A, Silber S, Torbicki A. ACC/AHA/ESC guidelines for the management of patients with atrial fibrillation: Executive Summary a report of the American College of Cardiology/American Heart Association Task Force on practice guidelines and the European Society of Cardiology Committee for practice guidelines and policy conferences (committee to develop guidelines for the management of patients with atrial fibrillation) developed in collaboration with the North American Society of Pacing and Electrophysiology. Circulation 2001;104:2118-50.

27. Nieuwlaat R, Capucci A, Lip GY, Olsson SB, Prins MH, Nieman FH, López-Sendón J, Vardas PE, Aliot E, Santini M, Crijns HJ. Antithrombotic treatment in real-life atrial fibrillation patients: a report from the Euro Heart Survey on Atrial Fibrillation. Eur Heart J 2006 (Epub ahead of print).

28. Beyth RJ, Quinn LM, Landefeld CS. Prospective evaluation of an index for predicting the risk of major bleeding in outpatients treated with warfarin. Am J Med 1998;105:91-9.

29. Kuijer PMM, Hutten BA, Prins MH, Buller HR. Prediction of the risk of bleeding during anticoagulant treatment for venous thromboembolism. Arch Intern Med 1999;159:457-60.

30. Cromheecke ME, Levy M, Colly LP. Oral anticoagulation self management and management by specialist anticoagulation clinic: a randomized cross over comparison. Lancet 2000;356:97-102.

31. Heneghan C, Alonso-Coello P, Garcia-Alamino JM, Perera R. Self monitoring of oral anticoagulation: a systematic review and meta analysis. Lancet 2006;367:404-11. 
32. Dinh T, Nieuwlaat R, Tieleman RG, Büller HR, van Charante NA, Prins MH, Crijns HJ. Antithrombotic drug prescription in atrial fibrillation and its rationale among general practitioners, internists and cardiologists in the Netherlands - the EXAMINE-AF study. A questionnaire survey. Int J Clin Pract 2007;61:24-31. 


\section{PART III}

Management of important subgroups of patients with atrial fibrillation

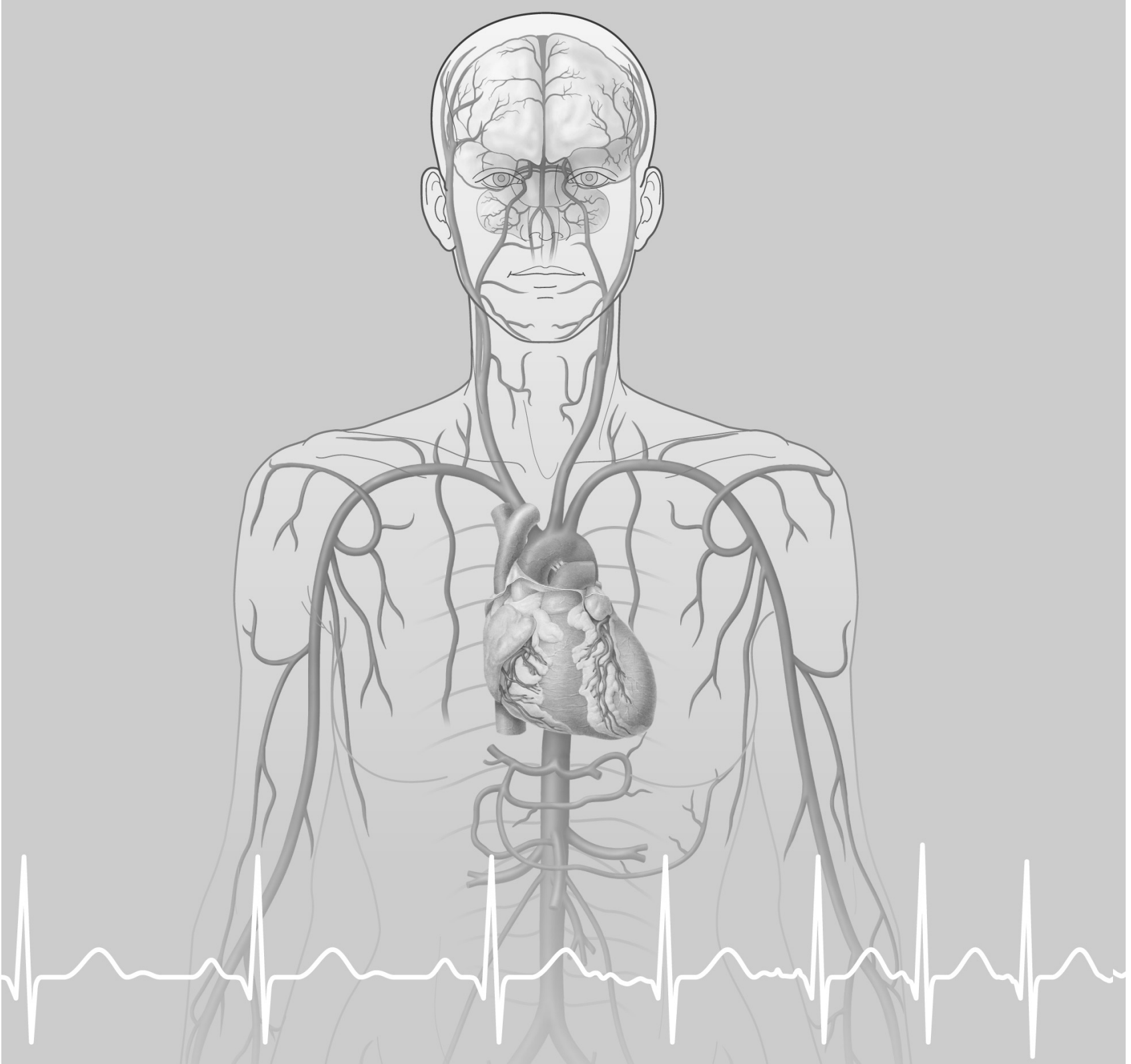



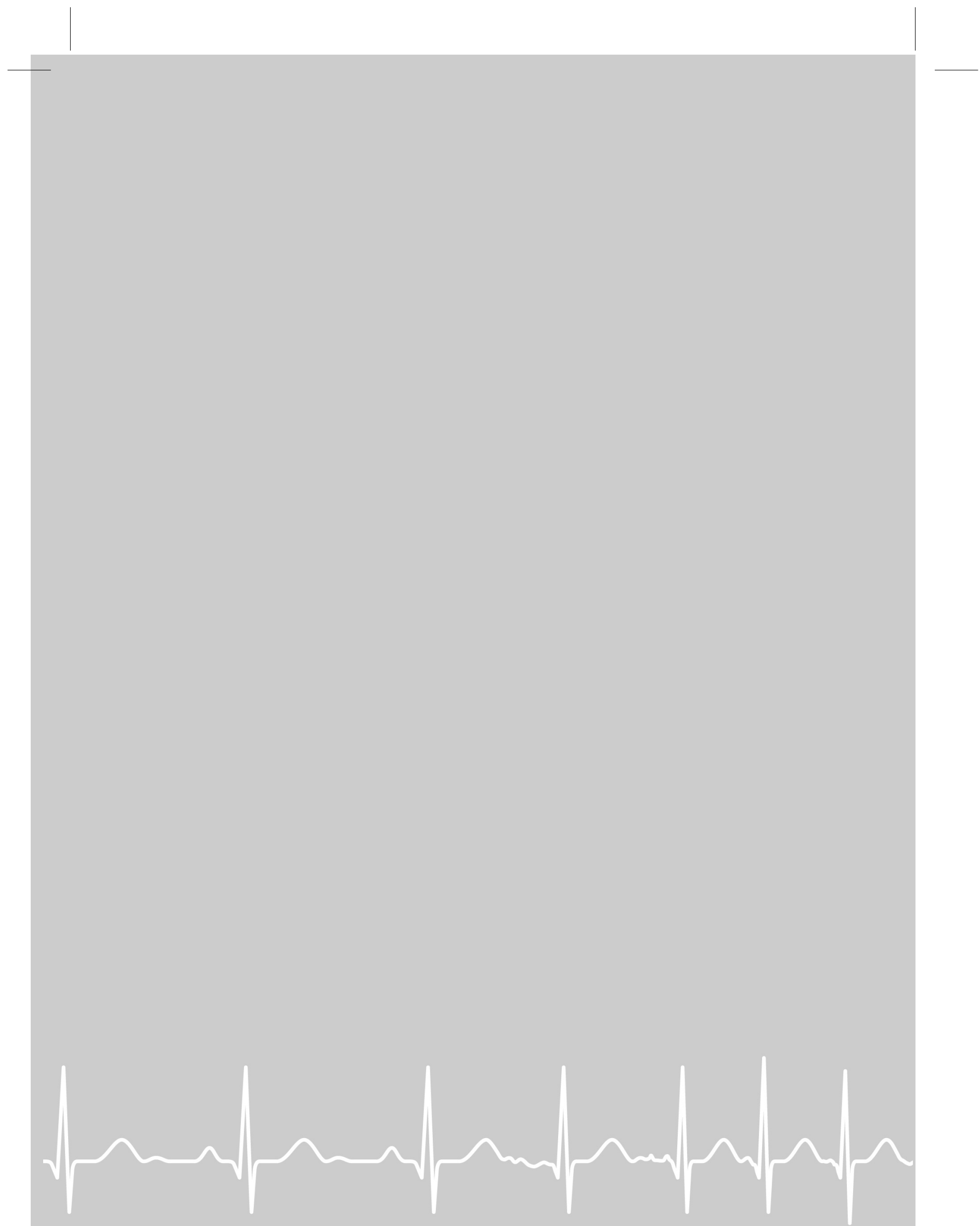
8

\section{Gender-related differences in} presentation, treatment and outcome of patients with atrial fibrillation in Europe

Nikolaos Dagres, Robby Nieuwlaat, Panos E. Vardas, Dietrich Andresen, Samuel Lévy, Stuart M. Cobbe, Dimitrios Th. Kremastinos, Günter Breithardt, Dennis V. Cokkinos, Harry J.G.M. Crijns

J Am Coll Cardiol. 2007;49(5):572-7

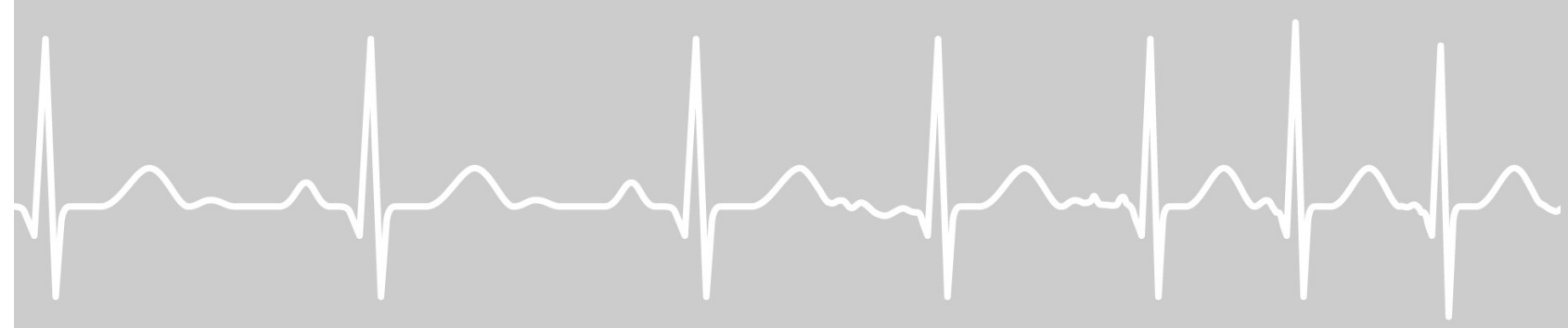




\section{ABSTRACT}

Objectives. This study sought to investigate gender-related differences in patients with atrial fibrillation (AF) in Europe.

Background. Gender-related differences may play a significant role in AF.

Methods. We analyzed the data of 5333 patients (42\% female) enrolled in the Euro Heart Survey on Atrial Fibrillation.

Results. Compared with men, the women were older, had a lower quality of life (QoL), had more comorbidities, more often had heart failure (HF) with a preserved left ventricular systolic function $(18 \%$ vs. $7 \%, \mathrm{P}<0.001)$, and less often had HF with systolic dysfunction $(17 \%$ vs. $26 \%, \mathrm{P}<0.001)$. Among patients with typical AF symptoms ( $56 \%$ of women, $49 \%$ of men), there was no gender-related difference in the choice of rate or rhythm control. Among patients with atypical or no symptoms (44\% of women, $51 \%$ of men), women less frequently underwent rhythm control $(39 \%$ vs. $51 \%, \mathrm{P}<0.001)$ than did men. Women underwent less electrical cardioversion $(22 \%$ vs. $28 \%, \mathrm{P}<0.001)$. Prescription of oral anticoagulants was identical $(65 \%)$ in both genders. One-year outcome was similar except that women had a higher chance for stroke (odds ratio 1.83 in multivariable logistic regression analysis, $\mathrm{P}=0.019)$.

Conclusions. Women with AF had more comorbidities, more HF with preserved systolic function, and a lower QoL than men. In the large group with atypical or no symptoms, women were treated appropriately more conservatively with less rhythm control than men. Women had a higher chance for stroke. Long-term QoL changes and other morbidities and mortality were similar. 


\section{INTRODUCTION}

Previous studies have reported significant gender differences in presentation and treatment of cardiovascular disorders, with a more conservative management in women. ${ }^{1,2}$

In patients with atrial fibrillation (AF), gender differences in patient characteristics have been described in several reports. ${ }^{3-5}$ However, data regarding differences in treatment and outcome are scarce. An underuse of anticoagulants in women has been suggested, but reports are not consistent. ${ }^{3,6-8}$ The RACE (RAte Control versus Electrical cardioversion) study, which compared rhythm versus rate control in persistent $\mathrm{AF}$, showed a gender-related difference in outcome ${ }^{5}$ : women with rhythm control had more cardiovascular morbidity and mortality compared with those with rate control, whereas this difference was not seen in men. Women also had a significantly lower quality of life (QoL) irrespective of strategy.

We examined gender differences in presentation, treatment, and outcome of patients with AF analyzing the data of the Euro Heart Survey on AF.

\section{METHODS}

The design and main results of the survey have been described recently. ${ }^{9}$ Between September 2003 and July 2004, 182 centers from 35 European Society of Cardiology (ESC) countries enrolled 5333 ambulant or hospitalised patients who had an electrocardiogram or Holter recording of AF during the qualifying admission or within the preceding 12 months.

Data were collected on patient characteristics and treatment. A clinical follow-up was performed at 1 year after discharge. Both at baseline and at 1-year follow-up, QoL was measured by the EuroQoL questionnaire, producing a sum score for 5 questions on health status (EQ-5D) and a score of self-reported health status on a visual analogue scale (EQ-VAS). ${ }^{10,11}$

\section{Definitions}

Symptoms typical for AF were considered to be palpitations and syncope. Dyspnea, chest pain, dizziness, and fatigue were classified as "other symptoms" possibly related to AF.

Heart failure (HF) was defined as the presence of signs and symptoms of either right (elevated central venous pressure, hepatomegaly, dependent edema) or left (exertional dyspnea, cough, fatigue, orthopnea, paroxysmal nocturnal dyspnea, cardiac enlargement, rales, gallop rhythm, pulmonary venous congestion) ventricular failure or both, and the diagnosis should be confirmed by noninvasive or hemodynamic measurements. Heart failure with left ventricular systolic dysfunction was defined as HF with a left ventricular ejection fraction $<45 \%$ or 
end-diastolic diameter $>55 \mathrm{~mm}$ in a recent echocardiographic study (within the preceding year). Heart failure with preserved systolic function was defined as HF in combination with a left ventricular ejection fraction $\geq 45 \%$ and end diastolic diameter $\leq 55 \mathrm{~mm}$.

For other definitions, we refer to the design paper. ${ }^{9}$ The American College of Cardiology (ACC)/American Heart Association (AHA)/ESC 2001 guidelines were used for patient classification into the different ACC/AHA/ESC stroke risk categories. ${ }^{12}$

\section{Statistical analysis}

Categorical variables are reported as percentage within gender, and were tested for differences between men and women with the $\chi^{2}$ test. Age is reported as mean \pm standard deviation, and was tested with the independent t-test. The QoL scores (i.e., [change in] EQ-5D and EQ-VAS) are reported as median with interquartile range, and were tested with the Mann-Whitney $U$ test because of a skewed distribution. Significant differences are indicated in the tables according to $\mathrm{P}<0.001$, $\mathrm{P}<0.01$, or $\mathrm{P}<0.05$; exact $\mathrm{P}$-values are reported in the Results section for differences not reported in the tables. Analyses were performed with the statistical software package SPSS (version 12.01, SPSS Inc., Chicago, Illinois). The large sample size may have caused differences that are statistically but not clinically significant. Therefore, the investigators focused on the findings that they considered clinically significant.

Multivariable stepwise logistic regression was performed to test the independent association of gender with occurrence of stroke and major bleeding during 1-year follow-up, correcting for differences in age, associated diseases, comorbidities, and treatment. Variables were removed stepwise from the model when the P-value exceeded 0.10. Variables with a P-value $<0.05$ in the final model were considered to be significant contributors and were kept in the model. The net odds ratio (OR) and its 95\% confidence interval (CI) and P-value are reported for gender regarding both analyses.

\section{RESULTS}

Of the 5333 enrolled patients, 2249 were female (42\%) (Table 1). Women were older, had a lower QoL, and more frequently had hypertension, valvular heart disease, diabetes, and hyperthyroidism. Men more frequently had coronary artery disease (CAD) and idiopathic (lone) AF.

Approximately one-third of both men and women had HF. However, the HF type differed significantly: HF with preserved systolic function was far more frequent among women, HF with systolic dysfunction was more common among men. In both genders, HF with systolic dysfunction was equally often associated 
GENDER DIFFERENCES

Table 1. Baseline characteristics

\begin{tabular}{|c|c|c|c|}
\hline & $\begin{array}{l}\text { Females } \\
(\mathrm{n}=2249)\end{array}$ & $\begin{array}{c}\text { Males } \\
(n=3084)\end{array}$ & P-value \\
\hline Age (years) & $70 \pm 12$ & $64 \pm 13$ & 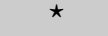 \\
\hline \multicolumn{4}{|l|}{ Concomitant diseases } \\
\hline Heart failure & $35 \%$ & $33 \%$ & NS \\
\hline \multicolumn{4}{|l|}{ Heart failure type: } \\
\hline Systolic dysfunction ${ }^{\mathrm{a}}$ & $48 \%$ & $79 \%$ & $\star$ \\
\hline Preserved systolic function ${ }^{a}$ & $52 \%$ & $21 \%$ & $\star$ \\
\hline \multicolumn{4}{|l|}{ NYHA class } \\
\hline I & $16 \%$ & $20 \%$ & NS \\
\hline II & $38 \%$ & $39 \%$ & NS \\
\hline III & $37 \%$ & $35 \%$ & NS \\
\hline IV & $8 \%$ & $7 \%$ & NS \\
\hline Hypertension & $69 \%$ & $60 \%$ & $\star$ \\
\hline Coronary artery disease & $30 \%$ & $36 \%$ & $\star$ \\
\hline Valvular heart disease (mitral stenosis or surgery) & $15 \%$ & $7 \%$ & $\star$ \\
\hline Hyperthyroidism & $7 \%$ & $4 \%$ & $\star$ \\
\hline Chronic obstructive pulmonary disease & $11 \%$ & $15 \%$ & $\star$ \\
\hline Idiopathic $\mathrm{AF}^{\mathrm{b}}$ & $7 \%$ & $13 \%$ & $\star$ \\
\hline More than one concomitant diseases ${ }^{c}$ & $53 \%$ & $46 \%$ & $\star$ \\
\hline \multicolumn{4}{|l|}{ Comorbidities } \\
\hline Diabetes mellitus & $21 \%$ & $16 \%$ & $\star$ \\
\hline Stroke & $7 \%$ & $5 \%$ & $\ddagger$ \\
\hline Transient ischemic attack & $6 \%$ & $5 \%$ & $\ddagger$ \\
\hline Other systemic thromboembolism & $4 \%$ & $2 \%$ & $\star$ \\
\hline Renal failure & $6 \%$ & $6 \%$ & NS \\
\hline Prior major bleeding & $2 \%$ & $2 \%$ & NS \\
\hline \multicolumn{4}{|l|}{ ACC/AHA/ESC stroke risk categories ${ }^{d}$} \\
\hline Lowest & $3 \%$ & $9 \%$ & $\star$ \\
\hline Low & $6 \%$ & $9 \%$ & $\star$ \\
\hline High & $63 \%$ & $65 \%$ & NS \\
\hline Highest & $28 \%$ & $18 \%$ & $\star$ \\
\hline \multicolumn{4}{|l|}{ AF type } \\
\hline First detected & $19 \%$ & $19 \%$ & NS \\
\hline Paroxysmal & $30 \%$ & $29 \%$ & NS \\
\hline Persistent & $21 \%$ & $24 \%$ & $\dagger$ \\
\hline Permanent & $31 \%$ & $29 \%$ & NS \\
\hline \multicolumn{4}{|l|}{ Symptoms } \\
\hline Currently symptomatic & $76 \%$ & $69 \%$ & $\star$ \\
\hline Palpitations & $54 \%$ & $47 \%$ & $\star$ \\
\hline Syncope & $4 \%$ & $4 \%$ & NS \\
\hline Dyspnea & $35 \%$ & $28 \%$ & $\star$ \\
\hline Chest pain & $18 \%$ & $15 \%$ & $\dagger$ \\
\hline Dizziness & $17 \%$ & $15 \%$ & NS \\
\hline Fatigue & $28 \%$ & $26 \%$ & NS \\
\hline Previously symptomatic, asymptomatic now & $14 \%$ & $16 \%$ & $\ddagger$ \\
\hline Never symptomatic & $10 \%$ & $15 \%$ & $\star$ \\
\hline \multicolumn{4}{|l|}{ Health status } \\
\hline EQ-5D & $0.73(0.59-0.85)$ & $0.85(0.69-1.00)$ & $\star$ \\
\hline EQ-VAS & $60(50-75)$ & $70(60-80)$ & $\star$ \\
\hline
\end{tabular}

$\star \mathrm{P}<0.001 ; \dagger \mathrm{P}<0.01 ; \ddagger \mathrm{P}<0.05$. ${ }^{\text {a }}$ Based on available information in $65 \%$ of women and $60 \%$ of men with heart failure who underwent echocardiography at the time of the survey or within the preceding year. ${ }^{b}$ No heart failure, hypertension, coronary artery disease, valvular heart disease, thyroid disease, cardiomyopathy, sick sinus syndrome, or chronic obstructive pulmonary disease. " Taking into account the diseases summarized at "b". d According to Fuster et al. ${ }^{19} \mathrm{NS}$, not significant. 
with CAD (both 49\%; $\mathrm{P}=0.976$ ), and $\mathrm{HF}$ with preserved systolic function was equally often associated with hypertension (both $75 \% ; \mathrm{P}=0.929$ ). However, HF with preserved systolic function was more often associated with valvular heart disease in women $(27 \%$ vs. $10 \% ; \mathrm{P}<0.001)$. Women had more comorbidities (including more than 1 associated disease). Especially the higher prevalence of hypertension and valvular heart disease resulted in more women being at the highest risk for stroke according to the ACC/AHA/ESC 2001 guidelines, and in women more often having multiple stroke risk factors ( $54 \%$ vs. $39 \%$; $\mathrm{P}<0.001)$. At enrollment, women were more often symptomatic, mainly because of a higher prevalence of palpitations and dyspnea.

Diagnostic procedures are presented in Table 2. Exercise testing was less commonly performed in women ( $14 \%$ vs. $25 \% ; \mathrm{P}<0.001)$, and when performed, was less often associated with CAD in women (51\% vs. $44 \% ; \mathrm{P}=0.023$ ). Transesophageal echocardiography was less often performed in women to identify left atrial thrombus $(73 \%$ vs. $81 \% ; \mathrm{P}=0.007)$, and more often to evaluate (artificial) valve function ( $33 \%$ vs. $23 \% ; \mathrm{P}=0.004)$.

Interventions for AF are given in Table 3. Women less often underwent electrical cardioversion or catheter ablation than did men. Other interventions showed no substantial difference.

Rhythm versus rate control related to symptoms is shown in Table 4. The treatment strategy did not differ between men and women with typical AF symptoms. In the remaining patients ( $44 \%$ of women and $51 \%$ of men) with symptoms other than palpitations or syncope or with asymptomatic AF, women were treated less aggressively, with a significantly lower percentage undergoing rhythm control and a higher percentage undergoing rate control compared with men.

Discharge therapy is shown in Table 5. Women were more commonly prescribed digitalis. The prescription of oral anticoagulants did not differ. Also, no significant differences were found in oral anticoagulation prescription rates among the different stroke risk categories according to the ACC/AHA/ESC 2001 guidelines and $\mathrm{CHADS}_{2}$ stroke risk score.

Regarding 1-year outcome, the univariable analysis yielded the following results. Women had a significantly higher rate of stroke ( $2.2 \%$ vs. $1.2 \%$ in men; $\mathrm{P}=0.011)$ and major bleeding ( $2.2 \%$ vs. $1.3 \% ; \mathrm{P}=0.028)$. No significant differences between genders were observed regarding mortality $(5.1 \%$ in women vs. $5.4 \%$ in men; $\mathrm{P}=0.567)$ or $\mathrm{HF}(11.2 \%$ vs. $11.4 \% ; \mathrm{P}=0.878)$. The $\mathrm{QoL}$ changes from baseline were minimal and did not differ significantly between genders (EQ-5D: 0.00 [-0.10 to $0.15]$ in women vs. 0.00 [-0.07 to 0.11$]$ in men; $\mathrm{P}=0.385$; EQ-VAS: 0 [ -5 to 15$]$ vs. 0 [ -5 to 10$] ; \mathrm{P}=0.125)$. When correcting for differences in age and stroke risk in multivariable logistic regression, women still had a higher chance for stroke (OR 1.83 [95\% CI 1.10 to 3.03]; $\mathrm{P}=0.019)$. Of note, a prior stroke/transient ischemic attack was the only acknowledged stroke risk factor that was more significantly associated with occurrence of stroke than female gender. The higher chance for 
Table 2. Diagnostic procedures

\begin{tabular}{lccc}
\hline & $\begin{array}{c}\text { Females } \\
(\mathrm{n}=2249)\end{array}$ & $\begin{array}{c}\text { Males } \\
(\mathrm{n}=3084)\end{array}$ & P-value \\
\hline Echocardiography & $85 \%$ & $86 \%$ & $\mathrm{NS}$ \\
Transthoracic & $84 \%$ & $85 \%$ & $\mathrm{NS}$ \\
Transesophageal & $12 \%$ & $14 \%$ & $\mathrm{NS}$ \\
Thyroid hormone level measurement & $50 \%$ & $44 \%$ & $\star$ \\
Chest X-ray & $82 \%$ & $81 \%$ & $\mathrm{NS}$ \\
Holter & $28 \%$ & $30 \%$ & $\mathrm{NS}$ \\
Exercise test & $14 \%$ & $25 \%$ & $\star$ \\
Electrophysiologic study & $4 \%$ & $7 \%$ & $\star$ \\
Event recorder & $2 \%$ & $2 \%$ & $\mathrm{NS}$ \\
$\star$ P $<0.001 . \mathrm{NS}$, not significant. & & &
\end{tabular}

Table 3. Interventions performed/planned at enrollment

\begin{tabular}{lccc}
\hline & $\begin{array}{c}\text { Females } \\
(\mathrm{n}=2249)\end{array}$ & $\begin{array}{c}\text { Males } \\
(\mathrm{n}=3084)\end{array}$ & P-value \\
\hline Electrical cardioversion & $22 \%$ & $28 \%$ & $\star$ \\
Pharmacological cardioversion & $25 \%$ & $23 \%$ & $\mathrm{NS}$ \\
Catheter ablation for AF & $3 \%$ & $6 \%$ & $\star$ \\
Pacemaker implantation & $6 \%$ & $5 \%$ & $\mathrm{NS}$ \\
ICD implantation & $1 \%$ & $2 \%$ & $\ddagger$ \\
AF surgery & $1 \%$ & $1 \%$ & $\mathrm{NS}$ \\
\hline
\end{tabular}

Catheter ablation for $\mathrm{AF}$ includes any ablation for $\mathrm{AF}$ treatment. ${ }^{\star} \mathrm{P}<0.001 ; \uparrow \mathrm{P}<0.05$. ICD, implantable cardioverter-defibrillator; NS, not significant.

Table 4. Treatment in relation to symptoms

\begin{tabular}{|c|c|c|c|}
\hline & Females & Males & P-value \\
\hline Typical AF symptoms & $N=1226$ & $N=1458$ & \\
\hline Rhythm control & $71 \%$ & $74 \%$ & NS \\
\hline Rate control & $25 \%$ & $22 \%$ & NS \\
\hline No rate/rhythm control & $4 \%$ & $4 \%$ & NS \\
\hline Other symptoms & $\mathrm{N}=349$ & $N=508$ & \\
\hline Rhythm control & $47 \%$ & $61 \%$ & $\star$ \\
\hline Rate control & $46 \%$ & $33 \%$ & $*$ \\
\hline No rate/rhythm control & $7 \%$ & $6 \%$ & NS \\
\hline No symptoms & $\mathrm{N}=584$ & $\mathrm{~N}=993$ & \\
\hline Rhythm control & $37 \%$ & $49 \%$ & $\star$ \\
\hline Rate control & $51 \%$ & $40 \%$ & $*$ \\
\hline No rate/rhythm control & $12 \%$ & $11 \%$ & NS \\
\hline
\end{tabular}




\begin{tabular}{lccc} 
Table 5. Drug therapy at discharge in patients discharged alive & & \\
\hline & $\begin{array}{c}\text { Females } \\
(\mathrm{N}=2208)\end{array}$ & $\begin{array}{c}\text { Males } \\
(\mathrm{N}=3056)\end{array}$ & P-value \\
\hline Antithrombotic treatment & & & \\
Oral anticoagulants & $65 \%$ & $65 \%$ & $\mathrm{NS}$ \\
Aspirin & $28 \%$ & $31 \%$ & $\ddagger$ \\
Clopidogrel/Ticlopidine & $5 \%$ & $6 \%$ & $\mathrm{NS}$ \\
Heparin/Low molecular weight heparin & $6 \%$ & $6 \%$ & $\mathrm{NS}$ \\
Other antithrombotic medication & $2 \%$ & $2 \%$ & $\mathrm{NS}$ \\
No antithrombotic medication & $8 \%$ & $9 \%$ & $\mathrm{NS}$ \\
Antiarrhythmic drugs & & & \\
Class Ia & $0.6 \%$ & $0.4 \%$ & $\mathrm{NS}$ \\
Class Ic & $9 \%$ & $10 \%$ & $\mathrm{NS}$ \\
Beta blocker ${ }^{\mathrm{a}}$ & $49 \%$ & $51 \%$ & $\mathrm{NS}$ \\
Class III & $29 \%$ & $32 \%$ & $\ddagger$ \\
$\quad$ Amiodarone & $23 \%$ & $26 \%$ & $\ddagger$ \\
Sotalol & $7 \%$ & $7 \%$ & $\mathrm{NS}$ \\
Class IV & $10 \%$ & $8 \%$ & $\ddagger$ \\
Digitalis & $30 \%$ & $25 \%$ & $\star$ \\
$\star$ P $<0.01 ; \dagger \mathrm{P}<0.05 .{ }^{a}{ }^{b}$ Including sotalol. ${ }^{\mathrm{b}}$ Diltiazem, verapamil. NS, not significant. &
\end{tabular}

major bleeding in women became nonsignificant in multivariable analysis (OR 1.28 [95\% CI 0.76 to 2.13]; $\mathrm{P}=0.351$ ). The difference in stroke rate was largely attributable to a higher stroke rate in women who did not receive oral anticoagulation, who had at least 1 stroke risk factor, and who underwent rhythm control $(5.0 \%$ vs. $1.2 \% ; \mathrm{P}=0.006)$. When stratifying to the number of stroke risk factors, this difference was only significant when 1 solitary stroke risk factor was present $(6.9 \%$ vs. $0.5 \% ; \mathrm{P}=0.001)$. In the latter group, of 9 strokes in women, 6 were associated with hypertension, 2 with HF, and 1 with mitral stenosis, whereas the only stroke in men was associated with hypertension. In contrast with the rhythm control group, there was no difference in outcome between men and women undergoing rate control.

\section{DISCUSSION}

Women with AF had a worse cardiovascular risk profile and a lower QoL than men. They were more symptomatic, had more comorbidities, and more often had HF with preserved systolic function. Women received less often rhythm control treatment if they had atypical or no symptoms. The use of antithrombotic drugs was similar in both genders, also when correcting for the higher prevalence of stroke risk factors in women. However, women had a higher risk for stroke, and withholding oral anticoagulation from patients at risk mainly seemed to affect women. 
In this regard, women undergoing rhythm control and women with hypertension as a solitary stroke risk factor seem to be at high risk for stroke. No substantial changes of QoL over time were seen in either gender. Our results suggest that female gender should be reconsidered as an independent risk factor for stroke. In addition, women may benefit from consistent anticoagulation as well as tailored HF management.

\section{Baseline characteristics and evaluation}

Female patients were older and more frequently had hypertension, valvular heart disease, diabetes, and thyroid disease; male patients more frequently had CAD and idiopathic AF. In total, women had more comorbidities, were more often at the highest risk for stroke, and were more often symptomatic than men. These findings agree with those of previous reports. ${ }^{3-5}$ The higher frequency of exercise tests in men cannot be ascribed fully to a higher prevalence of CAD. Apparently, women have a lower chance of undergoing an exercise test in general, and when they do undergo one, it is less often in association with CAD.

\section{Heart failure}

The overall frequency of HF was similar in both genders. However, HF with preserved systolic function was more frequent among women, HF with systolic dysfunction was more frequent among men. This is a novel finding in AF patients, and agrees with previous observations in the total population of HF patients. ${ }^{13}$ The higher prevalence of HF with systolic dysfunction in men partly can be explained by the higher prevalence of CAD, but not exclusively, because in both genders only half of the HF cases with systolic dysfunction were associated with CAD. The higher prevalence of HF with preserved systolic function in women seems mainly attributable to a higher prevalence of hypertension and valvular heart disease.

\section{Rhythm and rate control}

We found significant treatment differences between genders regarding rhythm or rate control in relation to symptoms. Approximately half of the patients had typical AF symptoms (palpitations or syncope). In these, the proportion of patients assigned to rhythm or rate control did not differ between genders. In the remaining half of the patients who had either atypical or no AF symptoms, treatment was more conservative in women, with significantly less rhythm control than in men. Consistently, fewer women underwent electrical cardioversion. These findings are also novel in the field of AF treatment and corroborate the previous reports on a generally more conservative management of women. This conservative approach may have precluded women from appropriate therapy, i.e., rhythm control of (atypical) AF symptoms. On the other hand, in asymptomatic patients, this conservative 
approach might have been beneficial for women, because potential adverse effects of rhythm control interventions and drugs are avoided. Appropriately withholding rhythm control might even be more beneficial in women than in men, because we found an excess of strokes among women on rhythm control and because rhythm control in women was associated with worse outcome than rate control in the RACE study.

\section{Antithrombotic medication}

In contrast with earlier studies, ${ }^{3,6}$ there were no differences in the prescription of antithrombotic medication, and also not when correcting for the higher prevalence of stroke risk factors in women. This could mirror a better guideline implementation, as also suggested by the higher rate of anticoagulant prescription in the present survey $(65 \%)$ compared with prior reports. ${ }^{6-8}$

\section{Gender and risk for stroke}

In the total population, women had a higher chance for stroke than men, but no further differences were found regarding 1-year outcomes. Previous investigations on outcomes in men and women provided contradictory results. ${ }^{3,5}$ The higher stroke rate in women in our survey was mainly observed when withholding oral anticoagulation from women undergoing rhythm control and having at least 1 stroke risk factor, mainly hypertension. Because this difference was not exclusively attributable to a higher prevalence of stroke risk factors in women, these results might indicate a subgroup of women that is at high risk for stroke.

These findings agree with the higher stroke rate among women in the Framingham study, ${ }^{14}$ which led to the incorporation of female gender in the Framingham stroke risk scheme. ${ }^{15}$ These findings also agree with the results of the SPAF (Stroke Prevention in Atrial Fibrillation) trials ${ }^{16}$ and the ATRIA (AnTicoagulation and Risk factors In Atrial fibrillation) study, which showed a higher risk for AF-related thromboembolism in women not receiving oral anticoagulation. ${ }^{17}$ Interestingly, in the ATRIA study the reduction in rates of thromboembolism with anticoagulation was larger in women than in men with similar rates of major bleeding. ${ }^{17}$ However, female gender is not incorporated in the most recent stroke risk classification scheme, $\mathrm{CHADS}_{2}{ }^{18}$, and the recently revised ACC/AHA/ESC guidelines classify female gender into the "less validated or weaker risk factors". ${ }^{19}$ Although the higher stroke rate did not affect mortality in our survey, we speculate that female gender should be reconsidered as an independent stroke risk factor. 


\section{Study limitations}

Results from surveys like the present one could be influenced by a potential center effect because a limited number of centers, of which a large proportion were university related and highly specialized, were recruited among the 35 participating countries. The older age of women may have affected some of the observed differences, especially in comorbidities. Obviously, in clinical practice these differences should be taken into account. In addition, some patients had a first detected episode of AF; others had paroxysmal, persistent, or permanent AF. However, because the patient proportions with these different AF types were almost identical in both genders, this heterogeneity should not have affected our main results.

\section{CONCLUSIONS}

Women with AF are older and sicker than men, with a lower QoL. They also seem to be at a higher risk of stroke, especially when left unprotected. Although applied equally among genders, our data suggest that antithrombotic treatment must receive more attention in women. The higher prevalence of HF with preserved systolic function is intriguing and should trigger special management approaches in women. The generally less aggressive management in women comes to their advantage with far less rhythm control in female AF patients with absent or atypical AF symptoms. However, this did not translate to a higher QoL, presumably because of higher age and higher disease burden.

\section{REFERENCES}

1. Ayanian JZ, Epstein AM. Differences in the use of procedures between women and men hospitalized for coronary heart disease. N Engl J Med 1991;325:221-5.

2. Wong CC, Froelicher ES, Bacchetti P, Bacchetti P, Barron HV, Gee L, Selby JV, Lundstrom R, Swain B, Truman A. Influence of gender on cardiovascular mortality in acute myocardial infarction patients with high indication for coronary angiography. Circulation 1997;96 Suppl: II51-7.

3. Humphries KH, Kerr CR, Connolly SJ, Klein G, Boone JA, Green M, Sheldon R, Talajic M, Dorian P, Newman D. New-onset atrial fibrillation. Sex differences in presentation, treatment, and outcome. Circulation 2001;103:2365-70.

4. Levy S, Maarek M, Coumel P, Guize L, Lekieffre J, Medvedowsky JL, Sebaoun A. Characterization of different subsets of atrial fibrillation in general practice in France. The ALFA study. Circulation 1999;99:3028 -35.

5. Rienstra M, van Veldhuisen DJ, Hagens VE, Ranchor AV, Veeger NJ, Crijns HJ, Van Gelder IC. Gender-related differences in rhythm control treatment in persistent atrial fibrillation. Data of the Rate Control versus Electrical Cardioversion (RACE) study. J Am Coll Cardiol 2005;46:1298 -306 .

6. Sudlow M, Thomson R, Thwaites B, Rodgers H, Kenny RA. Prevalence of atrial fibrillation and eligibility for anticoagulants in the community. Lancet 1998;352:1167-71.

7. Gage BF, Boechler M, Doggette AL, Fortune G, Flaker GC, Rich MW, Radford MJ. Adverse outcomes and predictors of underuse of antithrombotic therapy in Medicare beneficiaries with chronic atrial fibrillation. Stroke 2000;31:822-7. 
8. Brass LM, Krumholz HM, Scinto JM, Radford M. Warfarin use among patients with atrial fibrillation. Stroke 1997;28:2382-9.

9. Nieuwlaat R, Capucci A, Camm AJ, Olsson SB, Andresen D, Davies DW, Cobbe S, Breithardt G, Le Heuzey JY, Prins MH, Lévy S, Crijns HJ. Atrial fibrillation management: a prospective survey in ESC member countries. The Euro Heart Survey on Atrial Fibrillation. Eur Heart J 2005;26:2422-34.

10. Brooks R, with the EuroQOL Group. EuroQOL: the current state of play. Health Policy 1996;37:53-72.

11. Rabin R, de Charro F. EQ-5D: a measure of health status from the EuroQOL Group. Ann Med 2001;33:337- 43.

12. Fuster V, Ryden LE, Asinger RW, Cannom DS, Crijns HJ, Frye RL, Halperin JL, Kay GN, Klein WW, Lévy S, McNamara RL, Prystowsky EN, Wann LS, Wyse DG. ACC/AHA/ESC guidelines for the management of patients with atrial fibrillation. Eur Heart J 2001;22:1852-923.

13. Lenzen MJ, Scholte op Reimer WJM, Boersma E, Vantrimpont PJ, Follath F, Swedberg K, Cleland J, Komajda M. Differences between patients with a preserved and a depressed left ventricular function: a report from the EuroHeart Failure Survey. Eur Heart J 2004;25:1214 -20.

14. Wolf PA, Abbott RD, Kannel WB. Atrial fibrillation as an independent risk factor for stroke: the Framingham study. Stroke 1991;22: 983-8.

15. Wang TJ, Massaro JM, Levy D, Vasan RS, Wolf PA, D'Agostino RB, Larson MG, Kannel WB, Benjamin EJ. A risk score for predicting stroke or death in individuals with new-onset atrial fibrillation in the community. The Framingham Heart Study. JAMA 2003;290:1049-56.

16. Hart RG, Pearce LA, McBride R, Rothbart RM, Asinger RW, on behalf of the Stroke Prevention in Atrial Fibrillation (SPAF) Investigators. Factors associated with ischemic stroke during aspirin therapy in atrial fibrillation: analysis of 2012 participants in the SPAF I-III clinical trials. Stroke 1999;30:1223-9.

17. Fang MC, Singer DE, Chang Y, Hylek EM, Henault LE, Jensvold NG, Go AS. Gender differences in the risk of ischemic stroke and peripheral embolism in atrial fibrillation. The AnTicoagulation and Risk factors In Atrial fibrillation (ATRIA) Study. Circulation 2005;112:1687-91.

18. Gage BF, Waterman AD, Shannon W, Boechler M, Rich MW, Radford MJ. Validation of clinical classification schemes for predicting stroke: results from the National Registry of Atrial Fibrillation. JAMA 2001;285:2864 -70.

19. Fuster V, Ryden LE, Cannom DS, Crijns HJ, Curtis AB, Ellenbogen KA, Halperin JL, Le Heuzey JY, Kay GN, Lowe JE, Olsson SB, Prystowsky EN, Tamargo JL, Wann S. ACC/AHA/ESC 2006 guidelines for the management of patients with atrial fibrillation - executive summary. Eur Heart J 2006;27:1979 -2030. 
9

\section{Atrial fibrillation and heart failure}

Reciprocal impact and combined management from the perspective of atrial fibrillation

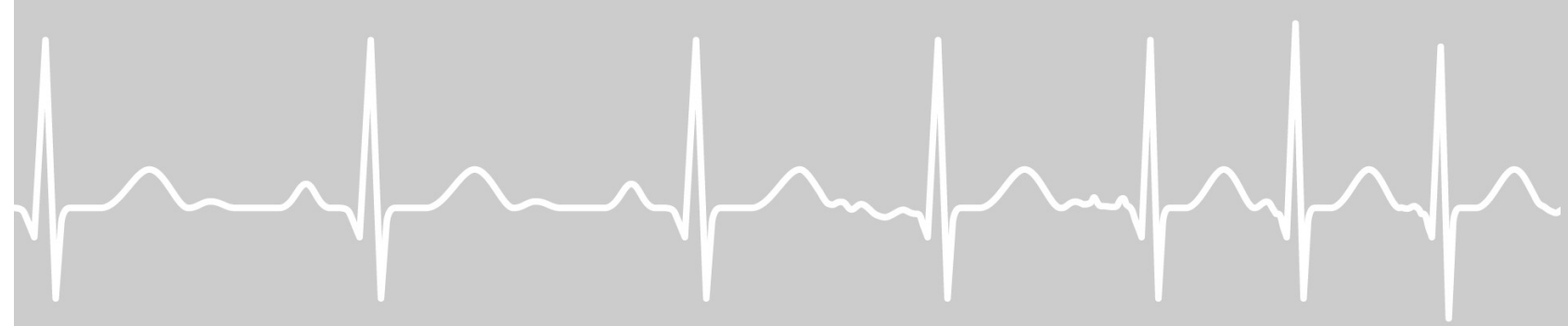




\section{ABSTRACT}

Aim. To assess management guideline adherence and prognosis in patients with the in cardiology practice frequently found combination of heart failure (HF) and atrial fibrillation (AF).

Methods. In the Euro Heart Survey on AF (2003-2004), 5333 hospitalized and ambulant cardiology-based AF patients were enrolled in 182 centers among 35 European countries. Observational data were collected on the characteristics, management and 1-year prognosis of AF patients.

Results. At baseline, 1816 patients (34\%) had HF besides their AF. Only 40\% of patients with HF received the recommended HF therapy of a beta blocker with either an ACE inhibitor (ACE-i) or AT II receptor blocker (ARB). Of all HF patients with NYHA class II to IV, 14\% did not receive an ACE-i, ARB nor a beta blocker. No more than $13 \%$ of patients with HF received the recommended drug therapy for both HF and AF, which is the combination of a beta blocker, either ACE-I or ARB, oral anticoagulation and digitalis. Further, among HF patients with permanent $\mathrm{AF}, 40 \%$ had a resting heart rate of $<80 \mathrm{bpm}$ and a mere $20 \%$ received the recommended rate control combination of a beta blocker with digitalis.

In the total cohort, HF patients had a higher risk for mortality (9.5 vs 3.3\%; $\mathrm{P}<0.001$ ) and $\mathrm{AF}$ progression ( 35 vs $19 \%$; $\mathrm{P}<0.001$ ). Among the HF patients, the only recommended drug that was associated with improved survival already during 1 year was an ACE-i (odds ratio $=0.47(0.28-0.77) ; \mathrm{P}=0.003)$. Although the presence of sinus rhythm indicated an improved survival (odds ratio $=0.38(0.21-0.66$ ); $\mathrm{P}<0.001)$, no difference was found between rhythm and rate control regarding mortality.

Conclusion. The prescription rate of recommended drug therapy for AF and HF is appallingly low. Keeping in mind the high prevalence and dreadful prognosis of patients with af and hf, management of this subgroup deserves full attention. 


\section{INTRODUCTION}

Atrial fibrillation (AF) and heart failure (HF) often coexist. The Framingham Heart Study showed that in a general population the incidence of HF among AF patients was 33 in 1000 patient years, and the incidence of AF among HF patients 54 in 1000 patient years. ${ }^{1}$ The Euro Heart Surveys on AF and HF I showed that HF is present in $34 \%$ of $\mathrm{AF}$ patients, and $\mathrm{AF}$ in $42 \%$ of HF patients, as encountered in cardiology practice., ${ }^{2,3}$

Both single pathologies are associated with increased mortality. Half of the patients having a diagnosis of HF will die within 4 years, and of patients with severe HF $65 \%$ dies within 1 year. ${ }^{4,5}$ AF has been shown to double mortality in general populations, when compared to patients without $\mathrm{AF}^{6,7}$ In addition, $\mathrm{AF}$ and $\mathrm{HF}$ promote each other's progression, resulting in an increased mortality when one develops in the presence of the other. ${ }^{1}$

Separate guidelines exist for the management of AF and HF, both with paragraphs on their combined management. ${ }^{8-10}$ The Euro Heart Surveys on AF and HF I showed that some gaps exist in the management of AF and HF separately. ${ }^{2,11}$ However, no information is available regarding the combined management of AF and HF. Because of a more complex perception of the diseases and the coexistence of two separate guidelines, we investigated whether guideline adherence, in particular for drug therapy, is worse when both AF and HF are encountered in the Euro Heart Survey on AF. In addition, we investigated the impact of HF and its management on the management, progression and prognosis of AF during 1 year follow-up.

\section{METHODS}

Survey methods, centre participation, patient characteristics, management and definitions of the Euro Heart Survey on AF have previously been described. ${ }^{2}$ In summary, patients with AF on ECG or Holter recording at baseline or within the preceding year were enrolled in 182 hospitals among 35 countries in 2003-2004.

\section{Baseline definitions}

Heart failure: the presence of signs and symptoms of either right (elevated central venous pressure, hepatomegaly, dependent oedema) or left ventricular failure (exertional dyspnoea, cough, fatigue, orthopnea, paroxysmal nocturnal dyspnoea, cardiac enlargement, rales, gallop rhythm, pulmonary venous congestion) or both and the diagnosis should be confirmed by non-invasive or haemodynamic measurements.

Heart failure with left ventricular systolic dysfunction (LVSD-HF): a clinical diagnosis of HF in combination with a recent echocardiographic study (within the preceding 
year) showing a left ventricular ejection fraction $<45 \%$ or a left ventricular end diastolic diameter $>55 \mathrm{~mm}$.

Heart failure with preserved left ventricular systolic function (PSF-HF): a clinical diagnosis of HF in combination with an echocardiographic left ventricular function with an ejection fraction $\geq 45 \%$ as well as a left ventricular end diastolic diameter $\leq 55 \mathrm{~mm}$.

Recommended drug therapy: according to both ESC and ACC/AHA 2001 HF guidelines ${ }^{12,13}$, the combination of a beta blocker and an ACE-inhibitor (ACE-i) or angiotensin II receptor blocker (ARB) was considered to be "recommended drug therapy for HF", although the guidelines are not conclusive for PSF-HF. Since it is also recommended in the 2001 guidelines for both $\mathrm{AF}^{14}$ and $\mathrm{HF}^{13}$ to prescribe oral anticoagulation $(\mathrm{OAC})$ and digitalis in HF patients who also have AF, a combination of beta blocker, ACE-i or ARB, OAC and digitalis is defined as "recommended drug treatment for HF \& AF".

Rate control: For the current analysis, rate control drugs were considered to be: beta blockers, digoxin, digitoxin, diltiazem, verapamil and also amiodarone and sotalol since these drugs have rate control properties.

\section{Follow-up definitions}

Ischemic stroke: focal neurological deficit of sudden onset as diagnosed by a neurologist, lasting $>24$ hours and caused by ischemia.

Major bleeding: hemorrhagic stroke (focal neurological deficit of sudden onset as diagnosed by a neurologist, lasting $>24$ hours and caused by bleeding) or other type of major bleeding (requiring hospitalisation and/or causing a drop of haemoglobin level of more than $2 \mathrm{~g} / \mathrm{L}$ and/or requiring blood transfusion).

Heart failure: onset of new HF, or worsening of known HF.

AF progression: $1^{\text {st }}$ detected becoming paroxysmal, persistent or permanent AF; paroxysmal becoming persistent or permanent AF; persistent becoming permanent AF.

\section{Statistics}

Data analysis was performed with SPSS statistical software (SPSS Inc., release 12.01). Continuous variables are reported as mean \pm standard deviation or median $\left(25^{\text {th }}-75^{\text {th }}\right.$ percentile) and categorical variables as observed number (percentage). Whether there was a difference between patients with and without HF, and between LVSD-HF and, PSF-HF was tested with independent t-test or Mann-Whitney for continuous variables and with $\chi^{2}$ statistic for categorical variables.

Multivariable logistic regression was performed to assess the independent effect of HF, type of HF (LVSD-HF and PSF-HF) and appropriate HF drug therapy on mortality and the occurrence of adverse events during 1 year follow-up. The effect 
of drugs in this observational cohort might be biased due to the absence of randomisation, and therefore it was chosen to add a propensity score for each drug and also appropriate HF drug therapy to the model. Propensity scores were calculated by means of a logistic regression model containing factors that significantly predicted the prescription of the drug.

Variables were removed stepwise from the model when the p-value exceeded 0.10. Propensity scores for each drug were kept in the model until the concerning drug was excluded. Variables with P-value $<0.05$ in the final model were considered to be significant contributors and were kept in the model. Interactions were tested for all variables in this model. Hereafter, these models were validated by means of bootstrapping, which was performed with 100 samples for each reported multivariable logistic regression analysis. Effects that were instable when bootstrapping were stepwise left out of the model, which eventually resulted in the final model with only stable significant associated factors, and results of these final models are reported here. For key variables the net odds ratio (OR) and its 95\% confidence interval (CI) and P-value are reported.

\section{RESULTS}

Among 5333 patients in the Euro Heart Survey on AF, 1816 patients (34\%) had HF, $3482(66 \%)$ did not and for 35 patients $(0.7 \%)$ the prevalence of HF was unknown.

\section{Patient characteristics}

AF patients with HF were older and in general had more comorbidities than AF patients without HF (Table 1). As a consequence, HF patients are far more often categorized in CHADS2 stroke risk score 2 or higher (Figure 1). Further, HF patients more often had permanent AF, left ventricular hypertrophy on ECG, a lower left ventricular ejection fraction and a larger left atrium. HF was diagnosed over 1 year ago in half of the cases, but also just recently ( $<1$ month) in 1 out of 4 HF patients. The majority had NYHA functional class II or III (74\%).

Among $1131 \mathrm{HF}$ patients with recent echocardiographic information, 66\% had a decreased and $34 \%$ a preserved left ventricular systolic function. AF patients with LVSD-HF were younger $(66 \pm 12$ vs $68 \pm 12$ years; $\mathrm{P}=0.001)$, more often had a history of CAD ( 49 vs $36 \% ; \mathrm{P}<0.001$ ), especially myocardial infarction ( 28 vs $15 \%$; $\mathrm{P}<0.001)$ and ventricular tachycardia (6 vs $2 \% ; \mathrm{P}=0.005)$. Patients with PSF-HF more frequently were female ( 65 vs $30 \% ; \mathrm{P}<0.001$ ) and more often had a history of mitral stenosis or mitral valve surgery ( $21 \mathrm{vs} 12 \% ; \mathrm{P}<0.001)$ and hypertension $(75$ vs $65 \% ; \mathrm{P}=0.002)$. LVSD-HF patients were more often free from any of the above mentioned associated diseases (17 vs $7 \% ; \mathrm{P}<0.001)$. On echocardiogram, left atrial size was larger in the LVSD-HF group ( $50 \pm 9$ vs $45 \pm 9 \mathrm{~mm} ; \mathrm{P}<0.001)$. 
Table 1. Baseline characteristics of atrial fibrillation patients with and without heart failure

\begin{tabular}{|c|c|c|c|}
\hline $\mathrm{N}$ & $\begin{array}{c}\text { Heart failure } \\
1816 \\
\end{array}$ & $\begin{array}{c}\text { No heart failure } \\
3482 \\
\end{array}$ & P-value \\
\hline \multicolumn{4}{|l|}{ Enrolment characteristics } \\
\hline Enrolled at outpatient clinic & 23 & 39 & $<0.001$ \\
\hline Enrolled at university hospital & 52 & 45 & $<0.001$ \\
\hline AF only reason for visit & 15 & 54 & $<0.001$ \\
\hline \multicolumn{4}{|l|}{ Demographics } \\
\hline Age, years & $69 \pm 12$ & $66 \pm 13$ & $<0.001$ \\
\hline Female & 44 & 41 & NS \\
\hline Body mass index, $\mathrm{kg} / \mathrm{m}^{2}$ & $28 \pm 6$ & $28 \pm 8$ & 0.025 \\
\hline \multicolumn{4}{|l|}{ Cardiac history } \\
\hline Valvular heart disease & 40 & 20 & $<0.001$ \\
\hline Valve surgery / Mitral stenosis & 10 & 4 & $<0.001$ \\
\hline Coronary artery disease & 45 & 27 & $<0.001$ \\
\hline Myocardial infarction & 25 & 12 & $<0.001$ \\
\hline Angina pectoris & 27 & 16 & $<0.001$ \\
\hline Percutanous coronary intervention & 7 & 6 & NS \\
\hline Coronary artery bypass grafting & 8 & 6 & $<0.001$ \\
\hline Congenital heart disease & 2 & 2 & NS \\
\hline Sick sinus syndrome & 6 & 4 & 0.004 \\
\hline Ventricular tachycardia & 5 & 2 & $<0.001$ \\
\hline Ventricular fibrillation & 2 & 1 & $<0.001$ \\
\hline Pacemaker implantation & 8 & 5 & $<0.001$ \\
\hline Implantable cardioverter-defibrillator & 2 & 1 & $<0.001$ \\
\hline Catheter ablation & 2 & 3 & $<0.001$ \\
\hline \multicolumn{4}{|l|}{ Other pathologies } \\
\hline Hypertension & 67 & 62 & $<0.001$ \\
\hline Diabetes & 24 & 15 & $<0.001$ \\
\hline Chronic obstructive pulmonary disease & 20 & 10 & $<0.001$ \\
\hline Malignancy & 6 & 5 & NS \\
\hline Peripheral vascular disease & 11 & 6 & $<0.001$ \\
\hline Renal failure & 10 & 3 & $<0.001$ \\
\hline Stroke / transient ischemic attack & 13 & 9 & $<0.001$ \\
\hline \multicolumn{4}{|l|}{ Clinical characteristics } \\
\hline \multicolumn{4}{|l|}{ AF type } \\
\hline $1^{\text {st }}$ detected & 14 & 21 & $<0.001$ \\
\hline Paroxysmal & 20 & 34 & $<0.001$ \\
\hline Persistent & 23 & 22 & NS \\
\hline Permanent & 43 & 23 & $<0.001$ \\
\hline \multicolumn{4}{|l|}{ Electrocardiogram } \\
\hline Ventricular rate, bpm & $94 \pm 29$ & $91 \pm 31$ & 0.001 \\
\hline QRS duration, mm & $105 \pm 33$ & $96 \pm 25$ & $<0.001$ \\
\hline QT interval, mm & $377 \pm 141$ & $369 \pm 59$ & 0.002 \\
\hline Left ventricular hypertrophy & 31 & 14 & $<0.001$ \\
\hline \multicolumn{4}{|l|}{ Echocardiogram } \\
\hline Left atrial size, $\mathrm{mm}$ & $49 \pm 9$ & $44 \pm 8$ & $<0.001$ \\
\hline Left ventricular ejection fraction, $\%$ & $47 \pm 15$ & $55 \pm 13$ & $<0.001$ \\
\hline Left ventricular end-systolic diameter, mm & $42 \pm 10$ & $35 \pm 7$ & $<0.001$ \\
\hline Left ventricular end-diastolic diameter, $\mathrm{mm}$ & $56 \pm 9$ & $51 \pm 7$ & $<0.001$ \\
\hline
\end{tabular}




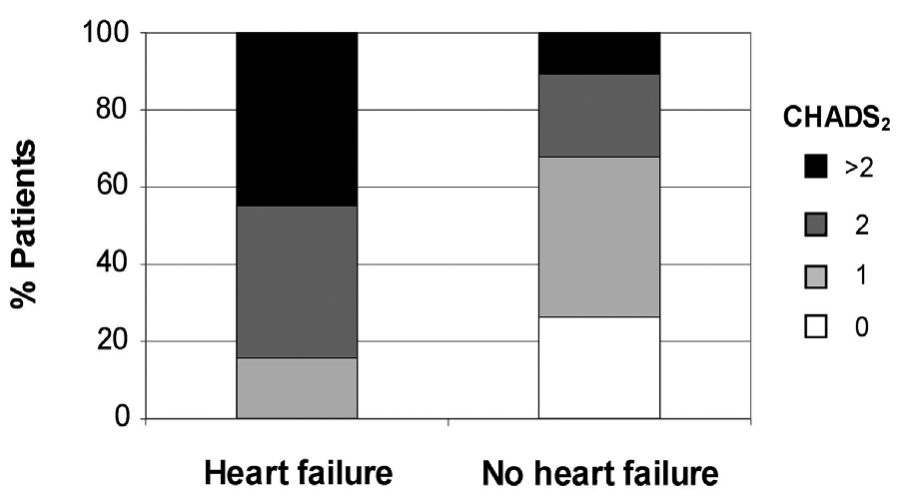

Figure 1. $\mathrm{CHADS}_{2}$ stroke risk score in $\mathrm{AF}$ patients with versus without $\mathrm{HF}^{\mathrm{C}} \mathrm{CHADS}_{2}$ stroke risk score: Congestive HF, Hypertension, Age $\geq 75$ years and Diabetes are appointed 1 point and a prior stroke or transient ischemic attack 2 points, producing a sumscore of 0 to 6

\section{Management of patients with $A F \& H F$}

Chest X-ray and transthoracic echocardiography were more often and interventions to restore sinus rhythm less often performed in HF patients (Table 2). Class I antiarrhythmic drugs and sotalol were less often applied in HF, but still in 4\% and $2 \%$ of cases respectively, whereas amiodarone was preferred in HF. Further, digitalis, beta blockers, diuretics, OAC and ACE-i were more often prescribed in HF, which was not observed for, ARB, verapamil and diltiazem.

Beta blocker and OAC prescription did not depend on NYHA class, whereas the prescription of a diuretic, digitalis and an ACE-I or ARB significantly increased with worsening NYHA class, although not consistently in NYHA class IV for ACE-I or ARB (Figure 2). Of all pts with NYHA class II to IV, 14\% did not receive an ACE-i, ARB nor a beta blocker.

In patients with LVSD-HF prescription of ACE-i (73 vs 61\%; $\mathrm{P}<0.001$ ), diuretics ( 85 vs $74 \% ; \mathrm{P}<0.001)$, amiodarone ( $33 \%$ vs $26 \% ; \mathrm{P}=0.016)$ and digitalis (46 vs $37 \% ; \mathrm{P}=0.003$ ) was significantly higher than in $\mathrm{PSF}-\mathrm{HF}$, while no difference was found in prescription of a beta blocker, verapamil, diltiazem, aspirin or OAC.

Recommended drug therapy for HF was given in $40 \%$ of 1816 patients with AF and HF (Figure 3), which changed only marginally to $44 \%$ after exclusion of 772 patients with potential contraindications for a beta blocker, ACE-i or ARB (ventricular rate $<50$ beats per minute, renal failure, chronic obstructive pulmonary disease (COPD), sick sinus syndrome, systolic blood pressure $<85 \mathrm{mmHg}$ and $\mathrm{AV}$ block grade 2 or 3). Multivariable analysis showed that recommended drug therapy for $\mathrm{HF}$ was more likely with hypertension (odds ratio $(\mathrm{OR})=1.85 ; \mathrm{P}<0.001$ ), diabetes $(\mathrm{OR}=1.46 ; \mathrm{P}=0.002)$, and a history of ventricular fibrillation (OR 1.90; $\mathrm{P}=0.009)$, and less likely with increasing age $(\mathrm{OR}=0.98$ per year increase; $\mathrm{P}=<0.001)$, female gender $(\mathrm{OR}=0.73 ; \mathrm{P}=0.004)$ and $\mathrm{COPD} \quad(\mathrm{OR}=0.34$; 
Table 2. Management of atrial fibrillation patients with and without heart failure

\begin{tabular}{|c|c|c|c|}
\hline & Heart failure & No heart failure & P-value \\
\hline \multicolumn{4}{|l|}{ Diagnostics $^{\mathrm{a}}$} \\
\hline Chest X-ray & 89 & 77 & $<0.001$ \\
\hline Trans-thoracic echocardiogram & 90 & 81 & $<0.001$ \\
\hline Trans-esophageal echocardiogram & 11 & 14 & 0.004 \\
\hline Holter monitoring & 31 & 28 & 0.049 \\
\hline Event recorder & 1 & 2 & 0.006 \\
\hline Exercise test & 17 & 23 & $<0.001$ \\
\hline Electrophysiology & 5 & 6 & NS \\
\hline Thyroid hormone & 41 & 50 & $<0.001$ \\
\hline \multicolumn{4}{|l|}{ Interventions ${ }^{b}$} \\
\hline Pharmacological cardioversion & 17 & 24 & $<0.001$ \\
\hline Electrical cardioversion & 14 & 19 & $<0.001$ \\
\hline Catheter ablation & 1 & 4 & $<0.001$ \\
\hline Pacemaker & 4 & 4 & NS \\
\hline Implantable cardioverter-defibrillator & 1 & 0 & $<0.001$ \\
\hline \multicolumn{4}{|l|}{ Rate / rhythm control drugs } \\
\hline Class I antiarrhythmic & 4 & 13 & $<0.001$ \\
\hline Amiodarone & 27 & 23 & 0.001 \\
\hline Sotalol & 2 & 9 & $<0.001$ \\
\hline Digitalis & 43 & 19 & $<0.001$ \\
\hline Diltiazem & 4 & 4 & NS \\
\hline Verapamil & 5 & 5 & NS \\
\hline Beta blocker $^{c}$ & 50 & 40 & $<0.001$ \\
\hline \multicolumn{4}{|l|}{ Antithrombotic drugs } \\
\hline Oral anticoagulation & 68 & 63 & 0.001 \\
\hline Antiplatelet drug & 33 & 32 & NS \\
\hline Heparin & 7 & 5 & 0.002 \\
\hline None & 6 & 10 & $<0.001$ \\
\hline \multicolumn{4}{|l|}{ Other drugs } \\
\hline ACE-i & 64 & 42 & $<0.001$ \\
\hline ARB & 12 & 13 & NS \\
\hline ACE-i/ARB & 75 & 54 & $<0.001$ \\
\hline Diuretic & 82 & 36 & $<0.001$ \\
\hline Dihydropyridin calcium channel blocker & 10 & 14 & $<0.001$ \\
\hline Statin & 24 & 26 & NS \\
\hline
\end{tabular}

Results are reported as percentage within the column. a Performed at the time of the survey or at any time prior to inclusion. ${ }^{b}$ Performed at the time of the survey or planned thereafter. ${ }^{c}$ Excluding sotalol. NS, not significant.

$\mathrm{P}<0.001)$. Also CAD was a predictor of recommended HF drug therapy in both LVSD-HF (OR=1.46; $\mathrm{P}=0.016)$ and PSF-HF $(\mathrm{OR}=2.47 ; \mathrm{P}<0.001)$, but in the absence of CAD LVSD-HF was more likely to receive recommended drug therapy for $\mathrm{HF}$ (OR 1.90; $\mathrm{P}<0.001)$. The latter effect was mainly due to a lower prescription rate of ACE-i among patients with PSF-HF in the absence of CAD. 


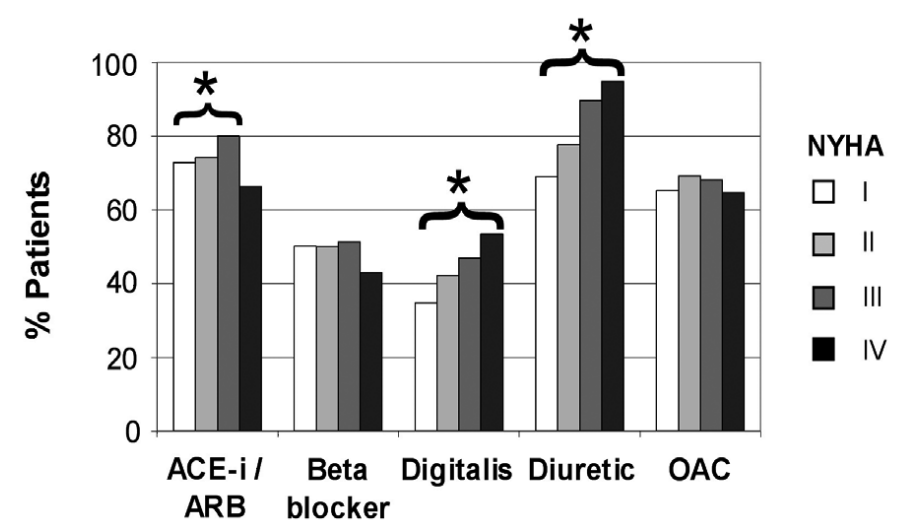

Figure 2. Drug therapy per NYHA functional class in AF patients with HF * $\mathrm{P}$ for trend $<0.05$.

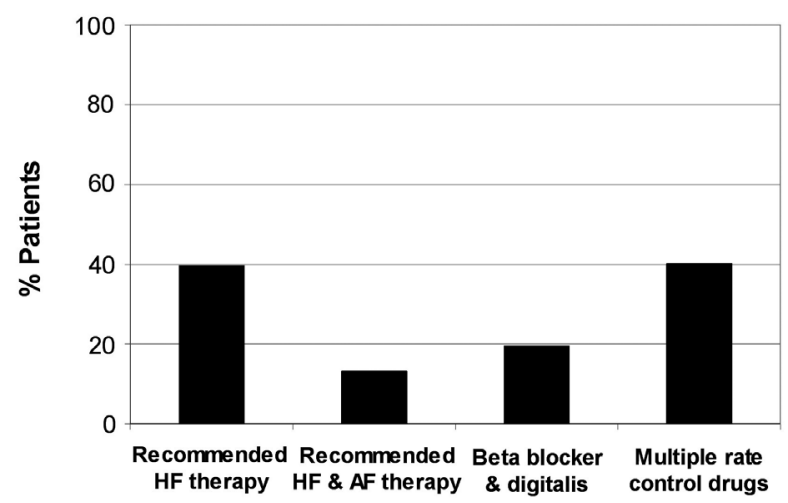

Figure 3. Application rates of recommended drug therapy in AF patients with HF.See Methods for definitions of recommended drug therapy for $\mathrm{HF}$ and $\mathrm{HF} \& \mathrm{AF}$, and of rate control drugs.

The full package of recommended drug therapy for HF \& AF was given in 13\% of the 1816 patients with AF and HF (Figure 3), which just slightly increased to 16\% after exclusion of 933 patients with the previously mentioned potential contraindications for recommended HF therapy and in addition the remaining potential contraindications for OAC and digitalis (major bleeding, malignancy, hypertrophic cardiomyopathy, ventricular tachycardia, ventricular fibrillation and Wolff Parkinson White syndrome). Female patients $(\mathrm{OR}=0.70 ; \mathrm{P}=0.014)$ and patients with COPD $(\mathrm{OR}=0.41 ; \mathrm{P}<0.001)$ or sinus rhythm at discharge $(\mathrm{OR}=0.24$; $\mathrm{P}<0.001)$ had a lower chance of receiving this optimal treatment, but no difference was observed between LVSD-HF and PSF-HF.

The combination of a beta blocker and digitalis was given in $20 \%$ of all HF patients, and $40 \%$ received any type of rate control drug combination (Figure 3). 
Table 3. Multivariable associations with all-cause mortality in atrial fibrillation patients with heart failure

\begin{tabular}{lcc}
\hline Risk factor & Odds ratio & P-value \\
\hline Age, per year increase & $1.06(1.03-1.08)$ & $<0.001$ \\
Major Bleeding & $3.99(1.94-8.19)$ & $<0.001$ \\
Sinus rhythm at discharge & $0.38(0.21-0.66)$ & $<0.001$ \\
ACE-inhibitor & $0.47(0.28-0.77)$ & 0.003 \\
Female gender & $0.55(0.35-0.85)$ & 0.006 \\
NYHA functional class (reference group = I) & & $0.008^{\mathrm{a}}$ \\
$\quad$ II & $0.64(0.35-1.17)$ & \\
$\quad$ III & $1.31(0.84-2.06)$ & \\
$\quad$ IV & $2.42(1.33-4.40)$ & \\
\hline a P for trend. & &
\end{tabular}

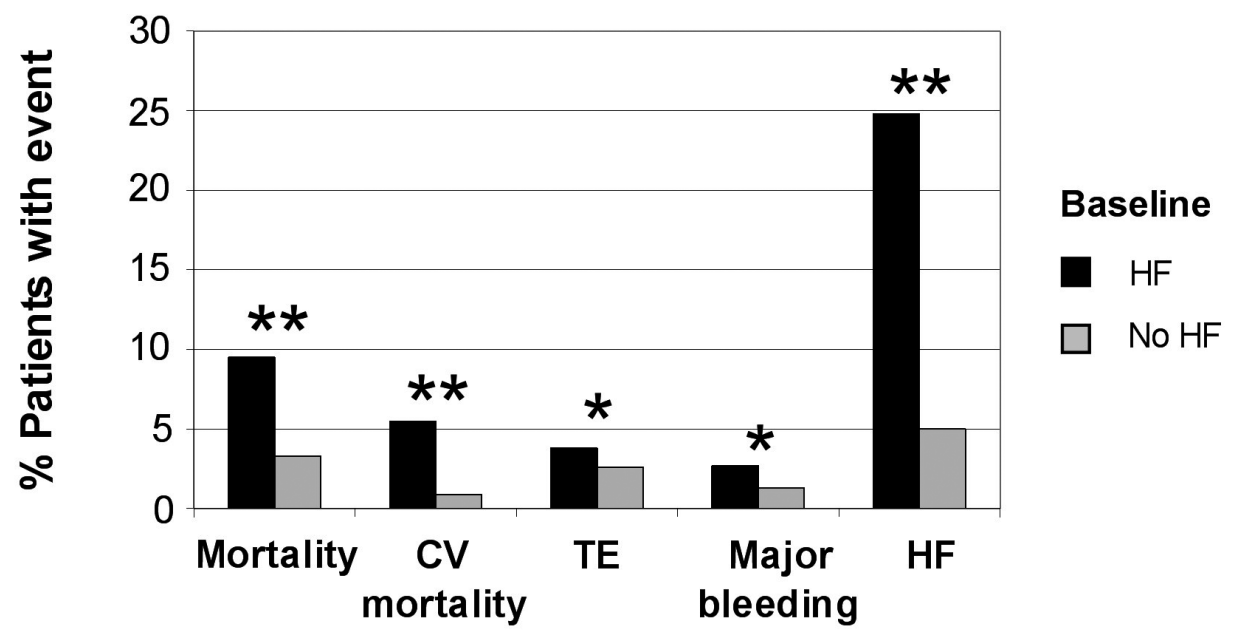

Figure 4. Major adverse events during 1 year follow-up in AF patients with versus patients without $H F$. $\mathrm{P}<0.05 ; \star \star \mathrm{P}<0.001$. CV, cardiovascular; TE, thromboembolism.

When selecting HF patients with permanent AF these application rates were comparable, $24 \%$ and $38 \%$ respectively, and $16 \%$ did not receive any rate control drugs. Of note, $40 \%$ of HF patients with permanent $\mathrm{AF}$ had a resting heart rate $\leq 80$ beats per minute. Patients with LVSD-HF more often received multiple rate control drugs than PSF-HF (46 vs $37 \%$; $\mathrm{P}<0.001$ ). The combination of a beta blocker and digitalis was more frequently applied in LVSD-HF (22 vs 17\%; $\mathrm{P}=0.049)$, whereas the application of verapamil (6\% in LVSD-HF vs $4 \% ; \mathrm{P}=0.274)$ and diltiazem (both $5 \% ; \mathrm{P}=0.928$ ) was similar. 


\section{Adverse events, disease progression and treatment during 1 year follow-up}

During 1 year follow-up patients with AF and HF clearly had a worse outcome than AF patients without HF (Figure 4). In multivariable analysis, HF was not significantly associated with having a stroke, any thromboembolic complication or major bleeding, but it was significantly associated with all-cause and cardiovascular mortality and HF during 1 year.

Among HF patients, increasing age, prior major bleeding, and worsening of NYHA class were significantly associated with a higher all-cause mortality (Table 3). On the other hand, having sinus rhythm at discharge, female gender and ACE-i use were associated with a lower mortality. No significant effects of rhythm versus rate control, type of AF, LVSD-HF versus PSF-HF, beta blocker, ARB, OAC, were found on any of the adverse events (all-cause mortality, cardiovascular mortality, thromboembolism, major bleeding and HF) or their combined endpoints. Also no effects of recommended drug therapy on any of the (combined) endpoints were found for among all HF patients, as well as in LSVD-HF and PSF-HF, even after exclusion of patients with relevant potential contraindications.

AF progression during 1 year was more often observed in HF patients ( 35 versus $19 \%$; $\mathrm{P}<0.001$ ), but was similar in LVSD-HF and PSF-HF (35 and $31 \%$ respectively; $\mathrm{P}=0.612$ ). When selecting patients with first detected AF at baseline, HF patients more often progressed to either persistent or permanent AF after 1 year follow-up (49 versus $12 \% ; \mathrm{P}<0.001)$ and these proportions were comparable in LVSD-HF and PSF-HF (49 versus $46 \%$ respectively; $\mathrm{P}=0.470$ ). HF worsening was observed in $25 \%$ of al HF patients and $7 \%$ of patients with first detected AF had new onset HF during 1 year.

\section{DISCUSSION}

Our subanalysis of the Euro Heart Survey on AF gives a complete overview of patient characteristics, treatment and outcome of patients having both HF and AF. Patients with AF and HF have significantly more comorbidity than AF patients without HF, which in turn is associated with a higher stroke risk. Although the rate of a prior stroke was indeed higher in HF, the stroke incidence during 1 year follow-up was similar in AF patients with and without HF. In contrast, having HF significantly increased short term all-cause mortality, cardiovascular mortality and $\mathrm{HF}$ worsening among AF patients. Guideline adherence is very poor in patients with $\mathrm{AF}$ and $\mathrm{HF}$ in terms of combined prescription of drugs for HF, rate control and stroke prevention. The positive effect of recommended HF medication has not been investigated extensively in this specific patient category. In our analysis, only ACE-i prescription was associated with favourable outcome. HF patients had more advanced atrial structural remodelling and a high prevalence of advanced types of $\mathrm{AF}$ at baseline, as well as more frequent AF progression after 1 year. Finally, this 
study confirms that in an AF population with HF, management and outcome are largely similar among PSF-HF and LVSD-HF patients. Synchronization of both guidelines on $\mathrm{AF}$ and $\mathrm{HF}$ management and randomized controlled trials assessing the exact role of recommended HF medication are needed to enhance standardized treatment and improve outcome in patients having both AF and HF.

\section{Stroke risk in $H F$ and $A F$}

The $2001 \mathrm{AF}$ and $2005 \mathrm{HF}$ guidelines10,14 recommended OAC in all AF patients with HF, which was not done in $32 \%$ of these patients and this could not be fully explained by the presence of potential contraindications. A previous subanalysis of the Euro Heart Survey also showed that HF did not significantly trigger OAC prescription. ${ }^{15}$ One has to keep in mind that the vast majority of HF patients also has another $\mathrm{CHADS}_{2}$ stroke risk factor. The $2006 \mathrm{AF}$ guidelines - which consider LVSD-HF to be at higher risk than PSF-HF - do not recommend OAC in all HF patients, ${ }^{8}$ but when assessing stroke risk according to this update still $94 \%$ of $\mathrm{HF}$ patients in the survey should receive OAC. It is therefore probably justified to advise prescription of OAC in all AF patients with HF in cardiology practice, also since the minority of patients with solely HF as a risk factor are likely to develop another risk factor sooner or later (e.g. due to reaching the age limit). This straightforward recommendation might improve OAC application in the long run in this subgroup.

Nevertheless, HF is not considered a very strong independent risk factor for stroke, since the updated guidelines do not consider HF a single indication for OAC like a previous stroke or transient ischemic attack, and they also recommend weighing left ventricular systolic function separately from the clinical diagnosis of HF. The survey indeed shows a variable impact of HF on stroke, considering its contradictory results that a prior stroke was more often observed in HF, but stroke incidence during 1 year was similar in HF and no HF, as well as in LVSD-HF and PSF-HF.

\section{Combined management of $H F$ and $A F$}

In HF, both ARB and ACE-i have a proven protective effect on morbidity and survival and are therefore recommended. ${ }^{16-18}$ Also, both drugs have the potential to decrease atrial pressure, reduce fibrosis and AF recurrence. ${ }^{19-22}$ Taking its positive effect on HF and potentially also on AF, it is encouraging to see that ACE-i prescription was higher in the HF group, although this was not observed for its substitute ARB. Also, a beta blocker is recommended in all HF patients, but only $50 \%$ actually received this drug. When comparing this prescription rate of beta blockers with that in the Euro Heart Survey on HF I (2000-2001:36.9\%) and the recently published HF II (2004-2005: 61,4\%), a positive trend is seen over time. ${ }^{11,23}$ Nevertheless, the combination of either an ACE-I or ARB with a beta blocker 
("recommended drug therapy for HF") was prescribed in only $40 \%$ of patients with HF and AF, which hardly increased to $44 \%$ after exclusion of patients with one or more potential contraindications.

Digitalis is highly recommended for its inotropic effect and also for rate control in patients with HF and AF and should - at least in LVSD-HF - for the latter purpose be added to a beta blocker. However, $72 \%$ of patients with LVSD-HF and permanent AF did not receive this combination, and any combination of rate control drugs was applied in only half of the patients. Considering the fact that the minority of these patients had a ventricular rate below 80 beats per minute, which is the target rate according to the HF guidelines, this might indicate that rate control therapy was suboptimal. Considering the model of the combined treatment with digitalis, OAC, beta blocker and ACE-i or ARB, an extremely low application rate of $13 \%$ was observed, which hardly increased after exclusion of patients with potential drug contraindications.

It was surprising to see that in some HF patients class I antiarrhythmics and sotalol were given. These drugs can cause severe side effects, among which life threatening ventricular arrhythmias and HF, and should be avoided in HF at any time. ${ }^{24,25}$ Finally, it was remarkable that the application of verapamil and diltiazem was comparable in patients with versus without HF and in LVSD-HF versus PSF-HF. These class IV rate control drugs have the potential to deteriorate HF and are contraindicated, especially in LVSD- $\mathrm{HF}^{26}$

Considering the above, it can be concluded that adherence to recommended drug therapy is inadequate. The fact that adherence was best in patients with hypertension and diabetes seems logical since in part these diseases warrant the same drugs as used in HF. On the other hand, supposed frailty (elderly, females), fear for side effects (COPD) or the notion that therapy was not needed (patients in sinus rhythm) was associated with low adherence. In addition, lack of confidence concerning the recommended drugs may have caused low adherence since recommendations are frequently based on trials in which elderly and females are often underrepresented.

\section{Reciprocal impact of HF and $A F$ and the effect of drug therapy}

In agreement with previous observational studies, we showed that HF dramatically worsens prognosis of AF patients. ${ }^{1}$ Having sinus rhythm at discharge (even though associated with low adherence to HF treatment) and receiving an ACE-i was associated with a lower risk for all-cause mortality, which was actually also observed in the total Euro Heart Survey on AF cohort. In contrast to ACE-i, the effect of beta blockers on mortality in the HF subgroup with AF is not yet established in a prospective manner and our results add doubt since no protective effect was found during short-term follow-up. 
No difference in mortality was found between a rate and rhythm control strategy. Probably, sinus rhythm simply reflects a better hemodynamic cardiac situation and might therefore be an independent prognostic marker rather than a treatment target. In view of women's lower likelihood of receiving recommended HF drug therapy, we cannot explain their lower mortality risk, especially since they exhibit a higher prevalence of comorbid conditions. ${ }^{27}$ Whether the higher prevalence of PSF-HF plays a role in this cannot be concluded from our data.

Besides significant ventricular remodelling, HF patients also had more severe left atrial structural remodelling than AF patients without HF as expressed in a larger left atrial size. In addition, HF patients more often had advanced forms of AF at baseline and more often progressed to persistent and permanent AF during 1 year. Obviously, also in the clinical setting, HF stimulates AF progression and increases the chance that physicians accept AF as permanent.

\section{LVSD-HF versus PSF-HF}

Our findings that PSF-HF patients were older, more often female and more often had a history of hypertension, and that LVSD-HF patients more often had a history of vascular disease, are in line with previous reports. ${ }^{28,29}$ Most PSF-HF patients $(93 \%)$ had an associated cardiovascular condition whereas 17\% of LVSD HF patients did not have another condition except LVSD. The latter patients obviously had either a tachycardiomyopathy or idiopathic HF. Interestingly, PSF-HF patients had less marked atrial remodelling than LVSD-HF expressed as a smaller echocardiographic left atrial size. It seems logical that prescription of an ACE-i and digitalis was more likely in LVSD-HF since their efficacy on survival is less well established in PSF-HF, and this in agreement with findings of the Euro Heart Survey on HF I. ${ }^{28}$ In contrast to the latter survey, we did not observe a higher application rate of beta blockers in LVSD-HF. No differences in major adverse events between PSF-HF and LVSD-HF were observed. This is in contrast to findings of a previous study that showed a higher mortality in LVSD-HF. ${ }^{30}$ Possibly, AF has a worse effect on PSF-HF than on LVSD-HF.

\section{Limitations}

We might have underestimated mortality and incidence of adverse events, especially among patients having both AF and HF, since patients lost to follow-up (20\%) were more often admitted in the hospital ( 65 vs $54 \%$ : $\mathrm{P}<0.001)$ at the time of the baseline survey and more often had HF (42 vs $32 \%$ : $\mathrm{P}<0.001$ ). Furthermore, for $63 \%$ of HF patients recent echo data were available, meaning that we could not determine whether it was LVSD-HF or PSF-HF in the remaining 37\%. We did not have dosages of prescribed drugs. Since dosing of recommended drugs in daily practice is frequently lower than proven effective in trials, this might partially explain the absence of efficacy of some drugs in our survey. 


\section{Clinical implications}

The combination of HF and AF has a grim prognosis. Management of these patients is far from optimal which might be due to lack of guideline knowledge. However, also doubt about appropriate therapy in patients that are often underrepresented in randomized controlled trials - such as elderly, females and patients with PSF-HF - and about inconsistent recommendations throughout separate guidelines might play a role. Synchronization of both guidelines on AF and HF management and randomized controlled trials assessing the exact role of recommended HF medication are needed to standardize treatment and improve outcome in patients having both AF and HF.

\section{REFERENCES}

1. Wang TJ, Larson MG, Levy D, Vasan RS, Leip EP, Wolf PA, D'Agostino RB, Murabito JM, Kannel WB, Benjamin EJ. Temporal relations of atrial fibrillation and congestive heart failure and their joint influence on mortality: the Framingham Heart Study. Circulation 2003;107:2920-5.

2. Nieuwlaat R, Capucci A, Camm AJ, Olsson SB, Andresen D, Davies DW, Cobbe S, Breithardt G, Le Heuzey JY, Prins MH, Levy S, Crijns HJ. Atrial fibrillation management: a prospective survey in ESC member countries: the Euro Heart Survey on Atrial Fibrillation. Eur Heart J 2005;26:2422-34.

3. Cleland JG, Swedberg K, Follath F, Komajda M, Cohen-Solal A, Aguilar JC, Dietz R, Gavazzi A, Hobbs R, Korewicki J, Madeira HC, Moiseyev VS, Preda I, van Gilst WH, Widimsky J, Freemantle N, Eastaugh J, Mason J. The EuroHeart Failure survey programme- a survey on the quality of care among patients with heart failure in Europe. Part 1: patient characteristics and diagnosis. Eur Heart J 2003;24:442-63.

4. McMurray J, McDonagh T, Morrison CE, Dargie HJ. Trends in hospitalization for heart failure in Scotland 1980-1990. Eur Heart J 1993;14:1158-62.

5. Bleumink GS, Knetsch AM, Sturkenboom MC, Straus SM, Hofman A, Deckers JW, Witteman JC, Stricker BH. Quantifying the heart failure epidemic: prevalence, incidence rate, lifetime risk and prognosis of heart failure The Rotterdam Study. Eur Heart J 2004;25:1614-9.

6. Kannel WB, Wolf PA, Benjamin EJ, Levy D. Prevalence, incidence, prognosis, and predisposing conditions for atrial fibrillation: population-based estimates. Am J Cardiol 1998;82:2N-9N.

7. Vidaillet H, Granada JF, Chyou PH, Maassen K, Ortiz M, Pulido JN, Sharma P, Smith PN, Hayes J. A population-based study of mortality among patients with atrial fibrillation or flutter. Am J Med 2002;113:365-70.

8. Fuster V, Ryden LE, Cannom DS, Crijns HJ, Curtis AB, Ellenbogen KA, Halperin JL, Le Heuzey JY, Kay GN, Lowe JE, Olsson SB, Prystowsky EN, Tamargo JL, Wann S, Smith SC, Jacobs AK, Adams CD, Anderson JL, Antman EM, Halperin JL, Hunt SA, Nishimura R, Ornato JP, Page RL, Riegel B, Priori SG, Blanc JJ, Budaj A, Camm AJ, Dean V, Deckers JW, Despres C, Dickstein K, Lekakis J, McGregor K, Metra M, Morais J, Osterspey, Tamargo JL, Zamorano JL. ACC/AHA/ESC 2006 guidelines for the management of patients with atrial fibrillation: full text: a report of the American College of Cardiology/American Heart Association Task Force on practice guidelines and the European Society of Cardiology Committee for Practice Guidelines (Writing Committee to Revise the 2001 guidelines for the management of patients with atrial fibrillation) developed in collaboration with the European Heart Rhythm Association and the Heart Rhythm Society. Europace 2006;8:651-745. 
9. Hunt SA. ACC/AHA 2005 guideline update for the diagnosis and management of chronic heart failure in the adult: a report of the American College of Cardiology/American Heart Association Task Force on Practice Guidelines (Writing Committee to Update the 2001 Guidelines for the Evaluation and Management of Heart Failure). J Am Coll Cardiol 2005;46:e1-82.

10. Swedberg K, Cleland J, Dargie H, Drexler H, Follath F, Komajda M, Tavazzi L, Smiseth OA, Gavazzi A, Haverich A, Hoes A, Jaarsma T, Korewicki J, Levy S, Linde C, Lopez-Sendon JL, Nieminen MS, Pierard L, Remme WJ. Guidelines for the diagnosis and treatment of chronic heart failure: executive summary (update 2005): The Task Force for the Diagnosis and Treatment of Chronic Heart Failure of the European Society of Cardiology. Eur Heart J 2005;26:1115-40.

11. Komajda M, Follath F, Swedberg K, Cleland J, Aguilar JC, Cohen-Solal A, Dietz R, Gavazzi A, Van Gilst WH, Hobbs R, Korewicki J, Madeira HC, Moiseyev VS, Preda I, Widimsky J, Freemantle N, Eastaugh J, Mason J. The EuroHeart Failure Survey programme-a survey on the quality of care among patients with heart failure in Europe. Part 2: treatment. Eur Heart J 2003;24:464-74.

12. Hunt SA, Baker DW, Chin MH, Cinquegrani MP, Feldman AM, Francis GS, Ganiats TG, Goldstein S, Gregoratos G, Jessup ML, Noble RJ, Packer M, Silver MA, Stevenson LW, Gibbons RJ, Antman EM, Alpert JS, Faxon DP, Fuster V, Gregoratos G, Jacobs AK, Hiratzka LF, Russell RO, Smith SC, Jr. ACC/AHA Guidelines for the Evaluation and Management of Chronic Heart Failure in the Adult: Executive Summary A Report of the American College of Cardiology/American Heart Association Task Force on Practice Guidelines (Committee to Revise the 1995 Guidelines for the Evaluation and Management of Heart Failure): Developed in Collaboration With the International Society for Heart and Lung Transplantation; Endorsed by the Heart Failure Society of America. Circulation 2001;104:2996-3007.

13. Remme WJ, Swedberg K. Guidelines for the diagnosis and treatment of chronic heart failure. Eur Heart J 2001;22:1527-60.

14. Fuster V, Ryden LE, Asinger RW, Cannom DS, Crijns HJ, Frye RL, Halperin JL, Kay GN, Klein WW, Levy S, McNamara RL, Prystowsky EN, Wann LS, Wyse DG. ACC/AHA/ESC guidelines for the management of patients with atrial fibrillation. A report of the American College of Cardiology/American Heart Association Task Force on Practice Guidelines and the European Society of Cardiology Committee for Practice Guidelines and Policy Conferences (Committee to develop guidelines for the management of patients with atrial fibrillation) developed in collaboration with the North American Society of Pacing and Electrophysiology. Eur Heart J 2001;22:1852-1923.

15. Nieuwlaat R, Capucci A, Lip GY, Olsson SB, Prins MH, Nieman FH, Lopez-Sendon J, Vardas $\mathrm{PE}$, Aliot E, Sanitini M, Crijns HJ. Antithrombotic treatment in real-life atrial fibrillation patients: a report from the Euro Heart Survey on Atrial Fibrillation. Eur Heart J 2006;27:3018-26.

16. Effect of enalapril on survival in patients with reduced left ventricular ejection fractions and congestive heart failure. The SOLVD Investigators. N Engl J Med 1991;325:293-302.

17. Cohn JN, Tognoni G. A randomized trial of the angiotensin-receptor blocker valsartan in chronic heart failure. N Engl J Med 2001;345:1667-75.

18. Pfeffer MA, Swedberg K, Granger CB, Held P, McMurray JJ, Michelson EL, Olofsson B, Ostergren J, Yusuf S, Pocock S. Effects of candesartan on mortality and morbidity in patients with chronic heart failure: the CHARM-Overall programme. Lancet 2003;362:759-66.

19. Webster MW, Fitzpatrick MA, Nicholls MG, Ikram H, Wells JE. Effect of enalapril on ventricular arrhythmias in congestive heart failure. Am J Cardiol 1985;56:566-9.

20. Li D, Shinagawa K, Pang L, Leung TK, Cardin S, Wang Z, Nattel S. Effects of angiotensin-converting enzyme inhibition on the development of the atrial fibrillation substrate in dogs with ventricular tachypacing-induced congestive heart failure. Circulation 2001;104:2608-14. 
21. Madrid AH, Bueno MG, Rebollo JM, Marin I, Pena G, Bernal E, Rodriguez A, Cano L, Cano JM, Cabeza P, Moro C. Use of irbesartan to maintain sinus rhythm in patients with long-lasting persistent atrial fibrillation: a prospective and randomized study. Circulation 2002;106:331-6.

22. Ueng KC, Tsai TP, Yu WC, Tsai CF, Lin MC, Chan KC, Chen CY, Wu DJ, Lin CS, Chen SA. Use of enalapril to facilitate sinus rhythm maintenance after external cardioversion of long-standing persistent atrial fibrillation. Results of a prospective and controlled study. Eur Heart J $2003 ; 24: 2090-8$.

23. Nieminen MS, Brutsaert D, Dickstein K, Drexler H, Follath F, Harjola VP, Hochadel M, Komajda M, Lassus J, Lopez-Sendon JL, Ponikowski P, Tavazzi L. EuroHeart Failure Survey II (EHFS II): a survey on hospitalized acute heart failure patients: description of population. Eur Heart J 2006;27:2725-36.

24. Preliminary report: effect of encainide and flecainide on mortality in a randomized trial of arrhythmia suppression after myocardial infarction. The Cardiac Arrhythmia Suppression Trial (CAST) Investigators. N Engl J Med 1989;321:406-12.

25. Pratt CM, Camm AJ, Cooper W, Friedman PL, MacNeil DJ, Moulton KM, Pitt B, Schwartz PJ, Veltri EP, Waldo AL. Mortality in the Survival With ORal D-sotalol (SWORD) trial: why did patients die? Am J Cardiol 1998;81:869-76.

26. Goldstein RE, Boccuzzi SJ, Cruess D, Nattel S. Diltiazem increases late-onset congestive heart failure in postinfarction patients with early reduction in ejection fraction. The Adverse Experience Committee; and the Multicenter Diltiazem Postinfarction Research Group. Circulation 1991;83:52-60.

27. Dagres N, Nieuwlaat R, Vardas PE, Andresen D, Levy S, Cobbe S, Kremastinos DT, Breithardt G, Cokkinos DV, Crijns HJ. Gender-related differences in presentation, treatment, and outcome of patients with atrial fibrillation in Europe: a report from the Euro Heart Survey on Atrial Fibrillation. J Am Coll Cardiol 2007;49:572-7.

28. Lenzen MJ, Scholte op Reimer WJ, Boersma E, Vantrimpont PJ, Follath F, Swedberg K, Cleland J, Komajda M. Differences between patients with a preserved and a depressed left ventricular function: a report from the EuroHeart Failure Survey. Eur Heart J 2004;25:1214-20.

29. Yancy CW, Lopatin M, Stevenson LW, De Marco T, Fonarow GC. Clinical presentation, management, and in-hospital outcomes of patients admitted with acute decompensated heart failure with preserved systolic function: a report from the Acute Decompensated Heart Failure National Registry (ADHERE) Database. J Am Coll Cardiol 2006;47:76-84.

30. Hogg K, Swedberg K, McMurray J. Heart failure with preserved left ventricular systolic function; epidemiology, clinical characteristics, and prognosis. J Am Coll Cardiol 2004;43:317-27. 


\section{0}

\section{General discussion}

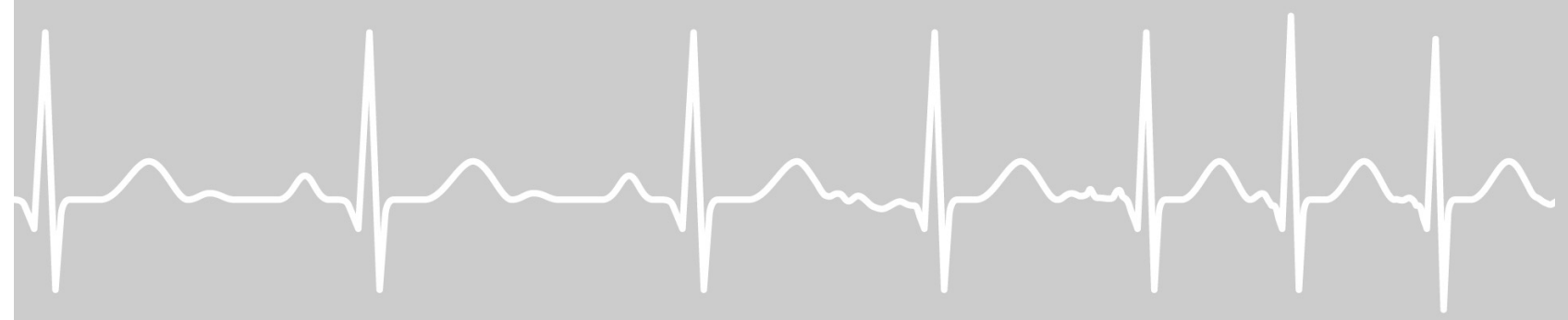


This thesis provides a unique snapshot of contemporary atrial fibrillation (AF) management in Europe, with a wealth of information. It clarifies the real-life situation on some important AF management issues. Observational studies like the Euro Heart Survey are vital for providing feedback regarding guideline application and to address management bottlenecks that require special attention. This general discussion aims to fuse the most important conclusions, to address how guideline adherence could be improved, to summarize the value and limitations of these survey data and to provide recommendations and future directions for the monitoring and quality improvement of AF care. Guideline adherence in this thesis is assessed in relation to the ACC/AHA/ESC $2001 \mathrm{AF}$ guidelines, which were of relevance at the time of our survey. ${ }^{1}$ Nevertheless, in this general discussion the updated guidelines of $2006^{2}$ are also taken in account in order to stress the dynamics of evolving guidelines and consequently AF treatment.

\section{Characteristics and consequences of guideline deviance}

The management of AF can be quite a difficult task, because of its many associated diseases, its variety of clinical presentations, the individual risk-benefit trade-off for antithrombotic drug prescription and the lack of a clear superiority of either rhythm or rate control regarding major adverse events. Nevertheless, our results allow us to indicate clear guideline deviant behaviors on some management issues. For example, thyroid hormone levels should always be measured ${ }^{1}$, which was actually only done in half of the patients. Probably, physicians often find another associated disease than thyroid dysfunction and do not deem checking thyroid hormone levels necessary. A substantial number of AF cases are associated with thyroid dysfunction at any time, although the proportion with overt hyperthyroidism is low. ${ }^{3}$ When amiodarone prescription follows, monitoring of thyroid function is definitely warranted ${ }^{4}$. Nevertheless, measurement rates were not higher in patients on amiodarone as compared to patients not on amiodarone in the Euro Heart Survey.

\section{Rhythm and rate control}

Patients classified as permanent AF - which is defined as AF in which cardioversion was unsuccessful, deemed not indicated or never attempted - often received a class III antiarrhythmic drug (amiodarone or sotalol). It is expected that rate control is the strategy of choice in permanent AF. Although amiodarone and sotalol have rate control properties, it is recommended to use typical rate control drugs, since class III antiarrhythmics can cause severe side effects such as heart failure (HF), ventricular arrhythmias, pulmonary and hepatic toxicity and thyroid dysfunction. Class I antiarrhythmic drugs are preferred to class III drugs for rhythm control, but only in the absence of underlying heart diseases such as heart failure (HF) and coronary artery disease (CAD) since class I drugs can cause HF and ventricular arrhythmias 
in these patients. ${ }^{1}$ Nevertheless, in our survey 3\% of paroxysmal and persistent AF patients had HF and/or CAD and yet received a class I drug. Another remarkable observation regarding rhythm control application is that many patients who never suffered any AF related symptoms received some form of rhythm control at the time of the survey. In several large randomized controlled trials (RCT) no clear benefit of rhythm control over rate control was found regarding mortality and major adverse events. ${ }^{5-9}$ Consequently, the 2006 guidelines state that rhythm control is the preferred strategy exclusively when the patient suffers severe limiting symptoms. However, we have to note that at the time of our survey the 2001 guidelines were of relevance and most of the important trials that assessed rhythm versus rate control were not yet incorporated in these guidelines. These 2001 guidelines indicated that prevention of thromboembolism could be a reason to apply rhythm control, which is not mentioned anymore in the 2006 guidelines. It is therefore to be expected that after the publication of the 2006 guidelines the application of rhythm control will decrease.

\section{Antithrombotic therapy}

A very important issue that was already firmly recommended in the 2001 guidelines concerns antithrombotic treatment for the prevention of thromboembolism, specifically ischemic stroke. Oral anticoagulation prescription (OAC) in the Euro Heart Survey was higher than in most previous observational studies with an overall application rate of $65 \%$. However, antithrombotic treatment appeared to be marginally tailored to the patient's stroke risk profile, regardless of which risk stratification scheme was used. Recommendations should be based on one single, simple to use, straightforward stroke risk scheme, to be applied by all medical specialties. The 2006 cardiology guidelines made a first step by providing recommendations mainly based on the $\mathrm{CHADS}_{2}$ score ${ }^{10}$, which will simplify risk stratification and improve guideline adherence - although Table 14 of these guidelines seems to spoil the straightforwardness of the recommendations. ${ }^{2}$ The 2006 recommendations basically state that with $\mathrm{CHADS}_{2}$ score 1 the physician can choose between OAC and an antiplatelet drug, but above score 1 OAC should be given. This is a different recommendation than in 2001 which stated that with any of the individual risk factors OAC should be prescribed. As a consequence, 282 high-risk patients in $\mathrm{CHADS}_{2}$ risk score 1 exclusively receiving an antiplatelet drug would be re-categorized from undertreatment in 2001 to guideline adherence in 2006 and guideline adherence in high-risk patients would increase from 61 to $69 \%$ and concomitantly undertreatment would decrease from 28 to $20 \%$. Nevertheless, it is to be expected that due to this re-categorization the negative association of antithrombotic undertreatment with cardiovascular outcome will be amplified, since undertreated patients ('2001 definition') in $\mathrm{CHADS}_{2}$ score 1 have a better prognosis than undertreated patients in $\mathrm{CHADS}_{2}$ scores $>1$. Our finding that antithrombotic 
guideline adherence is associated with improved outcomes is good news from daily practice, but should be re-evaluated with significant shifts in recommendations after guidelines are updated. Also, debate continues regarding some less well established and unfounded stroke risk factors, because of conflicting or lack of evidence, and obstinate presuppositions.

HF, either with a decreased or preserved left ventricular function, was not an important trigger for OAC prescription. Nevertheless, HF is incorporated as an independent risk factor in three out of four stroke risk stratification schemes we assessed, although it was not taken in account in the Framingham score. ${ }^{1,}{ }^{10-12}$ It seems plausible that $\mathrm{HF}$ is associated with an increased stroke risk, but OAC has not been established as beneficial in HF without AF. This might cause physicians to be reluctant with prescribing OAC in AF patients with HF. However, this reluctance might be justified now, since according to the 2006 guidelines HF alone is no firm indication for OAC prescription in the absence of other stroke risk factors. In agreement, the Euro Heart Survey data could not reveal an association of HF with an increased stroke incidence during 1 year follow-up. Nevertheless, $80 \%$ of patients with $\mathrm{AF}$ and $\mathrm{HF}$ also have at least one extra stroke risk factor, which means that $\mathrm{OAC}$ is definitely warranted according to the new ACC/AHA/ESC guideline.

The presence of hypertension, either treated or untreated, and either well-controlled or uncontrolled, did not significantly trigger OAC prescription in our survey. Information is needed on whether hypertension in general or specifically uncontrolled hypertension is the risk factor which causes increased AF incidence and stroke risk in AF. The latter seemed true in the SPORTIF trials since stroke incidence was higher when systolic blood pressure was $>140 \mathrm{mmHg} .{ }^{13}$ Over time, blood pressure averages seem to decrease in the RCTs due to better treatment. This might partially explain the lower stroke incidence in the Euro Heart Survey as compared to trial patients of earlier times, whether on no therapy (placebo), aspirin, or on OAC. ${ }^{12}$

One has to wonder whether leaving the choice for OAC in case of $\mathrm{CHADS}_{2}$ score 1 is helpful, also since many patients with score 1 will develop another risk factor over time - even if it is simply ageing - which might be overlooked due to a less stringent follow-up when AF and its stroke risk are thought to be under control. Although the individual risk-benefit ratio for OAC prescription should always be weighed by the attending physician, clear and simple recommendations will probably improve evidence based management. Continuous guidance and follow-up of patients may prevent patients from not receiving proper anticoagulation once they turn high risk over time.

One stroke risk factor in doubt is female gender. Although evidence is conflicting, some important high quality studies, such as the SPAF trials and Framingham ${ }^{11,14}$, found female gender to be independently associated with stroke. In addition, the EHS revealed a higher stroke incidence in women than in men. 
Bearing in mind that women in cardiology practice are often also older than men, with a higher prevalence of additional stroke risk factors, they deserve extra attention when deciding on antithrombotic treatment. This holds especially for women undergoing rhythm control since rhythm control was associated with a significant increased stroke risk. Therefore, women will probably benefit to a larger extent from OAC, especially under rhythm control, and certainly should not have a lower chance for receiving OAC. Frequent INR monitoring in especially elderly women is probably warranted since they might more readily bleed on OAC. ${ }^{15,16}$

The Euro Heart Survey clearly reveals that cardiologists today still consider paroxysmal AF - and AF that is considered to be 'cured' or incidental - to represent a lower stroke risk than persistent and permanent AF. This observation is confirmed by other recent studies. ${ }^{17,}{ }^{18}$ However, until now there has been no convincing evidence that paroxysmal AF truly holds a lower stroke risk than persistent and permanent AF. Moreover, this thesis shows a comparable stroke incidence in paroxysmal, persistent and permanent AF, with even a trend towards a higher incidence in paroxysmal $\mathrm{AF}$ if these patients undergo cardioversion. It seems likely that a high AF burden increases the stroke risk. But how should AF burden be defined when talking about stroke risk? Is a single long-lasting episode more thrombogenic than AF that frequently starts and stops? An adequate definition of AF burden needs to be formulated, including the burden of rhythm changes. In addition, specific noninvasive monitoring tools are needed to accurately assess this burden. It will be essential to assess the direct effect of the AF burden on stroke risk.

The discussion above focuses on the risk for stroke, but the risk for bleeding should of course also be weighed in the decision to anticoagulate or not. Until now, four bleeding risk stratification schemes in AF have been proposed. ${ }^{19-22}$ However, these schemes all address the risk for any major bleeding rather than intracranial hemorrhage (ICH) specifically. ICH is considered to be the natural counterpart of stroke in AF patients on OAC, but its incidence in our survey - even among patients on OAC - is very low, which is in agreement with observations from RCTs. ${ }^{12}$ Considering the very low incidence of ICH on OAC and keeping in mind the worse effect of undertreatment as compared to overtreatment, fear for stroke should outweigh the traditional fear for any major bleeding when deciding on OAC. However, specifically ICH risk might be of importance rather than the risk for any major bleeding. Many major bleedings can be treated appropriately, but ICH is usually lethal, which is comfirmed in the Euro Heart Survey. Factors that have been linked to an increased ICH risk on OAC are INR values $>3.5$, hypertension, a previous cerebrovascular thromboembolism and old age, although OAC might not further increase the high ICH incidence in the very old $(\geq 80) \cdot{ }^{23,24}$ Paradoxically, these factors are also associated with an increased risk for stroke, whereby their risk for stroke is higher than the ICH risk. At present it is unclear which patient has an excessive ICH risk even outweighing their stroke risk. In this context, there could be a potential role for imaging 'white matter lesions', microbleeds and 
lacunae in the brain. ${ }^{25,26}$ In addition, a simple score using the FGI triad of Forgetfulness, Gait problems and urinary Incontinence - which are associated with small vessel disease, microbleeds and white matter lesions on MRI - may serve as a quick and easy to use screening tool for high ICH risk. ${ }^{27}$ When this 'FGI triad' is encountered the patient's risk for ICH is around $5 \%$ on OAC. Physicians probably avoid OAC intuitively in these 'fragile' patients.

\section{Important subgroups}

Besides the discussion on their value as an independent predictor for stroke in AF, some other observations regarding the management of the important subgroups of females and HF patients are worth mentioning. On several occasions, it has been shown that females are less adequately treated than men. ${ }^{28-30}$ In contrast, in our survey we saw a lower application of rhythm control in the absence of symptoms which seems to favor women since they are less often unnecessarily exposed to the potential hazardous effects of rhythm control. The latter risk might even be higher in women since we showed that if women undergo rhythm control, they have a higher propensity to develop stroke than men at a similar rate of OAC. We also saw that women less often received recommended therapy for HF. Nevertheless, they had a better prognosis than their male counterparts with HF. Whether the latter relates to the higher prevalence of PSF-HF in women or to gender itself deserves further study.

The application of recommended therapy for the combined management of HF and AF was very poor. Possibly, lack of convincing evidence to support these recommendations and differences throughout separate guidelines cause cardiologists to be reserved with applying the full package of recommended drugs in all patients with AF and HF. Since HF dramatically worsens the prognosis of AF and leads to progression of AF, the combined management of AF and HF deserves full attention. More firm evidence on appropriate therapy, making recommendations uniform throughout separate guidelines and education on the optimal evidence based management could improve management and prognosis of this subgroup.

In summary, these are the most remarkable examples of management guideline deviance (2001 guidelines), with the matching level of evidence:

- Thyroid hormone levels are often not assessed, even not when on chronic amiodarone (Level C)

- Class III drugs amiodarone or sotalol are used as rate control drugs (Level C)

- Rhythm control is applied in patients without symptoms whatsoever (level C)

- Rhythm control with class Ic drugs is applied in patients with HF or CAD (Level A)

- Antithrombotic treatment is only marginally tailored to the stroke risk profile, i.e. patients are overtreated as well as undertreated (Level A) 
- Paroxysmal AF, AF that is considered 'cured' (e.g. after ablation) and AF that only occurs incidental, are assumed to represent a lower stroke risk than persistent and permanent $\mathrm{AF}$ and these patients do not receive adequate OAC (Level B)

- OAC is considered less urgent around pharmacological cardioversion than around electrical cardioversion, whereas it is recommended around both (Level B)

- Less than half of the AF patients with HF receive the highly recommended combination of beta blocker with an ACE-I or ARB for the management of HF (Level A)

- Only very few patients with AF and HF receive the recommended composite treatment of OAC, ACE-I or ARB, beta-blockade, and digitalis (Level A for all)

\section{Reasons for guideline deviance and potential methods to improve adherence}

Many factors play a role in adequately implementing guidelines into practice. ${ }^{31}$ Guidelines should be simple, concise, clear and easy to use. ${ }^{32,33}$ A great example to establish this, is the availability of the stroke risk scheme $\mathrm{CHADS}_{2} \cdot{ }^{10}$ Widespread use of such schemes will also improve uniformity amongst different guidelines. Slight differences - such as observed in the guidelines of AF and HF on each other's management - might spread doubt about the correct treatment and certainly enhance physicians' critical attitude towards guidelines in general. Unfortunately, guideline composers have allowed - clinically less relevant - intricacies to trickle into the recommendations, making them less straightforward. Many physicians do not feel encouraged to read the abundance of extensively written management guidelines, and therefore summaries, pocket versions, PDA downloadable versions and implementation of guidelines in education courses might help to increase familiarity with the guidelines. Opinion leaders can improve the widespread use of guidelines $^{34}$, also by stimulating the implementation of guidelines in electronic clinical decision aids. ${ }^{35,}{ }^{36}$ Specialized nurses could handle standardized care with the back-up of physicians for complex patients. ${ }^{37,38}$ An important problem for the implementation of guidelines that are externally imposed is to reach local consensus on the same guidelines and to arrange the local situation (facilities) in such a way that full implementation is possible. ${ }^{39-42}$ Local economical and health care situations can vary substantially, and substantial regional differences in the management of e.g. acute coronary syndromes have been observed. ${ }^{43}$ The best available treatments are often new and also quite costly, and might not be achievable in all regions. Nevertheless, organizations such as the ESC should aim to provide guidelines based on the best available evidence based treatments, regardless of the costs. $^{44}$

It seems that availability of facilities, local 'life-long' routines, and established appealing paradigms determine actual clinical practice, rather than new clinical trial 
data as incorporated in guidelines. Examples of appealing but erroneous concepts include the strong belief that paroxysmal AF patients do not need anticoagulation, that AF lasting less than 48 hours is not associated with stroke, that AF associated with stroke risk factors can easily be ablated and when AF is 'eliminated' anticoagulation may be stopped (which is not true since the underlying stroke risk factors are the very factors also determining the failure of rhythm control), and so on. In other words, it takes a long time before new data and concepts become accepted in clinical practice.

Our results suggest that a high level of evidence of a specific recommendation is not necessarily a guarantee for stringent adherence to that recommendation. Lack of physicians' guideline knowledge might underlie this observation, which is a problem that could be underestimated by the physicians themselves since they tend to overestimate guideline adherence. ${ }^{45}$ In case of good guideline knowledge, however, it seems plausible that a weak evidence base triggers physicians to divert from recommendations. The only method to prevent this reasoning is continuing high-quality clinical research to enlighten the best possible treatment on all management issues, which is the goal of clinical science per se. Special attention should be drawn to subgroups that are underrepresented in current clinical trials and that are more likely to be inadequately treated in order to improve the external validity of recommendations. ${ }^{46,47}$

\section{The evidence base for atrial fibrillation management}

In this thesis quality of AF care is evaluated according to the guidelines and it is tempting to label all guideline deviant behavior as not appropriate or at least suboptimal treatment. When assessing management guideline adherence, however, one has to keep in mind that these guidelines contain recommendations and not commandments. The evidence base for guidelines is and will never be perfect and a constant critical appraisal of the evidence is warranted. Research evidence has accumulated dramatically in the past decades. Indeed, the number of publications on AF - number of hits on the PubMed website (www.ncbi.nlm.nih.gov/sites/entrez?db =PubMed) when searching titles containing "atrial fibrillation" - has increased dramatically during the last 20 years to more than 1000 publications per year (Figure 1). One would expect that the evidence base for AF management is firm with this amount of research efforts. However, when summarizing the 2006 guideline recommendations, it appears that the vast majority of all recommendations has level of evidence $\mathrm{C}$ and is solely supported by expert opinion, case studies or standard-of-care (Figure 2). Few recommendations have level of evidence A and are supported by multiple randomized clinical trials or meta-analyses. These observations indicate that many AF management issues still need to be based more firmly.

It is therefore surprising that the number of publications on RCTs, the golden standard in clinical research, showed a downward tendency in the last three years 


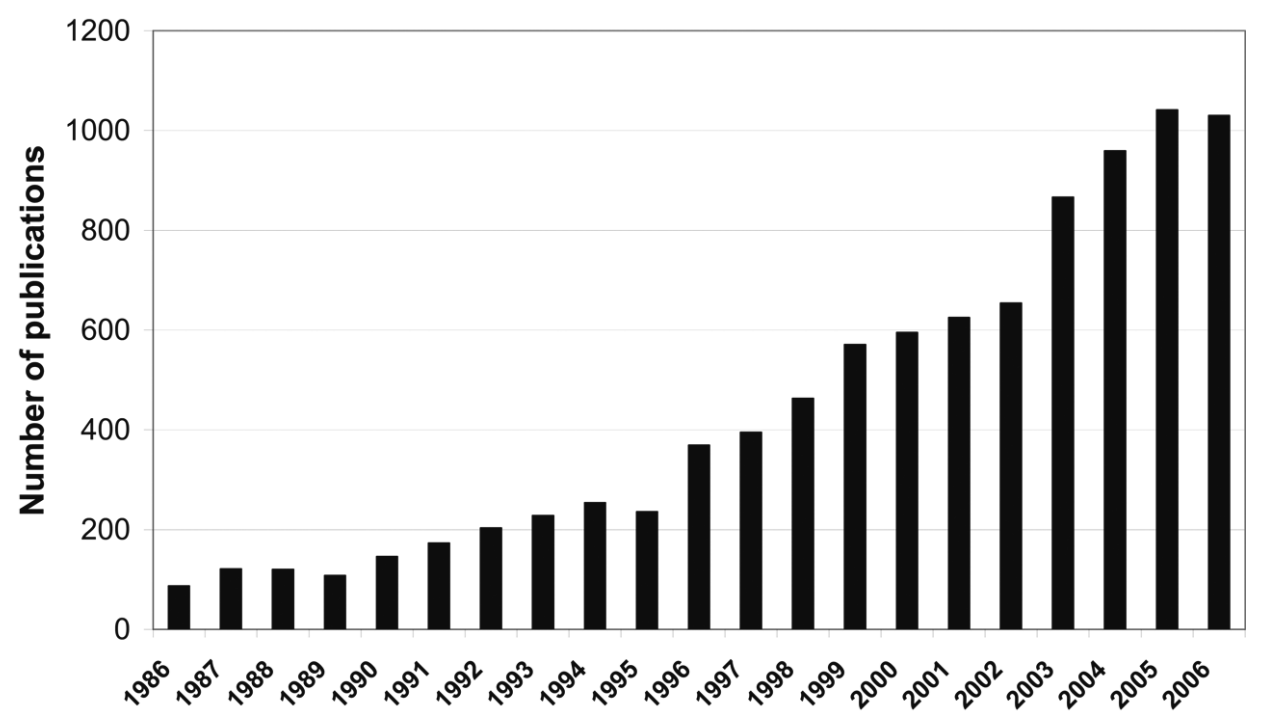

Figure 1.Number of PubMed publications on research containing "atrial fibrillation" in the title from 1986 to 2006

$\square$ I $\square$ Ila $\square$ Ilb $\square$ III

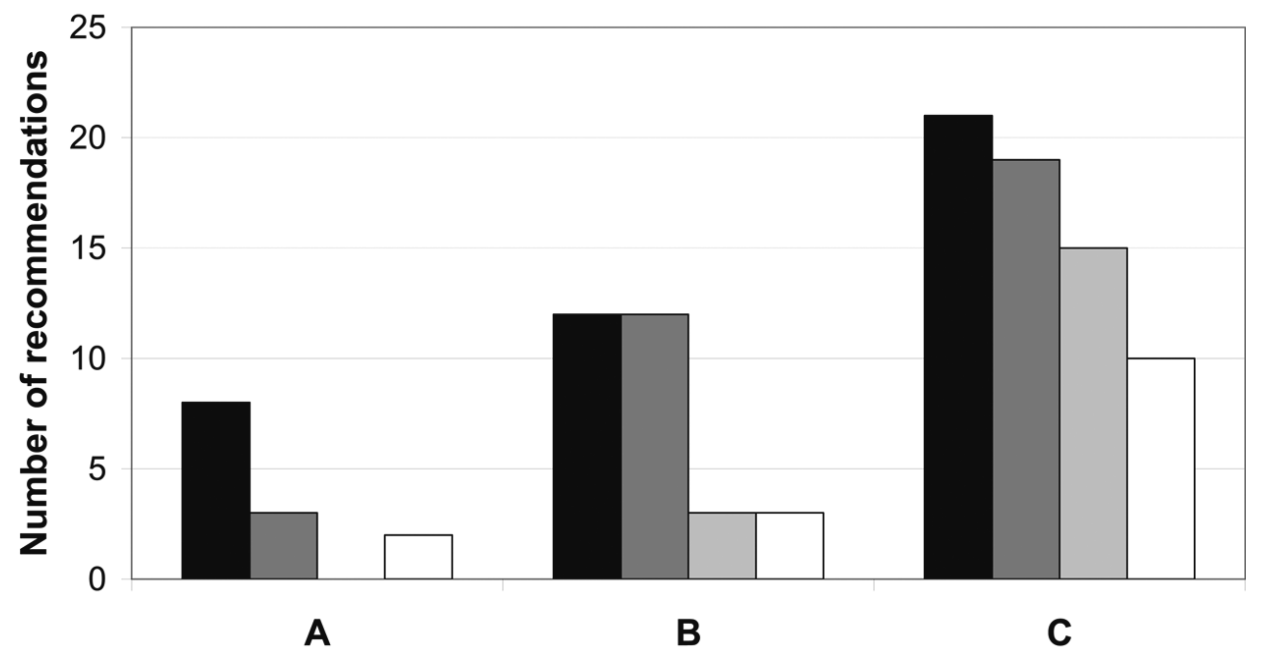

Figure 2. Number of $2006 \mathrm{AF}$ guideline recommendations per level of evidence (A,B and C) and per classification (I, IIa, IIb and III) 


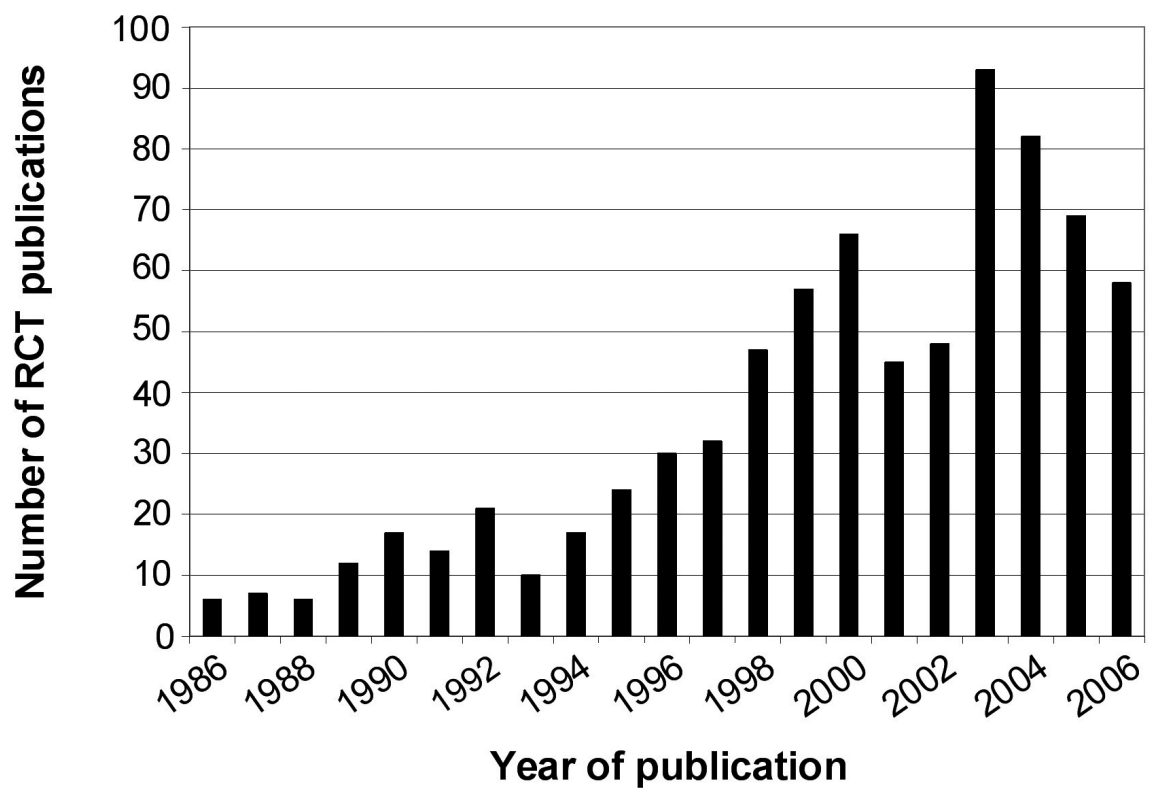

Figure 3. Number of PubMed publications on RCTs containing "atrial fibrillation" in the title from 1986 to 2006

(Figure 3). The difference between 2003 and 2006 was not attributable to less efforts on specific areas of AF research since this decrease was observed among all areas in general. A potential explanation could be that less trials are warranted since current RCTs might enroll larger number of patients. The latter seems plausible since it is challenging to establish efficacy of new therapeutic strategies on top of already existing quite effective strategies and this requires larger patient numbers. However, the number of trials enrolling $>100$ patients just slightly increased (41 (55\%) in 2003 versus $29(69 \%)$ in 2006), which was also the case for trials enrolling $>1000$ patients $(2(3 \%)$ in 2003 versus $3(7 \%)$ in 2006). Since the total number of publications on AF did not decrease (Figure 1), a shift from clinical towards basic research might be present. Growing financial opportunities for basic research could explain this trend. Also, new concepts of treatment have not yet fully evolved and new targets for molecular or cellular AF therapy have only been defined recently. ${ }^{48}$ In addition, catheter ablation studies are difficult to perform in a controlled and randomized way since the effects of ablation and medical treatment are quite different, but a recent consensus statement on ablation of AF might help in this regard. ${ }^{49}$ 
The Euro Heart Survey on AF as a trigger for furthering the knowledge base

Advancing management of AF can only be achieved effectively if we further our knowledge concerning the pathophysiology of AF and associated causes for morbidity and mortality. To achieve this some out of the box thinking may be rewarding. ${ }^{50}$ The survey suggests that European clinicians still do think and act a lot in the box. A few examples may illustrate this.

Rhythm control in asymptomatic patients while believing that control of rhythm reduces the cardiovascular morbidity and mortality associated with AF is still very frequent. Instead of killing the messenger we should start searching for underlying cardiovascular causes of AF leaving the arrhythmia alone especially if the patient is asymptomatic. Therefore, on top of classifying the arrhythmia according to the $3 \mathrm{P}$ classification (paroxysmal-persistent-permanent), ${ }^{49}$ we need a new classification for associated conditions split by AF-related mechanisms such as tachycardiomyopathy as well as background disease related mechanisms which act through ischemia, diastolic ventricular dysfunction, inflammation and enhanced atrial fibrosis. This also includes assessment of familial factors.

Stroke risk schemes are as accurate as the data which were used to construct them. For most current schemes the data were generated before the era of the novel biomarkers including advanced echocardiography and serum markers for thromogenicity. The diseases and conditions forming the basis of e.g. the $\mathrm{CHADS}_{2}$ score like hypertension and HF need to be diagnosed more precisely. At the end of the day we will be able to identify thrombogenic hypertension or thrombogenic paroxysmal AF as well as arrhythmogenic HF or HF not amenable to rhythm control.

\section{Value and limitations of the Euro Heart Survey and EXAMINE-AF}

As per February $15^{\text {th }} 2007,19$ observational AF studies are listed on the website www.clinicaltrials.gov, but these studies do not need to be registered there, and this overview underestimates the current observational efforts. Nevertheless, until now the Euro Heart Survey is a unique prospective observational study on contemporary AF management in Europe. Although a number of studies already addressed guideline adherence for AF, they mainly focused on antithrombotic therapy and were largely North-American. The Euro Heart Survey was a prospective survey with a 1 year follow-up, whereas most previous surveys and registries were retrospective or purely cross-sectional. Nevertheless, some limitations of this survey have to be addressed. This thesis mainly focuses on antithrombotic treatment, and the incomplete registration of potential contraindications for OAC is a missed opportunity. The analysis of rate and rhythm control strategies in this thesis is limited and mainly addresses on-treatment observations rather than intention-to-treat, and does not contain full information on adverse effects of a rhythm control strategy. To fill this gap, the RecordAF study will be a great opportunity to adequately assess the 
application, success and complications of rate versus rhythm control strategies in daily practice throughout the world. In this study, complete information will be available on treatment success (either maintaining sinus rhythm or ventricular rate $<80 \mathrm{bpm}$ ), (reasons for) treatment changes, complications and major adverse events in the "real-life" situation. In an international observational study like the Euro Heart Survey it is inevitable that a substantial number of patients will be lost-to-follow-up since participation is mainly on a voluntary basis. Non-responders at follow-up are often more diseased at baseline - as we also observed - and their absence probably underestimated mortality and event rates during 1 year. ${ }^{51}$ Finally, it is clear that there was a selection bias regarding the participating centers and countries. Enrolment per country was not equally divided, since mainly Mediterranean countries and The Netherlands highly contributed, whereas large Western European countries such as the United Kingdom, France and Germany were low includers. In addition, the proportion of hospitals with an electrophysiology laboratory was quite high, indicating that highly interested and specialized hospitals participated. Therefore, the results of the Euro Heart Survey might not be representative of average Europe and results cannot automatically be extrapolated to the whole of Europe.

The EXAMINE-AF is the first study to show that most antithrombotic treatment decisions in AF patients, even when treated by GPs or internists, are taken by cardiologists. In addition, antithrombotic guideline adherence was better when the cardiologist was the attending physician. These observations stress the importance of cardiologists' expertise when treating AF, also considering stroke prevention therapy. One has to keep in mind, however, that EXAMINE-AF was exclusively performed among Dutch physicians and extrapolation to other countries might not necessarily be appropriate. Furthermore, no prospective outcome data were collected, so unfortunately we could not assess the benefit of treatment by type of specialist in terms of cardiovascular prognosis.

In general, the strength of observational studies is to make physicians aware of the best available management and to identify management issues that need to be improved. In addition, to strengthen the physicians' beliefs towards the guidelines it is essential to show that adherence to evidence based management is profitable in the real-life situation. Previous studies on acute coronary syndromes, stroke and HF management have shown the benefit of guideline adherence ${ }^{52-54}$, and the Euro Heart Survey is the first to show that adhering to recent ACC/AHA/ESC antithrombotic guidelines for AF also is associated with improved outcomes.

\section{Future perspectives of improving quality of AF management}

The website reporting clinical trials in the pipeline (www.clinicaltrials.gov) contains 87 randomized studies on AF recruiting or on the verge of recruiting patients and 40 trials recently completed or still completing follow-up, as per 
February $15^{\text {th }} 2007$. When comparing these currently listed studies with the PubMed publications of 2003 and 2006, an increased attention is seen for catheter ablation and pacing studies, whereas studies on electrical cardioversion and post-operative AF clearly receive less attention. Other studies in the pipeline concern new antiarrhythmic drugs such as dronedarone and azimilide, antithrombotic drugs such as dabigatran and glycoprotein IIb/IIIa receptor blockers, the antiarrhythmic and anti-remodeling effect of angiotensin receptor blockers, and also antiarrhythmic effects of nutritional substances such as fish-oil. In summary, these are the most promising advances in AF management that are upcoming or generally deemed necessary:

1. Current antiarrhythmic drugs have limited efficacy in maintaining sinus rhythm in the long run, and they comprise a potential to cause life-threatening ventricular arrhythmias. A search for safer and more effective antiarrhythmic drugs is therefore warranted, including drugs that only affect the atria or drugs that have an in-built safety belt concerning proarrhythmia at the ventricular level, whilst maintaining antiarrhythmic efficacy at the atrial level. A summary of current breakthroughs in the knowledge on cardiac arrhythmia mechanisms and consequently specific targets for future drug development has recently been published. ${ }^{48}$

2. Current oral anticoagulants require constant INR monitoring and consequently dose adjustment to maintain INR within the appropriate range. Too low INR values are highly ineffective for preventing stroke and too high INR levels increase the risk for bleedings. ${ }^{2}$ Safer and more stable fixed-dose anticoagulants, not requiring constant INR monitoring, are therefore needed. In this regard the direct thrombin inhibitor ximelagatran was non-inferior to OAC ${ }^{55}$, but the Food and Drug Administration did not approve its application for chronic treatment in AF patients because of associated liver problems. ${ }^{56}$ Nevertheless, it is to be expected that fixed-dose anticoagulants will be introduced in the future, which will probably lead to higher prescription rates, better patient compliance, less bleedings and eventually a higher cost-effectiveness because of the absence of INR monitoring.

3. Upstream therapy directed at factors setting the stage for progression of AF itself and its associated stroke risk will improve AF prognosis. As this thesis shows, being in sinus rhythm - regardless of the application of rhythm or rate control - is associated with an improved cardiovascular prognosis. In this regard ACE inhibitors and AT II receptor blockers can play an important role. Due to their blood pressure lowering effect, which antagonizes left atrial dilatation, and by inhibiting fibrosis, these drugs might slow down AF progression. This effect is implied by studies showing an improved sinus rhythm maintenance when adding RAAS blockers to amiodarone..$^{57-59}$ It remains to be seen whether upcoming larger randomized studies will confirm this effect of RAAS blockers and whether this is associated with improved outcome in AF.

4. Although the $\mathrm{CHADS}_{2}$ score is a straightforward and easy to use scheme, risk stratification might be refined to enhance cost-benefit of anticoagulation and to 
lower bleeding risks. Recently it has been proposed to add the biomarker Von Willebrand factor to the $\mathrm{CHADS}_{2}$ score,$^{60}$ and there might be a role in the future for other plasma biomarkers and also imaging methods such as TEE, MRI or CT.

4. Catheter ablation is mainly reserved for the relatively young and healthy, since AF with multiple and severe associated disease is hard to cure with this technique. In fact we predict a negative relationship between $\mathrm{CHADS}_{2}$ score and success of ablation. This is confirmed by the low application rates of catheter ablation in the Euro Heart Survey. Nevertheless, improving the understanding of electrophysiological patterns and the arrhythmogenic substrate, and also technical advances, are expected to lead to more efficient, easy to use and safer ablation tools for application in a larger part of the AF population. In this way, a more aggressive rhythm control approach might lead to a higher curative rate of AF, while maintaining safety.

5. Specific subgroups of patients might benefit from strategies that are not applicable to the whole group of AF patients. For example, in patients with AF and HF an aggressive rate control approach - ablation of the atrioventricular junction with biventricular pacing - might be more effective than administering regular rate control drugs ${ }^{61}$, but large trials need to confirm this.

\section{Monitoring quality of care}

Assessment of guideline adherence as in this thesis needs to be repeated on a regular or continuous basis, since research evidence keeps on changing and refining the recommendations. As quality of clinical trials methods is expected to improve, observational studies also need to evolve in order to assess clinical practice as accurate as possible. For this purpose the following recommendations could help:

1. The use of standardized data definitions as published in 2004 for $A F^{62}$ Standardization of data collection can improve comparability of research results, not only for clinical trials but also for observational studies.

2. Quality of survey data needs to be critically assessed and some form of quantification is needed to label the quality of the data. ${ }^{63}$

3. Continuous registration of the management of acute coronary syndromes is more and more applied, and also the Euro Heart Survey currently runs an acute coronary syndromes registry rather than repeating surveys once in a while. A continuous registration requires the appropriate infrastructure, such as for the National Cardiovascular Data Registry of the Netherlands Society of Cardiology (NVVC-NCDR), but once established it provides continuous feedback on the quality of care. For AF specifically, the introduction of an AF outpatient clinic might help, in which guidelines are integrated in an electronic decision and registration system. In this way management will be based on the guidelines and registration of AF care would allow regular assessment of local management. Benchmarking, whether on a national or international level, enables comparisons 
between an institution and the average of all other centers and it certainly will provide triggers for clinicians to further improve quality of care.

\section{REFERENCES}

1. Fuster V, Ryden LE, Asinger RW, Cannom DS, Crijns HJ, Frye RL, Halperin JL, Kay GN, Klein WW, Levy S, McNamara RL, Prystowsky EN, Wann LS, Wyse DG. ACC/AHA/ESC guidelines for the management of patients with atrial fibrillation. A report of the American College of Cardiology/American Heart Association Task Force on Practice Guidelines and the European Society of Cardiology Committee for Practice Guidelines and Policy Conferences (Committee to develop guidelines for the management of patients with atrial fibrillation) developed in collaboration with the North American Society of Pacing and Electrophysiology. Eur Heart J 2001;22:1852-1923.

2. Fuster V, Ryden LE, Cannom DS, Crijns HJ, Curtis AB, Ellenbogen KA, Halperin JL, Le Heuzey JY, Kay GN, Lowe JE, Olsson SB, Prystowsky EN, Tamargo JL, Wann S. ACC/AHA/ESC 2006 guidelines for the management of patients with atrial fibrillation-executive summary: a report of the American College of Cardiology/American Heart Association Task Force on practice guidelines and the European Society of Cardiology Committee for Practice Guidelines (Writing Committee to Revise the 2001 Guidelines for the Management of Patients with Atrial Fibrillation). Eur Heart J 2006;27:1979-2030.

3. Kerr C, Boone J, Connolly S, Greene M, Klein G, Sheldon R, Talajic M. Follow-up of atrial fibrillation: The initial experience of the Canadian Registry of Atrial Fibrillation. Eur Heart J 1996;17 Suppl C:48-51.

4. Harjai KJ, Licata AA. Effects of amiodarone on thyroid function. Ann Intern Med 1997;126: 63-73.

5. Carlsson J, Miketic S, Windeler J, Cuneo A, Haun S, Micus S, Walter S, Tebbe U. Randomized trial of rate-control versus rhythm-control in persistent atrial fibrillation: the Strategies of Treatment of Atrial Fibrillation (STAF) study. J Am Coll Cardiol 2003;41:1690-6.

6. Hohnloser SH, Kuck KH, Lilienthal J. Rhythm or rate control in atrial fibrillation-Pharmacological Intervention in Atrial Fibrillation (PIAF): a randomised trial. Lancet 2000;356:1789-94.

7. Opolski G, Torbicki A, Kosior DA, Szulc M, Wozakowska-Kaplon B, Kolodziej P, Achremczyk P. Rate control vs rhythm control in patients with nonvalvular persistent atrial fibrillation: the results of the Polish How to Treat Chronic Atrial Fibrillation (HOT CAFE) Study. Chest 2004;126:476-86.

8. Wyse DG, Waldo AL, DiMarco JP, Domanski MJ, Rosenberg Y, Schron EB, Kellen JC, Greene HL, Mickel MC, Dalquist JE, Corley SD. A comparison of rate control and rhythm control in patients with atrial fibrillation. N Engl J Med 2002;347:1825-33.

9. Van Gelder IC, Hagens VE, Bosker HA, Kingma JH, Kamp O, Kingma T, Said SA, Darmanata JI, Timmermans AJ, Tijssen JG, Crijns HJ. A comparison of rate control and rhythm control in patients with recurrent persistent atrial fibrillation. N Engl J Med 2002;347:1834-40.

10. Gage BF, Waterman AD, Shannon W, Boechler M, Rich MW, Radford MJ. Validation of clinical classification schemes for predicting stroke: results from the National Registry of Atrial Fibrillation. JAMA 2001;285:2864-70.

11. Wang TJ, Massaro JM, Levy D, Vasan RS, Wolf PA, D'Agostino RB, Larson MG, Kannel WB, Benjamin EJ. A risk score for predicting stroke or death in individuals with new-onset atrial fibrillation in the community: the Framingham Heart Study. JAMA 2003;290:1049-56.

12. Singer DE, Albers GW, Dalen JE, Go AS, Halperin JL, Manning WJ. Antithrombotic therapy in atrial fibrillation: the Seventh ACCP Conference on Antithrombotic and Thrombolytic Therapy. Chest 2004;126:429S-56S. 
13. Lip GY, Frison L, Grind M. Effect of hypertension on anticoagulated patients with atrial fibrillation. Eur Heart J 2007;28:752-9.

14. Hart RG, Pearce LA, McBride R, Rothbart RM, Asinger RW. Factors associated with ischemic stroke during aspirin therapy in atrial fibrillation: analysis of 2012 participants in the SPAF I-III clinical trials. The Stroke Prevention in Atrial Fibrillation (SPAF) Investigators. Stroke 1999;30:1223-9.

15. van der Meer FJ, Rosendaal FR, Vandenbroucke JP, Briet E. Bleeding complications in oral anticoagulant therapy. An analysis of risk factors. Arch Intern Med 1993;153:1557-62.

16. Humphries KH, Kerr CR, Connolly SJ, Klein G, Boone JA, Green M, Sheldon R, Talajic M, Dorian P, Newman D. New-onset atrial fibrillation: sex differences in presentation, treatment, and outcome. Circulation 2001;103:2365-70.

17. Glazer NL, Dublin S, Smith NL, French B, Jackson LA, Hrachovec JB, Siscovick DS, Psaty BM, Heckbert SR. Newly detected atrial fibrillation and compliance with antithrombotic guidelines. Arch Intern Med 2007;167:246-52.

18. Waldo AL, Becker RC, Tapson VF, Colgan KJ. Hospitalized patients with atrial fibrillation and a high risk of stroke are not being provided with adequate anticoagulation. J Am Coll Cardiol 2005;46:1729-36.

19. Kuijer PM, Hutten BA, Prins MH, Buller HR. Prediction of the risk of bleeding during anticoagulant treatment for venous thromboembolism. Arch Intern Med 1999;159:457-60.

20. Shireman TI, Mahnken JD, Howard PA, Kresowik TF, Hou Q, Ellerbeck EF. Development of a contemporary bleeding risk model for elderly warfarin recipients. Chest 2006;130:1390-6.

21. Beyth RJ, Quinn LM, Landefeld CS. Prospective evaluation of an index for predicting the risk of major bleeding in outpatients treated with warfarin. Am J Med 1998;105:91-9.

22. Gage BF, Yan Y, Milligan PE, Waterman AD, Culverhouse R, Rich MW, Radford MJ. Clinical classification schemes for predicting hemorrhage: results from the National Registry of Atrial Fibrillation (NRAF). Am Heart J 2006;151:713-9.

23. Hart RG, Tonarelli SB, Pearce LA. Avoiding central nervous system bleeding during antithrombotic therapy: recent data and ideas. Stroke 2005;36:1588-93.

24. Fang MC, Go AS, Hylek EM, Chang Y, Henault LE, Jensvold NG, Singer DE. Age and the risk of warfarin-associated hemorrhage: the anticoagulation and risk factors in atrial fibrillation study. J Am Geriatr Soc 2006;54:1231-6.

25. Leys D, Englund E, Del Ser T, Inzitari D, Fazekas F, Bornstein N, Erkinjuntti T, Bowler JV, Pantoni L, Parnetti L, De Reuck J, Ferro J, Bogousslavsky J. White matter changes in stroke patients. Relationship with stroke subtype and outcome. Eur Neurol 1999;42:67-75.

26. Kang K, Lee YS, Kim NH, Kim DE, Park SH. Associated ischemic lesions in intracranial hemorrhage: MRI study. Eur Neurol 2003;49:94-7.

27. Kuo HK, Lipsitz LA. Cerebral white matter changes and geriatric syndromes: is there a link? J Gerontol A Biol Sci Med Sci 2004;59:818-26.

28. Mahon NG, McKenna CJ, Codd MB, O'Rorke C, McCann HA, Sugrue DD. Gender differences in the management and outcome of acute myocardial infarction in unselected patients in the thrombolytic era. Am J Cardiol 2000;85:921-6.

29. Ayanian JZ, Epstein AM. Differences in the use of procedures between women and men hospitalized for coronary heart disease. N Engl J Med 1991;325:221-5.

30. Tobin JN, Wassertheil-Smoller S, Wexler JP, Steingart RM, Budner N, Lense L, Wachspress J. Sex bias in considering coronary bypass surgery. Ann Intern Med 1987;107:19-25.

31. Wright J, Bibby J, Eastham J, Harrison S, McGeorge M, Patterson C, Price N, Russell D, Russell I, Small N, Walsh M, Young J. Multifaceted implementation of stroke prevention guidelines in primary care: cluster-randomised evaluation of clinical and cost effectiveness. Qual Saf Health Care 2007;16:51-9. 
32. Shekelle PG, Kravitz RL, Beart J, Marger M, Wang M, Lee M. Are nonspecific practice guidelines potentially harmful? A randomized comparison of the effect of nonspecific versus specific guidelines on physician decision making. Health Serv Res 2000;34:1429-48.

33. Erhardt LR. The essence of effective treatment and compliance is simplicity. Am J Hypertens 1999;12:105S-10S.

34. Soumerai SB, McLaughlin TJ, Gurwitz JH, Guadagnoli E, Hauptman PJ, Borbas C, Morris N, McLaughlin B, Gao X, Willison DJ, Asinger R, Gobel F. Effect of local medical opinion leaders on quality of care for acute myocardial infarction: a randomized controlled trial. JAMA 1998;279:1358-63

35. Lobach DF, Hammond WE. Computerized decision support based on a clinical practice guideline improves compliance with care standards. Am J Med 1997;102:89-98.

36. Persson M, Mjorndal T, Carlberg B, Bohlin J, Lindholm LH. Evaluation of a computer-based decision support system for treatment of hypertension with drugs: retrospective, nonintervention testing of cost and guideline adherence. J Intern Med 2000;247:87-93.

37. Shelton RJ, Allinson A, Johnson T, Smales C, Kaye GC. Four years experience of a nurse-led elective cardioversion service within a district general hospital setting. Europace 2006;8:81-85.

38. Ansari M, Shlipak MG, Heidenreich PA, Van Ostaeyen D, Pohl EC, Browner WS, Massie BM. Improving guideline adherence: a randomized trial evaluating strategies to increase beta-blocker use in heart failure. Circulation 2003;107:2799-804.

39. Katz DA, Griffith JL, Beshansky JR, Selker HP. The use of empiric clinical data in the evaluation of practice guidelines for unstable angina. JAMA 1996;276:1568-74.

40. Lichtman JH, Roumanis SA, Radford MJ, Riedinger MS, Weingarten S, Krumholz HM. Can practice guidelines be transported effectively to different settings? Results from a multicenter interventional study. Jt Comm J Qual Improv 2001;27:42-53.

41. Formoso G, Liberati A, Magrini N. Practice guidelines: useful and "participative" method? Survey of Italian physicians by professional setting. Arch Intern Med 2001;161:2037-42.

42. Fairhurst K, Huby G. From trial data to practical knowledge: qualitative study of how general practitioners have accessed and used evidence about statin drugs in their management of hypercholesterolaemia. BMJ 1998;317:1130-4.

43. Fox KA, Goodman SG, Klein W, Brieger D, Steg PG, Dabbous O, Avezum A. Management of acute coronary syndromes. Variations in practice and outcome; findings from the Global Registry of Acute Coronary Events (GRACE). Eur Heart J 2002;23:1177-89.

44. Bassand JP, Priori S, Tendera M. Evidence-based vs. 'impressionist' medicine: how best to implement guidelines. Eur Heart J 2005;26:1155-8.

45. Frykman V, Beerman B, Ryden L, Rosenqvist M. Management of atrial fibrillation: discrepancy between guideline recommendations and actual practice exposes patients to risk for complications. Eur Heart J 2001;22:1954-9.

46. Walsh CR, Lloyd-Jones DM, Camargo CA, Jr., Giugliano RP, O’Donnell CJ. Clinical trials of unfractionated heparin and low-molecular-weight heparin in addition to aspirin for the treatment of unstable angina pectoris: do the results apply to all patients? Am J Cardiol 2000;86:908-12.

47. Lenzen MJ, Boersma E, Reimer WJ, Balk AH, Komajda M, Swedberg K, Follath F, Jimenez-Navarro M, Simoons ML, Cleland JG. Under-utilization of evidence-based drug treatment in patients with heart failure is only partially explained by dissimilarity to patients enrolled in landmark trials: a report from the Euro Heart Survey on Heart Failure. Eur Heart J 2005;26:2706-13.

48. Nattel S, Carlsson L. Innovative approaches to anti-arrhythmic drug therapy. Nat Rev Drug Discov 2006;5:1034-49. 
49. Calkins H, Brugada J, Packer DL, Cappato R, Chen SA, Crijns HJ, Damiano RJ, Jr., Davies DW, Haines DE, Haissaguerre M, Iesaka Y, Jackman W, Jais P, Kottkamp H, Kuck KH, Lindsay BD, Marchlinski FE, McCarthy PM, Mont JL, Morady F, Nademanee K, Natale A, Pappone C, Prystowsky E, Raviele A, Ruskin JN, Shemin RJ.HRS/EHRA/ECAS expert Consensus Statement on catheter and surgical ablation of atrial fibrillation: recommendations for personnel, policy, procedures and follow-up. A report of the Heart Rhythm Society (HRS) Task Force on catheter and surgical ablation of atrial fibrillation. Heart Rhythm 2007;4:816-61.

50. Wyse DG, Gersh BJ. Atrial fibrillation: a perspective: thinking inside and outside the box. Circulation 2004;109:3089-95.

51. Tolonen H, Dobson A, Kulathinal S. Effect on trend estimates of the difference between survey respondents and non-respondents: results from 27 populations in the WHO MONICA Project. Eur J Epidemiol 2005;20:887-98.

52. Micieli G, Cavallini A, Quaglini S. Guideline compliance improves stroke outcome: a preliminary study in 4 districts in the Italian region of Lombardia. Stroke 2002;33:1341-7.

53. Giugliano RP, Lloyd-Jones DM, Camargo CA, Jr., Makary MA, O’Donnell CJ. Association of unstable angina guideline care with improved survival. Arch Intern Med 2000;160:1775-80.

54. Komajda M, Lapuerta P, Hermans N, Gonzalez-Juanatey JR, van Veldhuisen DJ, Erdmann E, Tavazzi L, Poole-Wilson P, Le Pen C. Adherence to guidelines is a predictor of outcome in chronic heart failure: the MAHLER survey. Eur Heart J 2005;26:1653-9.

55. Diener HC. Stroke prevention using the oral direct thrombin inhibitor ximelagatran in patients with non-valvular atrial fibrillation. Pooled analysis from the SPORTIF III and V studies. Cerebrovasc Dis 2006;21:279-93.

56. Boudes PF. The challenges of new drugs benefits and risks analysis: lessons from the ximelagatran FDA Cardiovascular Advisory Committee. Contemp Clin Trials 2006;27:432-40.

57. Ueng KC, Tsai TP, Yu WC, Tsai CF, Lin MC, Chan KC, Chen CY, Wu DJ, Lin CS, Chen SA. Use of enalapril to facilitate sinus rhythm maintenance after external cardioversion of long-standing persistent atrial fibrillation. Results of a prospective and controlled study. Eur Heart J $2003 ; 24: 2090-8$.

58. Madrid AH, Bueno MG, Rebollo JM, Marin I, Pena G, Bernal E, Rodriguez A, Cano L, Cano JM, Cabeza P, Moro C. Use of irbesartan to maintain sinus rhythm in patients with long-lasting persistent atrial fibrillation: a prospective and randomized study. Circulation 2002;106:331-6.

59. Yin Y, Dalal D, Liu Z, Wu J, Liu D, Lan X, Dai Y, Su L, Ling Z, She Q, Luo K, Woo K, Dong J. Prospective randomized study comparing amiodarone vs. amiodarone plus losartan vs. amiodarone plus perindopril for the prevention of atrial fibrillation recurrence in patients with lone paroxysmal atrial fibrillation. Eur Heart J 2006;27:1841-6.

60. Roldan V, Marin F, Garcia-Herola A, Lip GY. Correlation of plasma von Willebrand factor levels, an index of endothelial damage/dysfunction, with two point-based stroke risk stratification scores in atrial fibrillation. Thromb Res 2005;116:321-5.

61. Stevenson WG, Tedrow U. Management of atrial fibrillation in patients with heart failure. Heart Rhythm 2007;4:S28-S30.

62. McNamara RL, Brass LM, Drozda JP, Jr., Go AS, Halperin JL, Kerr CR, Levy S, Malenka DJ, Mittal S, Pelosi F, Jr., Rosenberg Y, Stryer D, Wyse DG, Radford MJ, Goff DC, Jr., Grover FL, Heidenreich PA, Peterson ED, Redberg RF. ACC/AHA key data elements and definitions for measuring the clinical management and outcomes of patients with atrial fibrillation: a report of the American College of Cardiology/American Heart Association Task Force on Clinical Data Standards (Writing Committee to Develop Data Standards on Atrial Fibrillation). Circulation 2004;109:3223-43.

63. Tolonen H, Dobson A, Kulathinal S. Assessing the quality of risk factor survey data: lessons from the WHO MONICA Project. Eur J Cardiovasc Prev Rehabil 2006;13:104-14. 
Summary

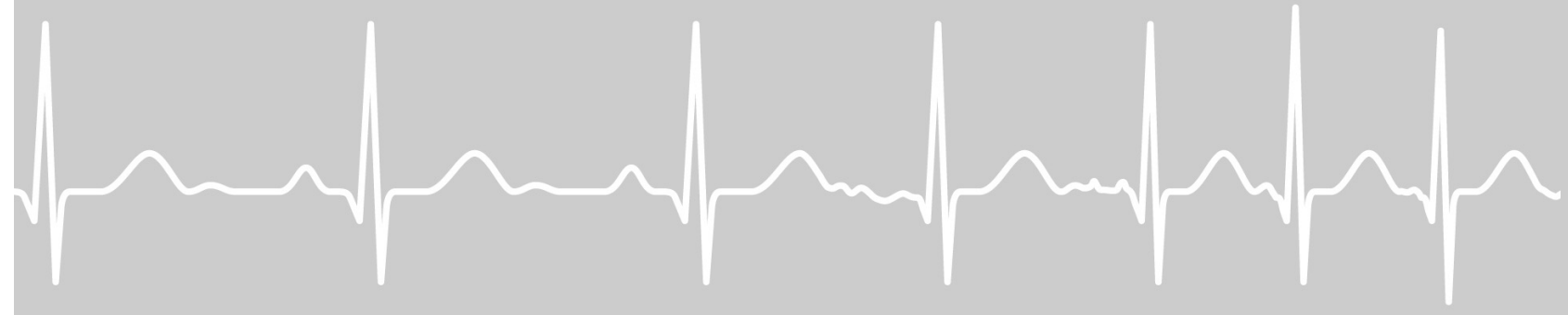


The general introduction of this thesis (chapter 1) describes the cardiac arrhythmia atrial fibrillation (AF), its management and the background and aims of the research as presented in this thesis.

$\mathrm{AF}$ is the most prevalent cardiac arrhythmia in the Western world. Its prevalence increases dramatically with advancing age, and of persons older than 40 years one out of four will develop AF at some time in life. Due to ageing of the population, the prevalence of $\mathrm{AF}$ is increasing with a consequent significant burden on the health care system.

AF is characterized by the uncoordinated and rapid activation of the atria. With a wide variety of episode durations and frequencies the presence of $\mathrm{AF}$ can range from a single episode through short and spontaneous stopping episodes (paroxysmal AF) to long persistent forms (persistent AF) or even continuous presence (permanent AF). AF results in a diminished ability to pump blood to the ventricles and in a fast and irregular ventricular response rate, which affect the patients quality of life and can cause pump failure of the ventricles. The latter can eventually lead to the clinical diagnosis of heart failure, but the other way around heart failure can also cause $\mathrm{AF}$, and as a consequence these two pathologies often coexist. Besides heart failure, also hypertension, coronary artery disease and valvular heart disease are frequently found in AF patients. Further, due to the diminished atrial blood flow, blood clots can be formed in the atria which can enter the circulation and cause thromboembolisms. In this regard AF patients have a five-fold increased risk for stroke as compared to patients with a normal sinus rhythm. Several patient characteristics and concomitant cardiovascular pathologies can increase the risk for stroke even further.

Due to the multiple manifestations and concomitant diseases of AF, management can be quite complicated. Some concomitant pathologies can be the cause of AF and treating this disease might temper or terminate AF. Therefore, when AF is encountered for the first time it has to be investigated whether a reversible cause is underlying AF before embarking full blown AF treatment. For the management of AF itself, two strategies are available. Rate control can be applied with the aim to restore a normal ventricular response rate thereby relieving symptoms and also reverting or preventing a diminished ventricular pump function. When severe limiting symptoms are present, rhythm control should be applied with the aim to terminate AF and restore a normal sinus rhythm. For the prevention of stroke in AF patients, oral anticoagulation is more effective than antiplatelet drugs. However, oral anticoagulation is also associated with an increased bleeding risk and it requires continuous monitoring. Therefore, risk stratification with evidence based risk factors for stroke and bleeding should identify high risk patients who need oral anticoagulation and low risk patients in whom an antiplatelet drug should suffice.

Management as described above is recommended in the joint AF guidelines of the American Heart Association, American College of Cardiology and the European Society of Cardiology (ESC). Based on results of the Euro Heart Survey on 
AF, this thesis aims to assess actual guideline adherence among European cardiologists, to address consequences of guideline deviance, to assess which barriers in the management of AF exist and whether there are undertreated subgroups of patients. Furthermore, the EXAMINE-AF study is reported to assess antithrombotic guideline adherence in AF in The Netherlands, thereby comparing practice of cardiologists, internists and general physicians.

Part I of this thesis focuses on the methodology and general results of the baseline survey and one year follow-up of the Euro Heart Survey on AF. In this study, 5333 AF patients were enrolled in 182 hospitals among 35 ESC member countries.

Chapter 2 depicts the baseline survey and shows that patients with permanent AF were clearly older and more diseased than patients with first detected, paroxysmal or persistent AF. Noteworthy was the high prevalence of evidence based stroke risk factors, especially hypertension, among all clinical AF types. Thyroid hormone levels were never measured in half of the patients, which is recommended since thyroid dysfunction might underlie AF. Class I antiarrhythmic drugs were applied in some AF patients with heart failure or coronary artery disease, although they are contraindicated in these patients. The vast majority of patients received some form of rate control, either as main treatment target or as background therapy for rhythm control. Almost half of the patients who never suffered any symptoms received rhythm control, whereas this is only recommended in patients with severe symptoms. Oral anticoagulation was withheld in a substantial proportion of patients who should receive it. On the other hand, oral anticoagulation was given in half of the patients for whom it was not recommended.

Chapter 3 describes the one year follow-up survey and shows that almost half of the patients with newly detected AF at baseline did not have an AF recurrence during one year. Paroxysmal AF largely remained paroxysmal AF and many persistent AF patients had progressed to permanent AF. From baseline, substantial shifts in the application of antithrombotic therapy and of rhythm and rate control therapy were observed after 1 year, which could be due to the complicated and dynamic clinical picture of AF patients. Mortality and morbidity were highest and quality of life lowest in permanent AF. In multivariable analysis, prescription of either an ACE inhibitor or AT II receptor blocker and also sinus rhythm at baseline were associated with a lower mortality, but no significant effect was observed regarding the application of either rhythm or rate control.

Part II describes the characteristics and consequences of antithrombotic treatment for AF in the Euro Heart Survey and the EXAMINE-AF study.

In the Euro Heart Survey, antithrombotic drug prescription was just marginally tailored to the patient's stroke risk profile according to four different stroke risk stratification schemes (chapter 4). Although the guidelines dissuade weighing the clinical type of AF to decide on oral anticoagulation, patients with first detected 
and paroxysmal AF had a much lower chance of receiving oral anticoagulation than patients with persistent and permanent AF. Further, the absence of centralized anticoagulation monitoring facilities was associated with withholding oral anticoagulation. Oral anticoagulation is also recommended around all cardioversions and in most instances it was indeed given around electrical cardioversions, but not in half of the patients around pharmacological cardioversions.

The question remains which consequences antithrombotic guideline deviance has. Since few major adverse events were observed in the small group of patients at low risk for stroke (chapter 5), this question seems mainly important in patients at high risk. High risk patients were twice as much undertreated than overtreated. As compared to patients in whom the guidelines were followed, undertreatment was associated with a worse cardiovascular prognosis, whereas overtreatment was not associated with a significantly increased bleeding risk. Improving antithrombotic guideline adherence seems therefore largely a matter of preventing undertreatment.

There is no convincing evidence that paroxysmal AF is associated with a lower stroke risk than persistent and permanent AF, but paroxysmal AF patients less often receive oral anticoagulation. During 1 year follow-up in the Euro Heart Survey, paroxysmal AF patients had a comparable risk for stroke and any thromboembolism as persistent and permanent $\mathrm{AF}$ (chapter 6). This finding strengthens the guideline recommendation not to take in account the clinical AF type when deciding on oral anticoagulation prescription. The risk for a stroke or any thromboembolism during one year following cardioversion was even higher in paroxysmal AF patients than in patients with persistent or permanent AF, which requires further investigation.

The Dutch EXAMINE-AF study showed that antithrombotic drug prescription was most often instituted and controlled by a cardiologist, also among patients from general physicians and internists (chapter 7). The fact that cardiologists performed best in tailoring antithrombotic treatment to the patient's stroke risk profile justifies the pivotal role of cardiologists. Further, the number of contraindications for oral anticoagulation gradually increased with a worsening stroke risk profile indicating that risk for stroke and bleeding go hand in hand.

Part III describes two subgroups of AF patients that were potentially less well treated than their counterparts with AF: females and heart failure patients.

Of the total Euro Heart Survey cohort $42 \%$ was female. Compared with men, the women were older, had a lower quality of life, had more co-morbidities and more often had heart failure with a preserved left ventricular systolic function (chapter 8). Among patients with less typical or no AF symptoms women less frequently underwent rhythm control. This might be beneficial for women since they are less often exposed to potential adverse side effects of rhythm control. Prescription of oral anticoagulation was identical in both genders. Female gender was the second most significant predictor of stroke, following a prior stroke or tran- 
sient ischemic attack, and should be reconsidered as an independent stroke risk factor.

One-third of all AF patients in the Euro Heart Survey also had heart failure. Patients with AF and heart failure were older, more diseased, at a higher stroke risk and more often had permanent AF than AF patients without heart failure (chapter 9). Recommended drug therapy for heart failure, which is the combination of a beta blocker with either an ACE-inhibitor or an AT II receptor blocker, was prescribed in less than half of the patients with AF and heart failure. When additionally considering oral anticoagulation and digitalis as recommended drug therapy for the combination of AF and heart failure, an appallingly low proportion of patients received the full package of recommended drug therapy. ACE-inhibitor prescription and sinus rhythm at baseline were associated with improved survival during one year.

In chapter 10 it is concluded that management of $\mathrm{AF}$ is on several items guideline deviant and several recommendations which can improve practice are given. One simple and easy-to-use risk stratification scheme, incorporating both the risk for stroke as well the risk for bleeding, will improve guideline adherence for antithrombotic treatment in AF. Better antithrombotic guideline adherence, especially by preventing undertreatment, will improve the prognosis of AF patients. An important contribution to the prevention of antithrombotic undertreatment can be achieved by clearly stating that oral anticoagulation should not be prescribed based on the clinical AF type but on the evidence based stroke risk. Female gender is not a convincing evidence based stroke risk factor in the guidelines, but our results indicate that female gender should be reconsidered as an independent stroke risk factor. Since cardiologists better tailor antithrombotic drug prescription to the patient's stroke risk profile than general physicians and internists, it is advisable to send AF patients at least once to a cardiologist. Patients with the often found combination of $\mathrm{AF}$ and heart failure represent a subgroup that deserves extra attention, since guideline adherence is very poor in these patients.

The findings in this thesis provide insights in the management and prognosis of AF in daily cardiology practice. Specific AF management issues and subgroups are identified that require extra attention. Educational efforts will raise cardiologists' awareness of firmly evidence based medicine for AF and ongoing research should clarify less well established management issues. 
Samenvatting

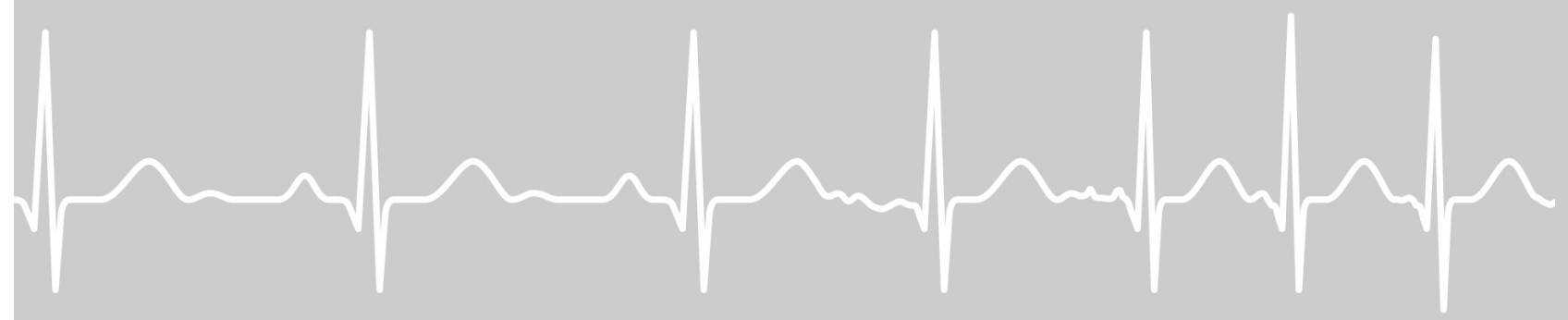


De algemene inleiding van dit proefschrift (hoofdstuk 1) beschrijft de hartritmestoornis atriumfibrilleren (AF), de behandeling van $\mathrm{AF}$ en de achtergrond en doelstellingen van het in dit proefschrift gerapporteerde onderzoek.

$\mathrm{AF}$ is de meest voorkomende hartritmestoornis in de westerse wereld. De prevalentie van AF stijgt dramatisch met toenemende leeftijd, en één op de vier personen van 40 jaar of ouder zal AF krijgen op enig moment in het resterende leven. Doordat de algemene populatie momenteel veroudert, stijgt de prevalentie van AF met als gevolg een significante belasting op de gezondheidszorg.

AF wordt gekarakteriseerd door een ongecoördineerde en snelle activering van de atria. Met een grote verscheidenheid aan duur en frequentie van episodes kan AF zich manifesteren variërend van een eenmalige episode via korte en spontaan eindigende episodes (paroxismaal AF) tot langdurige episodes (persisterend AF) of zelfs continue anwezigheid (permanent AF). AF resulteert in zowel een verminderd vermogen om bloed naar de ventrikels te pompen als in een snelle en onregelmatige ventriculaire frequentie. Het laatste kan uiteindelijk leiden tot de klinische diagnose hartfalen, maar omgekeerd kan hartfalen ook de oorzaak van AF zijn, waardoor deze twee ziektes vaak naast elkaar bestaan. Naast hartfalen zijn hypertensie, coronairlijden en hartkleplijden ook vaak aanwezig in AF patiënten. Verder kunnen door de verminderde atriale bloedstroom bloedpropjes gevormd worden in de atria, die vervolgens in de lichaamscirculatie terecht kunnen komen en een tromboembolie veroorzaken. AF patiënten hebben hierdoor een vijf maal verhoogde kans op een beroerte in vergelijking met mensen met een normaal sinusritme. Verschillende patiëntkarakteristieken en samengaande cardiovasculaire ziektes kunnen het risico op een beroerte nog verder verhogen.

De vele varianten en samengaande ziektes van AF kunnen de behandeling behoorlijk compliceren. Sommige samengaande ziektes kunnen de oorzaak van AF zijn en de behandeling van deze ziekten kan AF in toom houden of zelfs beëindigen. Als AF voor de eerste keer geconstateerd wordt moet daarom onderzocht worden of een omkeerbare oorzaak ten grondslag ligt aan AF voordat uitgebreide AF therapie wordt toegepast. Voor de behandeling van AF zelf zijn twee strategieën beschikbaar. Frequentiecontrole kan toegepast worden met als doel de ventriculaire frequentie te normaliseren ter verlichting van symptomen en de verminderde ventriculaire pompfunctie te herstellen. Indien hevige beperkende symptomen aanwezig zijn dient ritmecontrole toegepast te worden met als doel AF te beëindigen en normaal sinusritme te bewerkstelligen. Voor de preventie van een beroerte in AF patiënten is orale antistolling effectiever dan plaatjesaggregatie-remmers. Orale antistolling is echter geassocieerd met een verhoogd bloedingsrisico en vraagt om continue controle. Daarom dient risicostratificatie op basis van bewezen risicofactoren voor een beroerte patiënten te identificeren die een hoog risico voor een beroerte hebben en orale antistolling moeten krijgen evenals patiënten met een laag risico voor een beroerte voor wie een plaatjesaggregatiremmer voldoende is. 
De behandeling zoals boven beschreven is aanbevolen in de gemeenschappelijke richtlijnen van de American Heart Association, American College of Cardiology en de European Society of Cardiology (ESC). Op basis van de resultaten van de Euro Heart Survey beoogt dit proefschrift te beoordelen in hoeverre de richtlijnen gevolgd worden door Europese cardiologen, wat de consequenties zijn van het afwijken van de richtlijnen, welke barrières er in de behandeling van AF zijn en of er onderbehandelde subgroepen van patiënten zijn. Daarnaast wordt de EXAMINE-AF studie gerapporteerd om te beoordelen hoe de antitrombotische richtlijnen voor AF in Nederland gevolgd worden, waarbij de praktijk van cardiologen, internisten en huisartsen vergeleken wordt.

Deel I van dit proefschrift richt zich op de methodologie en algemene bevindingen van de basis survey en de één jaar follow-up van de Euro Heart Survey van AF. In deze studie waren 5333 AF patiënten geïncludeerd in 182 ziekenhuizen uit 35 ESC lidstaten.

Hoofdstuk 2 beschrijft de basis survey en laat zien dat patiënten met permanent AF duidelijk ouder en zieker waren dan patiënten met nieuw gedetecteerd, paroxismaal of persisterend AF. Opmerkelijk was de hoge prevalentie van bewezen risicofactoren voor een beroerte, voornamelijk hypertensie, in alle klinische AF typen. Schildklierhormoonwaardes waren nooit gemeten in de helft van de patiënten, hetgeen wel aanbevolen is aangezien schildklierdisfunctie een oorzaak van AF kan zijn. Klasse I antiaritmica werden gegeven in sommige AF patiënten met hartfalen of coronairlijden, terwijl dit gecontraïndiceerd is in deze patiënten. De meeste patiënten ondergingen frequentiecontrole, mogelijk als primair behandelingsdoel dan wel als achtergrondtherapie voor ritmecontrole. Bijna de helft van patiënten die nooit symptomatisch waren geweest ondergingen ritmecontrole, terwijl dit slechts aanbevolen is in patiënten met hevige beperkende symptomen. Orale antistolling was niet gegeven in een substantieel deel van de patiënten die het hadden moeten ontvangen. Aan de andere kant werd orale antistolling wel gegeven in de helft van de patiënten voor wie dit niet was aanbevolen.

Hoofdstuk 3 rapporteert de één jaar follow-up survey en laat zien dat bijna de helft van de patiënten met nieuw gedetecteerd AF in de basis survey geen nieuwe AF episode had gedurende één jaar. Paroxismaal AF bleef voornamelijk paroxismaal $\mathrm{AF}$ en vele patiënten met persisterend AF waren gevorderd naar permanent AF. Er waren substantiële verschuivingen geobserveerd in het gebruik van antitrombotica en in de toepassing van ritmecontrole en frequentiecontrole, hetgeen veroorzaakt kan zijn door het gecompliceerde en dynamische ziektebeeld van AF patiënten. Mortaliteit en morbiditeit waren het hoogst en kwaliteit van leven het laagst in patiënten met permanent AF. In multivariabele analyse waren het voorschrijven van een ACE remmer of een AT II receptor blokker en ook sinusritme in de basis 
survey geassocieerd met een lagere mortaliteit, maar er was geen significant effect wat betreft de toepassing van ritmecontrole dan wel frequentiecontrole.

Deel II beschrijft de karakteristieken en consequenties van de antitrombotische behandeling voor AF in de Euro Heart Survey en de EXAMINE-AF studie.

In de Euro Heart Survey was het voorschrijven van antitrombotica slechts marginaal afgestemd op het risicoprofiel van een patiënt voor een beroerte volgens vier verschillende risicostratificatie schema's (hoofdstuk 4). Ondanks dat de richtlijnen het afraden om het klinische AF type te wegen in de beslissing om orale antistolling voor te schrijven hadden patiënten met nieuw gedetecteerd en paroxismaal AF een kleinere kans om orale antistolling te ontvangen dan patiënten met persisterend en permanent AF. Verder was de afwezigheid van een centrale trombosedienst om orale antistolling te controleren geassocieerd met het niet voorschrijven van orale antistolling. Orale antistolling is ook aanbevolen rondom alle cardioversies en dit werd ook in de meeste gevallen gegeven rondom elektrische cardioversies, maar in de helft van de patiënten die een farmacologische cardioversie ondergingen niet.

Het blijft de vraag welke gevolgen het afwijken van de antitrombotische richtlijnen heeft. Aangezien weinig complicaties waren geobserveerd in de kleine groep met een laag risico op een beroerte (hoofdstuk 5) lijkt deze vraag voornamelijk van belang in patiënten met een hoog risico. Patiënten met een hoog risico voor een beroerte werden twee keer zo vaak onderbehandeld dan overbehandeld. In vergelijking met patiënten die antitrombotica volgens de richtlijnen ontvingen hadden onderbehandelde patiënten een slechtere cardiovasculaire prognose, terwijl overbehandeling niet geassocieerd was met een significant verhoogde bloedingsrisico. Verbetering van het volgen van de richtlijnen lijkt daarom vooral een zaak van het voorkomen van onderbehandeling.

$\mathrm{Er}$ is geen duidelijk bewijs dat paroxismaal AF geassocieerd is met een lager risico op een beroerte dan persisterend en permanent AF, maar toch ontvangen paroxismaal AF patiënten minder vaak orale antistolling. Gedurende één jaar in de Euro Heart Survey hadden paroxismaal AF patiënten een vergelijkbaar risico op een beroerte en tromboembolie als patiënten met persisterend of permanent AF (hoofdstuk 6). Deze bevinding versterkt de aanbeveling in de richtlijnen om geen rekening te houden met het klinische AF type in de beslissing om al dan niet orale antistolling voor te schrijven. Het risico op een beroerte en tromboembolie was gedurende één jaar na een cardioversie zelfs hoger in paroxismaal AF patiënten dan in patiënten met persisterend of permanent $\mathrm{AF}$, hetgeen verder onderzocht dient te worden.

De Nederlandse EXAMINE-AF studie liet zien dat antitrombotica voornamelijk opgestart en gecontroleerd worden door een cardioloog, ook in patiënten die bij internisten en huisartsen geïncludeerd waren (hoofdstuk 7). Het feit dat cardiologen antitrombotica het best afstemden op het risicoprofiel voor een 
beroerte van een patiënt rechtvaardigt de centrale rol van cardiologen. Verder nam het aantal contraindicaties voor orale antistolling toe met een verslechterend risicoprofiel voor een beroerte hetgeen erop duidt dat het risico voor een beroerte en voor een bloeding hand in hand gaan.

Deel III beschrijft twee subgroepen van AF patiënten die mogelijk minder goed behandeld werden dan hun tegenhangers met AF: vrouwen en patiënten met hartfalen.

In het gehele Euro Heart Survey cohort was $42 \%$ vrouw. Vergeleken met mannen waren de vrouwen ouder, hadden een lagere kwaliteit van leven, hadden meer comborbiditeiten en hadden vaker hartfalen met een behouden systolische linker ventrikel functie (hoofdstuk 8). Onder patiënten met minder typische of geen AF symptomen ondergingen vrouwen minder vaak ritmecontrole. Dit kan een gunstig effect met zich meebrengen aangezien zij minder vaak blootgesteld worden aan potentiële schadelijke neveneffecten van ritmecontrole. Mannen en vrouwen ontvingen even vaak orale antistolling. Vrouwelijk geslacht was de op één na meest significante voorspeller van een beroerte, na een voormalige beroerte of transiënte ischemische aanval, en zou daarom opnieuw gewogen moeten worden als een onafhankelijke risicofactor voor een beroerte.

Eenderde van alle AF patiënten in de Euro Heart Survey had ook hartfalen. Patiënten met AF en hartfalen waren ouder, zieker, hadden een slechter risicoprofiel voor een beroerte en hadden vaker permanent AF dan AF patiënten zonder hartfalen (hoofdstuk 9). Aanbevolen medicatie voor hartfalen, hetgeen de combinatie van een bèta-blokker met een ACE-remmer dan wel een AT II receptor blokker betreft, was voorgeschreven in minder dan de helft van de patiënten met AF en hartfalen. Als daarbij orale antistolling en digitalis ook als aanbevolen medicatie voor AF en hartfalen worden beschouwd, ontving een ontstellend klein deel van de patiënten dit volledige pakket van aanbevolen medicatie. Het voorschrijven van een ACE-remmer en sinusritme in de basis survey waren geassocieerd met een betere overleving gedurende één jaar.

In hoofdstuk 10 wordt geconcludeerd dat de behandeling van AF op meerdere punten afwijkt van de richtlijnen en er worden enkele aanbevelingen gedaan die de behandeling kunnen verbeteren. Eén eenvoudig en makkelijk te gebruiken risicostratificatie schema, welke zowel de risicofactoren voor een beroerte als voor een bloeding bevat, zal het volgen van de antitrombotische richtlijnen voor AF verbeteren. Een verbeterde navolging van de antitrombotische richtlijnen, voornamelijk door onderbehandeling te voorkomen, zal de prognose van AF patiënten verbeteren. Een belangrijke bijdrage aan het tegengaan van antitrombotische onderbehandeling kan geleverd worden door duidelijk te stellen dat orale antistolling niet afgestemd dient te worden op het klinische AF type, maar op bewezen risicofactoren voor een beroerte. Vrouwelijk geslacht is geen 


\section{SAMENVATTING}

overtuigend bewezen risicofactor voor een beroerte volgens de richtlijnen, maar onze resultaten geven aan dat vrouwelijk geslacht opnieuw gewogen dient te worden als onafhankelijke risicofactor. Aangezien cardiologen antitrombotische medicatie beter op afstemmen op het risicoprofiel van AF patiënten dan huisartsen en internisten, is het aan te bevelen dat elke AF patiënt minimaal één maal door de cardioloog wordt gezien. Patiënten met de veel voorkomende combinatie van AF en hartfalen vertegenwoordigen een subgroep die extra aandacht verdient, gezien de slechte prognose en aangezien de richtlijnen slecht gevolgd worden in deze patiënten.

De bevindingen in dit proefschrift geven inzicht in de behandeling en prognose van AF patiënten in de dagelijkse cardiologische praktijk. Specifieke punten in de behandeling van AF en subgroepen met AF zijn geïdentificeerd die extra aandacht vereisen. Intensieve (na)scholing dient cardiologen bewuster te maken van de punten waarop de behandeling van AF sterk bewezen is en voortdurend onderzoek zou minder sterk bewezen punten in de behandeling moeten verduidelijken. 


\section{Dankwoord}

Onderzoek doen is een teamsport, zeker voor zo'n omvangrijk project als de Euro Heart Survey. Er zijn meerdere mensen die mij in de afgelopen jaren geholpen hebben met het totstandkomen van dit proefschrift, met wie ik goed heb samengewerkt, van wie ik veel geleerd heb en die voor de nodige ontspanning naast het werk hebben gezorgd.

Ten eerste wil ik uiteraard prof. Crijns bedanken. Beste Harry, enorm veel dank voor de geweldige begeleiding en samenwerking in de afgelopen jaren. Ik heb enorm veel van je geleerd op het gebied van cardiologie, projectcoördinatie en onderzoek in het algemeen. Onze besprekingen leken soms wel colleges. Wat de samenwerking nog prettiger maakte was dat je ook zeer makkelijk te benaderen was, altijd mijn ideeën aanhoorde en open stond voor een geintje op zijn tijd. Vanaf het begin gaf je me veel vrijheid en vertrouwen waardoor ik erg zelfstandig te werk heb leren gaan. De mogelijkheid om voor 1500 mensen te presenteren was wat dat betreft een mooi voorbeeld.

Prof. Prins, beste Martin. Bedankt voor je bereidheid om mij te begeleiden en de zeer prettige samenwerking. Ik heb qua methodologische rapportage van artikelen heel veel van je opgestoken. Wat me van het begin af aan opviel was het gemak waarmee je een artikel doorziet en essentiële tips kunt geven. Tevens wil ik hierbij dr. Fred Nieman bedanken voor de statistische ondersteuning die nodig was, voornamelijk bij onze tweede 'significante' publicatie.

Graag wil ik ook de dataverzamelaars en lokale onderzoekers bedanken voor de aangename samenwerking in "ons" cluster voor de Euro Heart Survey: Heidi, Adrie, Herman, Chris, Jos, Jobst, Leo en Joan. Vooral ook bedankt voor het aanvaarden dat ik als beginnend onderzoeker soms wat fouten moest maken, ik heb er veel van geleerd. De volgende mensen worden ook bedankt voor hun bijdrage in de dataverzameling: Mohammed Alsoodany, Theo Kessels, Nezar Gadalla, Christina Firanescu, Igor Wollersheim, Rosemiek Eterman en Petra Erkens.

Miriam, de 'poortwachter' van prof. Crijns. Heel erg bedankt voor je assistentie en gesprekken de afgelopen jaren. Om in voetbaltermen te spreken ben je moeilijk passeerbaar, maar altijd aanspeelbaar. Ann, bedankt voor de financiële huishouding van ons project en het altijd lastige papierwerk wat betreft contracten en hun verlenging. Frank Vermeer wil ik bedanken voor mijn aanstelling en begeleiding in het eerste half jaar. 
Ik wil de leden van de beoordelingscommissie bedanken voor het beoordelen van mijn proefschrift: voorzitter prof. Stehouwer, prof. Allessie, prof. Limburg, prof. Pinto en prof. Simoons.

Mijn dank gaat ook uit naar een aantal mensen in het Erasmus MC. Prof. Simoons, beste Maarten, als kartrekker van de Euro Heart Survey wil ik je, naast de beoordeling van mijn proefschrift, ook bedanken voor de promotiebegeleiding in het begin van mijn traject. Dr. Boersma, beste Eric. Bedankt voor de begeleiding wat betreft mijn eerste ACS artikelen, dit was een goede voorbereidende oefening voor de rapportage in dit proefschrift. Dr. Scholte op Reimer, beste Wilma. Ik wil jou graag bedanken voor het altijd plezierige overleg en je goede begeleiding. Dr. Lenzen, beste Mattie. Ik wil jou hartelijk danken voor het overleg als we problemen in ons promotietraject tegen kwamen en we wederzijds advies konden inwinnen. Tevens wil ik nog de volgende mensen uit het EMC bedanken voor de aangename samenwerking in de afgelopen jaren: Esther, Jaap, Chris, Colinda, Saskia, Maria, Sanne, Sebastiaan.

De volgende mensen wil ik ook bedanken voor de prettige samenwerking wat betreft de Euro Heart Survey in Nederland: Marina Senten, Annelies Speksnijder, Menko-Jan de Boer, Marjan Beijering, Karin Nijenbrinks, Metske van der Wal, Henriette Tebbe, Christel Ephraim, Ingrid Middelveld, Nitolanda van Rijn en Annette Bootsma.

The Euro Heart Survey team at the European Heart House in Sophia Antipolis was vital for the performance of the Euro Heart Survey on atrial fibrillation and I would like to thank the following persons for their great work: Malika, Keith, Claire, Valerie, Susan and Charles.

The following people I would like to thank for their contribution in reporting the results as presented in this thesis: Etienne Aliot, Dietrich Andresen, Günter Breithardt, Harry Büller, John Camm, Allessandro Capucci, Stuart Cobbe, Dennis Cokkinos, Nikolaos Dagres, Wyn Davies, Dimitrios Kremastinos, Jean-Yves Le Heuzey, Samuel Lévy, Gregory Lip, José López-Sendón, Nico Mensing van Charante, Bertil Olsson, Massimo Santini and Panos Vardas.

Wat is er mooier dan een op elkaar ingespeeld duo als paranimfen te hebben. Cees en Luc, ik vind het prachtig dat jullie mijn paranimfen willen zijn en bedankt dat jullie, en dus ook Judith en Lisette, de vakantieplannen daarvoor hebben willen aanpassen. De samenwerking wat betreft het schrijven van artikelen vond ik erg prettig en ook heb ik enorm genoten van de hilarische opmerkingen die we bij tijd en wijlen door de kamer en kroeg strooiden. Cees, ik hoop dat deze rol je 'triggered' om snel zelf als hoofdpersoon in de aula te staan...en Français peut-être. Luc, 
je familiaire afkomst heeft me nooit doen vermoeden dat je politiek incorrecte humor en trash tv adoreert en prins carnaval van Valkenburg zou worden, het wordt nog wel wat met jou.

'Het hok', 'de stal', het is maar hoe je de onderzoekskamer van Cardiologie wilt betitelen...feit is dat ik jarenlang - als vreemde eend in een bijt vol artsen - mijn achterste daar heb laten vastgroeien aan een bureaustoel. Ik zou dit nooit zonder psychische problemen hebben kunnen voltooien als ik niet een gros figuren, naast Cees en Luc, om me heen had zitten waar ik mooie momenten en frustraties mee kon delen. Om te beginnen wil ik Jop bedanken voor de steun bij mijn begin op Cardiologie en de gezellige dinsdagavonden in de Mullins. Ik hoop dat de whiskeys in Cincinnati net zo goed smaken, veel succes als professor in wording. Klaartje, respect dat je zo lang het gezever van deze onnozelaar heb kunnen aanhoren. Roland, ik zal nooit je timing wat betreft roddelen-met-de-deur-open vergeten, ongeëvenaard. Umesh, I enjoyed sitting next to this funny Nepalese guy and I was honoured to be your paranimf. Trang, bedankt voor de mooie samenwerking, vooral de lunchbesprekingen waren kleurrijk. Dr. Wanda, je bent een aanwinst voor de kamer, de stabiele moeder voor een hoop kleuters. Miguel, ik wens je veel succes met het combineren van promotieonderzoek, acteerwerk en piano optredens. Robert, ooit hoop ik nog eens over je heen te dunken. Ron, zodra jij promoveert krijg je van mij een 'bossie rooie rozen'...not. Lilian, hopelijk heb je de zwarte band karate niet nodig om je promotie te bewerkstelligen. Yuka and Wendel, it was a pleasure to get to know you. I wish you lots of luck in Tokyo and Brasilia, hopefully we'll meet again in the future.

Ook wil ik Robert Tieleman bedanken voor de nuttige tips wat betreft mijn onderzoek en de gezelligheid vooral op de Amerikaanse congressen, ik wens je veel succes in Groningen. Dan, thanks for checking my thesis on English language. Rogier bedankt voor de mooie ontwerpen voor mijn proefschrift en uitnodigingen. Verder bedank ik Richard, Audrey, Dominique, Jeroen, cardiologen, assistentcardiologen, de dames van Cardio Research, de dames van het secretariaat en alle overige mensen die ik bij Cardiologie tegen het lijf ben gelopen voor het gezelschap en discussies.

Werk is belangrijk, maar niet alles, en daarom is het ook schitterend dat ik mensen om me heen heb met wie ik van alles en nog wat kan bepraten, een potje kan voetballen en eens goed kan feesten. Christian, we zien elkaar minder vaak sinds ik uit het Roosendaalse weg ben, maar als dat wel gebeurt is het altijd weer feest. Daniël, ik zit met smart te wachten op je memoires "Gedestilleerde lacunes in Roosendaalse herinneringen", succes met jouw promotie in Antwerpen. Criston, bij rotzooi kom je er op commando altijd eensgauwtussen. Ik weet dat jij je al maanden zit te verkneukelen om mij aan te pakken op mijn promotiefeest...als je 
echt te ver gaat geef ik je een vat È voor je verjaardag. Klien, ouwe (of jonge?) droogkloot. Het was een genoegen om je paranimf te zijn, ik wens je heel veel geluk in Eindhoven. Dominique, ik weet dat je dol bent op onderzoek en ik zal dan ook elke avond via de webcam uit dit meesterwerk voorlezen. Ramon, ook al voert je doelgerichtheid je naar Den Haag of terug naar je hooiberg, ik zal ook op afstand je aangever zijn. Frankie P, je typische danstijl en strijdkreet (Stimmung!) zullen over 100 jaar Maastrichtse folklore zijn. Brouwer(s), de kraanvogel heeft een ICD geimplanteerd gekregen en hij schijnt weer in de Platielstraat gesignaleerd te zijn. Tony, al beschouw ik je als de maatschappelijke begeleider van de vorige twee heren, ook jij bent een tuup. Smeets, sinds jij mijn huisarts bent heb ik echt nergens meer last van. Nicole, bedankt voor onze tijd samen en je steun en begrip als ik aan de slag moest voor dit proefschrift. Deirdre en Jan, met jullie in de Frankenstraat wonen was een mooie ervaring, ik hoop jullie nog vaak in Amsterdam te bezoeken. Ik wil dit gedeelte besluiten - zonder iemand tekort te willen doen - met een algemene dank aan alle overige mensen, waaronder BW-ers, DBSV-ers, Tumudo futsalers, Lloret futsalers, parkvoetballers en feestneuzen, die de afgelopen jaren zeer aangenaam gemaakt hebben.

Hetty, "grote" zus. Als ik in Roosendaal ben probeer ik altijd bij jou, Peter, Jesse en Mickel langs te komen. Ik heb er bewondering voor dat je naast de zorg voor je gezin je eigen bedrijfje regelt. Peter, je bent nog steeds een Butthead, blijf gezond. Natuurlijk ben ik nog wel het meest trots om de oom van die twee types te zijn.

Breurke Leon, je zult wel denken, heeft die eeuwige student alweer een papiertje erbij. Je heb je goed bij de Landmacht ontwikkeld en ik heb er respect voor hoe je de uitzendingen in Joegoslavië en vooral Afghanistan goed doorstaan hebt. Veel plezier in je eigen huis in Roosendaal, de logeerkamer is voor mij.

Pa en ma,jullie bedank ik het meest van allemaal voor jullie onvermoeibare steun en interesse. Ook al heb ik jullie elf jaar geleden flink laten schrikken en lijk ik ook af en toe wat makkelijk over zaken te denken, jullie zullen er intussen toch achter zijn dat het hoe dan ook altijd goed komt met mij. Geniet met volle teugen van jullie pensioen! 


\section{Curriculum vitae}

Robby Nieuwlaat was born on the 1st of June 1975 in Roosendaal, The Netherlands. After completing secondary school at the Gertrudis Lyceum (VWO) in Roosendaal 1993, he graduated in 1998 as a first degree teacher on physical education and sports at the Academy of Physical Education in Tilburg. In 2001 he received his MSc degree for the study Health Sciences at the University of Maastricht, with the sub-specialization Movement Sciences. Thereafter, he started in 2001 to work as a research fellow at the department of Cardiology in the University Hospital of Maastricht. In 2004 he graduated for the Master Epidemiology at Health Sciences of the University of Maastricht. His work as a research fellow on the Euro Heart Survey project - performed in The Netherlands as the 'Netherlands Heart Foundation Health Care Programme' - resulted in this thesis. 


\section{List of publications}

R. Nieuwlaat, S.B. Olsson, G.Y.H. Lip, A.J. Camm, G. Breithardt, A. Capucci, J.G. Meeder, M.H. Prins, S. Lévy, H.J.G.M. Crijns. Guideline-adherent antithrombotic treatment is associated with improved outcomes compared to undertreatment in high-risk atrial fibrillation patients. The Euro Heart Survey on Atrial Fibrillation. Am Heart J. 2007;153(6):1006-12.

N. Dagres, R. Nieuwlaat, P.E. Vardas, D. Andresen, S. Lévy, S. Cobbe, D.Th. Kremastinos, G. Breithardt, D.V. Cokkinos, H.J.G.M. Crijns. Gender-related differences in presentation, treatment and outcome of patients with atrial fibrillation in Europe: a report from the Euro Heart Survey on Atrial Fibrillation. J Am Coll Cardiol. 2007;49(5):572-7.

T. Dinh, R. Nieuwlaat, R.G. Tieleman, H.R. Büller, N.A. Mensing van Charante, M.H. Prins, H.J.G.M. Crijns. Antithrombotic drug prescription and its rationale among general,practitioners, internal medicine specialists and cardiologists in The Netherlands. The EXAMINE-AF study. A questionnaire study. Int J Clin Pract. 2007;61(1):24-31

R. Nieuwlaat, A. Capucci, G.Y.H. Lip, S.B. Olsson, M.H. Prins, F.H. Nieman, J. López-Sendón, P.E. Vardas, E. Aliot, M. Santini, H.J.G.M. Crijns, on behalf of the Euro Heart Survey Investigators. Antithrombotic Treatment in Real-Life Atrial Fibrillation Patients. A report from the Euro Heart Survey on Atrial Fibrillation. Eur Heart J. 2006;27(24):3018-3026.

R. Nieuwlaat, M. Lenzen, H.J.G.M. Crijns, M.H. Prins, W.J. Scholte op Reimer, A. Battler, D. Hasdai, N. Danchin, A.K. Gitt, M.L. Simoons, E. Boersma. Which factors are associated with the application of reperfusion therapy in ST-elevation acute coronary syndromes? Lessons from the Euro Heart Survey on Acute Coronary Syndromes I. Cardiology. 2006;106(3):137-146.

R. Nieuwlaat, A. Capucci, A.J. Camm, S.B. Olsson, D. Andresen, D.W. Davies, S. Cobbe, G. Breithardt, J.Y. Le Heuzey, M.H. Prins, S. Lévy, H.J.G.M. Crijns, on behalf of the Euro Heart Survey Investigators. Atrial Fibrillation Management: A Prospective Survey in ESC Member Countries. The Euro Heart Survey on Atrial Fibrillation. Eur Heart J. 2005;26(22):2422-34. 
R.T. Van Domburg, K. Sonnenschein, R.Nieuwlaat, O. Kamp, C.J. Storm, J.J. Bax, M.L. Simoons. Sustained benefit 20 years after reperfusion therapy in acute myocardial infarction. J Am Coll Cardiol. 2005;46(1):15-20.

R. Nieuwlaat, F. Vermeer, W.J.M. Scholte op Reimer, E. Boersma, A.W.J. van 't Hof en M.L. Simoons. Treatment of patients with acute coronary syndromes in the Netherlands in 2000-2001; a comparison with other European countries and with the guidelines. Ned. Tijdschr. Geneeskd (Dutch). 2004;148(38):1878-82.

M.L. Simoons, M.J. de Boer, E. Boersma, H.J.G.M. Crijns, J.W. Deckers, J. Funke Küpper, M. Lenzen, K.I. Lie, H.R. Michels, R. Nieuwlaat, J.P. Ottervanger, P. Polak, W. Scholte op Reimer, E. de Swart, F. Vermeer, E.E. van der Wall. Continuously improving the practice of cardiology. Neth Heart J. 2004;12(3):110-6.

M.K.C. Hesselink, P.L. Greenhaff, D. Constantin-Teodosiu, E. Hultman, W.H.M. Saris, R. Nieuwlaat, G. Schaart, E. Kornips, P. Schrauwen. Increased uncoupling protein 3 content does not affect mitochondrial function in human skeletal muscle in vivo. J Clin Invest. 2003;111(4):479-86. 
